MONITORING LANDSLIDE RISK DYNAMICS AFTER A MAJOR EARTHQUAKE IN A MOUNTAINOUS ENVIRONMENT 



\title{
MONITORING LANDSLIDE RISK DYNAMICS AFTER A MAJOR EARTHQUAKE IN A MOUNTAINOUS ENVIRONMENT
}

\author{
DISSERTATION
}

to obtain

the degree of doctor at the University of Twente, on the authority of the rector magnificus, prof.dr. T.T.M. Palstra,

on account of the decision of the Doctorate Board, to be publicly defended on Friday June 28 , 2019 at 12.45 hrs

by

Chenxiao Tang

born on March 30, 1988

in Chengdu, PR China 
This thesis has been approved by

Dr. C.J. van Westen, supervisor

Prof.dr. V.G. Jetten, co-supervisor

ITC dissertation number 358

ITC, P.O. Box 217, 7500 AE Enschede, The Netherlands

ISBN 978-90-365-4792-5

DOI $10.3990 / 1.9789036547925$

Cover designed by Job Duim Printed by ITC Printing Department

Copyright $@ 2019$ by Chenxiao Tang

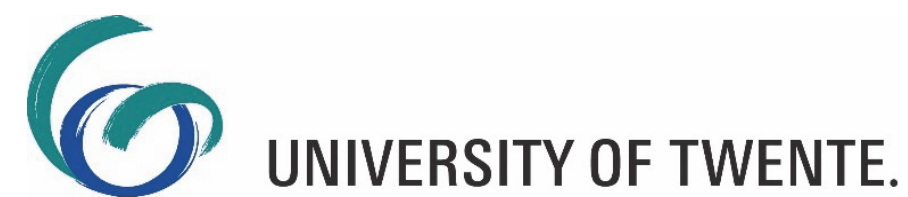

14C FACULTY OF GEO-INFORMATION SCIENCE AND EARTH OBSERVATION 
Graduation committee:

Chairman/Secretary

Prof.dr.ir. A. Veldkamp

University of Twente

Supervisor(s)

Dr. C.J. van Westen

University of Twente

Prof.dr. V.G. Jetten

University of Twente

\section{Members}

Prof.dr.ir. A. Veldkamp

Prof.dr. N. Kerle

University of Twente

Prof.dr. S.M de Jong

University of Twente

University of Utrecht

Prof.dr. M. Jaboyedoff

University of Lausanne

Dr. T. Hales

University of Cardiff 



\section{Acknowledgements}

After a six-years-long struggle, I am finally able to finish this book. After graduating from college in 2010, I did not what to do with my life. My parents arranged me to pursue a master's degree in ITC. I learned many skills from the very well-organized teaching. I felt I found the direction of my career and decided to start a PhD in the same institute in 2012 without knowing what a PhD's life would be and what is research. As a kid raised up in China, I always do what I am told to do and never thought I needed to take initiative. I was completely lost in the first three years and hardly made any progress. As my age getting older, I felt the necessity of taking responsibility of my own life. In the last two years I worked hard, overcoming a lot of obstacles, and finally reached here. There are many people who supported me. I could not achieve this thesis without them.

My most sincere thank is to my promoters. My promoter Cees van Westen, who is very knowledgeable and experienced in our field, and is the most patient and kind supervisor I ever knew. He did not give up on me and pushed me through this PhD even I slacked off for the first three years. He reviewed my manuscripts in such details that I could learn exactly where I did wrong and how to properly carry out analysis. He taught me research is not just about sitting in front of a computer, but also communicate and collaborate with others. Although we had some misunderstandings, I give my most respect to him. I wish to pass on his way of guiding if I got my own students. My copromoter Victor Jetten is a very easy-going professor with countless ideas. As the former head of our department I thought he was a strict person. After went for a fieldwork together I was amazed he was very nice and we could chat like friends. After that I overcame my fear of seniors and could communicate evenly with them.

I thank the ones that are closest to me. As most Chinese do, my parents always overprotect me. We have many disagreements since I started living in Netherlands, because the way of life, ideals and values I learned was very different from Chinese culture. Two years ago, I went back home and saw their hair started turning grey. At that moment I felt the disagreements are not important anymore. we are family and I would never want to be apart from you. I am grateful that my parents sent me to ITC and funded my PhD. They also provided data for my research and arranged several fieldworks. I thank my good friend and fiancée Jing Tang for her support and taking care of me during my thesis writing. Thank you for the good memories we made together and accepting me as your partner.

I thank the friends I made in the Netherlands. Thanks to them I did not feel lonely in a foreign country. Theo van Asch, Niek Rengers and Koert Sijmons 
are my good friends despite our large difference in age. They gave me valuable advices and shared their experiences as researchers/cartographer with me. Mathhew Dimal was my neighbour and officemate. He helped me to improve my English a lot and pushed me to join activities so that I could get to know people. Bastiaan van den Bout, my officemate, is very talented in programming and always try to help anyone in need. We collaborated on debris flow modelling and had some nice results. Oscar Kamps is a fellow PhD who often organize group activities and likes to drop by to have dinner with us. He is a friend always bring us laugh and joy, and always willing to lend a hand when I need help. My office mate Eveline Rost likes to tease me with her jokes and always explain me Dutch culture when I'm confused by it. Hakan Tanyas is a serious-looking Turkish guy with handsome beards. His serious look occasionally scares some people, but actually is a very nice and friendly person. We had some successful collaborations which turned into publications, and he introduced me the best baklava bakery in Enschede. Riswan Sianturi is our Indonesia friend who is not always reliable, but with a very kind heart. He brought us a lot of laughs and good memories. Chanitnart Mahakanta is our little sister from Thailand. She taught me Tom Yam recipe. I wish her a success in getting a PhD. Nanette Kingma is kind lady and a lecturer of our department. She cares a lot of students and gave me advices on life choices. Ruosha Zeng and Xu Yuan are my friends who 'research' cooking and play majiang poker with me. Anahita was like my big sister. She always gives me ice cream and Iranian sweets as gifts. Jonathan Franco Hempenius was our buddy in PC gaming and majiang poker. We had a lot of fun and laugh together. I thank ITC staff members Theresa Burker, Loes Colenbrander, Wim Feringa, Tina Tian, Roelof Schoppers for offer their kind help during my stay. I also thank Xuanmei Fan, Yuangen Jiang, Chao Yang, Yaojun Cao, Jialong Duanmu, Yinan Wu, Wei Liu, Tingting Wei, Yu Yang, Yi Wang, Chenhao Xia, Xinlei Liu, Feilong Wang, Chengzhang, Yang, Yinghua Cai, Naijing Du, Jingyun Zhen, Oliver Macapinlac, John Ray Bergado, Sofia Tilon, Mahid Ahmed, Arjen van Veen, Vasily Kokorev, Fardad Maghsoudi Moud, Sobhan Emtehani, Marlina Jaspers Faijer, Giulia Campone, Greta Savannah Simonelli, Luigi Lombardo, Islam Fadel, and Yan Freski for the friendship and support you gave to me

It was a tough but meaningful six years. I doubted myself and thought about giving up. Thanks to my mentors, family and friends, I learned to face my responsibility and weaknesses. I give my deepest thanks to them and will cherish the memories we share. 


\section{Table of Contents}

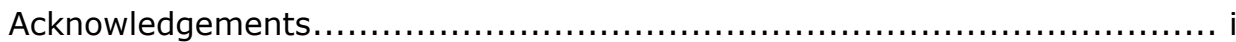

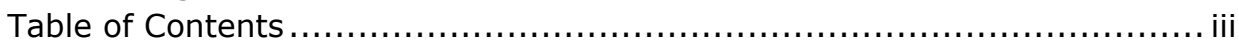

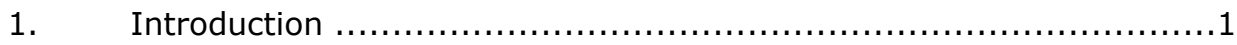

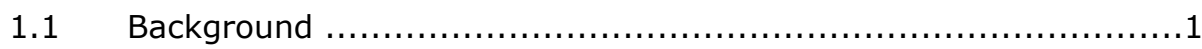

1.2 Examples of post-seismic landslide monitoring ........................ 4

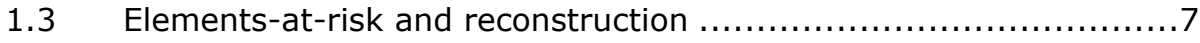

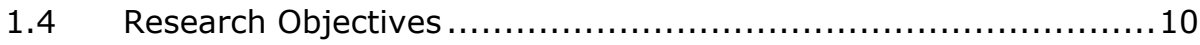

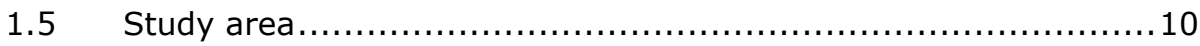

1.6 Thesis structure ...................................................... 14

2. Analyzing post-earthquake landslide activity using

multi-temporal landslide inventories.................................. 17

$2.1 \quad$ Background ............................................................. 17

$2.2 \quad$ Data \& Methods ........................................................ 18

2.2.1 Remote sensing data and pre-processing ....................... 18

2.2.2 Multi-temporal landslide inventories...........................20

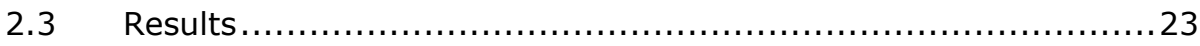

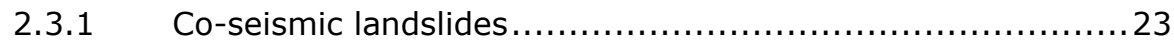

2.3.2 Post-seismic landslide inventories .............................. 29

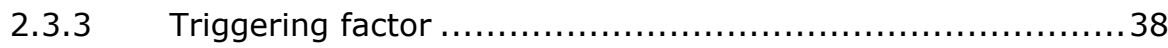

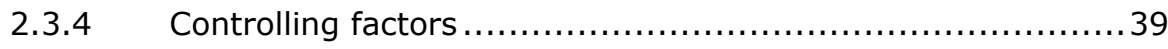

2.4 Discussion and conclusions.......................................... 41

3. Multi-temporal landslide volumetric analysis with multi-source

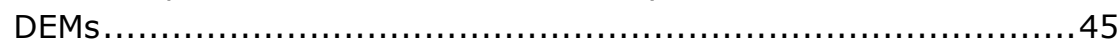

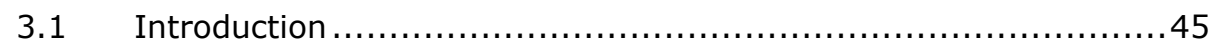

3.2 Data collection ..................................................... 47

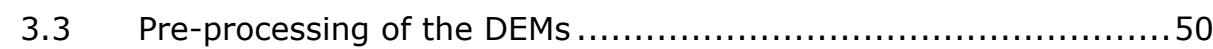

3.3.1 Geo-referencing ................................................ 51

3.3.2 Minimizing vertical bias ....................................... 52

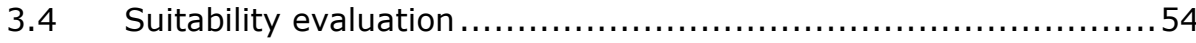

3.4.1 Assessing accuracies ............................................ 54

3.4.2 Assessing terrain representation................................ 54

3.5 Mobilized landslide volume analysis ................................ 58

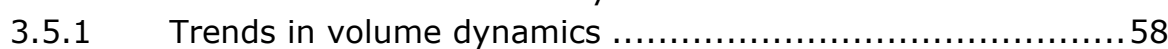

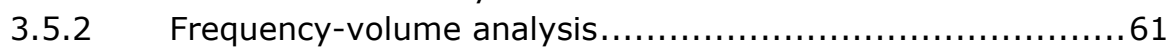

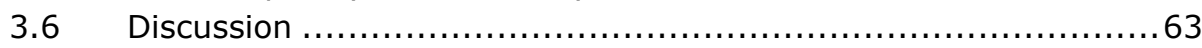

3.6.1 The efficiency of defining activity levels ........................63

3.6.2 Landslide volume and the hidden slip surface ...................64

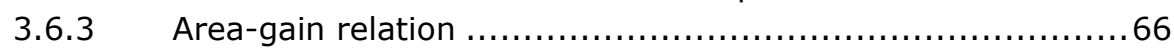

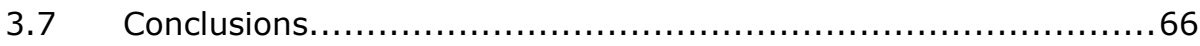

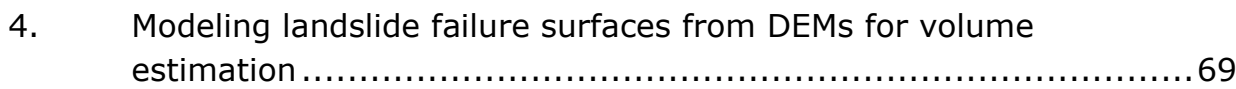

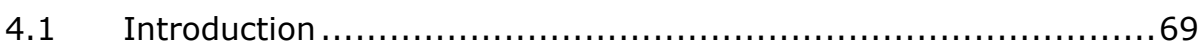




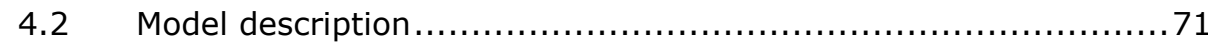

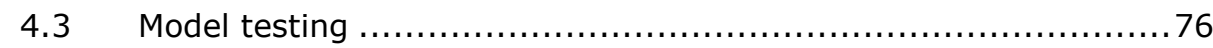

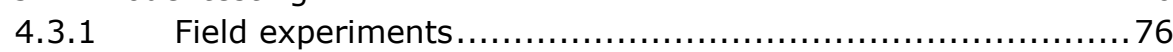

4.3.2 Failure surface modeling ....................................... 77

4.4 Volume estimation on earthquake induced landslides ................82 82

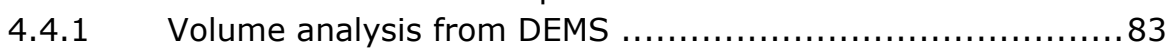

4.4.2 Comparison with Empirical methods............................. 83

4.5 Discussion $\&$ conclusion ................................................ 85

5. Monitoring recovery in an earthquake affected mountain

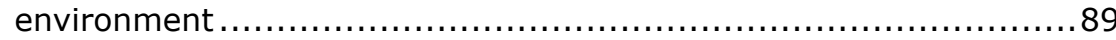

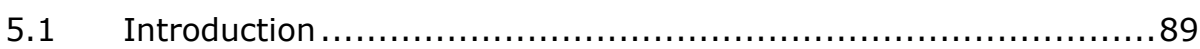

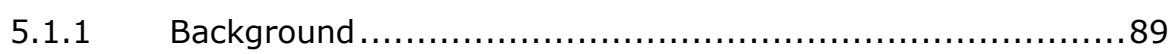

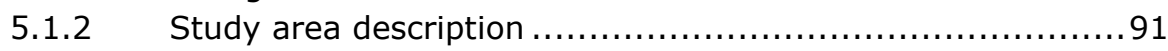

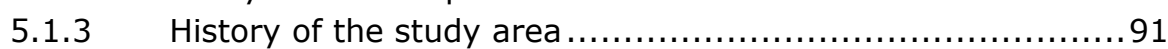

5.2 Data \& methodology.................................................. 94

$5.3 \quad$ Monitoring reconstruction ............................................. 98

5.3.1 Pre-earthquake (2007) .................................... 98

5.3.2 The impact of the earthquake (2008) ........................... 99

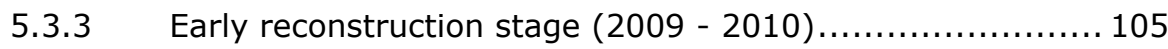

5.3.4 The August 2010 debris flows ................................ 107

5.3.5 The late reconstruction stage $(2010-2013) \ldots \ldots \ldots \ldots \ldots \ldots \ldots \ldots . \ldots 108$

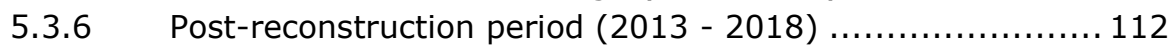

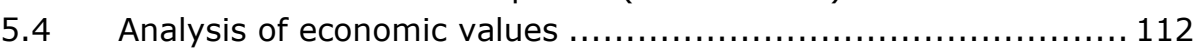

$5.4 .1 \quad$ Value estimation ............................................... 113

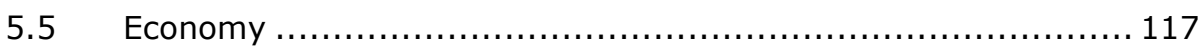

5.6 Discussion \& conclusions.......................................... 118

6. A catchment-based (semi) quantitative approach to estimate potential losses caused by post-earthquake debris flows ............ 121

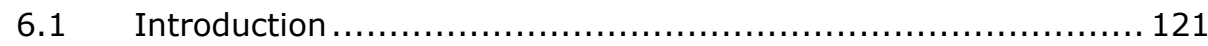

6.2 Data description .................................................. 122

6.3 Indicative hazard probability estimation ............................ 124

6.3.1 Data preparation................................................. 124

6.3.2 Debris flow history ............................................ 125

6.3.3 Hazard scores................................................. 128

6.3.4 Calculating indicative debris flow probability.................. 131

$6.4 \quad$ Estimating exposed economic value................................. 136

6.4.1 Quantifying value of exposure .............................. 137

6.4.2 Debris flow potential loss estimation ............................ 137

6.5 Discussion and conclusions........................................ 141

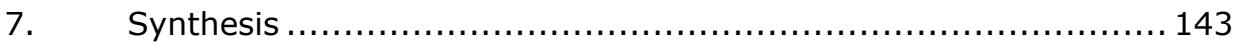

7.1 Summary and discussion .......................................... 143

7.1.1 Post-seismic landslide hazard.................................. 143

7.1 .2 Post-seismic landslide risk ..................................... 146

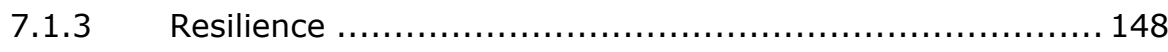




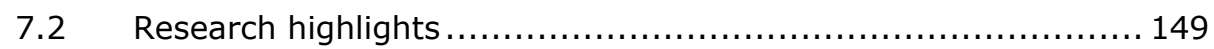

$7.3 \quad$ Recommendations .............................................. 150

$7.4 \quad$ Limitations and future research.................................. 153

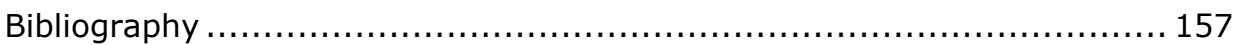

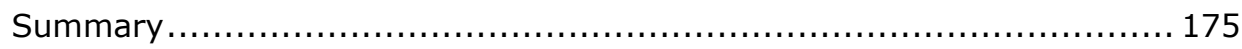

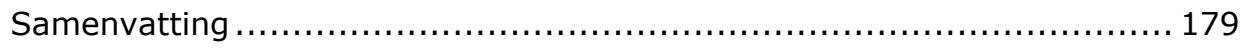

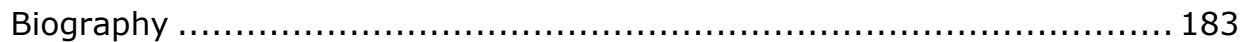




\section{Introduction}

\subsection{Background}

Major disasters, such as earthquakes, have a large impact on society, causing massive direct and indirect losses. Large earthquakes may also seriously affect the natural environment, in the form of secondary hazards. In mountainous regions one of the most severe secondary effects is the triggering of co-seismic landslides. These may result in the loss of vegetation and the production of large volumes of landslide deposits, which drastically change the susceptibility to rainfall-induced landslides and flooding after the earthquake. In such circumstances human settlements are not only threatened by co-seismic hazards such ground shaking or landslides, but also face a continuous threat of landslides, debris flows and flash floods during and after the reconstruction phase. The monitoring of changes in post-seismic hazards, exposure and vulnerability is important for addressing changing risk as a basis for recovery planning. Among the catastrophic earthquakes in the past 20 years, the 1999 Chi-chi earthquake ( $M_{w}$ 7.7) in Taiwan (ROC) and the 2008 Wenchuan earthquake $\left(M_{w}\right.$ 7.9) in Sichuan province of PR China highlighted the destructive potential of these post-seismic landslides (Tang and Westen, 2018).

Risk components keep changing after a major earthquake, depending on the environmental recovery speed and how reconstruction is carried out. A conceptual figure was made based on Fan et al. (2019b) to describe the expected dynamics of landslides activities, element-at-risk and associated factors (Figure 1.1).

A major earthquake may trigger many more landslides in an area than rainfall events in the pre-earthquake period. Large areas of vegetation cover are destroyed, and loose materials are created by co-seismic landslides (Figure 1.1 $A$, Node 1). After the earthquake the affected region enters the early postseismic period (Node $1-6$ ), in which the geo-environment is highly unstable and threats of landslides are high. Shortly after the earthquake impact, frequent aftershocks trigger reactivation of the landslides induced by the main shock and produce some new landslides, increasing the total loose material amount (Node 2). In the early post-seismic stage, low magnitude rainfall events are able to activate many more landslides than the same amount in the pre-earthquake stage (Node 3 ). Loose materials start to be detached by erosion and transported into rivers and vegetation starts to regrow gradually (Node 2 - 3). Large landslide events, mainly in the form of debris flows, may be triggered by moderate-magnitude (Node 4) and high-magnitude rainfall (Node 5), resulting in a fast depletion of loose material and slight decreases in vegetated areas. Vegetation regrowth occurs at a fast rate after the events, 
because many slopes become stabilized, given that there is a sufficient amount of rainfall. The region enters the late post-seismic period after a major reduction of removable materials and an increment in vegetation cover, which results in a relatively low but still higher than pre-earthquake level of landslide activity (Node $6-8$ ).

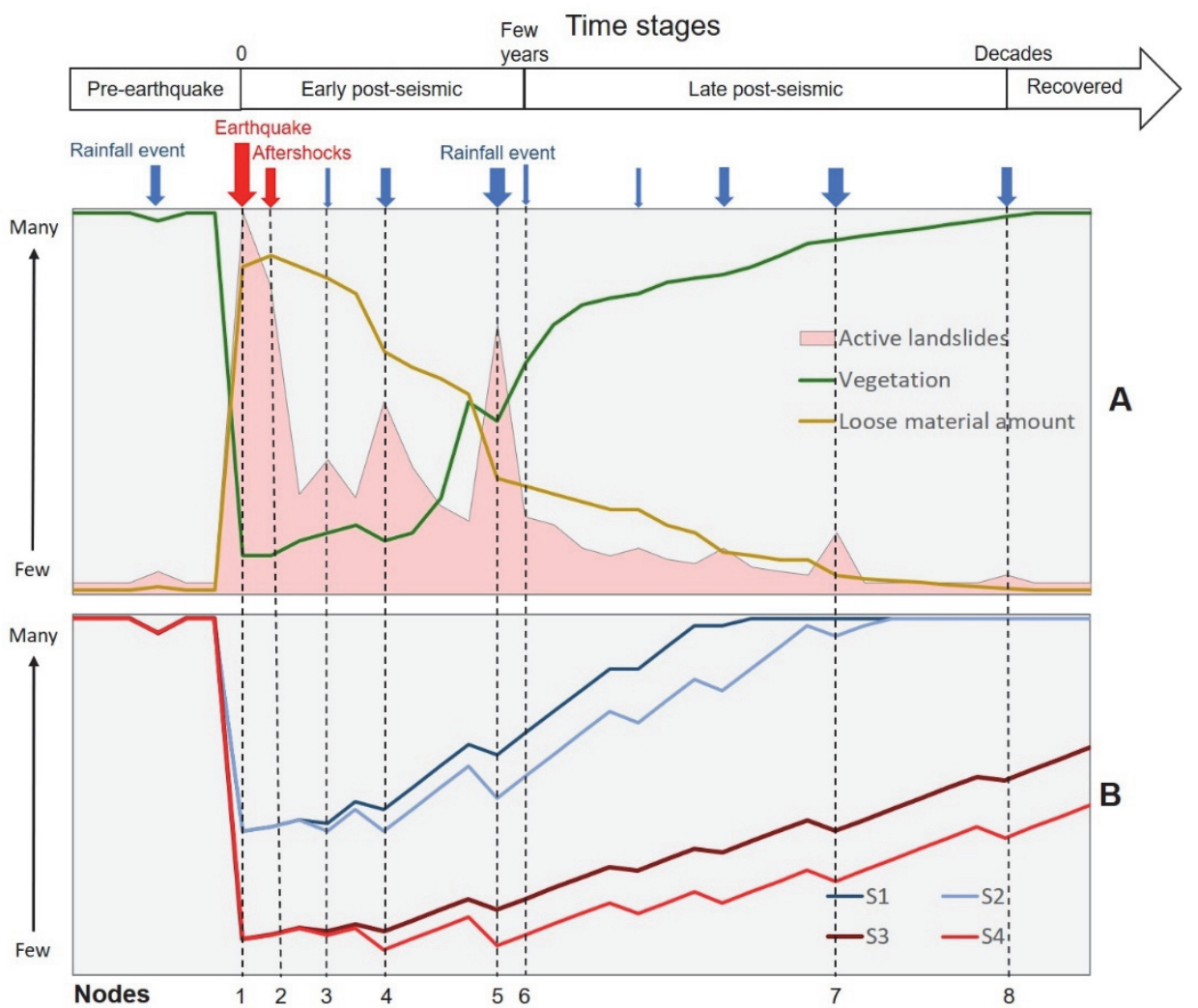

Figure 1.1: A conceptual figure about post-earthquake hazards and reconstruction. The arrows above the figure indicate triggering events. Red stands for earthquakes and blue for rainfall. A larger thickness means a higher event magnitude. The nodes are described in the text. A: The evolution of landslide activity, vegetation and amount of loose materials after an earthquake. B: Scenarios showing numbers of permanent element-at-risk (e.g. buildings) over time. Four scenarios are plotted: Strong buildings and fast recovery with Build-Back-Better (BBB) awareness of avoiding/mitigating disasters (S1); Scenario S1 without awareness (S2); Weak buildings and slow recovery with BBB awareness (S3); Scenario S3 without BBB awareness (S4). After Fan et al. (2019b).

Most slopes are stabilized and loose materials decrease steadily due to erosion and some low magnitude landslide activities. Vegetation regrowth slows down near the end of this stage because the remaining bare surfaces are located in active channels and valley floors where surface runoff removes young plants, and very steep slopes which lost their soil mantle due to landslides (Node 7). The environment is fully recovered when vegetation and loose material amount 
are restored to pre-earthquake level, and landslide frequency and magnitude also returned to the pre-earthquake level (after Node 8).

The lower part of Figure 1.1 (B) illustrates the possible changes with respect to the number of permanent elements-at-risk (excluding temporary shelters) caused by disaster impacts and reconstruction, highlighting four possible scenarios (Figure $1.1 \mathrm{~B}$ ). The first one (S1) is a society with a strong economy to support Building-Back-Better (BBB) with strong buildings and fast reconstruction, and having awareness to avoid rebuilding in hazard-prone zones, applying early warning systems and constructing mitigation measures. The second scenario (S2) is of the same society as S1 but without the BBB awareness (S2). The third scenario (S3) is of a society that could not afford strong buildings, fast reconstruction and mitigation measures, but has awareness to avoid building in dangerous locations and can develop a basic early warning system (S3). The fourth scenario (S4) is the same society as S3 but without risk awareness. The earthquake destroyed less buildings in $\mathrm{S} 1$ and $\mathrm{S} 2$ than in S3 and S4, because of stronger building structures (Figure 1.1 B, Node 1). All scenarios have low reconstruction speed initially due to disaster relief actions (Node $1-3$ ), after which S1 and S2 have a faster speed of reconstruction than S3 and S4. During the early post-seismic stage, landslides cause losses to all scenarios. S1 and S3 experience less damage because of applying building codes and construction in low risk locations (Node 3, 4, and 5 ). In the late post-seismic stage, many mitigation measures have been constructed in S1, and secondary hazards only slow down reconstruction instead of causing losses. This scenario is the earliest to complete reconstruction. S2 experiences damage from many secondary landslide events, and complete reconstruction takes more time than in S1. In scenario S3 there are no resources for constructing mitigation measures but losses are limited by proper planning and basic early warning systems. Scenario S4 experiences damage every year and has the lowest reconstruction progress, even when landslide activity is restored to normal. Due to the slow pace of recovery, S3 and S4 do not reach complete reconstruction before the environment recovers to the pre-earthquake situation.

Figure 1.1 describes several hypothetical scenarios. The post-seismic landslide evolution for actual events was investigated in several countries, such as Japan, Taiwan of ROC, Nepal, Pakistan and the People's Republic of China (PR China) (Chang et al., 2006; Kargel et al., 2016; Khan et al., 2013; Khattak et al., 2010; Koi et al., 2008; Lin et al., 2004; Lin et al., 2006b; Nakamura et al., 1999; Owen et al., 2008; Shou et al., 2011a). Several studies monitored postearthquake reconstruction through field surveys and analysis of recovery data (Bolin and Stanford, 1998; Sakamoto and Yamori, 2009; Wang et al., 2012; Wu and Lindell, 2004), and several studies have applied remote sensing techniques (Burton, 2015; Contreras Mojica et al., 2015; Platt et al., 2016; 
Yang et al., 2015b). However, there is relatively limited monitoring carried out of post-earthquake reconstruction in an unstable geo-environment threatened by post-seismic hazards. The aim of this thesis is to carry out the monitoring of hazardous events, geo-environment setting and elements-at-risk in a decade after a major earthquake, in order to provide a better understanding of the dynamics of the post-earthquake risk components, which can assist future reconstruction planning in mountainous regions hit by a major earthquake.

\subsection{Examples of post-seismic landslide monitoring}

One of the earliest documented studies of tracking post-seismic landslides was carried out by Nakamura et al. (1999) after the 1923 Kantō Earthquake in Japan. They tracked the number of landslides induced by precipitation from 1923 to 1990 and discovered that the hillslopes were highly unstable over a period of 15 years, returning to pre-earthquake conditions after another 24 years (Figure 1.2 A). This study only showed a general trend of large events and ignored low-magnitude events. Koi et al. (2008) examined the relation between landslides and sediment discharge in the Nakagawa River basin from 1920 to 2005, and concluded that the earthquake caused a high sediment discharge in a period of 25 years, even though vegetation recovery was nearly complete. They discovered that co-seismic landslide debris could still be found in sediment discharge behind check dams 80 years after the earthquake.

The severity of post-seismic landslide hazards was deeply studied after the Chi-chi earthquake that occurred in 1999 in Taiwan, as subsequent tropical cyclones and rainstorms triggered much more landslides than the earthquake itself. The landslide occurrence and rainfall are shown in Figure 1.2 B.

A large difference was recognized in landslide frequency before and after the earthquake. Lin et al. (2004) analyzed landslide triggering conditions, concluding that the earthquake created a large volume of loose sediments, which significantly lowered landslide triggering rainfall thresholds. Later a similar conclusion was drawn by Shieh et al. (2009b) and Chen (2011). Lin et al. (2006a) studied landslides triggered by Typhoon Herb (1996) and Toraji (2001), and discovered that both the total landslide area and number of landslides were much larger after the earthquake. Landslides were much more likely to occur on steep slopes on mountain ridges than the pre-earthquake mid-slope areas. They also concluded that the co-seismic loose sediments discharged into rivers seriously interrupted the sediment balance and caused a change in the channel topography.

In the 10 years after the Chi-chi earthquake, several studies of multi-temporal landslide evolution and environmental recovery were carried out. Hovius et al. 
(2011) monitored mass wasting and sediment discharge from 1995 to 2006 and found an increment of more than four times compared to the preearthquake level in the first years after the earthquake, which returned to normal in about 6 years. A series of multi-temporal landslide maps were generated by Shou et al. (2011b) for a river basin in the area affected by the Chi-chi earthquake. The analysis showed that the landslide activities decayed to $50 \%$ in about $1-3$ years after the earthquake and to $10 \%$ in about 10 years. Later this work was expanded to a much larger area, involving the neighboring catchments (Shou et al., 2011a), resulting in a consistent conclusion. Liu et al. (2013) analyzed the enlargement of pre-existing landslides and new landslide occurrences from 1996 to 2008 over an area of $6384 \mathrm{~km}^{2}$. They proposed a statistical model to predict post-earthquake landslide density. Marc et al. (2015) analyzed post-seismic landslide evolution of four earthquakes including the Chi-chi earthquake. They concluded that landslides were extremely active after the earthquake and recovered after about 4 years. There is an ongoing debate on the length of landslide activity recovery time. Hovius et al. (2011) and Marc et al. (2015) claimed that a back ground rate was reached in 4 to 6 years. On the other hand, Shieh et al. (2009b) concluded that the landslide triggering rainfall threshold was still lower than the pre-earthquake level after 7 years. Shou et al. (2011a) proposed a conceptual model investigating the correlation of rainfall and landslides, and the results indicate that the background rate was not reached after 10 years.

In the region that was hit by the 2005 Kashmir earthquake in Pakistan, a very different evolution pattern was observed. Owen et al. (2008) mapped coseismic landslides through remote sensing and field verification. The same locations were revisited by (Khattak et al., 2010) in 2006 to 2007, who generated a second inventory and concluding that $80 \%$ of the landslides were dormant. Both studies made a prediction that landslides could be reactivated given sufficient amounts of ground water. Khan et al. (2013) revisited the sites in 2010 and analyzed landslide activity based on a third set of photos. They concluded that landslide activity was very limited and a significant vegetation regrowth had taken place. The lack of landslide activity could be associated with the dry climate in the region (Khattak et al., 2010). 

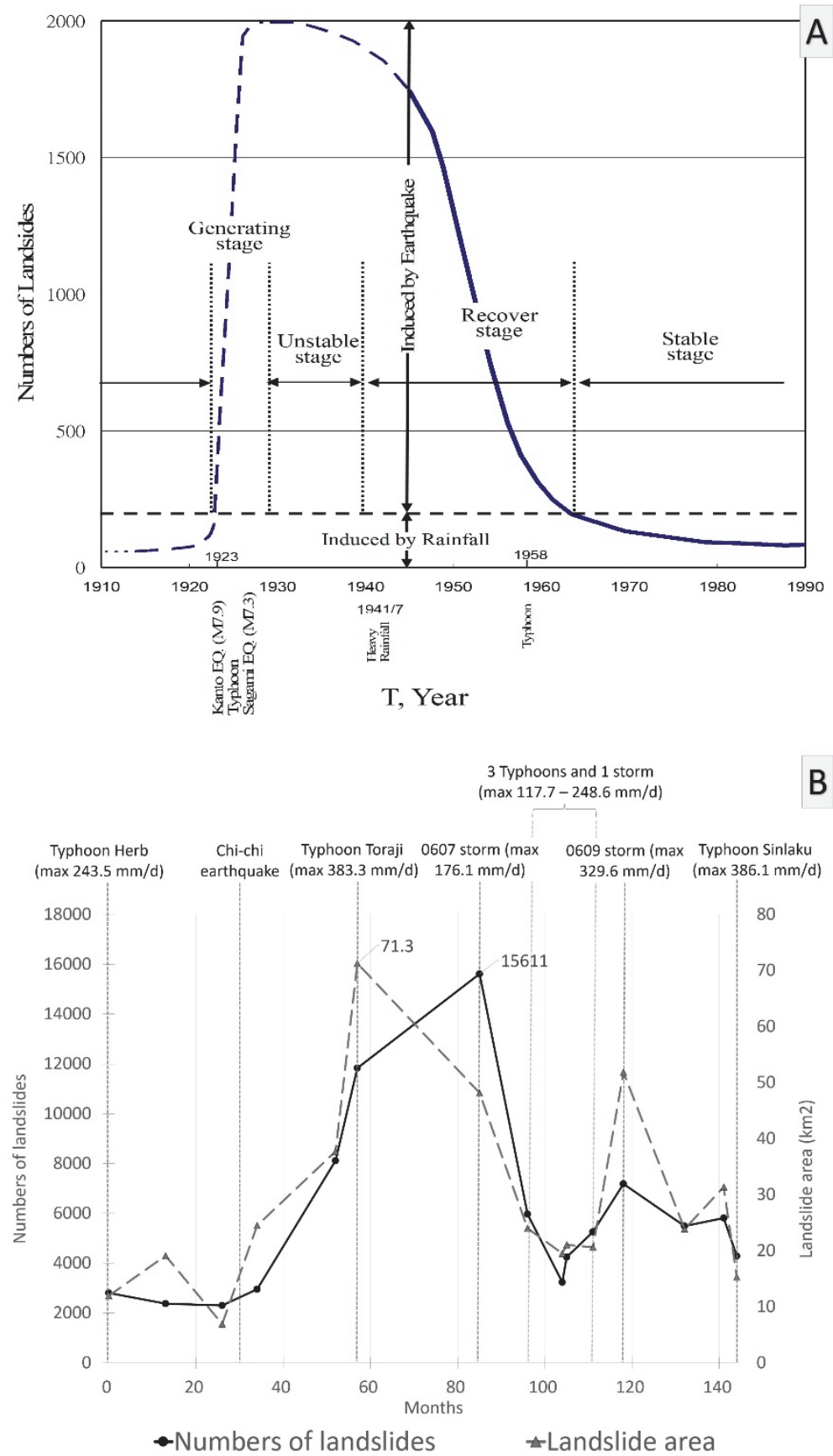

Figure 1.2: $A$ : The number of landslides triggered by precipitation after the 1923 Kanto earthquake (Nakamura et al., 1999). B: Active landslides observed over 144 months in an area of $6384 \mathrm{~km}^{2}$ in central Taiwan, from 1996 to 2008 (Liu et al., 2013). 
The nature of post-seismic landslides varies largely depending on many conditions. The landslide development after the Kanto earthquake somewhat matches the trend shown in Figure 1.1 A, if small events were excluded. As for the Chi-chi earthquake, more landslides were triggered by the typhoon following the earthquake instead of the earthquake itself, and the trend after the typhoon matches with Figure 1.1 A. For the Kashmir earthquake landslides decayed at a fast rate without any major reactivation.

Due to the highly dynamic nature of the post-earthquake environment, in terms of vegetation recovery, landslide activity, and reconstruction work, hazard and risk change continuously. The huge losses resulting from postseismic landslides in the Chi-chi and the Wenchuan earthquake highlighted that there is a lack of knowledge on dynamic post-seismic risk assessment and management.

Although post-seismic landslide evolution was studied in previous earthquakes, the results cannot be directly applied to the Wenchuan or other earthquakeaffected areas, due to differences in climate, geology, topography and amount of co-seismic mass wasting. In most of the previous studies, co-seismic and post-seismic landslides were analyzed based on remote sensing images, and volume estimation was based on empirical equations. The volume change caused by co-seismic and post-seismic mass movements was not investigated by analyzing the actual changes in elevation using Digital Elevation Models from different periods.

\subsection{Elements-at-risk and reconstruction}

Risk depends on the components of hazard (temporal, spatial, intensity probability), elements-at-risk (location, land use, construction type, economic value, number of people) and vulnerability (physical, social, environmental, systemic) (Fell, 1994; van Westen et al., 2006; Varnes, 1984). In a postseismic environment risk keeps changing not only because of the dynamic hazard situation, but also changes in elements-at risk due to reconstruction and impact of disasters. Depending on the policy, economy and the awareness of post-earthquake risk management, element-at-risk could change in different paths, as shown in Figure 1.1 B.

After a major earthquake a society needs to reconstruct its building stock and infrastructure and recover its economy, while improving its resistance to the next earthquake. Land-use planning is a critical action for Priority 4 of the Sendai framework "Enhancing disaster preparedness for effective response" and to "Build Back Better" in recovery, rehabilitation and reconstruction" (United Nations Office for Disaster Risk Reduction (UNISDR), 2015). While 
spatial planning is traditionally seen as the key for preventive measures, it underlines its importance for the recovery phase (Greiving et al., 2007).

The process related with physical recovery can be classified into three phases: pre-earthquake preparedness, relief and reconstruction. The change in element at risk is depending on the action take in the three phases.

In the pre-earthquake phase sustainable urban planning and policies considering the impact of earthquake could be made (Tarhan and Deniz, 2013), by limiting constructions near faults and possible post-earthquake-disasterprone zones, by limiting constructions that could trigger or amplify hazards, by using strong-structure building and by establishing political and professional awareness (Ciborowski, 1982; Ghafory-Ashtiany and Hosseini, 2008; Ioane et al., 2014; Ying Wu and Lindell, 2004). Secondary disasters such as earthquake-induced landslides, tsunami and industrial disasters should be considered as well (Bostenaru Dan et al., 2014). The assessment of the secondary disasters should be constantly updated, as they are influenced by the global changing climate, sea level rise and urban development (Baills et al., 2013; Baron, 2011; Bjarnadottir et al., 2011; Deppisch and Dittmer, 2015; Forzieri et al., 2016; Hufschmidt and Crozier, 2007; Martin et al., 2001; Nam et al., 2015; Nelson et al., 2002). However the preparedness can only limit damage and may even become ineffective if the hazard magnitude was unexpectedly high. For example, the 2011 Tohoku earthquake triggered a tsunami that struck eastern Japan, and caused nuclear melt down of the Fukushima Daiichi nuclear power plant (Mikami et al., 2012; Ohnishi, 2011). Even though Japan is one of the most advanced country in dealing with earthquake and tsunami hazards, the disaster magnitude exceeded the capacity of existing mitigation measures (Jayaratne, 2013).

During the disaster relief period, the major physical elements-at-risk are changed from pre-earthquake built-up features, to post-earthquake temporary shelters, survived buildings, and equipment and resources used for relief. The placement of shelters and relief resources has been studied by many researchers that are considering terrain, space, transportation, health, sanitary system, and electricity and water supply (Anhorn and Khazai, 2014; Chen et al., 2013a; Kılcı et al., 2015; Li et al., 2017; Tai et al., 2010; Xu et al., 2018; Yang et al., 2016). Only limited studies, for example Anhorn and Khazai (2014), considered post-earthquake hazards, as many of the cases are not located in regions with significant post-earthquake hazard problems.

Reconstruction from a major earthquake is a difficult process influenced by cultural, political, economic and environmental constraints. Many problems were witnessed during the reconstruction processes after earthquakes. Immense confusion and conflicts between stakeholders and governments are 
likely to occur, in cases where comprehensive reconstruction policies and preparation plans were not made prior to earthquakes (Ying Wu and Lindell, 2004). For example, political issues that slowed down reconstruction occurred for instance in Iran (Asgary et al., 2006), Nepal (Adhikari, 2017) and Haiti (Jesselyn, 2017). Poor management due to lack of experience was observed in Turkey (Akgiray et al., 2004) and Pakistan (Naviwala, 2017). The reconstruction speed is largely depending on the economy of earthquakeaffected countries. For example, fast reconstructions were witnessed in California of the United States (US), Taiwan of ROC (Ying Wu and Lindell, 2004) and Sichuan province of PR China (Zuo et al., 2013), while economic restraints slowed down recovery in Haiti (Jesselyn, 2017) and Nepal (von Meding et al., 2017). The reconstruction could be obstructed by disasters that occur following earthquakes. For instance, Taiwan of ROC (Lin et al., 2004) and Haiti (Jesselyn, 2017) were hit by hurricanes during the reconstruction period. Pakistan was affected by the worst flood in its history during the earthquake recovery (Naviwala, 2017). PR China (Xu et al., 2012) and Taiwan of ROC (Lin et al., 2004) experienced highly active post-seismic landslides.

The preparedness, relief and reconstruction actions that are used nowadays are mostly based on the experience from previous events (Nadim et al., 2004; Tarhan and Deniz, 2013). However in many cases the knowledge is not widely spread due to political issues, language barriers and unique academic environments, or government/researchers do not concern with such issues until large losses are taken. For example, the 1923 Kanto earthquake enhanced typhoon-triggered landslides for a prolonged period in Japan, but the related researches (Koi et al., 2008; Nakamura et al., 1999; San-Nami et al., 2011) were only published many years later most probably due to the Second World War, and many of the early studies were written in Japanese (for example Nakamura et al. (1999)). Without sufficient knowledge, Taiwan of ROC showed a lack of awareness of enhanced landslide activities after the 1999 Chi-chi earthquake, causing many losses. Although varies studies about the amplification (Chang et al., 2006; Cheng et al., 2005; Lin et al., 2006a; Lin et al., 2004; Lin et al., 2006b) were published in international journals before the 2008 Wenchuan earthquake, post-seismic landslides still caused large losses to the reconstructed settlements in Sichuan province of PR China (Fan et al., 2017; Tang et al., 2011c; Xu et al., 2012). This was due to a rush in reconstruction without careful planning, as described by C. Topping et al. (1998) and Ying Wu and Lindell (2004): "a rush to restore the community to its pre-impact pattern of social and economic functioning tends to reproduce its vulnerability to disaster". 


\subsection{Research Objectives}

The main objective of this research is to analyze the changing risk in a mountainous area that has been hit by a major earthquake. The area impacted by the 2008 Wenchuan earthquake was taken as the study area, as this event was one of the largest in recent decades and caused a major impact to the natural and built-environment. The aim of the study was to monitor postearthquake landslide activity, and exposure changes over a time period of a decade following the earthquake. The risk dynamics and controlling factors were analyzed to obtain a better understanding of post-earthquake landslide hazard and risk as a basis for reconstruction planning.

The specific objectives of this research are:

1. To monitor the changes in frequency, magnitude and controlling factors of post-seismic landslides by creating a comprehensive database based on remote sensing images from different years (Chapter 2);

2. To investigate if it is possible to accurately determine the evolution of loose materials in the area with Digital Elevation models from multiple sources, with an acceptable accuracy (Chapter 3, 4);

3. To study what is the changes in exposure brought by disaster impact and reconstruction by creating a database of elements-at-risk based on multitemporal image interpretation and field investigation (Chapter 5).

4. To assess potential losses from debris flows by combining the information on debris flow hazards and exposure on a yearly basis for the decade following the earthquake (Chapter 6).

\subsection{Study area}

The study area (Figure 1.3) is located near the epicenter of the Wenchuan earthquake, around the towns of Yingxiu and Longchi, in Sichuan province, China, covering approximately $242 \mathrm{Km}^{2}$. The elevation varies from $767 \mathrm{~m}$ to $3950 \mathrm{~m}$, with an average of $1736 \mathrm{~m}$. The Yingxiu area, in the western side, is steeper than the Longchi area in the eastern side (Figure $1.4 \mathrm{~A}$ ). Areas with slopes steeper than $45^{\circ}$ cover $21 \%$ of Yingxiu and only $2 \%$ of the Longchi area. One of the two major faults that ruptured during the Wenchuan earthquake pass through the area: the Yingxiu -Beichuan fault, which had a horizontal displacement of $4.5 \mathrm{~m}$ and a vertical displacement of $6.2 \mathrm{~m}$ (Gorum et al., 2011) (Figure $1.4 \mathrm{~B}$ ). The Guanxian - Jiangyou fault located in the south-east was ruptured as well ( $\mathrm{Li}$ et al., 2010). The major surface ruptures discontinued in the eastern side of the study area and the follow-up rupture is $3 \mathrm{~km}$ to the north-east (Figure 1.3). The predominant lithologies are granite $(47 \%$ of the area), diorite (18\%) in the western part, and feldspar sandstone with shale and coal strata (22\%), limestones and shales in the south-eastern part which are bounded by faults. 


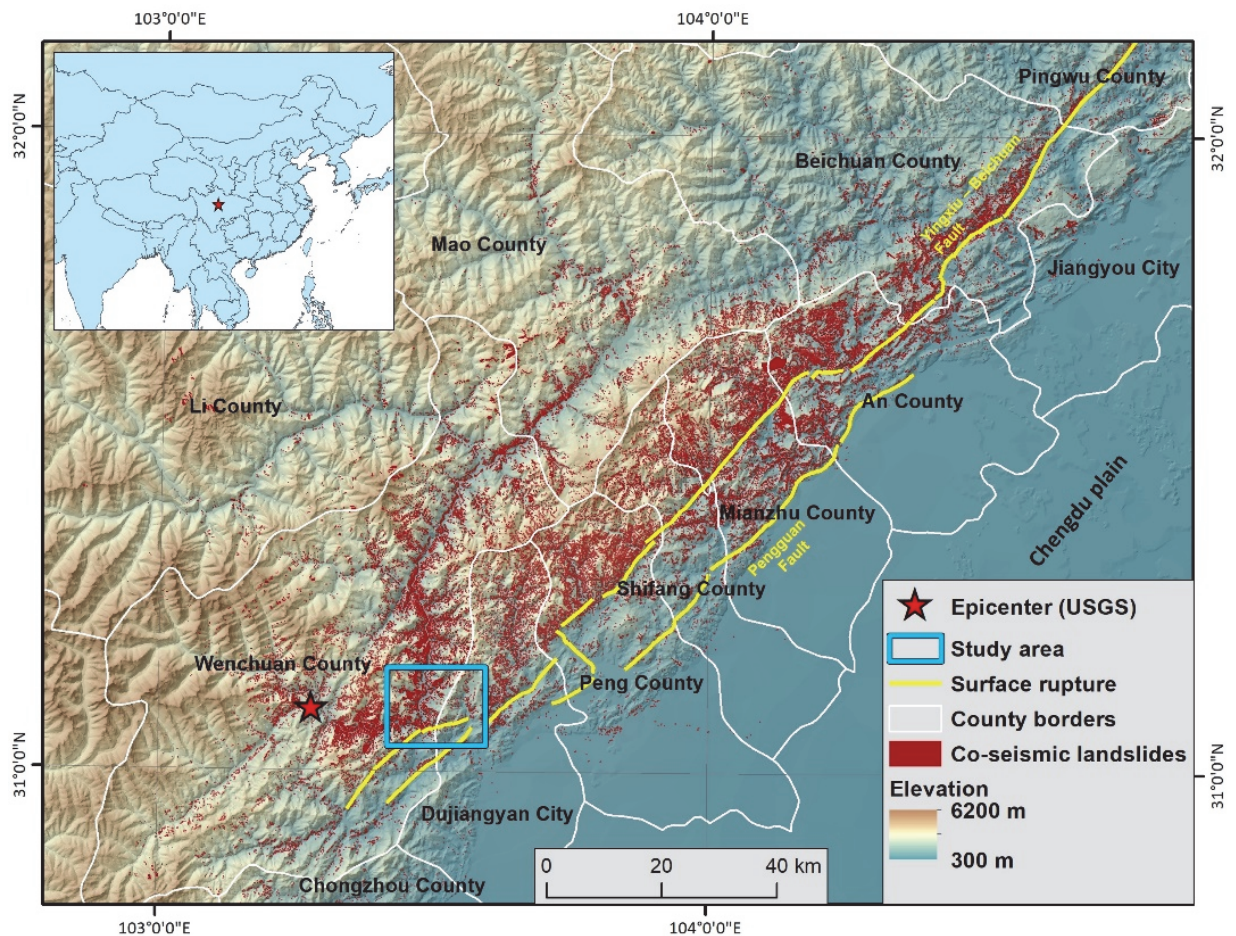

Figure 1.3: The location of the study area. Co-seismic landslides are from the inventories made by Dai et al. (2011) and Gorum et al. (2011). The total landslides mapped by Dai et al. (2011) is 48,007 and by Gorum et al. (2011) it is 60,109.

The climate is humid subtropical with an annual average temperature of $13^{\circ} \mathrm{C}$. The average yearly precipitation in the area is $1134 \mathrm{~mm}$, and $70 \%$ of the precipitation occurs from June to September. The highest precipitation is in August, with an average monthly rainfall of $289.9 \mathrm{~mm}$. The recorded maximum monthly, daily, and hourly precipitation amounts are $593 \mathrm{~mm}, 234 \mathrm{~mm}$ and 84 $\mathrm{mm}$ respectively (Liu et al., 2010). Three rivers flow through in this region (Figure 1.4 A): the Erhe River and Longxi River are the tributaries of Minjiang River (which is again a tributary of Yangtze River). The river flows through the Zipingpu Hydropower Reservoir, which is also one of the major water sources of the province, providing drinking water to the settlements on Chengdu Plain, including the city of Chengdu with 16.3 million inhabitants. 


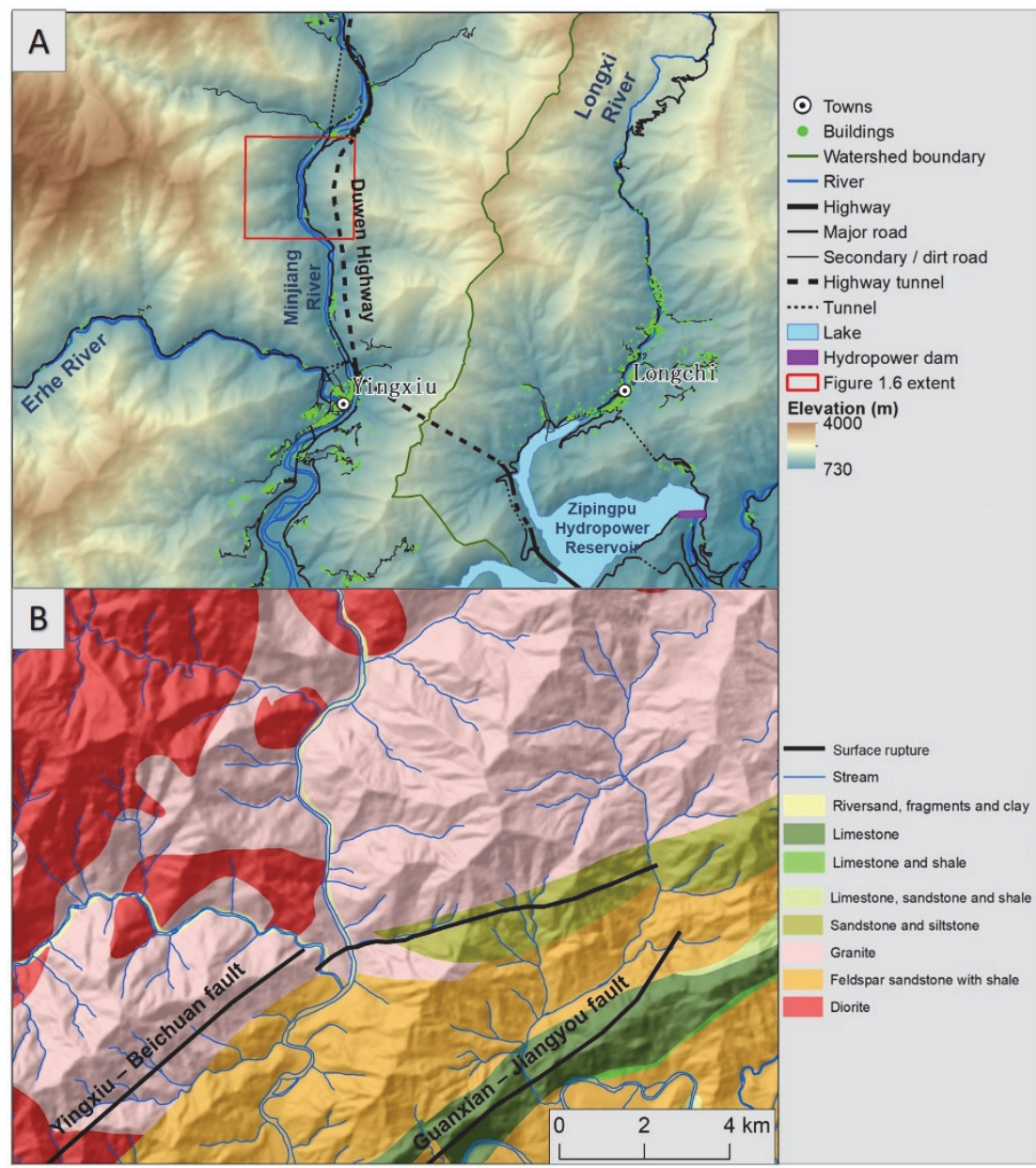

Figure 1.4: A: Elevation map, with main built-up and hydrological features of the study area. The western part of the dark green line is the Yingxiu area and the east part is the Longchi area. The built-up features represent the situation of 2014, after completion of the reconstruction. B: Geological map of the study area

Due to the limited space in the mountainous region, buildings in both pre- and post-earthquake periods were built along the rivers (Figure $1.4 \mathrm{~A}$ ). Some of the pre-earthquake buildings were located on historical debris flow fans and landslide deposits. Due to the strong shaking generated by the ruptured Yingxiu - Beichuan fault, the majority of the buildings and transportation networks were destroyed. After the relief stage the reconstruction began in 2009, and 19 of the Chinese provinces supported each one of the affected counties or cities in the recovery by using at least $1 \%$ of their annual provincial revenue for a period of 3 years (Dunford and Li, 2011; Huang et al., 2011; United Nations Office for Disaster Risk Reduction (UNISDR), 2010; Zuo et al., 2013). The city of Dongguan, in Shandong province, was assigned 
responsibility to execute the recovery activities in the Yingxiu region, and the city of Shanghai was assigned to assist the nearby Dujiangyan city, and the surrounding area, including the Longchi region.

Most of the reconstruction was finished by 2010, but in the monsoon of the same year a storm triggered debris flows from most of the catchments, severely damaging the new buildings. The reconstruction was finished in 2012 .

The region was densely covered by shrubs and broadleaf forest, with sparse patches of coniferous forest before the earthquake (Figure $1.5 \mathrm{~A}$ ).
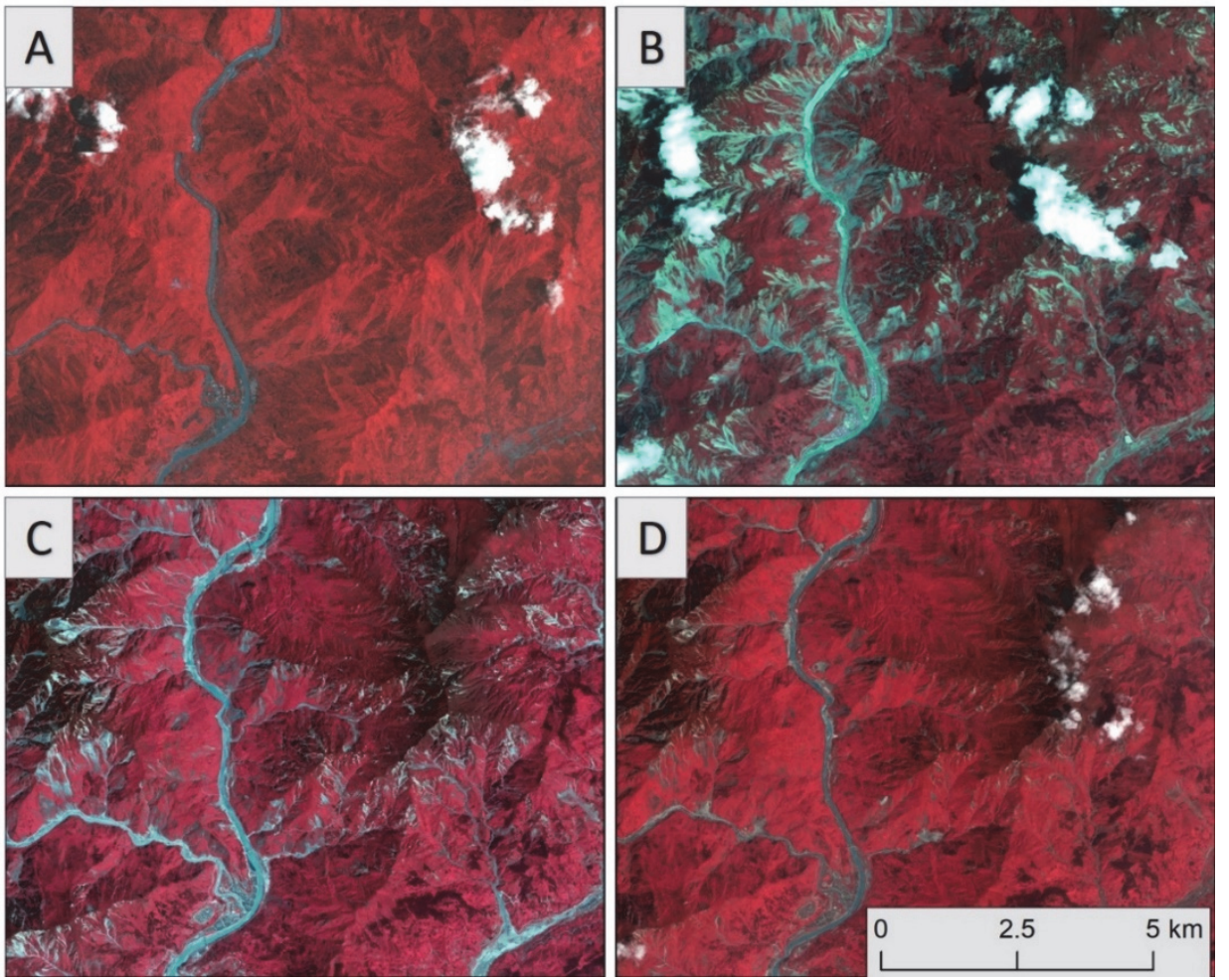

Figure 1.5: False color composite satellite images before and after the earthquake, showing the large extend of forested areas before the earthquake, the numerous unvegetated slopes due to landslides, and the gradual vegetation recovery. A: SPOT 5 image from 2005. B: SPOT 5 image from 2009. C: Pleiades image from 2014. D: Pleiades image from 2018.

As a result of the earthquake, large bare areas caused by landslides covered the slopes and their foot zones (Fig 1.5 B). After the 2010 disaster vegetation recovered rapidly (Figure 1.5 C, D). By April 2018, bare surfaces were restricted to streams of large watersheds and on steep slopes near mountain ridges (Figure $1.5 \mathrm{D}$ ). 
Co-seismic landslides were mapped in this region by different groups of researchers. Dai et al. (2011) first mapped polygon-based co-seismic landslides throughout the entire earthquake-hit region. Due to limited time and resources this inventory ignored small-size landslides, resulting in only 55 landslides in the example area shown in Figure 1.6 A. In the same year Gorum et al. (2011) generated a point-based inventory which contained 68 landslides for the example area. Later $\mathrm{Xu}$ et al. (2013) included small-size landslides based on the work of Dai et al. (2011), resulting in 286 landslides (Figure 1.6 B). Fan et al. (2019a) mapped co-seismic landslides with a more detailed boundary in the Wenchuan county, containing 289 landslides in the example area (Figure $1.6 \mathrm{C}$ ).

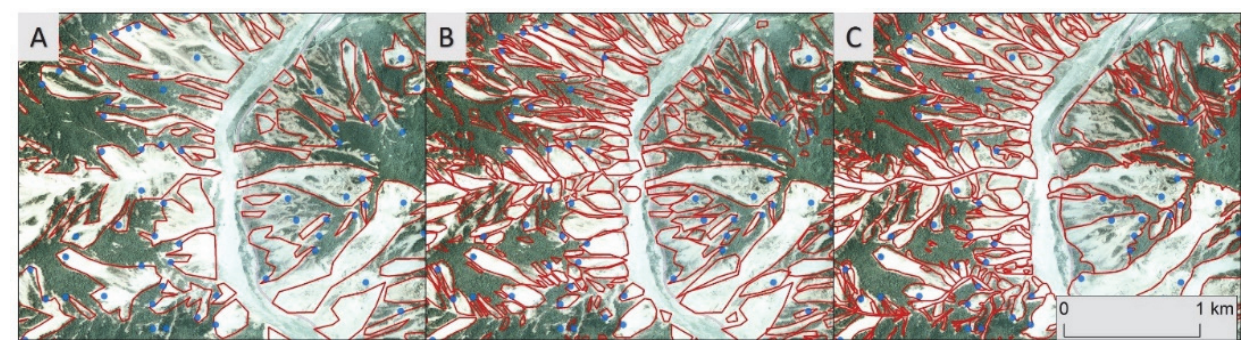

Figure 1.6: Differences in co-seismic landslide mapping. The example area located in the study area shown in Figure 1.4. The background image is an aerial photograph taken in June 2008. Three polygon-based (red) and one point-based (blue) inventories are shown. The point-based inventory is from Gorum et al. (2011), and polygon-based inventories are from: A: Dai et al. (2011) with 55 landslides; B: Xu et al. (2013) with 286 landslides; C: Fan et al. (2019a) with 289 landslides. After Fan et al. (2019b). The extent of the figure is illustrated in Figure 1.4.

\subsection{Thesis structure}

The thesis consists of seven chapters, including five core chapters.:

Chapter 1 (this chapter) introduces the general background of the research, problem statement, research objectives, and description of the study area.

Chapter 2 presents a series of multi-temporal landslide inventories generated through digital visual image interpretation, in order to analyze the changes in post-seismic landslide activity.

Chapter 3 presents a study based on nine DEMs taken at different years and from different sensors to analyze the volume changes caused by co-seismic and post-seismic landslides over a period of 9 years.

Chapter 4 presents a method developed in MATLAB to model landslide volume based on the geometry of failure surfaces. 
Chapter 5 presents the generation and analysis of a multi-temporal elementat-risk database. The results showed that the total economic value of the new buildings in 2010 were more than 10 times that of the buildings in 2007 and the loss caused by post-seismic debris flows was more that the loss caused by the earthquake.

Chapter 6 presents a catchment-based semi-quantitative debris flow loss assessment using an empirical method with historical events over a 10-year period since the earthquake.

Chapter 7 summarizes the results and provides conclusions, and recommendations. 


\section{Analyzing post-earthquake landslide activity using multi-temporal landslide inventories $^{1}$}

\subsection{Background}

Large earthquakes can cause huge losses to human society due to ground shaking, fault rupture, liquefaction, tsunamis and also due to co-seismic landslides that can be triggered in mountainous areas. Some examples of earthquake-triggered landslide events are the 1976 Guatemala earthquake ( $\mathrm{M}_{\mathrm{w}}$ 7.5), with 50,000 landslides (Cruden and Varnes, 1996a), the 1994 Northridge Earthquake ( $M_{w}$ 6.7) in California with more than 11,000 landslides (Harp and Jibson, 1996), the 1999 Chi-Chi earthquake $\left(M_{w} 7.6\right)$ in Taiwan of ROC with 26,000 co-seismic landslides (Cheng et al., 2005), and the 2008 Wenchuan earthquake ( $M_{w}$ 7.9) in China with about 200,000 landslides (Xu et al., 2013). In areas that have been affected by such large earthquakes, the threat of landslides persists in the years following the earthquake, as huge amounts of deposits loosened by the earthquake on hillslopes provide sufficient source materials for landslide reactivations and debris flow occurrences during heavy rainstorms. For example, after the 1999 Chi-Chi earthquake (Mw 7.6), a number of extreme precipitation events reactivated the co-seismic landslides and triggered several catastrophic mass movements, such as the debris flow which destroyed Daxing village on 30 July 2001, and the landslide that buried Hsiaolin village forming a barrier lake in 2009 (Dong et al., 2011). Many studies about post-earthquake landslides were carried out after the Chi-Chi earthquake, including Fan et al. (2003), Chang et al. (2006), and Lin et al. (2006a).

The devastating Wenchuan earthquake occurred in the western part of Sichuan province in China on May 12, 2008. In the years following the earthquake, several catastrophic debris flows occurred, demonstrating many of the postseismic landslide problems. Some significant examples are the debris flows that destroyed part of Beichuan town on September 24 2008, the debris flow which dammed the Minjiang River on August 13 2010, and the debris flow which damaged Qipangou village on July 102013 (Tang et al., 2009; Xu et al., 2012). These post-earthquake mass movements highlighted the need for more research to provide critical information for assessing post-earthquake landslide

\footnotetext{
${ }^{1}$ This chapter is based on the following paper: Tang, C., Van Westen, C. J., Tanyas, H., and Jetten, V. G., 2016, Analyzing post-earthquake landslide activity using multitemporal landslide inventories near the epicentral area of the 2008 Wenchuan earthquake: Nat. Hazards Earth Syst. Sci., v. 16, no. 12, p. 2641-2655.
} 
hazards as a basis for reconstruction planning in earthquake affected mountain areas.

The majority of the research thus far in the Wenchuan area focused on the analysis of case studies (e.g. Xu et al. (2012); Ni et al. (2011); Tang and Liang (2008)), co-seismic landslides (e.g. Dai et al. (2011); Fan et al. (2012); Gorum et al. (2011)) and post-seismic landslide mechanisms (e.g. Zhuang et al. (2012); Zhang et al. (2013a); You et al. (2011)). Some also studied vegetation recovery (e.g. Liu et al. (2010), Lu et al. (2012), Wang et al. (2014)). Limited research has concentrated on the long-term evolution of landslide activities, and the changes in the geo-environment after earthquakes. Hovius et al. (2011) analyzed the long-term erosion and mass balance effects of the ChiChi earthquake. They concluded that the enhanced mass wasting and sediment removal after the earthquake was more than five times the pre-earthquake rate, and it required about six years to return to pre-earthquake levels. For the Chi-Chi earthquake this was reported by several authors (Lin et al., 2008; Shieh et al., 2009a; Shou et al., 2011a; Shou et al., 2011b). For the Wenchuan earthquake area, some researchers have studied the short term (within 3 years) changes in landslide reactivation after storms (Tang et al., 2011a; Wang et al., 2014). Huang and Fan (2013a) made a prediction that it will take about 20 years before the landslide activity will return to pre-earthquake levels; however, this was not based on long-term studies.

The objective of this study is to analyze the changes in landslide activity after the Wenchuan earthquake, based on detailed landslide inventory maps, generated from seven high-resolution images from 2005 to 2015, in order to contribute to the long term monitoring of post-earthquake landslide activity. (Fan et al., 2019a)

\subsection{Data \& Methods}

\subsubsection{Remote sensing data and pre-processing}

We have acquired multiple remote sensing images from various sources for generating the multi-temporal landslide inventories. Based on the resolution, cloud coverage, and shadows, a total of 6 images taken in 2008, 2009, 2011, 2013 and 2015 were selected to monitor the landslide activities after the earthquake and 1 image was selected from 2005 representing the preearthquake situation (Table 2.1). 
Table 2.1: Data used in this research. The two images taken in 2008 have $7 \%$ of the study area covered by clouds on both images. The other images are cloud free. Information area (\%) represents the percentage of the area not covered by clouds and inside of the image boundaries.

\begin{tabular}{|c|c|c|c|c|c|c|}
\hline Type & Source & $\begin{array}{c}\text { Acquisition } \\
\text { date }\end{array}$ & $\begin{array}{c}\text { Resolution } \\
(\mathrm{m})\end{array}$ & $\begin{array}{c}\text { Information } \\
\text { area (\%) }\end{array}$ & Band & Usage \\
\hline \multirow{7}{*}{ Images } & Spot 5 & Jul 2005 & 2.5 & 95 & Multi-spectral & \multirow{7}{*}{$\begin{array}{l}\text { Generating } \\
\text { landslide } \\
\text { inventories }\end{array}$} \\
\hline & $\begin{array}{c}\text { Arial } \\
\text { photographs }\end{array}$ & Jun 2008 & 1 & 69 & RGB & \\
\hline & \multirow{2}{*}{ Spot 5} & July 2008 & 2.5 & 74 & Panchromatic & \\
\hline & & Feb 2009 & 2.5 & 100 & $\mid \begin{array}{c}\text { Panchromatic + } \\
\text { multi-spectral }\end{array}$ & \\
\hline & Worldview 2 & Apr 2011 & 1 & 100 & Pansharpened & \\
\hline & Pleiades & Apr 2013 & 0.5 & 69 & $\begin{array}{c}\text { Panchromatic }+ \\
\text { multi-spectral }\end{array}$ & \\
\hline & Spot 6 & Apr 2015 & 1.5 & 97 & Pansharpened & \\
\hline DEM & $\begin{array}{l}\text { Government, } \\
\text { academic } \\
\text { institute }\end{array}$ & 2006 & 25 & \multirow{6}{*}{ - } & \multirow{6}{*}{-} & $\begin{array}{c}\text { Digitizing } \\
\text { landslides, } \\
\text { factor analysis }\end{array}$ \\
\hline Lithology & $\begin{array}{c}\text { Official geology } \\
\text { map, } \\
\text { Geological } \\
\text { Survey } \\
\end{array}$ & 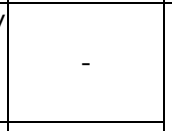 & \multirow{5}{*}{ - } & & & $\begin{array}{c}\text { Factor } \\
\text { analysis }\end{array}$ \\
\hline \multirow{4}{*}{$\begin{array}{l}\text { Peak rainfall } \\
\text { intensity and } \\
\text { cumulative } \\
\text { precipitation }\end{array}$} & $\begin{array}{c}\text { Tang and Liang } \\
(2008)\end{array}$ & 2008 & & & & \multirow{4}{*}{$\begin{array}{l}\text { Analyzing } \\
\text { post-seismic } \\
\text { landslide } \\
\text { activities }\end{array}$} \\
\hline & $\begin{array}{l}\text { Liu et al. } \\
(2010)\end{array}$ & 2009 & & & & \\
\hline & $\begin{array}{l}\text { Ma et al. } \\
\text { (2011) }\end{array}$ & 2010 & & & & \\
\hline & $\begin{array}{l}\text { Rain gauges } \\
\text { installed by } \\
\text { SKLGP }\end{array}$ & $2011-2015$ & & & & \\
\hline
\end{tabular}

To assist landslide digitizing with stereo visualization and to analyze controlling factors of post-seismic landslide activities, a Digital Elevation Model derived from $20 \mathrm{~m}$-interval contour lines was collected from the State Key Laboratory of Geo-hazard Prevention and Geo-environment Protection (SKLGP) in Chengdu, Sichuan province. 
Erdas and ArcMap were used for producing the image dataset. The Pleiades and the Worldview 2 images have very high resolution and are geometrically consistent with the dataset provided by State Key Laboratory for Geohazard Prevention and Environmental Protection (SKLGP). Thus they were used as the reference images for geometric calibration. The other satellite images were ortho-rectified with the Digital Elevation Model (DEM) in Erdas. Dozens of GCPs and hundreds of auto tie points were used to calibrate the images in Erdas Autosync Station. One of the problematic images was the 2009 Spot 5 image, which showed geometric errors in the steep mountain peak areas. About 180 co-seismic landslides were located in these problematic areas. The mass movement traces with bright tones and loss of vegetation could still be seen except for the pre-existing small landslides, a simplification was applied for the inventory of 2009: all the not enlarged pre-existing small landslides were considered as dormant. By digitizing post-seismic landslides based on the coseismic landslide inventory, the landslide boundaries were kept consistent, minimizing the errors caused by image qualities.

\subsubsection{Multi-temporal landslide inventories}

Digital stereoscopic image interpretation was used for mapping the landslide inventories. The images were combined with the DEM, and a series of artificial stereo images were generated using ArcScene. Co-seismic landslides were digitized first. We carefully compared the pre-and post-earthquake images to determine which of the landslides were co-seismic, and which were already existing before the earthquake. Existing landslide inventories, generated by Gorum et al. (2011), Dai et al. (2011) , Xu et al. (2014), and Li et al. (2014) were evaluated. These inventories didn't match very well with each other, and also not with the geo-rectified remote sensing images used in this study (See Figure 1.6). Therefore, also co-seismic landslide inventory mapping was carried out new for the study area. The mapping accuracy was kept at a high level by comparing the landslides on different images and by checking the landslides in the field. All the landslides were categorized based on the system proposed by British Geological Survey (BGS) which follows the scheme based on Liu et al. (2010) and Fan et al. (2012). The landslides were classified by their material component and mass movement types (Figure 2.1). Two types of material were differentiated: debris and rock. Debris, a mixture of soil and rock fragments, was interpreted from images when a fine material texture covers most of the deposition area. The parent material was interpreted as rock when rock fragments or blocks or textures of rock deposits could be clearly seen on the images. Comparing images of different years also helped to distinguish debris and rock, since landslides with rock blocks are re-vegetated much slower than debris related mass movements, even when there is no further landslide activity observed. 
We differentiated the following mass movement types: fall, slide and flow. In the case of fall, materials fall from steep cliffs, with little additional displacement. Bedrock can be seen very clearly in the scarp area and the accumulation area often tends to be cone-shaped. Slide-type movements are characterized by clear back scarps, and the identification of a sliding mass, either translational or rotational in form. Flow-type movements are mostly confined to channels and occur mostly as debris flows.

Also combinations of movement types have been observed. The most frequent combinations were slide and flow, and slide and fall types. Fall-slide, a combination of fall and sliding, can be observed when a fall-type movement occurs on a steep slope and the deposits slide down further during or after deposition. Slide-fall movements initiate as a slide on top of a steep cliff, and the slided materials subsequently fall over a cliff. A very common combination of landslide types is slide-flow, where the source areas of a debris flow are formed by one or more slide-type movements. This is more difficult to identify in the post-seismic landslides since they are often caused by a combination of initiation features, such as accelerated erosion, bank failure and shallow landslides in the sediment source areas. For post-earthquake landslide inventories we only use the types fall, slide and flow to represent their movement types, since the combined types are difficult to identify for reactivations of co-seismic landslides and the predominance of debris flows caused by different processes made it problematic to differentiate.

The earthquake-induced landslides were interpreted using an ortho-rectified mosaic of very high resolution color aerial photographs taken shortly after the earthquake and two Spot 5 images: one from 2005 and the other one taken shortly after the earthquake. The satellite image from 2005 revealed almost no landslide activity prior to the earthquake. Landslides were identified based on image characteristics such as tone, texture, shape and pattern, and using topographic, vegetation and drainage indicators identified through stereoscopic image interpretation (Soeters and van Westen, 1996). Individual landslides were identified based on their unique scarp areas, even though the accumulation areas were often merged downslope. Each landslide polygon was assigned a unique identifier. Areas covered by clouds were digitized and were not considered for the 2008 - 2009 change analysis. 

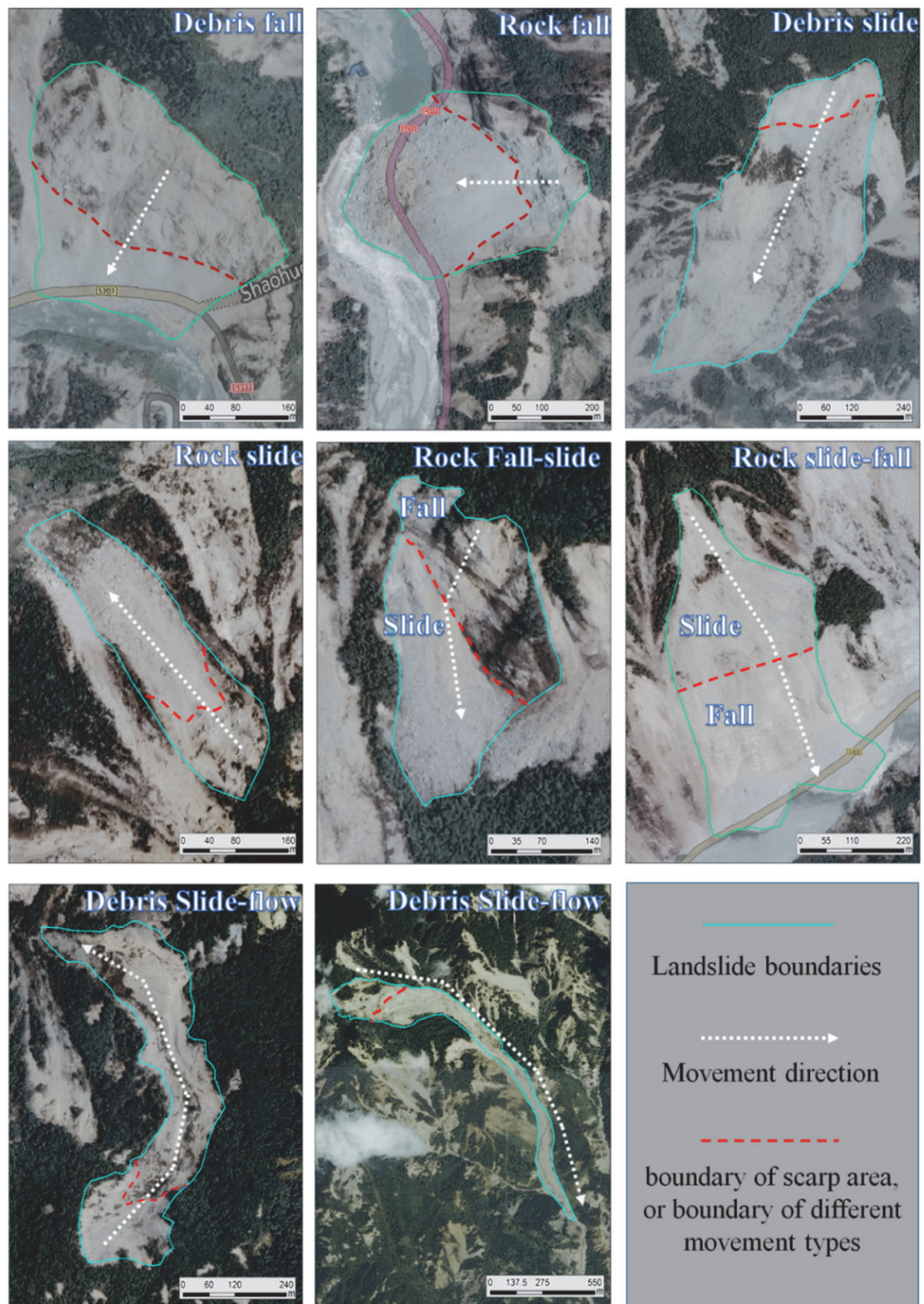

boundary of scarp area, or boundary of different movement types

Figure 2.1: Examples of landslide classifications used. The background is the aerial photo taken in 2008.

The interpretation of post-earthquake landslides was carried out by comparing remote sensing images of different years, starting from the earliest postearthquake image in 2009. The co-seismic landslide inventory was used as the basis for the inventory of the post-earthquake landslides of the following year. 
Then this inventory was used as the basis for the next, and so on. All landslide polygons from the co-seismic landslide inventory were classified for each period with a landslide activity level and a vegetation cover level. Changes caused by the enlargement of existing landslides and newly triggered landslides were included in the digital inventories, and also changes in landslide classifications were marked in the associated attribute tables. If in a later year landslide activity was confined within the polygon of a pre-existing landslide, no digitization was done and the polygon of the pre-existing landslide was assigned with a landslide activity class value based on the level of the activity. This was done for all the consecutive years. If there is no activity in a preexisting landslide polygon, the landslide is considered as a dormant landslide. Several tools in ArcMap were used to calculate attributes for the landslide polygons related to area, slope, aspect, and major lithology in the landslide polygons. The attribute table of the landslide inventories is shown in Table 2.2.

The landslide activity levels were defined based on the changes in the diagnostic features between remote sensing images taken in different periods. The vegetation cover alone does not determine whether a landslide is active or not. A landslide can be bare and dormant, or partly covered by vegetation and active. The following landslide activity classes were used: level 0 , no landslide activity and the landslide is dormant; level 1 , less than $1 / 3$ of the area of a landslide is active; level 2 about $1 / 3$ to $2 / 3$ of the area of a landslide is active; level 3 , more than $2 / 3$ of a landslide is active or the landslide is newly formed.

The vegetation cover level was judged by the area of vegetation cover on landslides and was classified into four classes: level 0 , most area of the landslide is covered by vegetation; level 1 , more than $2 / 3$ of the landslide is covered by vegetation; level $2,1 / 3$ to $2 / 3$ of the landslide is covered by vegetation; level 3 , less than $1 / 3$ of the area of a landslide is covered by vegetation.

\subsection{Results}

\subsubsection{Co-seismic landslides}

The co-seismic landslide inventory map for the study area is shown in Figure 2.2. 
Table 2.2: Attributes collected for the landslide inventories.

\begin{tabular}{|l|l|}
\hline Attributes & Description \\
\hline ID & Landslide identifier \\
\hline Material & The material component of the landslide (rock or debris) \\
\hline Mass movement type & $\begin{array}{l}\text { The mass movement type (fall, slide, flow, fall-slide or slide- } \\
\text { flow) }\end{array}$ \\
\hline No information & $\begin{array}{l}\text { The landslide is covered by clouds or located outside of the } \\
\text { image boundary }\end{array}$ \\
\hline Landslide activity level & $\begin{array}{l}\text { The landslide activity class }(0: \text { dormant; } 1:<1 / 3 \text { active, } 2: \\
1 / 3-2 / 3 \text { active; } 3:>2 / 3 \text { active). }\end{array}$ \\
\hline Vegetation cover level & $\begin{array}{l}\text { The vegetation cover class }(0: \text { vegetated; } 1: \quad 2 / 3 \\
\text { vegetated, } 2: 1 / 3-2 / 3 \text { vegetated; } 3:<1 / 3 \text { vegetated). }\end{array}$ \\
\hline New landslide & $\begin{array}{l}\text { Landslide that does not occur on pre-existing landslide. The } \\
\text { year in which it is first seen is indicated }\end{array}$ \\
\hline Area & The area of the landslide in ${ }^{2}$ \\
\hline Lithology & $\begin{array}{l}\text { The major lithology within the scarp area of a landslide } \\
\text { polygon }\end{array}$ \\
\hline Aspect & The orientation of slopes in the scarp area \\
\hline Max slope angle & $\begin{array}{l}\text { The highest slope angle which is calculated from the DEM in } \\
\text { a landslide polygon }\end{array}$ \\
\hline
\end{tabular}

The co-seismic landslide inventory contains 6727 landslides with a total area of $54.6 \mathrm{~km}^{2}$, covering about $29.4 \%$ of the $179 \mathrm{~km}^{2}$ interpretation area. The average and median area of the co-seismic landslides are $8122 \mathrm{~m}^{2}$ and 2141 $\mathrm{m}^{2}$ respectively. About $25 \%$ of all the landslides have an area of $100-800 \mathrm{~m}^{2}$. When we apply the empirical area-volume relationships presented by Guzzetti et al. (2009), the total volume of the interpreted co-seismic landslides is 0.48 $\mathrm{Km}^{3}$. Obviously the size of the individually mapped landslides has a large influence on the volume estimation, and the degree of generalization of a landslide inventory is therefore of importance. When we use the same relation using the inventory of Dai et al. (2011) which has large landslide polygons merging multiple individual landslides, the result is $0.63 \mathrm{Km}^{3}$. Most of the large earthquake-triggered landslides are in the western part of the study area, which has a steeper terrain and is closer to the epicentre. The mean size of the landslides in the western part is about $10,000 \mathrm{~m}^{2}$. Most of the co-seismic landslides in the eastern part of the study area are small and medium-size with an average area of $3782 \mathrm{~m}^{2}$. Table 2.3 shows the relation between lithology and landslides, which shows that most landslides occurred in granite and diorite. 
Table 2.3: The relation between lithology and co-seismic landslides

\begin{tabular}{|l|l|l|l|l|}
\hline Lithology type & $\begin{array}{l}\text { Number of } \\
\text { landslides }\end{array}$ & $\begin{array}{l}\text { Number density } \\
\text { (landslides/km²) }\end{array}$ & $\begin{array}{l}\text { Area of } \\
\text { landslides } \\
\left(\mathrm{km}^{2}\right)\end{array}$ & $\begin{array}{l}\text { Area density } \\
(\%)\end{array}$ \\
\hline Diorite & 1208 & 34.2 & 16.4 & 46 \\
\hline Granite & 4713 & 46.4 & 34.1 & 34 \\
\hline Sandstone with & 522 & 48.3 & 2.5 & 23 \\
\hline $\begin{array}{l}\text { Feldspar } \\
\text { sandstone } \\
\text { shale }\end{array}$ & 12.3 & 1.6 & 7 \\
\hline
\end{tabular}

Table 2.4 gives a summary of the co-seismic landslide inventory generated in this study. The most common landslide type were debris slides (5604 out of a total of 6727), due to the strong topographic amplification leading to the failure of the weathering soil mantle. In specific locations, where the structural geology was favorable, rock slides took place along discontinuities (262 events). In a number of cases the presence of steep cliffs resulted in fall type of movements (513 events) or a combination of fall and slide types (177). It is remarkable that the number of flow-related co-seismic mass movements was relatively limited (171 cases) which is also due to the fact that the earthquake occurred during the dry season.

Table 2.4: co-seismic landslide types

\begin{tabular}{|l|l|l|l|l|l|}
\hline & Slide & Fall & Fall-slide & Slide-flow & Sum \\
\hline Debris & 5604 & 272 & 124 & 171 & 6171 \\
\hline Rock & 262 & 241 & 53 & 0 & 556 \\
\hline sum & 5866 & 513 & 177 & 171 & 6727 \\
\hline
\end{tabular}




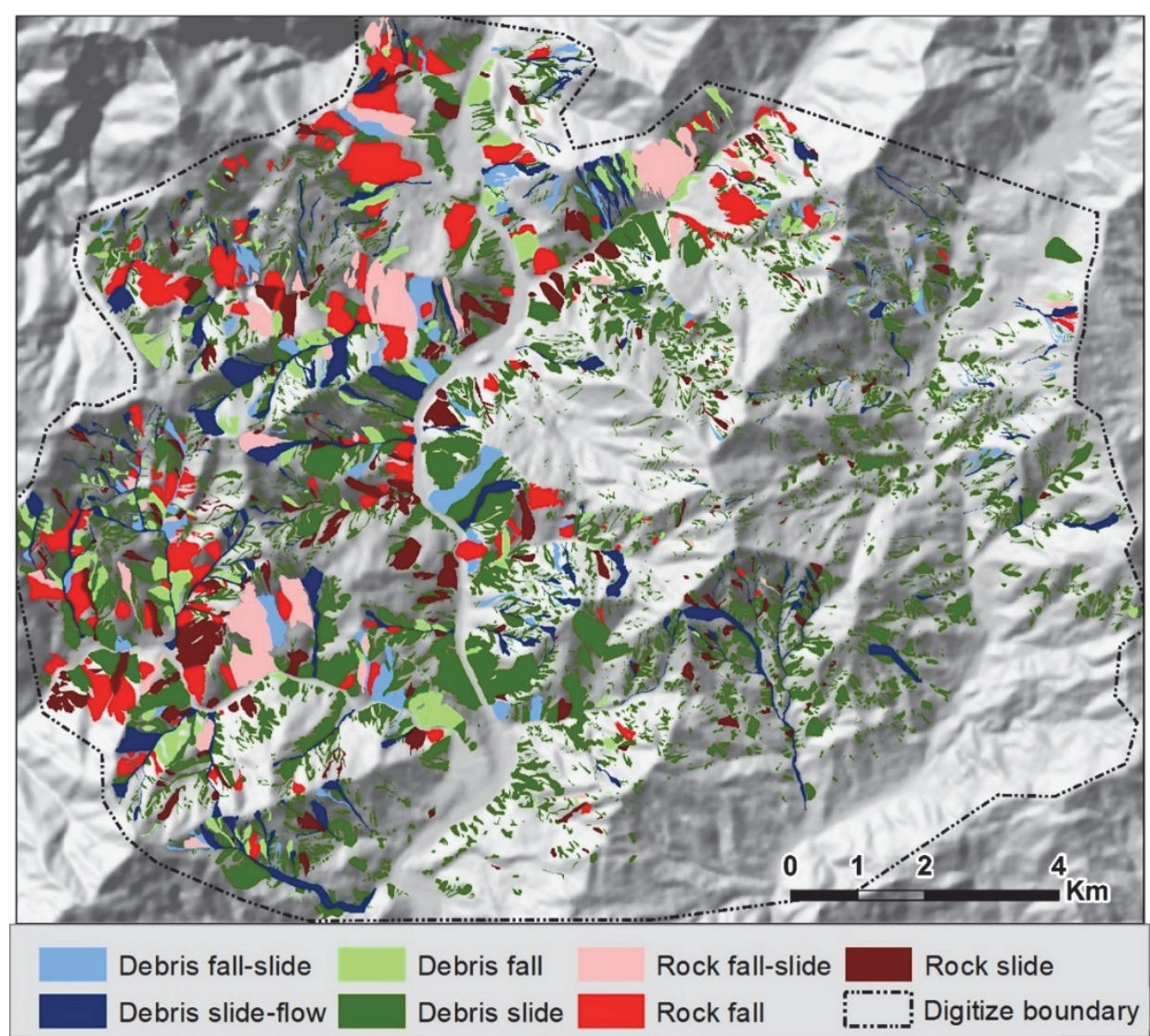

Figure 2.2: Co-seismic landslide inventory.

Both the number of landslides in our inventory and the area affected are much higher than the values reported by Dai et al. (2011). They mapped only 661 landslides as polygons with a total area of $33.8 \mathrm{Km}^{2}$ within the Yingxiu part of the study area. Due to clouds in their available image they didn't map the landslides in the Longchi area. In our inventory, we distinguished 4175 landslides with an area of $45.9 \mathrm{~km}^{2}$ in the Yingxiu area. Gorum et al. (2011) mapped 1141 landslide initiation points in our interpretation area. Our inventory contained approximately 6 times more landslides than the ones detected by Dai et al. (2011) and 3.5 times more than mapped by Gorum et al (2011). This difference is partly caused by the different aims of the studies, as the previous studies mapped landslides in the entire area affected by the Wenchuan earthquake. Apart from that the availability of very high-resolution aerial photographs taken shortly after the earthquake provided better resolution and lower cloud cover than the satellite images used by the other two studies. The other two studies ignored many small landslides because they had to map the entire earthquake affected area, while we devoted our time on 
landslide mapping for this smaller area. Dai et al. (2011) also merged several individual landslides into larger polygons (Figure. 2.3).

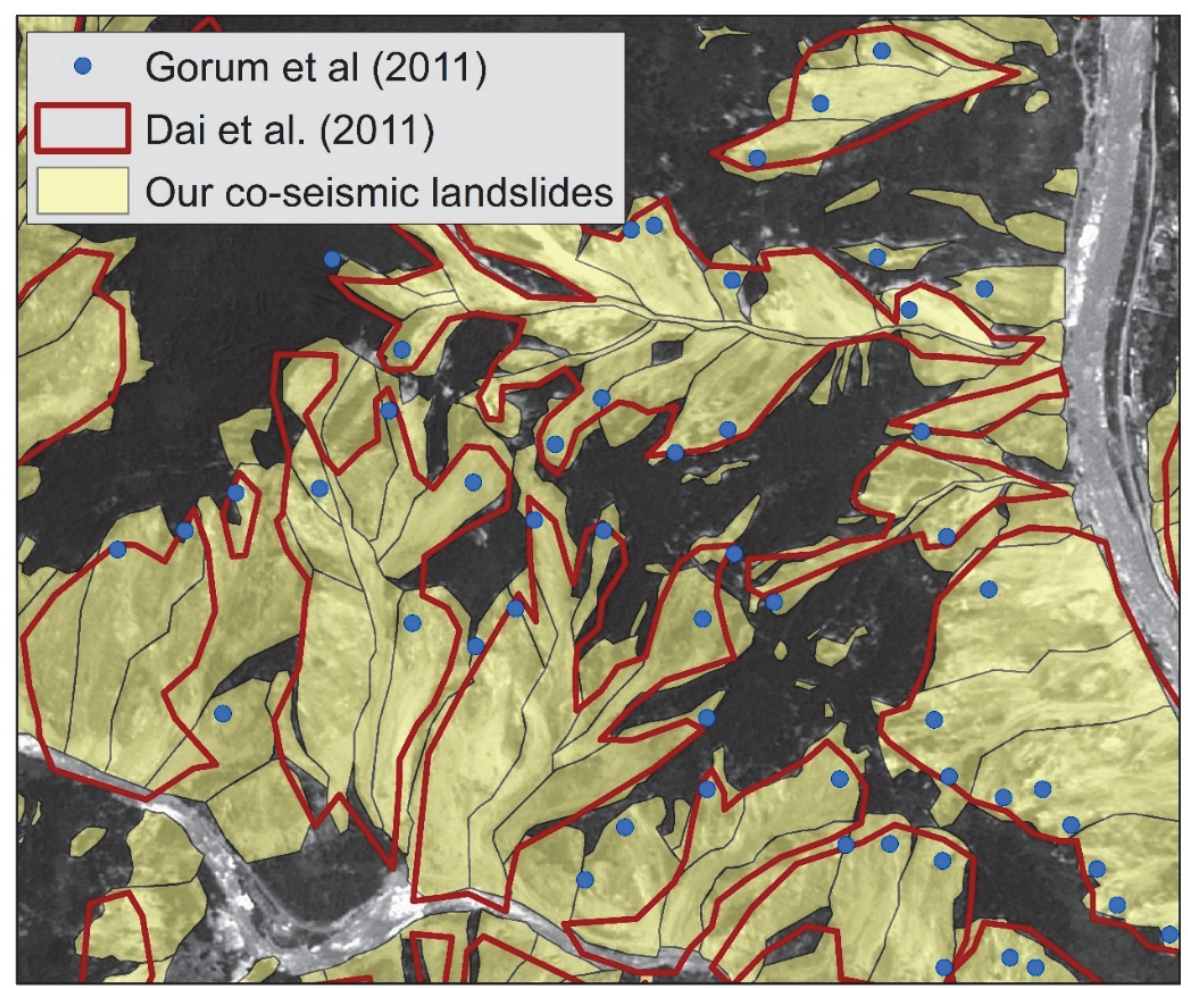

Figure 2.3: Comparing our inventory with the landslide initiation point inventory by Gorum et al. (2011) and the polygon-based inventory by Dai et al. (2011) for a small part of the area

For a more detailed comparison between the observed landslide sizes of the different Wenchuan inventories, we have utilized the polygon-based Wenchuan inventories provided by Xu et al. (2014), Li et al. (2014) and (Dai et al., 2011). Since these inventories cover a much larger landslide- affected area, we have extracted the landslides located inside our study area. The inventory from Gorum et al. (2011) could not be used as it only contained points, and no polygons.

We have analyzed the frequency-area distribution (FAD) of landslide areas and observed the power-law scaling (e.g. Guzzetti et al., 2002; Hovius et al., 1997; 2000; Malamud et al., 2004; Stark and Hovius, 2001) in all inventories (Figure. 2.4). In other words, we have observed an increasing trend in the number of the landslides from large to medium following a power-law. For each inventory, the slope of the FAD, which is called as the power-law exponent $(\beta)$, was calculated based on the method suggested by Clauset et al. (2009). The 
obtained $\beta$ values change from 2.4 to 2.7 (Table 2.5 ), which is consistent with the literature that points out an interval having a central tendency around 2.32.5 (Stark and Guzzetti, 2009; Van Den Eeckhaut et al., 2007). Towards the tail of the power-law where we have fewer large landslides, the FADs of the inventories follow a similar line. The position of the power-law tail is assumed as the manifestation of landslide magnitude (Malamud et al., 2004). Although we are analysing different inventories with a varying completeness level, illustrated by different rollover points and distributions of the smaller landslides, all inventories show similar magnitudes. This observation supports the landslide event quantification theory of Malamud et al. (2004).

In all inventories, we have also observed a divergence from the power-law distribution for the small landslides. The frequency of landslide areas begins to decrease after a certain size and follows a positive power-law decay; a phenomenon referred to as rollover (Stark and Hovius, 2001). Since the frequency of landslide areas keeps increasing up to the rollover point, the rollover point is considered as the most frequently occurring landslide area in the inventory (e.g. Parker et al., 2015). In this regard, we have evaluated the relative completeness level of the inventories. Since the inventory of Dai et al. (2011) is one of the pioneer inventories generated soon after the Wenchuan event, it has a relatively lower resolution. The average landslide area of this inventory is around $53000 \mathrm{~m}^{2}$, while for the other inventories this value changes between $5500 \mathrm{~m}^{2}$ and $8000 \mathrm{~m}^{2}$ (Table 2.5). Therefore, in the inventory from Dai et al. (2011) the rollover point is observed around 3850 $\mathrm{m}^{2}$, which is the largest rollover point among all the Wenchuan inventories. On the other hand, our inventory gives the lowest rollover point and it is nearlycomplete up to around $340 \mathrm{~m}^{2}$. This finding can be interpreted as the relatively higher completeness level of our inventory. The inventory of Xu et al. (2014) shows a similar completeness level as our product and it is nearly complete up to $500 \mathrm{~m}^{2}$. Furthermore, our inventory gives relatively smoother positive power-law decay than the inventory of Xu et al. (2014). It indicates that our inventory includes a higher number of smaller landslides as compared to the inventory from Xu et al. (2014). The rollover point for the inventory of Li et al. (2014) is around $1140 \mathrm{~m}^{2}$, and it can be considered as less complete compared to our inventory and the one by Xu et al. (2014). 


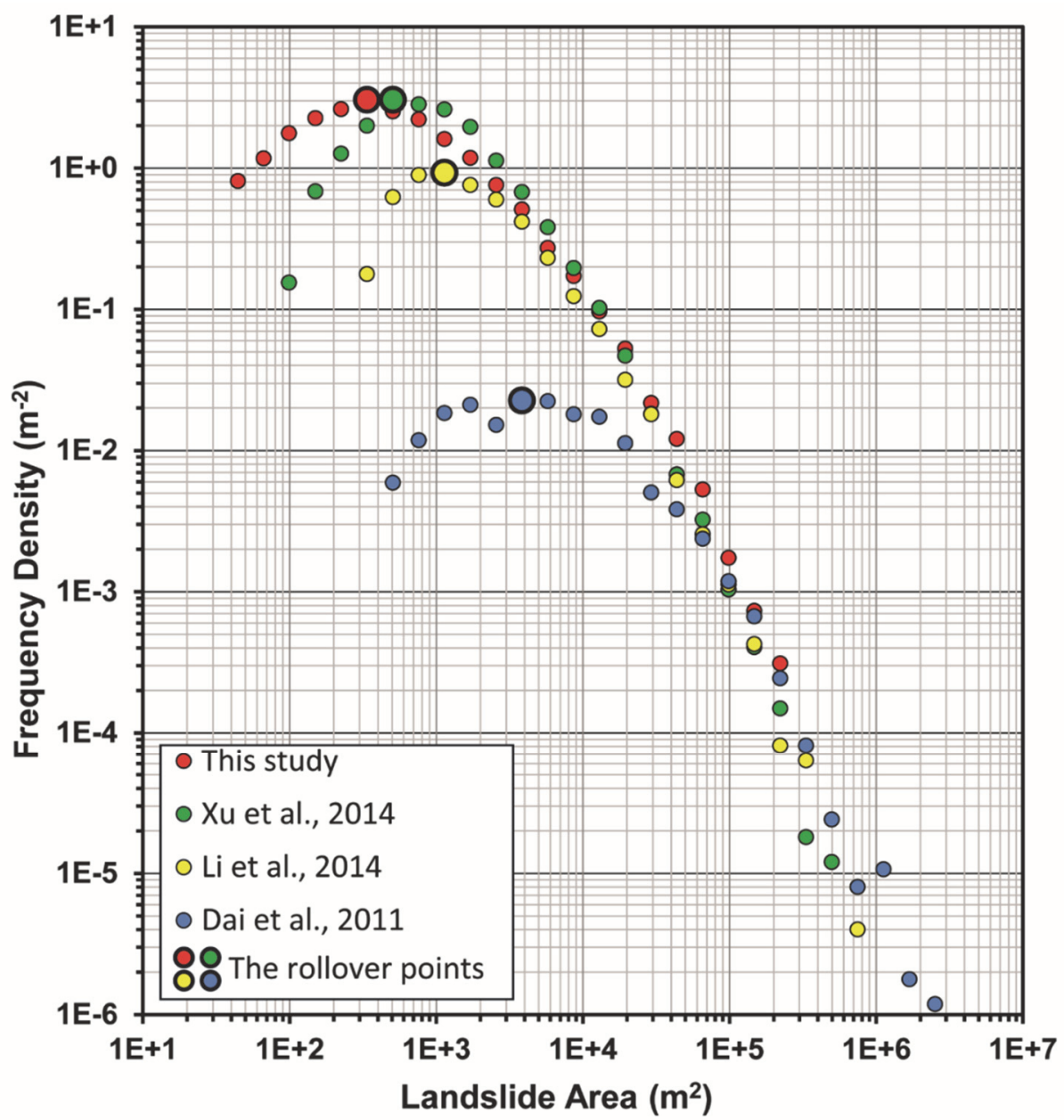

Figure 2.4: The frequency-area distributions (FAD) of the different co-seismic landslide inventories collected for the study area.

\subsubsection{Post-seismic landslide inventories}

In the years after the earthquake, large numbers of mass movements were induced by rain storms, whereas many others were slowly covered by vegetation regrowth. Using the available satellite images (Table 2.1), four new landslide inventories were generated.

An inventory for 2009 was made using a Spot 5 image from February 2009, with a spatial resolution of 2.5 meters. The inventory reflects the state of activity after the rainy season of 2008 , during which a large number of debris flows were formed. 
Table 2.5: Summary information for the co-seismic landslide inventories collected for the study area. $\beta$ is the power-law exponent of the frequency-area distribution (FAD).

\begin{tabular}{|c|c|c|c|c|c|c|c|}
\hline 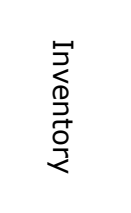 & 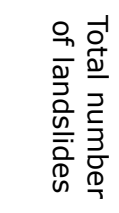 & 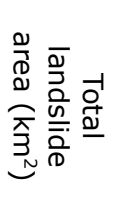 & 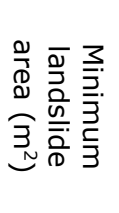 & 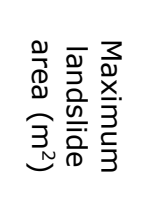 & 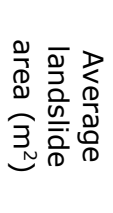 & $\varpi$ & 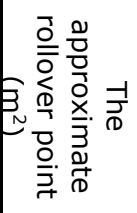 \\
\hline $\begin{array}{l}\text { This } \\
\text { Study }\end{array}$ & 6727 & 54,6 & 30 & 556381 & 8122 & 2,72 & 340 \\
\hline $\begin{array}{l}\text { Xu et } \\
\text { al., } \\
2014\end{array}$ & 7985 & 44,6 & 69 & 397408 & 5588 & 2,47 & 500 \\
\hline $\begin{array}{l}\text { Li et al., } \\
2014\end{array}$ & 3896 & 34,2 & 306 & 525126 & 8789 & 2,51 & 1140 \\
\hline $\begin{array}{l}\text { Dai et } \\
\text { al., } \\
2011\end{array}$ & 576 & 30,9 & 714 & 2142126 & 53713 & 2,25 & 3850 \\
\hline
\end{tabular}

The landslide inventory map is shown in Figure 2.5. Due to cloud cover in the 2008 images, part of the landslide changes in the eastern side could not be identified. Even though there had been significant rainfall events in the monsoon of 2008, the number of active landslides was reduced to 967 including an additional 83 new landslides. Most of the active landslides (69\%) were debris flows. Except for the areas covered by clouds in the 2008 images, 13\% of the earthquake triggered landslides were reactivated.

We were not able to find suitable images for 2010, therefore we decided to make a new inventory every two years after the earthquake. The next landslide inventory was made based on a Worldview Image from April 2011 with 1-meter spatial resolution. The image was cloud free except for a small area in the eastern side. In this inventory $28 \%$ of the pre-existing landslides were active during this period, and the number of active landslides has increased significantly to $2633,66 \%$ of which are debris flows. As can be seen from Figure 2.6 this inventory is almost complete (44 no information landslides) for the entire area. There were also 569 new landslides mapped between 2009 and 2011. 


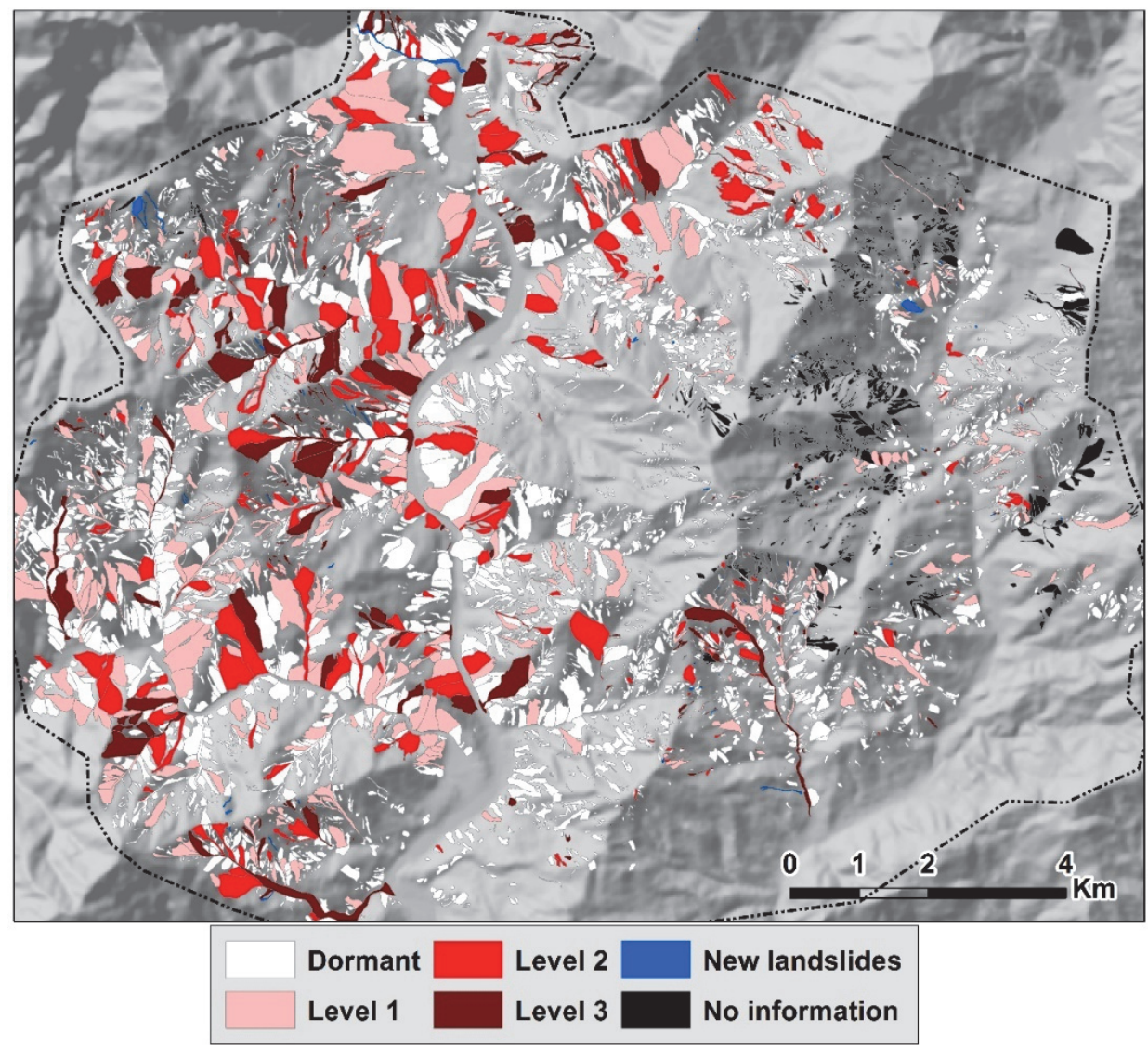

Figure 2.5: Landslide inventory map based on the image taken in February 2009, reflecting the state of activity after the rainy season of 2008 .

This indicates that between February 2009 and April 2011 there have been one or more extreme rainfall events, which will be further discussed in the next section.

A Pleiades image from April 2013, with a spatial resolution of 0.5 meters, was used to map the next landslide inventory. However, due to the different image size, only $69 \%$ of the interpretation area could be mapped in 2013 (Figure 2.7). It is obvious that the activity levels in 2013 were much lower than in the previous periods. Except for the areas outside the image boundary, only $3 \%$ of the pre-existing landslides were active and $88 \%$ of them were identified with a landslide activity level 1 (dormant).

The last landslide inventory map was made using a Spot 6 image, with a spatial resolution of 1.5 meter from April 2015. This image covers most of the study area except for a small part in the North (Figure 2.8). 


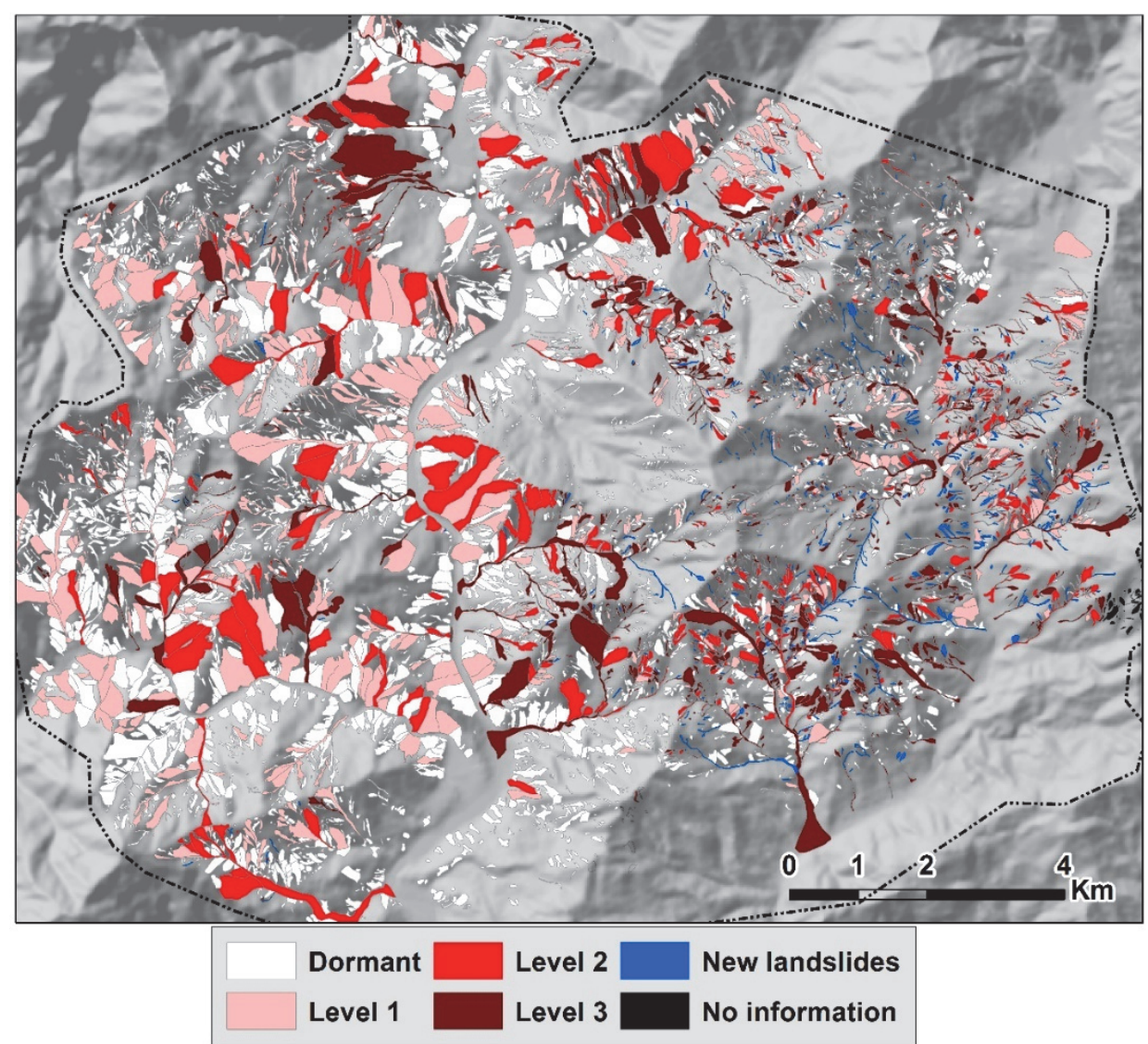

Figure 2.6: Landslide inventory map based on the image taken in April 2011, reflecting the state of activity after the rainy seasons of 2009 and 2010.

Only 66 active landslide are identified on the image, of which only two were new landslides. Less than $1 \%$ of the pre-existing landslides were active. Compared with the images of the earlier period, the vegetation cover on landslides in 2015 was significantly higher.

After the earthquake, from 2008 till April 2015, the number of landslides (including the dormant landslides) in the study area increased by 660 , to a total of 7387. The total landslide area increased from $54.6 \mathrm{~km}^{2}$ to $58.3 \mathrm{~km}^{2}$. This indicates that the landslide activity in the post-earthquake period was not restricted to the co-seismic landslide area only. This is important to consider when making post-earthquake reconstruction planning in other mountainous environments. 


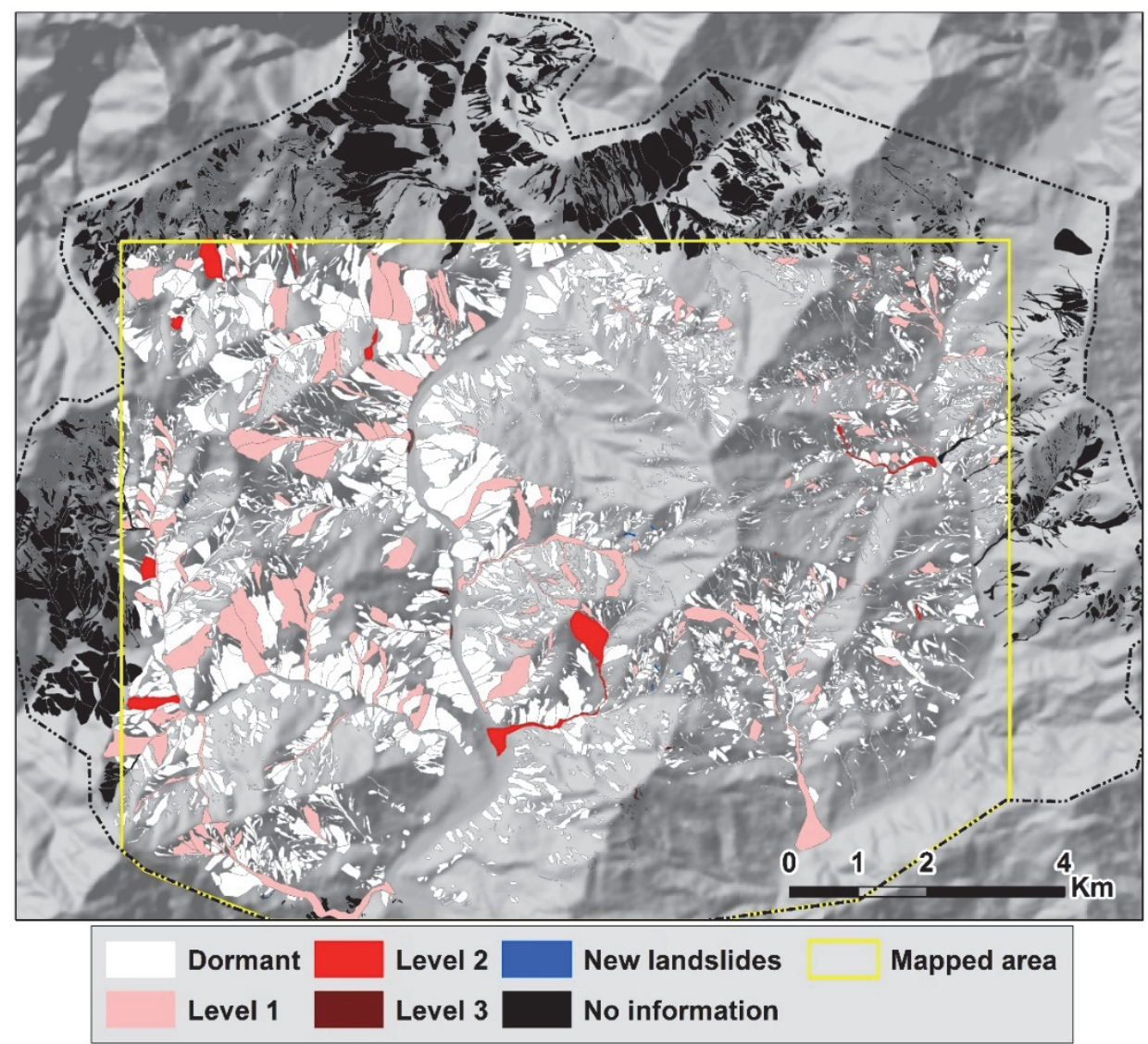

Figure 2.7: Landslide inventory map based on the image taken in Apr 2013, reflecting the state of activity after the rainy season of 2011 and 2012. The actual mapped area was limited within the yellow polygon due to the smaller area covered by the available Pleiades image.

Landslide activity evolved in different ways. The first type of reactivation observed was by slide-type movements of the bare surfaces of co-seismic landslides. Also flow-type movement caused by run-off erosion in the landslide deposits of the pre-existing landslides, with deposition either occurring on top of earlier debris flow materials, or covering new areas. This was considered as the main cause for the enlargement of co-seismic landslides. The third observed mechanism was a retrogressive activity of the scarps in the initiation area. Of the total of 6727 co-seismic landslides, 2221 had one or more phases of reactivation after they were triggered by the earthquake until April 2015. The most frequent post-earthquake landslide type is flow, accounting for $66 \%$ of all the active landslides in the post-earthquake inventories. 


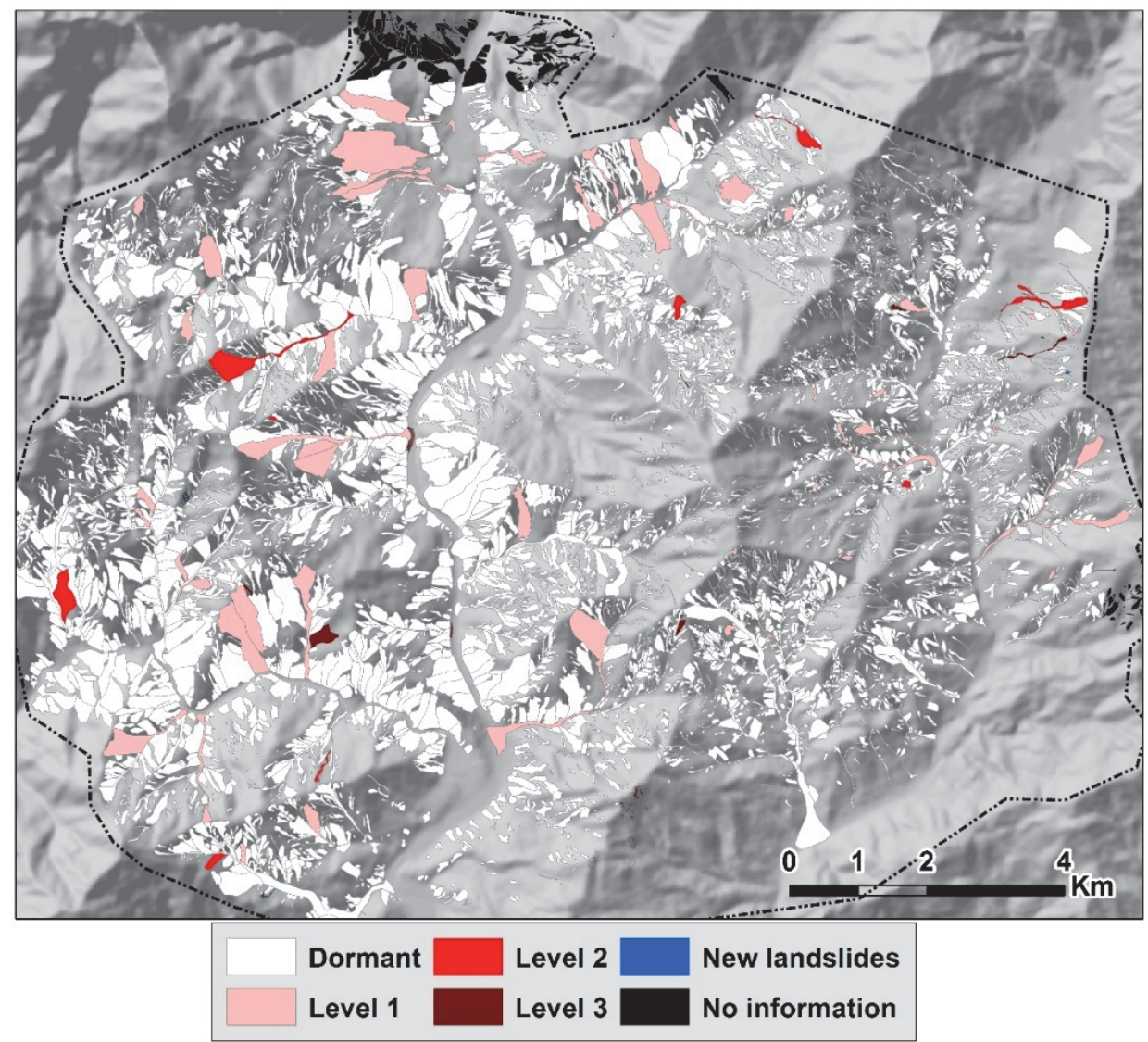

Figure 2.8: Landslide inventory map based on the image taken in Apr 2015, reflecting the state of activity after the rainy seasons of 2013 and 2014.

Table 2.6 summarizes the statistics of the four post-earthquake landslide inventories. In general the landslide activity decreased considerably from May 2008 until April 2015, with a total of active landslides reducing from 6727 coseismic landslides to 66 active landslides in 2015. After the 2010 monsoon season, the activity of the post-earthquake landslides dropped considerably and most of the active landslides were marked with activity level 1 (Figure 2.9). Table 2.7 shows details of the landslide activity changes for the various inventories. Between the inventories of 2009 and 2011, at least 1834 landslides had an increased activity level. About half of the active landslides in the 2011 inventory are co-seismic which were dormant in the 2009 inventory, and $39 \%$ of the active landslides in the inventory of 2009 became dormant in 2011. 
Table 2.6: Statistics of post-earthquake landslide inventories. (1) The total number of landslides in each inventory including those without information (which are either located in cloud covered areas, or areas outside of the image boundaries). (2) Total number of landslides in each inventory excluding those without information, and those that are dormant (activity level 0).

\begin{tabular}{|c|c|c|c|c|}
\hline Activity level & Fall & Slide & Flow & Sum by activity level \\
\hline \multicolumn{5}{|c|}{ The inventory of 2009} \\
\hline No information & \multirow{2}{*}{\multicolumn{3}{|c|}{-}} & 988 \\
\hline 0 & & & & 4855 \\
\hline 1 & 8 & 91 & 353 & 452 \\
\hline 2 & 2 & 73 & 175 & 250 \\
\hline 3 & 0 & 70 & 112 & 182 \\
\hline New landslide & 1 & 51 & 31 & 83 \\
\hline Sum by type & 11 & 285 & 671 & $6810^{(1)} 967^{(2)}$ \\
\hline \multicolumn{5}{|c|}{ The inventory of 2011} \\
\hline No information & \multirow{2}{*}{\multicolumn{3}{|c|}{-}} & 44 \\
\hline 0 & & & & 4718 \\
\hline 1 & 7 & 182 & 622 & 811 \\
\hline 2 & 2 & 180 & 323 & 505 \\
\hline 3 & 4 & 292 & 436 & 732 \\
\hline New landslide & 1 & 215 & 353 & 569 \\
\hline Sum by type & 14 & 869 & 1734 & $7379^{(1)} 2617^{(2)}$ \\
\hline \multicolumn{5}{|c|}{ The inventory of 2013} \\
\hline$\frac{\text { No information }}{0}$ & \multicolumn{3}{|c|}{-} & $\frac{1862}{5348}$ \\
\hline 1 & 2 & 3 & 149 & 154 \\
\hline 2 & 0 & 0 & 12 & 12 \\
\hline 3 & 0 & 0 & 3 & 3 \\
\hline New landslide & 0 & 4 & 2 & 6 \\
\hline Sum by type & 2 & 7 & 166 & $\begin{array}{c}7385^{(1)} \\
175^{(2)}\end{array}$ \\
\hline \multicolumn{5}{|c|}{ The inventory of 2015} \\
\hline No information & \multirow{2}{*}{\multicolumn{3}{|c|}{-}} & 150 \\
\hline 0 & & & & 7171 \\
\hline 1 & 0 & 3 & 41 & 44 \\
\hline 2 & 0 & 1 & 9 & 10 \\
\hline 3 & 0 & 3 & 7 & 10 \\
\hline New landslide & 0 & 0 & 2 & 2 \\
\hline Sum by type & 0 & 7 & 59 & $\begin{array}{c}7387^{(1)} \\
66^{(2)}\end{array}$ \\
\hline
\end{tabular}


From April 2011 to April 2013, 66\% of the active landslides in the inventory of 2011 became dormant in the inventory of 2013. Sixty-five percent of the active landslides in 2013 are active pre-existing landslides with a higher activity class level in 2011. During April 2013 to April 2015, 90\% of the active landslides in the inventory of 2013 became dormant, $44 \%$ of the active landslides in 2015 kept the same activity level as in 2013 , and $46 \%$ of the active landslides occurred on pre-existing landslides that were dormant in 2013. We can conclude from this analysis that the pattern of active landslides changes constantly over time. It is not possible to predict after the earthquake which landslides will remain active over the next decade, as this pattern changes constantly, most probably related to the specific variation of rainfall intensity during rainstorms in the post-earthquake period.

Most of the new landslides occurred during the period of 2009-2011. The most frequent landslide type for the new landslides was slide (60.4\%), followed by flow (36\%) and fall. The average area of the new landslides is $1339 \mathrm{~m}^{2}$, with a range from $34 \mathrm{~m}^{2}$ to $31356 \mathrm{~m}^{2}$. The large new landslides are mainly debris flows with long run-out distances. Overall the new landslides are mainly small and medium-sized landslides: 90\% of the new landslides are less than 3023 $\mathrm{m}^{2}$.

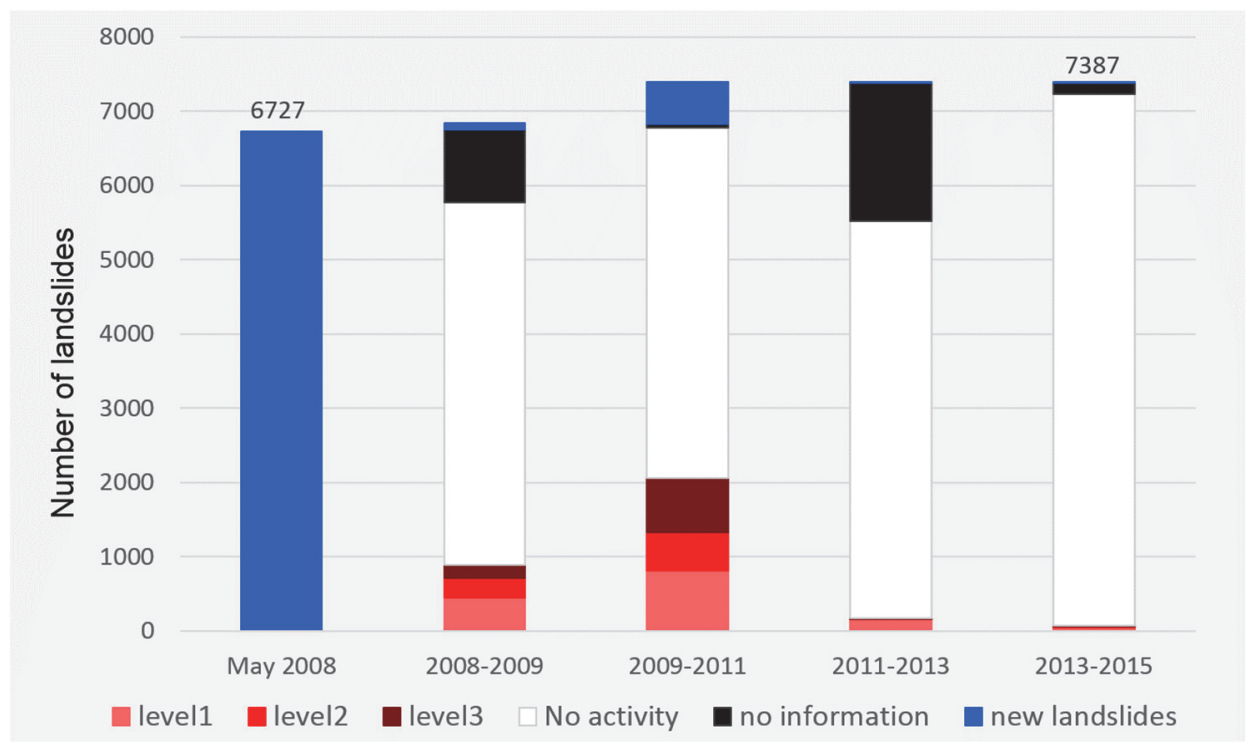

Figure 2.9: Activity levels of the five landslide inventories.

When we compare the number of 66 active landslides in the inventory of 2015 with the 132 landslides recorded from 1961 to 2005 (Varnes, 1978) in the whole $3936 \mathrm{~km}^{2}$ Wenchuan county, the frequency of the landslide occurrence has increased significantly after the earthquake, and it is still not back to the pre-earthquake levels. 
Table 2.7: Changes in landslide activity level of the consecutive years. (1) Total number of landslides with increased activity level compared with the previous period. (2) Number of landslides that became dormant. (3) Number of landslides with decreased activity level, excluding dormant. (4) Number of landslides with the same activity level as the previous period. (5) Number of landslides that remain dormant in both inventories. The number mismatches were caused by small landslides which were ignored by ArcMap software during rasterizing the inventories to do this analysis.

\begin{tabular}{|c|c|c|c|c|c|c|c|}
\hline Year & $\begin{array}{c}\text { Activity } \\
\text { level }\end{array}$ & 0 & 1 & 2 & 3 & No info & sum \\
\hline \multicolumn{8}{|c|}{2011 Inventory } \\
\hline \multirow{7}{*}{$\begin{array}{c}2009 \\
\text { Inventory }\end{array}$} & 0 & $3710^{(5)}$ & 368 & 283 & 457 & 37 & \multirow{6}{*}{$1263^{(1)}$} \\
\hline & 1 & 183 & 148 & 72 & 52 & 0 & \\
\hline & 2 & 89 & 88 & 44 & 31 & 0 & \\
\hline & 3 & 49 & 65 & 37 & 31 & 0 & \\
\hline & New & 58 & 4 & 3 & 14 & 0 & \\
\hline & No info & 634 & 145 & 65 & 139 & 7 & \\
\hline & sum & $379^{(2)}$ & \multicolumn{4}{|c|}{$197^{(3)}$} & $237^{(4)}$ \\
\hline \multicolumn{8}{|c|}{2013 Inventory } \\
\hline \multirow{7}{*}{$\begin{array}{c}2011 \\
\text { Inventory }\end{array}$} & 0 & $3578^{(5)}$ & 23 & 3 & 2 & 1095 & \multirow{6}{*}{$29^{(1)}$} \\
\hline & 1 & 502 & 34 & 1 & 0 & 279 & \\
\hline & 2 & 293 & 40 & 1 & 0 & 173 & \\
\hline & 3 & 528 & 53 & 6 & 1 & 157 & \\
\hline & New & 444 & 5 & 0 & 0 & 117 & \\
\hline & No info & 1 & 0 & 0 & 0 & 43 & \\
\hline & sum & $1767^{(2)}$ & \multicolumn{4}{|c|}{$104^{(3)}$} & $36^{(4)}$ \\
\hline \multicolumn{8}{|c|}{2015 Inventory } \\
\hline \multirow{7}{*}{$\begin{array}{c}2013 \\
\text { Inventory }\end{array}$} & 0 & $5322^{(5)}$ & 7 & 6 & 7 & 0 & \multirow{6}{*}{$22^{(1)}$} \\
\hline & 1 & 132 & 21 & 1 & 1 & 0 & \\
\hline & 2 & 8 & 3 & 0 & 0 & 0 & \\
\hline & 3 & 3 & 0 & 0 & 0 & 0 & \\
\hline & New & 6 & 0 & 0 & 0 & 0 & \\
\hline & No info & 1689 & 20 & 3 & 2 & 150 & \\
\hline & sum & $149^{(2)}$ & \multicolumn{4}{|c|}{$3^{(3)}$} & $21^{(4)}$ \\
\hline
\end{tabular}

It can be observed further that the increase of post-earthquake landslides both in number and in area were $8.9 \%$ and $6.8 \%$ respectively, which are much lower than observed in Taiwan after the Chi-Chi earthquake $(42.8 \%$ increase in area within 2 years according to Lin et al. (2006a)). The landslide increment after the Chi-Chi earthquake could be caused by its location in relation to the path of typhoons, as the areas was affected several times by rainfall events with more than $100 \mathrm{~mm} / \mathrm{h}$ precipitation intensity. In the Wenchuan area, the recorded rainfall intensity and cumulative rainfall are much lower (Table 2.8). 
Also, the lithology in both areas is completely different, with the Wenchuan areas underlain mostly by volcanic rocks, while in the area affected by the ChiChi earthquake sedimentary rocks and metamorphic rocks are most common(Lin et al., 2006a).

\subsubsection{Triggering factor}

The large differences in landslide activity that were observed between the postearthquake landslide inventories, especially the increase in activity observed in the 2011 inventory, were expected to be caused by differences in rainfall extreme events.

Previous works (Lin et al., 2006a; Zhou et al., 2013) have indicated that the magnitude and scale of the post-seismic landslide activity is related to the spatial distribution and intensity of rainfall events.

Table 2.8: Maximum rainfall intensity, duration and accumulated rainfall of the largest rainfall events of each year. The sources of rainfall data are indicated in Table 2.1.

\begin{tabular}{|c|c|c|c|c|}
\hline $\begin{array}{c}\text { Related } \\
\text { inventory }\end{array}$ & Date (D/M/Y) & $\begin{array}{c}\text { Peak intensity } \\
(\mathrm{mm} / \mathrm{h})\end{array}$ & $\begin{array}{c}\text { Accumulated } \\
\text { rainfall }(\mathrm{mm})\end{array}$ & Duration (hours) \\
\hline 2009 & 23.9 .2008 & 60 & 347 & 10 \\
\hline \multirow{2}{*}{2011} & 17.7 .2009 & 70 & 219 & 6 \\
\cline { 2 - 5 } & 13.8 .2010 & 75 & 229 & 17 \\
\hline \multirow{2}{*}{2013} & 29.7 .2011 & 54 & 150 & 20 \\
\cline { 2 - 5 } & 18.8 .2012 & 39.5 & 117 & 6 \\
\hline \multirow{2}{*}{2015} & 10.7 .2013 & 64 & 108.5 & 1 \\
\cline { 2 - 5 } & 10.4 .2014 & 53 & 53 & 6 \\
\hline
\end{tabular}

Unfortunately, there are very few rain gauges in the direct surroundings of the study area that were operational from 2008 onwards. After a large number of landslides were triggered by the storm in 2010, several rain gauges were installed in 5 catchments that were considered as highly dangerous.

From the 18 available rain gauges and literature study we analysed the maximum intensity, duration and accumulated precipitation of the largest rainfall event of each year as indicators for the importance of the monsoon of that year in landslide reactivation. The rainfall data of the largest rainfall events from 2011 to 2015 are average values calculated from several rain gauges distributed across the area (Table 2.8). The two largest rainfall events occurred during the monsoons of 2009 and 2010. They have reactivated a considerable number of landslides as can be observed from the inventory of 2011. The maximum rainfall intensity and accumulated precipitation of the monsoon of 2008 were similar with those during 2011 to 2014. However, in the 2009 inventory there were more active landslides than in the inventories of 2013 and 2015. This is due to the fact that most of the landslide scarps were not re- 
vegetated yet in the months following the earthquake. In 2011 many more landslides were re-vegetated and the same magnitude of rainfall reactivated much less landslides than in 2008. Also the availability of loose materials in the initiation zone was likely much less in 2011 as compared to 2008 due to landslide activity in the period in-between. The loose materials were transported downstream as debris flows (Figure 2.10). The vegetation cover class on the earthquake-triggered landslides in 2008 was 3 ( $>2 / 3$ bare). In the inventory of 2009, this had changed to 2, and then 3 again in the inventory of 2011 due to massive landslide reactivations. The value was lowered to 1 $(<1 / 3$ bare) in the inventory of 2015 .

The pattern of reactivation of landslides can also be related to different spatial distributions of the rainfall events that occurred in the period in between two dates for which landslide inventories are available. However, the available rainfall data didn't allow us to generate rainfall distribution maps for the various landslide events. This should be investigated further in future.

\subsubsection{Controlling factors}

The relation between landslide activity changes and topographic factors, such as slope direction, and slope angle were also analyzed, and also the relation with lithology. We calculated the ratio of the area of active landslides over the total landslide area within each factor class. The results indicate that aspect is not a significant factor in determining the presence of active post-seismic landslides. 


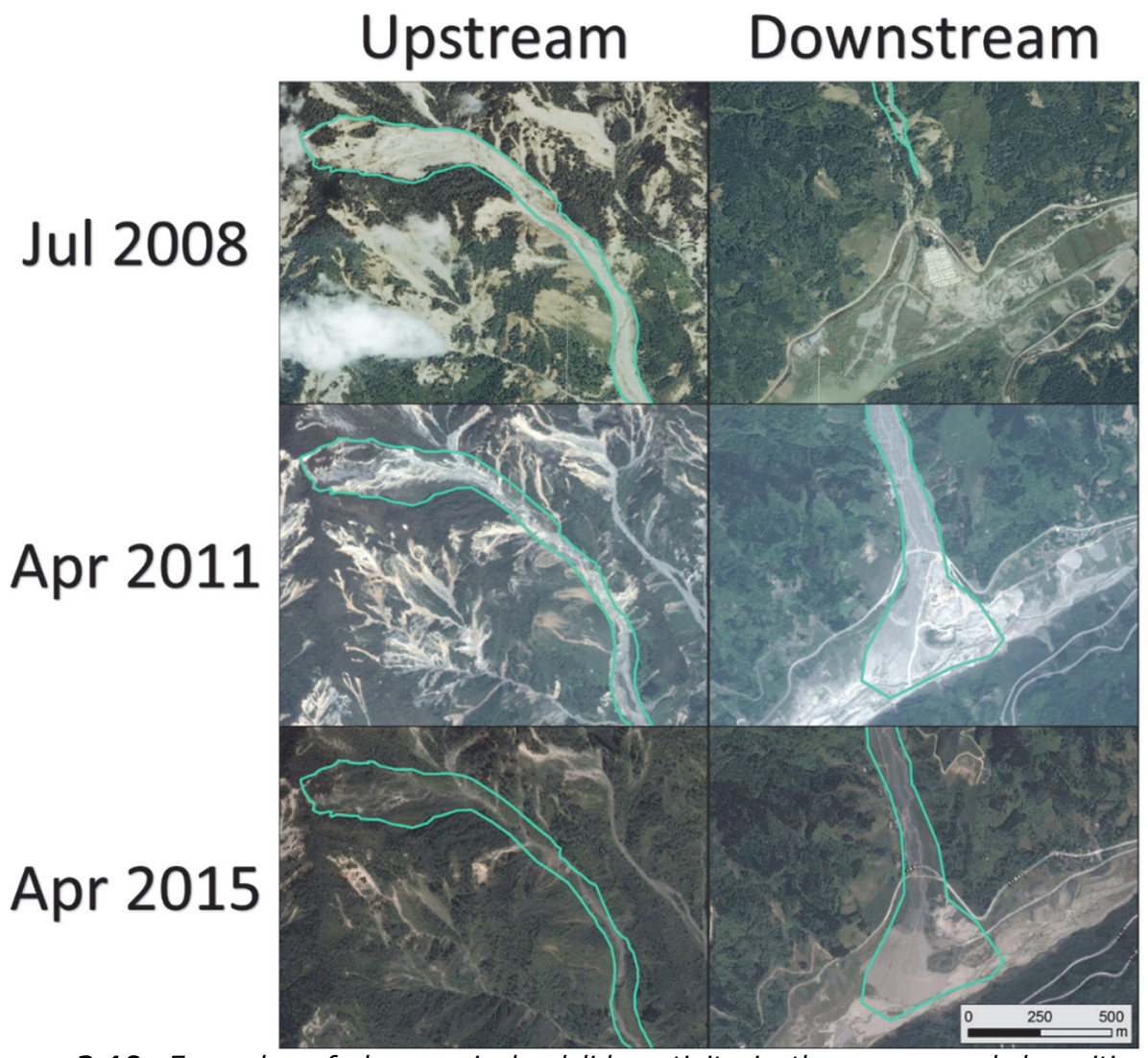

Figure 2.10: Examples of changes in landslide activity in the source and deposition areas of a typical debris flow gulley. In 2008 the loose materials produced by this coseismic landslide were still located in the valley in the upslope part. After three rainy seasons, debris flows and erosion transported the materials to the downstream area. In 2015, most of the upstream area was covered by vegetation again, and debris flow activity in the downstream part had reduced considerably.

In the areas with granite, diorite and sandstone the percentage of active landslides were $41 \%, 28 \%$ and $43 \%$ respectively. The areas with other lithology types were too small in size to make a proper analysis. A comparison of active landslide percentages for different slope classes showed that slopes steeper than 20 degrees had a much higher degree of reactivation. However, lower slope angles occurring in the channels and alluvial fans also had a very high percentage of landslide activity, caused by the occurrence of debris flow deposits.

There is also an important difference in active landslide percentage when comparing the western (Yingxiu) and the eastern part (Longchi). The Yingxiu area had much more and larger sized co-seismic landslides than the Longchi area. However in the 2011 inventory, the eastern part had $46 \%$ of the 
landslides active which is $22 \%$ more than the western part. This was caused by the large amount of new landslides in the eastern part, which contained $83 \%$ of all new landslides. This phenomenon indicates that the effect of the earthquake was much stronger in the western part, which had more rugged topography, where the weathering soil mantle was removed by co-seismic landslides. This was different in the eastern area, where there were less coseismic and more post-seismic landslides. Some slopes were loosened by the earthquake but did not yet fail immediately after the earthquake, and in later years landslides were triggered by large rainfall on those unstable slopes.

\subsection{Discussion and conclusions}

We analyzed changes in landslide activity in a period of seven years after the 2008 Wenchuan earthquake, with five multi-temporal landslide inventories, which we interpreted stereoscopically from high resolution images, followed by field investigation. The results show that most of the post-seismic landslide activities were concentrated within the first three years following the earthquake. The landslide activity decreased considerably from May 2008 until April 2015, from 6727 co-seismic landslides to 66 active landslides in 2015. After the 2010 monsoon season, the activity of the post-earthquake landslides dropped considerably and most of the active landslides became dormant. Of the total of 6727 co-seismic landslides, 2221 had one or more phases of reactivation. Apart from the reactivation of co-seismic landslides also 660 new landslides occurred after 2008. This indicates that the landslide activity in the post-earthquake period was not restricted to the co-seismic landslide area only. This is important to consider when making post-earthquake reconstruction planning in other mountainous environments.

In the digital stereo image interpretation we did not adopt a minimum threshold for landslide area. When comparing our results with other landslide inventories in this area through frequency-area distribution (FAD) our inventory shows the highest level of completeness, the highest number of small landslides, and also the highest total landslide area. However, the inventory also shows a lower total landslide volume calculated from the empirical method presented by Guzzetti et al. (2009). This might be an indication that the number and area of the landslides reported so far for the whole earthquakehit area may be under estimated and the volume could be overestimated.

In this study we were able to devote more time on this local scale area to make a detailed landslide mapping than the previous studies which were mapping the entire earthquake- affected area. We were also able to collect more highresolution remote sensing image data than previous studies. Also the use of digital stereo image interpretation was important for mapping landslide boundaries and making landslide classifications. However, the mapping 
process was much more time consuming, as compared to semi-automatic image classification or monoscopic image interpretation procedures. The mapping process also requires specific skills and different people can produce different image interpretation results. We included an extensive procedure for double checking the mapped landslides by different interpreters in order to ensure consistency of the inventory. The largest differences in interpretation occurred in areas with very steep and complex slopes, where the terrain could not be represented well due to the relatively poor quality of the available DEM. When determining the activities of the post-earthquake landslides, we carefully compared the images from different periods, looking for differences in the image characteristics. This gave us more detailed results compared with common landslide mapping methods which define landslides activity directly from vegetation cover, and allowed us to distinguish the actual active landslide from dormant bare landslides.

Though the landslide activity reduced after April 2011, extreme rainfall events could still trigger large amount of landslides. After the extreme rainstorm in August 2010, there have not been any other extreme rainfall events up to 2015 in the area. However, we can observe in recent images and fieldwork that there are still large volumes of loose materials on the slopes and in the upper parts of the catchments. Though these areas mostly being covered by vegetation regrowth, they could be activated by extreme rainfall events. In the coming years and decade the chance of landslide re-activation will be determined by the speed of vegetation re-growth, the available volumes of loose materials and the occurrence of extreme rainfall events. The limited available rainfall data show that the rainfall threshold to trigger landslides is rising, leading to less landslides in the last two inventories. However, we lack enough rainfall data to do a comprehensive rainfall threshold analysis. Also we were only able to estimate landslide volumes using an empirical method. The actual volume of landslides in the area is unknown due to the lack of a high-resolution preearthquake DEM. It is still hard to make a prediction of how long it will take before landslide activity is back at pre-earthquake levels. Monitoring landslide activities over a longer period is required.

During our mapping process we have noticed that the large co-seismic landslides (like the one in Figure 2.10), are very likely to generate major debris flows in future. Eleven out of eighteen co-seismic landslides with an area larger than $20,000 \mathrm{~m}^{2}$ had the highest level of activity recorded and six of them had the second highest level in the post-seismic landslide inventories. All the recorded large debris flows in the area were initiated from these eleven large landslides. In some of the downstream parts, extensive debris flow mitigation works have been carried out, although some of these have been destroyed or almost covered by debris. It is recommended to monitor the activity of these 
large landslides, and in some cases early warning systems have already been installed.

The main sources of errors in the landslide inventory mapping are related to the image rectification quality, which varied for the different types of images used, and the different resolution of the images (in particular the Spot5 image), and the skill and experience of the interpreters in mapping landslides and classifying the landslide activity. The image wraps of the Spot5 image in steep terrain affected 180 landslides, and the low resolution of this image roughly affected $300-400$ landslides. The uncertainty of the landslide activity level is largely based on the interpreters' experience and judgement based on observing images. The best way to minimize these errors is to have good quality images of every single years since the earthquake. However for our study area this is not possible since high resolution images of 2010 and 2012 could not be found in any image database. Also interpreters' skill and experiences of the mapping area are important. The uncertainty was reduced by comparing the interpretations carried out by different investigators.

We recommend to continue the monitoring of landslides through image analysis. Beside remote sensing images, multi-temporal DEMs generated from Lidar data and UAV photogrammetry can be useful for monitoring, and quantifying the changes. Rainfall data with good spatial and temporal resolution, essential for designing an early warning system, should also be collected to make a comprehensive rainfall threshold analysis.

We can conclude from this analysis that the pattern of active landslides changes constantly over time. It is not possible to predict after the earthquake which landslides will remain active over the next decade, as this pattern changes constantly, most probably related to the specific variation of rainfall intensity during rainstorms in the post-earthquake period. 


\section{Multi-temporal landslide volumetric analysis with multi-source DEMs²}

\subsection{Introduction}

Volume is a crucial component in landslide studies, as it is required in estimating hazard intensities for risk assessment and the planning of risk mitigation measures. It is also very important in order to understand or model subsequent hazards, e.g. the damming potential of landslides, or postearthquake debris flow hazards. The methods for landslide volume estimation can be classified into five types with different focuses: field surveys, physicallybased modelling, empirical modelling, multi-temporal DEM analysis, and geometrical estimation. Field surveys for the measurement of subsurface terrain are implemented in many cases (Le Roux et al., 2011; Lugaizi, 2008; Samyn et al., 2012). Geophysical measurements and borehole data are used for the reconstruction of the surface of rupture at site investigation level. A review of geophysical methods for landslide volume estimation is given by Jongmans and Garambois (2007). This method is usually time and budget consuming, and usually applied on individual landslides only, and not over larger areas. Physically-based modelling is an approach to simulate failure processes using soil and rock mechanics, and the estimation of landslide volume is linked with the mechanism of slope stability. Applications like Scoops3D (Reid et al., 2015), r.rotstab (Mergili et al., 2014)and the script made by Marchesini et al. (2009) were developed for this purpose. Their drawback is that it is often difficult to parameterize these models given the spatial variation of geotechnical and hydrological parameters (Reid et al., 2015). The most frequently used method for landslide volume estimation is to apply empirical relationships between landslide area and volume, which have been developed in several regional studies with site-specific parameters (e.g. Guzzetti et al., 2009b; Larsen et al., 2010; Tseng et al., 2013). The results may also vary based on the quality of the landslide mapping (Guzzetti et al., 2009). Some studies tried to estimate the geometry of the landslide body using geometrical equations (Cruden and Varnes, 1996b) or the surrounding terrain (Chen et al., 2013b). These methods are site specific and difficult to apply for large numbers of landslides.

With the fast developments in remote sensing technology, the comparison of pre- and post-event Digital Elevation Models (DEMs) has become a common technique to estimate the volume of mass movements. Landslide volume can

\footnotetext{
2 This chapter is based on the following paper: Tang, C., Tanyas, H., van Westen, C. J., Tang, C., Fan, X., and Jetten, V. G., 2019, Analysing post-earthquake mass movement volume dynamics with multi-source DEMs: Engineering Geology, v. 248, p. 89-101.
} 
be calculated using the elevation difference between a pre-landslide and a post-landslide DEM. As long as they are precise enough and with good coregistration, the accumulated and removed material volumes could be calculated by subtraction of the two DEMs (Chen et al., 2014), although problems may occur when a part of the landslide deposits remains on top of the failure surface. DEMs from many different sources were applied in landslide studies: contour lines (Kerle, 2002; van Westen and Lulie Getahun, 2003), photogrammetry from aerial photos taken from airplanes, helicopters or UAV's (Chen et al., 2006; Dewitte et al., 2008; Kerle, 2002; Pesci et al., 2004), photogrammetry from satellite images (Martha et al., 2010; Stumpf et al., 2014), airborne laser scanning (ALS)(Chen et al., 2006; Dewitte et al., 2008; Tseng et al., 2013), ground surveys using terrestrial laser scanning (TLS) (Barbarella et al., 2015; Pesci et al., 2004; Prokop and Panholzer, 2009), and GPS kinematic surveys (Pesci et al., 2004).

Several investigations have been done on landslide volume estimation in the Wenchuan area. The earthquake occurred in 2008, before the new national topographic survey (available since 2011) could be finished. Unfortunately, the pre-earthquake elevation data was very general and lacks sufficient accuracy for co-seismic volume estimation. Many studies on post-earthquake landslide mechanisms were carried out, but volume estimations of co-seismic and postseismic landslides over large areas were complicated due to the lack of suitable Digital Elevation Models (DEMs). An early general estimation of the co-seismic landslide volume, conducted by Parker et al. (2011) based on space-borne INSAR, resulted in a total landslide volume of $2.6 \mathrm{~km}^{3}$ with an uncertainty of $1.2 \mathrm{~km}^{3}$. empirical area-volume relationships were applied in local regions (Fan et al., 2011; Tang et al., 2012b), and the results varied considerably due to the differences in landslide mapping and areas covered.

Volume measurements of individual landslides were mostly carried out by drilling bore holes and applying geophysics methods in those catchments that produced catastrophic debris flows. These field measurements aimed to provide information for the design of debris flow mitigation works and early warning systems. Studies were carried out for example in the Hongchun catchment which produced a large debris flow that temporally dammed the Minjiang river (Li et al., 2011), in the Niujuan catchment that produced more than ten debris flows since 2008, damaging the national road and partially blocking the Minjiang river (Hao et al., 2011), and the Wenjia catchment which produced the largest debris flow in China since 1949 (Yu, 2010). Researchers have applied remote sensing for volume estimation for a limited number of individual landslides in the Wenchuan area (Chen et al., 2014a; Scaringi et al., 2018). However, the volume change of landslide materials over the years after the earthquake has not been investigated with the use of DEMs. This study aims to analyse the dynamic development of landslide volumes over a period 
of nine years, starting with the 2008 Wenchuan earthquake until 2017, using nine DEMs from different sources. A method to register the DEMs was developed and volume differences caused by co-seismic landslides and postseismic erosion and entrainment were analysed.

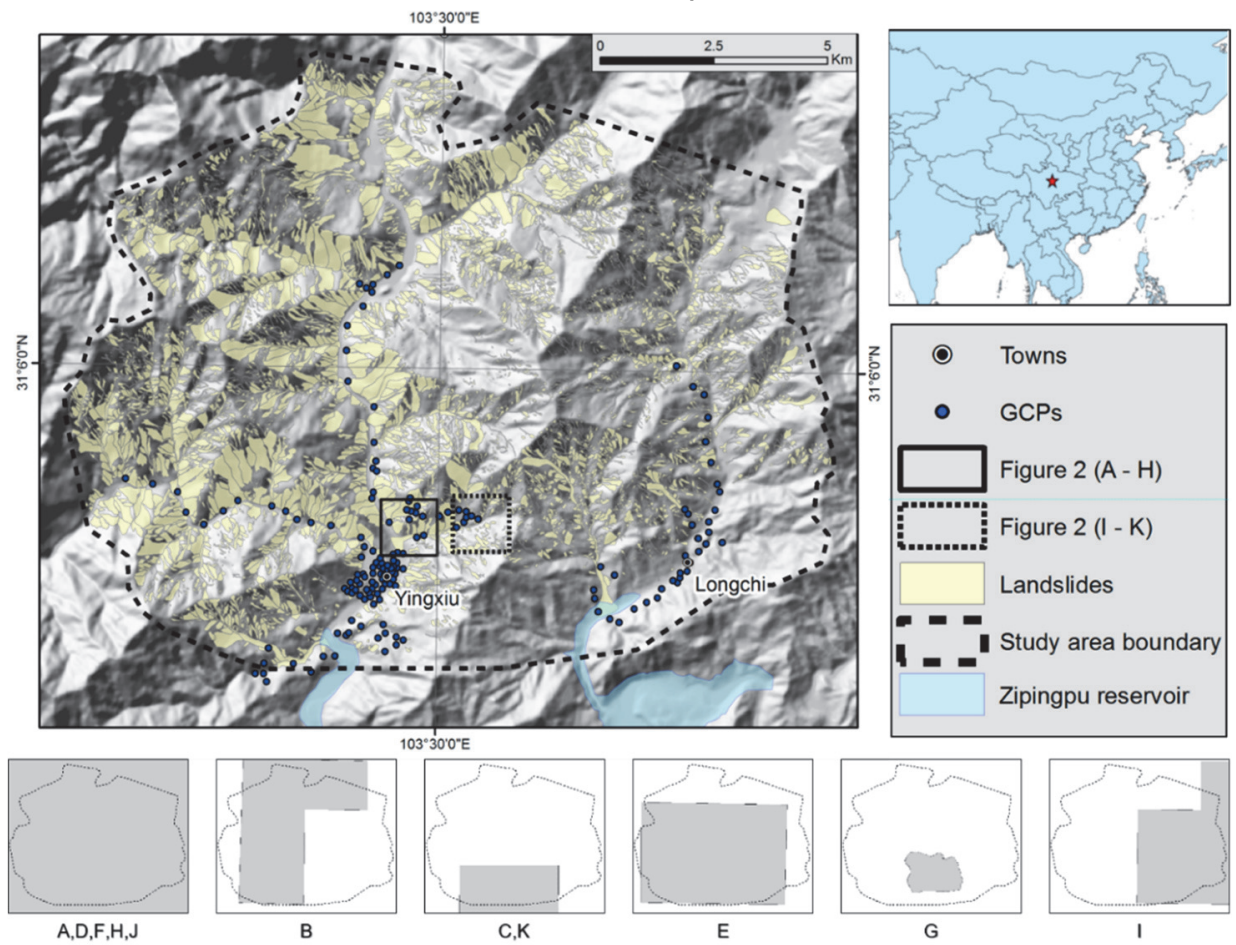

Figure 3.1: Study area with co-seismic landslides mapped by Tang et al. (2016). Also the location of ground control points (GCPS) for co-registration of the DEMs is indicated. The coverage of the nine DEMs is shown in the bottom. The capital letters refer to the DEMs in Figure 3.2.

\subsection{Data collection}

We collected nine DEMs from different years and from different sensors. The set of collected DEMs contain free access, commercial and self-collected DEMs, with resolutions ranging from 1 to $30 \mathrm{~m}$. Three were available as Digital Terrain Models (DTMs) with all landcover removed and six as Digital Surface Models (DSMs) in which objects on the terrain surface were also included. A summary of the main characteristics of the nine DEMs is given in Table 3.1. The coverage of elevation data and location of collected control points are shown in Figure 3.1. Figure 3.2 shows examples of the hillshaded DEMs for a small sample area. 
Table 3.1: Description of the DEMs collected for this study.

\begin{tabular}{|c|c|c|c|c|c|c|}
\hline Name & Type & Source & $\begin{array}{l}\text { Acquisiti } \\
\text { on date }\end{array}$ & $\begin{array}{l}\text { Pixel } \\
\text { size } \\
(\mathrm{m})\end{array}$ & $\begin{array}{c}\text { Vertical } \\
\text { reference }\end{array}$ & $\begin{array}{l}\text { Coverage of } \\
\text { the study } \\
\text { area }(\%)\end{array}$ \\
\hline LI1999 & & $\begin{array}{l}\text { Aerial LiDAR } \\
\text { survey, }\end{array}$ & 1999 & 5 & $\begin{array}{l}1985 \text { national } \\
\text { elevation } \\
\text { benchmarks }\end{array}$ & 40 \\
\hline SG2006 & DTM & $\begin{array}{c}\text { Stereo satellite } \\
\text { image \& ground } \\
\text { survey }\end{array}$ & 2006 & 25 & $\begin{array}{l}1985 \text { national } \\
\text { elevation } \\
\text { benchmarks }\end{array}$ & 100 \\
\hline SG2014 & & $\begin{array}{l}\text { Stereo satellite } \\
\text { image \& ground } \\
\text { survey }\end{array}$ & 2014 & 5 & $\begin{array}{c}1985 \text { national } \\
\text { elevation } \\
\text { benchmarks }\end{array}$ & 52 \\
\hline LI2008 & \multirow{6}{*}{ DSM } & $\begin{array}{l}\text { Aerial LiDAR } \\
\text { survey }\end{array}$ & $\begin{array}{c}2008 \text { May } \\
\text { - June }\end{array}$ & 2.5 & $\begin{array}{l}1985 \text { national } \\
\text { elevation } \\
\text { benchmarks }\end{array}$ & 20 \\
\hline $\begin{array}{c}\text { ASTER20 } \\
11\end{array}$ & & Aster GDem 2 & 2011 & 30 & EGM96 & 100 \\
\hline PLE2014 & & $\begin{array}{l}\text { Pleiades stereo } \\
\text { image }\end{array}$ & Dec 2014 & 1 & EGM96 & 72 \\
\hline $\begin{array}{c}\text { ALOS201 } \\
5\end{array}$ & & ALOS World 3D & 2015 & 30 & EGM96 & 100 \\
\hline UAV2017 & & F1000 UAV & Jul 2017 & 1 & WGS84 & 10 \\
\hline TAN2017 & & TanDEM-X & Jan 2017 & 12 & EGM2008 & 100 \\
\hline
\end{tabular}

Contour-based DTMs from NASG: two digital contour maps were acquired from the National Administration of Surveying, Mapping and Geo-information of China (NASG). The first one (SG2006, Figure 3.2 A, J) collected in 2006, was in the form of a $20 \mathrm{~m}$ interval contour and covered the entire earthquakeaffected area. This data was interpolated into a DTM with a cell size of $25 \mathrm{~m}$ which was widely used in research work on the Wenchuan earthquake as it was the only pre-earthquake DEM covering the entire affected area. The second contour map (SG2014, Figure $3.2 \mathrm{~B}$ ) had $10 \mathrm{~m}$ interval and was collected in 2014. Both contour maps were generated by photogrammetry using satellite images, combined with ground surveys. Based on the observation of the horizontal contour line distances, we used pixel sizes of $20 \mathrm{~m}$ for SG2006 and $5 \mathrm{~m}$ for SG2014 during the interpolation with the "Topo to raster" tool in Arcmap. They differed considerably in representing localized terrain features such as small sub-catchments and ridges. SG2006 ignored most of the small 
scale features, while SG2014 showed much more detail, although only the larger landslides were visible in SG2014.

LiDAR DEMs: Two LiDAR data sets were provided by the NASG. The first one represents the situation before the earthquake (LI1999, Figure 3.2 I). Unfortunately this DTM was not-provided as a point cloud or raster files, but as a digital contour map with $10 \mathrm{~m}$ contour interval, which we interpolated to a $5 \mathrm{~m}$ raster DTM. The description file indicates the data collection date was in 1999. This DTM only covers the eastern part of the study area. The second LiDAR-derived dataset (LI2008, Figure $3.2 \mathrm{C}, \mathrm{K}$ ) was provided as a $2.5 \mathrm{~m}$ raster DSM, surveyed in June 2008, within one month after the earthquake. It has a very high level of detail, showing all damaged buildings and temporary shelters and tents. It only covers the south of the study area with limited overlap with the pre-earthquake LiDAR DTM.

Aster Gdem 2 and Alos World 3D: Both are freely accessible DEMs that are generated from stereo satellite images and have $30 \mathrm{~m}$ (1 arcsec) resolution. Both DEMs were very general, although the Alos DEM from 2015 (ALOS2015, Figure $3.2 \mathrm{~F}$ ) was able to show some of the localized terrain features while the Aster DEM from 2011 (ASTER2011, Figure 3.2 D) showed very poor results. This could be caused by the fact that the Alos World 3D free DEM is produced based on its $5 \mathrm{~m}$ commercial product "World 3D Topographic Data". According to Rexer and Hirt (2014) the root mean square error (RMSE) of Aster Gdem 2 is about $9 \mathrm{~m}$, and about $11 \mathrm{~m}$ in mountainous terrain. The vertical accuracy of Alos World 3D $30 \mathrm{~m}$ is ranging from 4.3 to $6.7 \mathrm{~m}$ RMSE (Santillan et al., 2016).

Pleiades DSM (Figure 3.2 E): Three Pleiades stereo images were acquired in December 2014. PCI Geomatics was used to generate a $1 \mathrm{~m}$ resolution DSM from the $0.5 \mathrm{~m}$ panchromatic images. Only one pair of the images were used since the third one had too large viewing angle, causing significant errors in the DSM. The DSM is able to show terrain and landcover features with a high level of detail (See Figure 3.2). However due to the shadows in the images, many of the north-west facing slopes suffered very high systematic errors, a problem also reported by Poli et al. (2013). According to AIRBUS (2017), the relative vertical accuracy can reach $1.5 \mathrm{~m}$. A study of elevation changes caused by earthquakes by Zhou et al. (2015) concludes that the vertical accuracy of the Pleiades DEMs is able to reach about $0.3 \mathrm{~m}$.

TanDEM (Figure $3.2 \mathrm{H}$ ): This data was obtained from WorldDEM, which is a worldwide DEM data set derived from radar interferometry using the TerraSAR$\mathrm{X}$ and TanDEM-X. The product has a reported vertical accuracy better than 2 $\mathrm{m}$ and $12 \mathrm{~m}$ spatial resolution (German Aerospace Center, 2014). However, the data we acquired appears to have very large systematic errors across more than half of the study area, in accordance with reported problems of SAR 
generated DEMs in steep mountainous terrain (Gonzalez et al., 2014; Tridon et al., 2013). After analysing the large errors we decided not to include this DEM in the further analysis.

UAV DSM (Figure 3.2 G): In 2017 the State Key Laboratory of Geo-hazard Prevention and Geo-environment Protection (SKLGP) of the Chengdu University of Technology conducted a drone mission near Yingxiu. A F1000 fixed-wing drone carrying a SONY a5100 camera was used (Feima Robotics). PIX4D software, and GCPs were used to generate a DSM with $1 \mathrm{~m}$ resolution. Due to the prevailing weather conditions and the high mountains in the region, the coverage of the DSM was limited to $17.6 \mathrm{~km}^{2}$.

Multi-temporal landslide inventories: multi-temporal satellite and UAV images were available as well as a set of landslide inventories from five periods after the Wenchuan earthquake, generated by Tang et al. (2016). The landslides are mapped individually and attribute tables contain information on landslide type and landslide activity level, which was defined based on visual analysis of the diagnostic features and their changes between remote sensing images taken in different periods.

Ground control points (GCPs): A total of 104 ground control points were measured with a set of Real Time Kinematic GPS equipment in October 2017 at accessible locations, with the datum of WGS84. The vertical error is generally about $3 \mathrm{~cm}$, with a maximum of $9 \mathrm{~cm}$. The equipment was calibrated based on the elevation of the check dam surfaces, which were mentioned in the engineering reports (Hao et al., 2011; Li et al., 2011; Yang, 2010). As can be seen from Figure 3.1, ground control points are limited to the accessible parts of the study area, along roads. The locations of the measurements should not be severely disturbed by human or landslides, and should not be too close to tall land cover features.

\subsection{Pre-processing of the DEMs}

Since the nine DEMs were obtained from different sources with different vertical and horizontal accuracies, a process of horizontal and vertical adjustment was required to match them as good as possible. This section describes how did we improved the horizontal match and vertical bias among the DEMs, using ArcMap. 

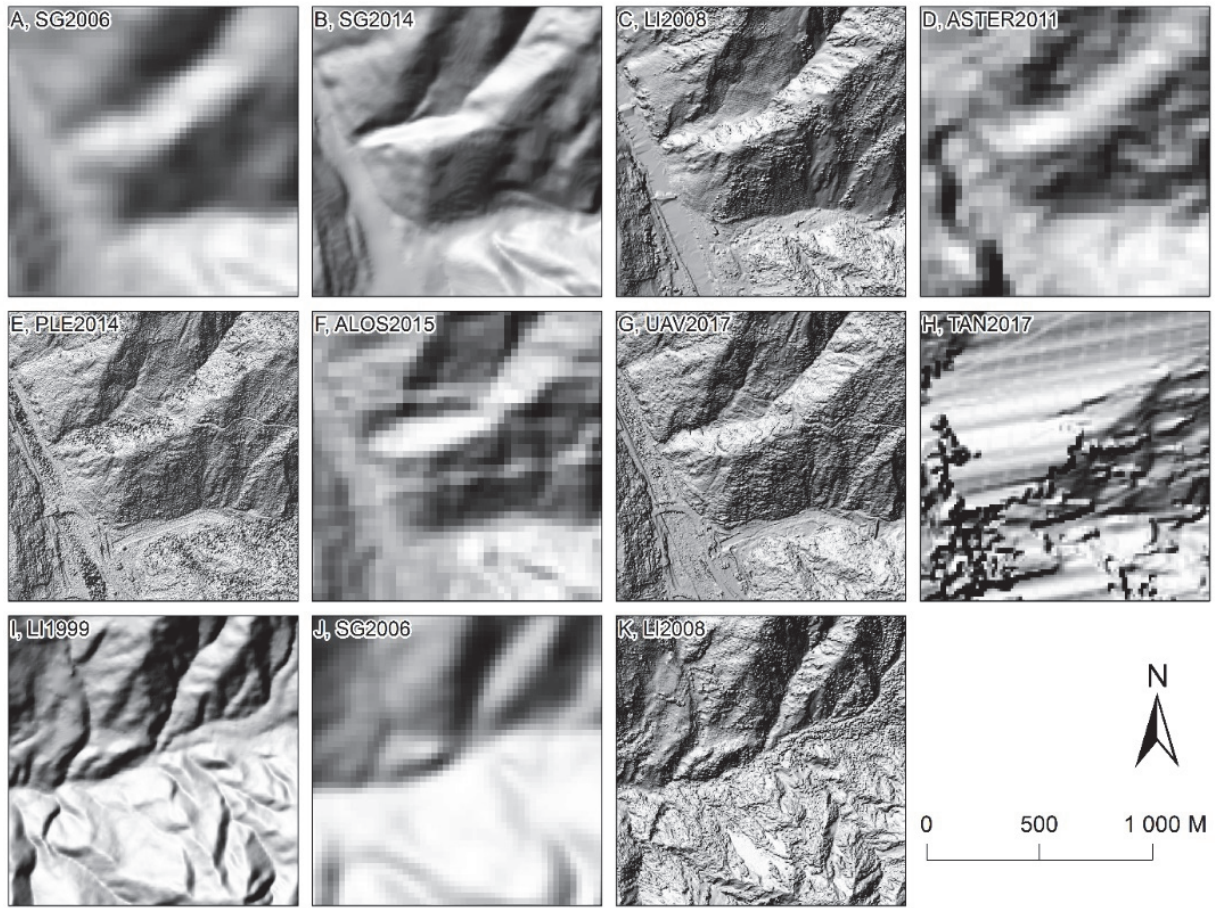

Figure 3.2: Hillshaded DEMs. As there is no area where all nine DEMs are overlapping, figure $I$ to $K$ are from a different area (See Figure 3.1 for the location) than $A$ to $H$.

\subsubsection{Geo-referencing}

All the coordinate systems of the DEMs were transformed into WGS 1984 UTM Zone $48 \mathrm{~N}$. A horizontal mismatch ranging from 5-20 m was observed and registration was essential to carry out the further steps. Since the UAV2017 DEM was made in a controlled manner with the GCPs that we collected ourselves, leading to a highly detailed product, this DEM was used as the reference layer, in order to geo-reference the other target DEMs. Depending on the types of DEMs and the mismatches, different approaches of georeferencing were used. All DEMs were resampled to $1 \mathrm{~m}$ using a bilinear interpolation method.

As UAV2017 (See Table 3.1) was a highly detailed DSM and all landcover features are clearly visible, it was possible to register the other high-resolution DSMs (PLE2014 and LI2008) directly using the geo-referencing tool in ArcMap, applying the same approach as geo-referencing images. UAV2017 and PLE2014 were also coupled with their corresponding orthoimages which helped to identify tie points.

For the other DEMs, it was not feasible to carry out visual matching using tie points, as it was very difficult to find exact similar points in DEMS, even when 
making use of hillshaded images. Therefore a method of comparing profile lines was applied. A straight linear terrain feature, such as a channel or a ridge, was selected, which was not modified significantly by landslide events during the post-earthquake period. The following steps were carried out, as illustrated in Figure 3.3:

1. A short profile was drawn perpendicular to the feature. The land cover on the both sides of the linear feature should be the same. It is important to choose the linear features based on the terrain situation. For lower resolution DEMs it is required to select larger terrain features than for high resolution ones.

2. A shift was carried out to match the target profile and the reference profile. This could be done by reaching a minimum Standard Deviation (STDEV) of the elevation differences from the two profiles.

3. A long profile should be made to ensure that matching and STDEV were acceptable.

4. The same approach in 1 and 2 was carried out for another profile line parallel to the linear terrain feature. An example is shown in Figure 3.3.

If the target DEM only had to be shifted (zero order polynomial), this method can produce a better result than direct visual referencing. When multiple tie points were needed, it was necessary to find all the tie points before making any adjustment. We also applied the method to the high resolution DSMs to ensure optimal registration results as this method is able to create more accurate tie points than direct visual registration. Since UAV2017 has a very small coverage, a cross check among all the DEMs needs carried out to ensure the geo-referencing result.

\subsubsection{Minimizing vertical bias}

The vertical bias was mostly caused by the different vertical datum of the DEMs. A direct calibration by adding or subtracting elevation values was applied. Cross checks among all the DEMs were carried out after all the elevation adjustments. A proper horizontal registration needed to be done before carrying out the methods described below. 

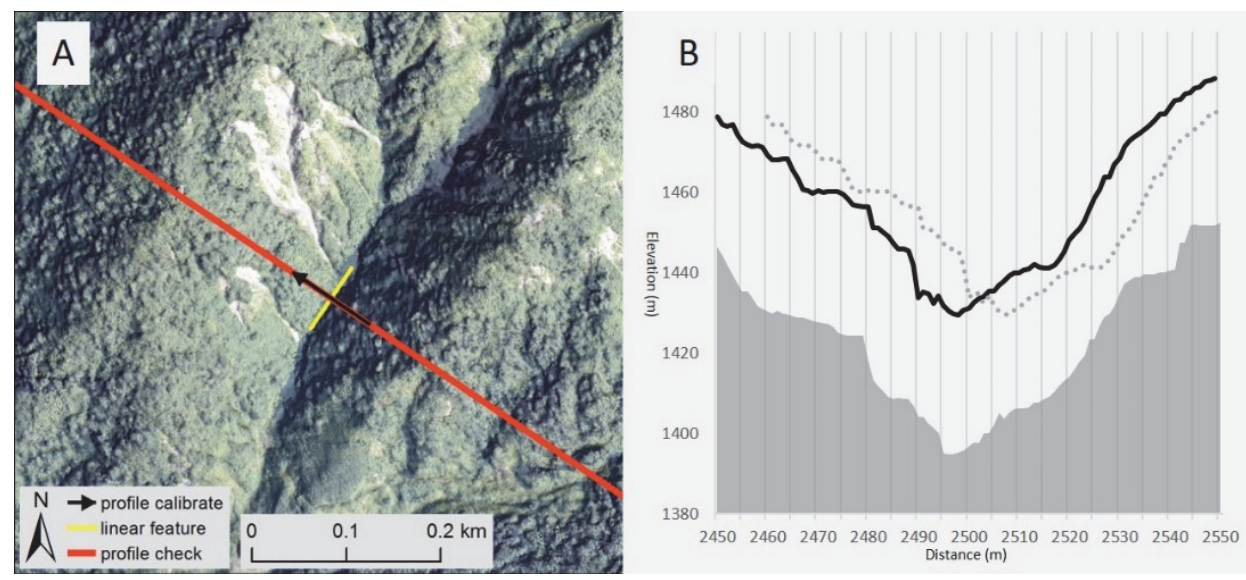

Figure 3.3: Illustrating the method to match DEMs based on profile lines. A: a linear feature was chosen in the channel of a sub-catchment and a profile was drawn perpendicular to it. B: shifting based on the STDEV of the difference estimated from the profile. The dashed and solid lines are the profiles of PLE2014 before and after adjustment. The grey area represents the profile of the reference DEM (UAV2017).

When addressing the same types of DEMs, histograms of the elevation difference maps for the areas without landslides were used. The bias was estimated by the distance of the histogram peak to zero, meaning a minimum overall difference could be reached by adjusting this value (Figure $3.4 \mathrm{~A}$ ). It should be noticed that this only works when most part of the terrain and land cover remain the same for the dates of data collection. In our study UAV2017 was used as the reference for the DSMs. Profiles lines were used to validate the results after the adjustment (Figure 3.4 B-D).

The bias between a DTM and a DSM was estimated based on samples taken from relatively flat and smooth surfaces, and analysis of landcover types. This method was used to adjust LI1999 and SG2014 as they did not overlap (See Figure 3.1). Plantations and farmlands located on smooth slopes were taken as samples. Elevations of major landcover types were measured in a number of sample locations during the field work. Tea trees were $0.6 \mathrm{~m}$ tall and Kiwis were cultivated with $2 \mathrm{~m}$ racks and other farmlands that grow vegetables were $0.1 \mathrm{~m}$ above ground. The vertical bias is estimated to be the corresponding plant height subtracted from the average elevation difference within the samples. A total of 7416 cells were sampled for LI1999, with a vertical bias estimated to be $7.1 \mathrm{~m} \pm 0.9 \mathrm{~m}$. SG2014 was adjusted using the same approach, but taking buildings as samples. The bias ranged from 4.0 to $7.0 \mathrm{~m}$ with a mean value of $5.2 \mathrm{~m}$ and STDEV of $1 \mathrm{~m}$. The adjusted LI1999 was used as the reference for the adjustment of SG2006. 


\subsection{Suitability evaluation}

In this section we present the method and results of the analysis on the accuracies and suitability of the available DEMs for landslide volume calculation, after which the selection of DEMs suitable for volumetric analysis is made.

\subsubsection{Assessing accuracies}

The error of the DEMs was expressed as standard deviation (STDEV) of the elevation difference between GCPs and the DEMs. Given the coverage of the DEMs, either all 104 GCP's could be used, or only a subset, as shown in Table 3.2. The high-resolution DSMs (LI1999, LI2008, PLE2014, UAV2017) had the lowest STDEV. LI1999 had the fourth lowest error, being only surpassed by the high-resolution ones. SG2006 and ASTER2011 had high errors due to their coarse resolution. ALOS2015 had a much lower STDEV than ASTER2011, which could be caused by the fact that it was derived from a $5 \mathrm{~m}$ commercial product. Due to the large amount of systematic errors in the DEM, TAN2017 has a very high STDEV. However when estimating only from the points located in error free zones, its accuracy appears to be much better (Table 3.2).

\subsubsection{Assessing terrain representation}

The results from the error analysis using the GCPs, presented in Table 3.2, could be affected by the fact that some of the points could have changed between the time of the DEMs and the GCPs were taken. This is particularly the case for the DEMs from early periods (LI1999, SG2006, LI2008). Thus additionally, profiles were made across ridges and valleys to assess how the DEMs represent the changing surface. From Figure 3.5 it can be concluded that ASTER2011 and SG2006 show smooth profiles which failed to properly represent local terrain features. 

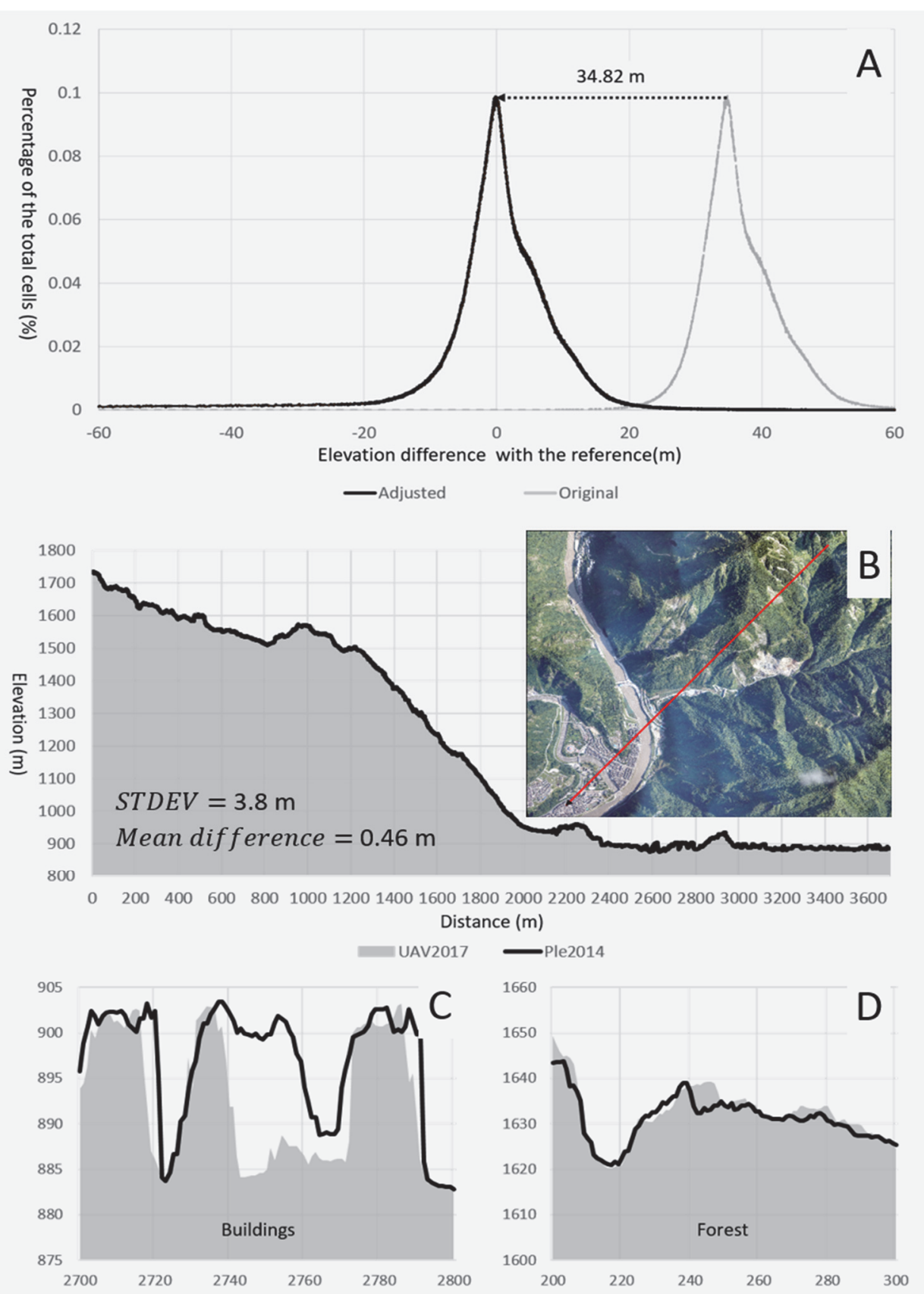

Figure 3.4: An example of minimizing vertical bias. A: estimating vertical bias between PLE2014 and the reference DEM (UAV2017). B: overall matching after the adjustment. The colour image was captured in 2017. C: Detailed view of elevation for buildings. D: Detailed view of elevation for a forest area. 
ALOS2015 fits the reference DEM better than the previous two, but was overestimating the elevation at many locations. SG2014 has the best matching in this group, although some over estimation could be observed (Figure 3.5 A1).

The surface elevation of the high-resolution DSMs varied based on the types of land cover, nevertheless they all fitted well with the reference DEM (Figure $3.5 \mathrm{~B} 1$ ). LI2008 was higher than the others in the channels due to extensive co-seismic landslide deposits, much of which was eroded in later years LI1999 fitted well with the reference DEM, and was only higher than the DSMs at about $110 \mathrm{~m}$ to $150 \mathrm{~m}$, where a landslide scarp was located.

Table 3.2: Vertical errors after horizontal and vertical calibration, measured from the differences between the elevation of the GCP's and the DEMs. * Only points located in the error free zones were used.

\begin{tabular}{|c|c|c|c|c|c|}
\hline & \multirow{2}{*}{$\begin{array}{c}\text { Number of } \\
\text { GCP's in the } \\
\text { DEM area }\end{array}$} & \multicolumn{4}{|c|}{ Elevation difference with GCP's in meters. } \\
\cline { 4 - 6 } & 30 & -14.7 & 8.5 & 0.1 & 4.8 \\
\hline LI1999 & 104 & -25.5 & 46.7 & -3.9 & 12.6 \\
\hline SG2006 & 104 & -26.0 & 12.0 & 1.0 & 6.4 \\
\hline SG2014 & 88 & -6.6 & 8.2 & 1.7 & 2.4 \\
\hline LI2008 & 104 & -44.7 & 45.1 & -3.5 & 12.9 \\
\hline ASTER2011 & 104 & -5.7 & 6.4 & 0.6 & 2.1 \\
\hline PLE2014 & 104 & -16.2 & 22.2 & 2.7 & 6.0 \\
\hline ALOS2015 & 66 & -4.6 & 6.0 & 0.6 & 1.8 \\
\hline UAV2017 & $104(37 *)$ & -544.1 & 171.5 & -53.0 & $94.3(3.5 *)$ \\
\hline TAN2017 & 104 & & & \\
\hline
\end{tabular}

Two landslides that gives the most obvious patterns were taken as examples to visualize the DEM differences (Figure 3.6). The corresponding statistics are shown in Table 3.3. A rockslide with an area of $38.2 * 10^{3} \mathrm{~m}^{2}$ was chosen as example (Figure 3.6 A - H). It was triggered by the earthquake and blocked the local drainage channel. The channel blockage was later partially removed by debris flows. Since it is mainly composed of rocks with limited soil cover, a slow vegetation regrowth was observed in the images (Figure $3.6 \mathrm{G}$ and $H$ ). The elevation difference between the post- (LI2008) and the pre-earthquake DEM (LI1999) shows a logical pattern (Figure $3.6 \mathrm{~A}$ ) with a clear loss at the 
scarp and significant gain at the toe. Also the difference of the post-earthquake DEMs, PLE2014 and UAV2017, with the pre-earthquake DEM (LI1999) showed similar patterns, but the accumulation in the channel was less due to erosion of the co-seismic landslide materials in later years (Figure 3.6 C and E). The losses were larger than those estimated by LI2008, due to reactivations of the co-seismic rockslide body and the construction of a local road. The difference of LI1999 with ASTER2011 and ALOS2015 both showed poor results (Figure 3.6 $B$ and D). When SG2006 was used as the pre-earthquake DEM and subtracted with UAV2017, the pattern was mainly controlled by the surface of UAV2017 (Figure 3.6 F). The statistics (Table 3.3 UAV2017 - SG2006) showed a very large loss and small gain which is not making sense for a landslide. Due to the different data coverage, another landslide was used to do the pattern analysis for SG2014.

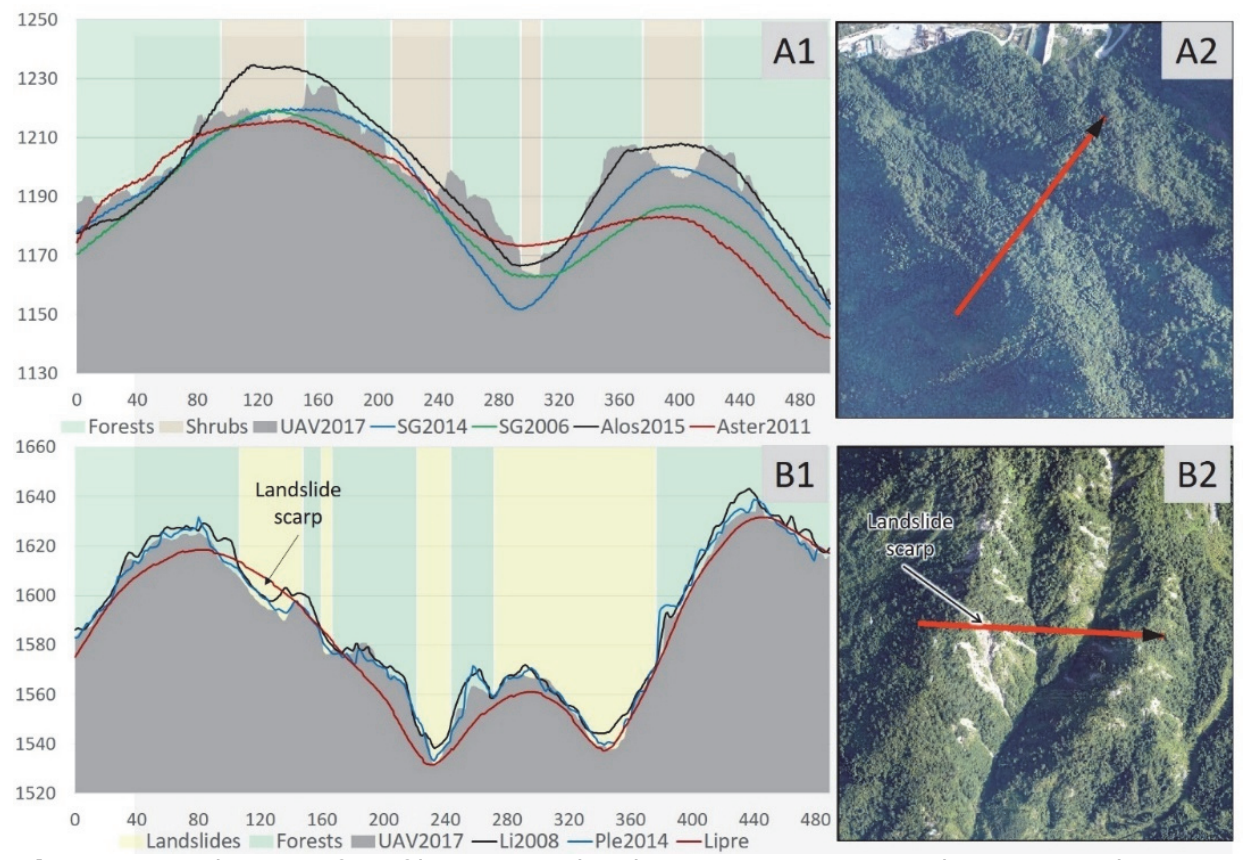

Figure 3.5: The use of profiles to visualize how DEMs represent the terrain. The $X$-axis is the distance along the profile (in $\mathrm{m}$ ) and the $Y$-axis is the elevation in meters. UAV2017 was used as the reference DEM (grey area). Land cover is displayed as background colours. A1: Profiles of the relatively low resolution (>10m) DEMs and SG2014. A2: image at the A1 profile location B1: Profiles of the high resolution DEMs. B2: image at the $B 1$ profile location

LI2008 was used as the pre-event DEM and UAV2017 was used for comparison. As can be seen in Figure 3.6 I, SG2014 showed the removal of the loose materials in the main channel but was not able to portray the entrainment in the branch channels, nor the slope surface modified by mitigation works. On the other hand subtracting UAV2017 with LI2008 clearly showed all surface changes caused by entrainment, vegetation growth and construction of 
mitigation works (Figure $3.6 \mathrm{~J}, \mathrm{~K}$ and $\mathrm{L}$ ). Based on the analysis results presented above, we concluded that only four DEMs were accurate enough to be used in the subsequent landslide volume analysis: LI1999, LI2008, and PLE2014 with shadows removed and UAV2017.

Table 3.3: Mobilized volume $(103 \mathrm{m3})$ of the landslide shown in Figure 3.7 calculated by the difference in DEMS.

\begin{tabular}{|c|c|c|c|c|c|c|c|c|}
\hline & 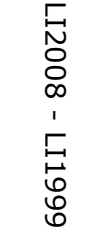 & 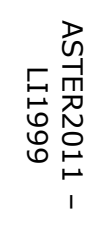 & 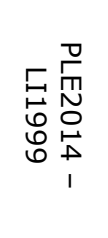 & 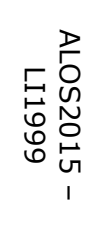 & 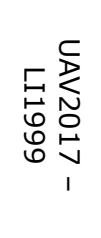 & 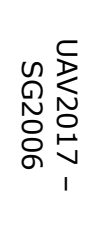 & 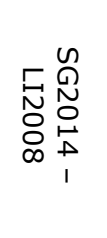 & 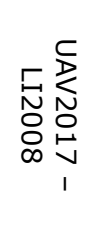 \\
\hline Loss & 164.5 & 66.0 & 221.0 & 333.8 & 300.3 & 529.0 & 679.0 & 418.9 \\
\hline Gain & 197.1 & 415.5 & 101.4 & 215.3 & 60.9 & 9.9 & 339.5 & 140.9 \\
\hline
\end{tabular}

\subsection{Mobilized landslide volume analysis}

In this session we analyse the landslide material volume dynamics within the period between 2008 to 2017 using the DEM-differencing method. We analyse the trend of the volume change using frequency-volume analysis. As mentioned before, only four DEMs were suitable for the analysis: LI1999, LI2008, PLE2014 and UAV2017. For PLE2014 we only used the area that was not affected by shadows in the satellite images.

\subsubsection{Trends in volume dynamics}

Figure 3.7 shows the major trends for the overlapping area of LI1999, LI2008 and PLE2014, and Table 3.4 shows the resulting statistics. Unfortunately the overlapped data only cover two small parts of the study area. To make the numbers comparable between the two locations, the volume dynamics are expressed in loss and gain rate per square kilometre (per $106 \mathrm{~m} 3 / \mathrm{km} 2$ ). 

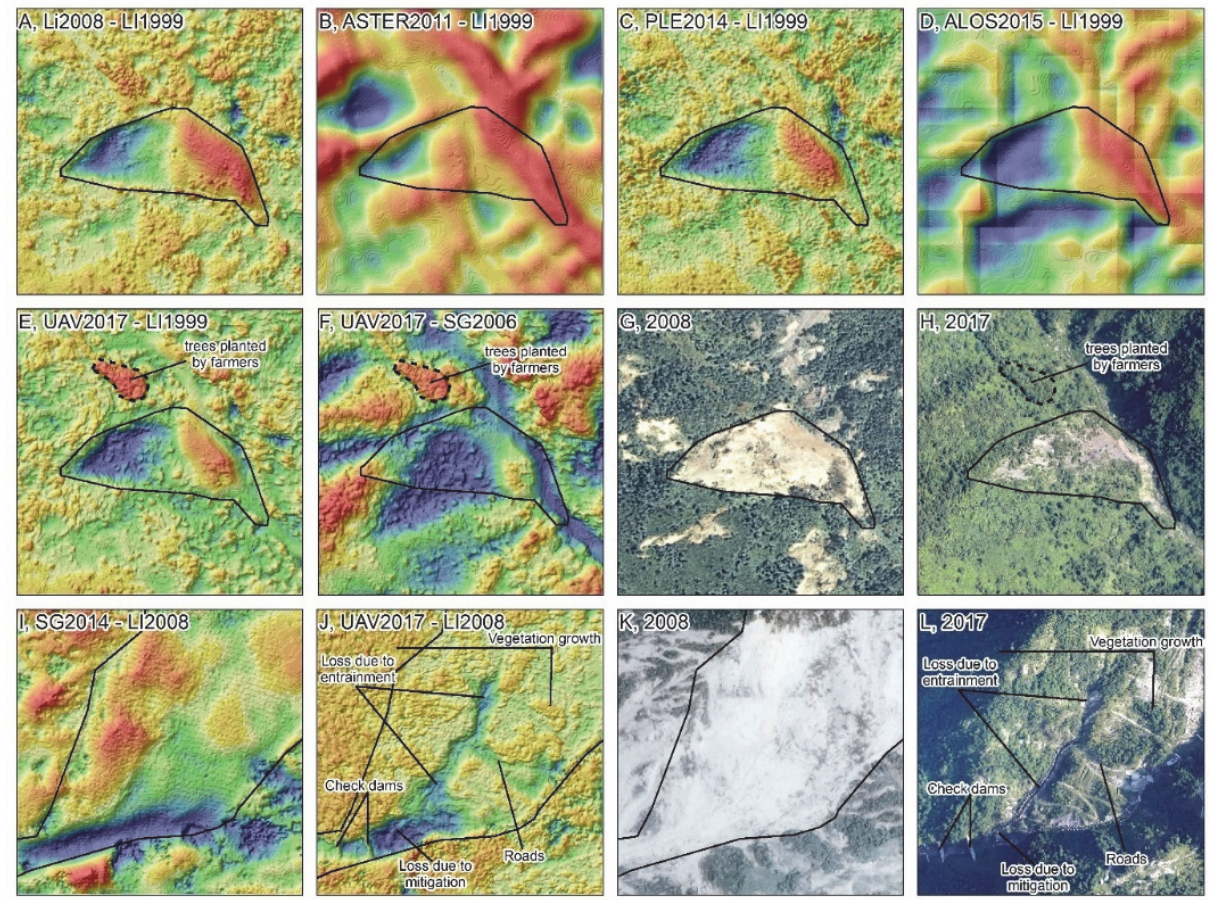

Elevation difference $(\mathrm{m})$
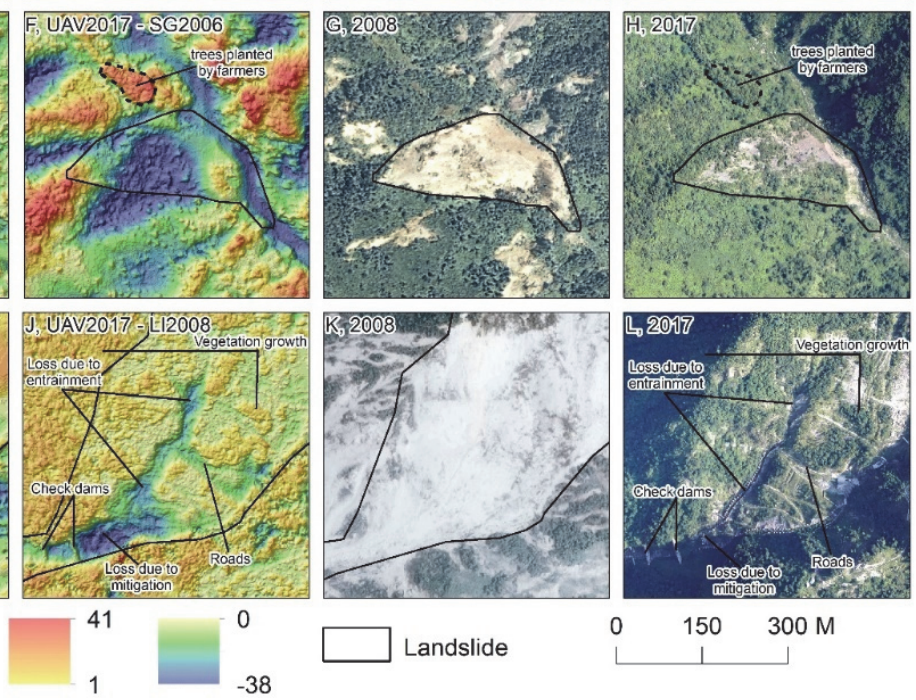

o $150 \quad 300 \mathrm{M}$

Figure 3.6: Elevation differences for a landslide by subtracting different DEMs. A to $H$ and $I$ to $L$ are showing two different landslides.

Table 3.4 Statistics of the trend analysis. *including the two landslides excavated by sand mining.

\begin{tabular}{|c|c|c|c|c|c|c|c|c|c|}
\hline \multirow{2}{*}{$\begin{array}{c}\text { DEM } \\
\text { subtraction }\end{array}$} & \multirow{2}{*}{$\begin{array}{c}\text { Area } \\
\text { covered by } \\
\text { DEMs } \\
\left(\mathrm{km}^{2}\right)\end{array}$} & \multicolumn{2}{|c|}{$\begin{array}{c}\text { Number of } \\
\text { landslides in area } \\
\text { covered by DEMs }\end{array}$} & \multicolumn{2}{|c|}{$\begin{array}{c}\text { Area of landslides } \\
\qquad\left(\mathrm{km}^{2}\right)\end{array}$} & \multicolumn{2}{|c|}{$\begin{array}{c}\text { Loss rate }\left(10^{6} \mathrm{~m}^{3}\right. \\
\left./ \mathrm{km}^{2}\right)\end{array}$} & \multicolumn{2}{|c|}{$\begin{array}{c}\text { Gain rate }\left(10^{6} \mathrm{~m}^{3}\right. \\
\left.\qquad / \mathrm{km}^{2}\right)\end{array}$} \\
\hline & & Dormant & Active & dormant & Active & dormant & Active & dormant & Active \\
\hline $\begin{array}{l}\text { LI2008 - } \\
\text { LI1999 }\end{array}$ & \multirow{2}{*}{7.2} & 0 & 350 & 0 & 1.4 & 0.0 & 1.4 & 0.0 & 3.9 \\
\hline $\begin{array}{l}\text { PLE2014 - } \\
\text { LI2008 }\end{array}$ & & 205 & 195 & 0.6 & 1.2 & 1.4 & 3.2 & 1.1 & 1.2 \\
\hline $\begin{array}{l}\text { UAV2017 - } \\
\text { PLE2014 }\end{array}$ & 5.2 & 104 & 2 & 1.2 & 0.2 & $0.5\left(1.6^{*}\right) \mid$ & 0.8 & 1.7 & 0.9 \\
\hline
\end{tabular}

The following trends can be observed:

1. The landslides triggered by the earthquake can be detected and quantified 
in a detailed manner by calculating the difference between the LiDARderived DEMs: LI1999 and LI2008. Vegetation did not have much influence on the comparison between the DSM and the DTM since most vegetation was removed by mass movement. The area contains 350 co-seismic landslides with a volume loss rate of $1.4 \times 10^{6} \mathrm{~m}^{3} / \mathrm{km}^{2}$ and a volume gain rate of $3.9 \times 10^{6} \mathrm{~m}^{3} / \mathrm{km}^{2}$. Elevation decrease at the scarps and increase at the toes could be clearly observed on several landslides (Figure $3.7 \mathrm{~A}$ ). Channels were blocked or completely filled up by co-seismic landslide materials.

2. Comparing the post-earthquake LiDAR DSM (LI2008) and the Pleiadesderived DSM (PLE2014) allowed to model the elevation change caused by the early post-seismic mass movements. The gain and loss were estimated separately on the dormant landslides and the active ones, based on the activities recorded in our post-seismic landslide inventories. Most of the loose materials deposited in the drainage channels were eroded in the years after the earthquake (2008 to 2014), leading to significant volume loss at the toes of landslides, and the occurrence of reactivations (Figure $3.7 \mathrm{~B})$. The total loss rate caused by post-seismic landslide activities $\left(3.2 \times 10^{6} \mathrm{~m}^{3} / \mathrm{km}^{2}\right)$, was close to the gained rate of the co-seismic landslides in the investigated area. This is because the thickest depositional zones are mostly at the toes of the co-seismic landslides, or in the nearby channels, where the most severe erosion would take place. Some gain could be observed at downstream locations near the catchment outlet, but not comparable to the loss. This is because a large portion of the debris flow deposition fan was later submerged by the Zipingpu hydropower reservoir lake and the part above the water level was partly excavated for road repair and sand mining. There were 50 newly triggered landslides that initiated in the post-earthquake period from 2008 to 2014 . They had a total area of $0.5 \mathrm{~km}^{2}$, a loss rate of $0.6 \times 10^{6} \mathrm{~m}^{3} / \mathrm{km}^{2}$ and a gain rate of $0.2 \times 10^{6} \mathrm{~m}^{3} / \mathrm{km}^{2}$, which is rather small compared to the total post-earthquake landslide volume.

3. The late post-seismic elevation change was analysed by the comparison between PLE2014 and UAV2017. A smaller area with only 106 landslides could be used for the analysis due to the small coverage of the UAV photogrammetry derived DSM (UAV2017) and the shadow problem of the Pleiades images. Only two of the landslides were active during this period and no significant volume changes were detected. A fast vegetation growth was observed in the form of elevation gain on most of the dormant landslides, resulting in a higher gain rate $\left(1.7 \times 10^{6} \mathrm{~m}^{3} / \mathrm{km}^{2}\right)$ than the loss rate $\left(0.5 \times 10^{6} \mathrm{~m}^{3} / \mathrm{km}^{2}\right)$ on dormant landslides, excluding those affected by human activities (Table 3.4). A sand mine that is located in this area almost dug out two landslides with a total area of $75,000 \mathrm{~m}^{2}$, leading to a 
significant loss rate if included in the statistics.

\subsubsection{Frequency-volume analysis}

A frequency-volume analysis was carried for three periods: 1 . the gain and loss of co-seismic landslides (LI2008 - LI1999); 2 . the loss in the early post-seismic period (PLE2014 - LI2008); 3. the loss from the late post-seismic stage (UAV2017 - PLE2014). The gain from the post-seismic periods was not included as most of the deposition occurred near the catchment outlets, with a large portion taken away by rivers and human activities. We used the method described by Clauset et al. (2009) to calculate power-law exponents ( $\beta$ ). In addition, we used the code (landslide-mLS) provided by Tanyas et al. (2018) to plot the power-law fits.

The data points show the frequency and volume of mass movements for the three periods and the trend lines of the power-law fits show the balance between small and large landslide volumes (Figure 3.8). The frequencies of coseismic landslide gain and loss were similar, except there is no co-seismic landslide with a loss larger than $10^{5} \mathrm{~m}^{3}$ within the study area. This resulted in a steeper power-law fitting of the loss $(\beta=-2.7036)$ than the fitting of the gain ( $\beta=-2.1445)$, as large landslides have more influence in the fitting of the gain. The early post-seismic loss has a very similar power-law fitting $(\beta=-2.1109)$ as the co-seismic landslide gain, as the most intensive depletion took place at locations with the thickest co-seismic deposition. The early post-seismic landslides with small volumes have less impact on volume dynamics as compared with co-seismic landslides. The late post-seismic loss has a gentler trend $(\beta=-1.6354)$, suggesting the power-law fitting is dominated by areas with large losses, caused mainly by sand mining.

The overall frequency of the volume decreased during the first six years after the earthquake. This is consistent with the studies of Hovius et al. (2011), who analyzed changes during five years following the Chi-Chi earthquake, and Tang et al. (2016), who investigated the changes in three years following the Wenchuan earthquake. 

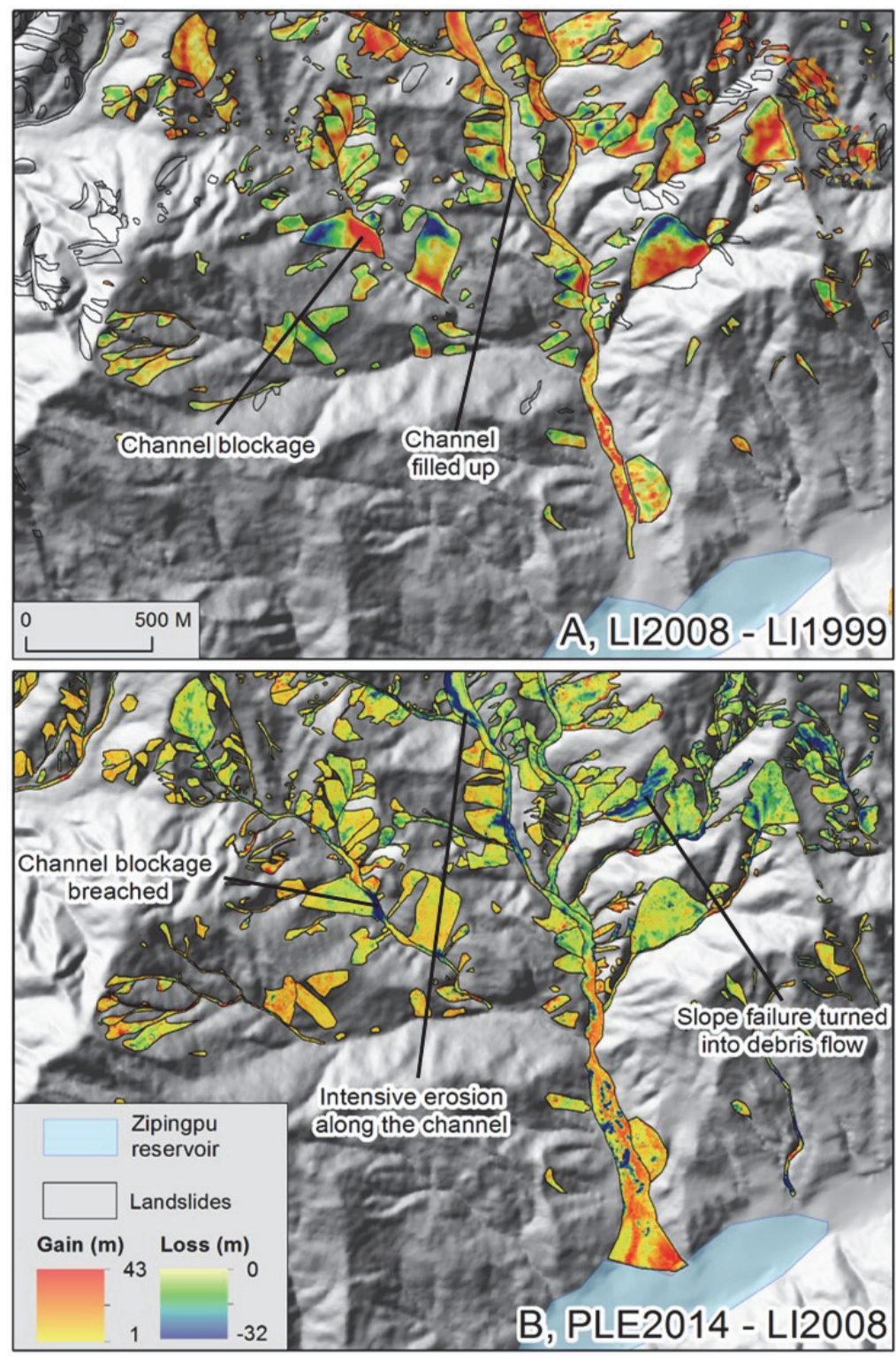

Figure 3.7: DEM comparison maps. The non-coloured landslide polygons are either not overlapping with the DEMs or affected by shadows in PLE2014. A: depletion (loss) and accumulation (gain) by co-seismic landslides calculated by subtracting the LiDAR-derived DEMs before the earthquake (LI1999) and after the earthquake (LI2008). B: Elevation changes due to post-earthquake landslide reactivations, by calculating the difference between the LIDAR-derived DEM from 2008 and the DEM derived from Pleiades images in 2014. 


\subsection{Discussion}

In the following section we will compare the measured post-seismic volume loss with the activity levels that were previously obtained using visual image interpretation from multi-temporal images, and analyze the area-gain relationship.

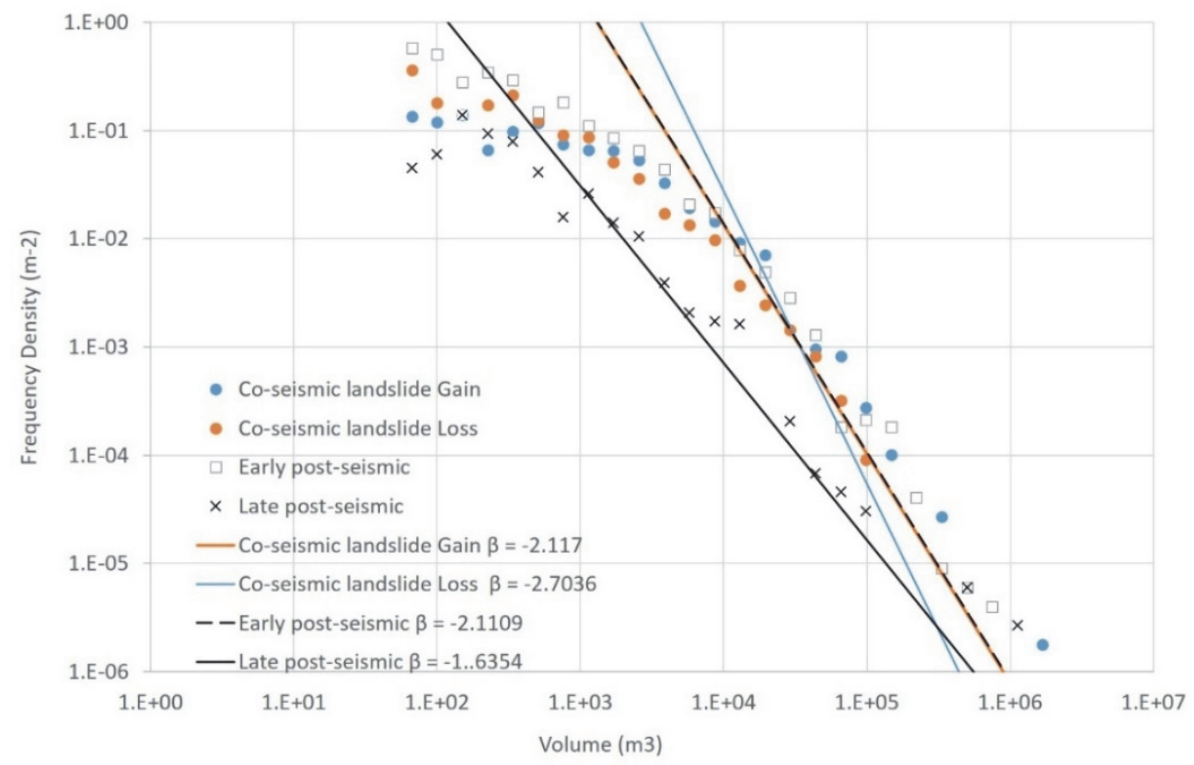

Figure 3.8: Frequency-volume analysis.

\subsubsection{The efficiency of defining activity levels}

During the visual image interpretation of satellite images from different years (Tang et al., 2016) a qualitative method of defining activity levels was used, based on the approximate active area visible of the co-seismic landslides in later years. Four landslide activity classes were used (Tang et al., 2016):

- level 0: no landslide activity and the landslide is dormant;

- level 1: less than one-third of the area of a landslide is active;

- level 2: about one-third to two-thirds of the area of a landslide is active;

- level 3: more than two-thirds of a landslide is active or the landslide is newly formed

To test the efficiency of this method, the volume loss rate $\left(\mathrm{m}^{3} / \mathrm{m}^{2}\right)$, calculated from the difference between PLE2014 and LI2008 within the landslide polygons, was categorized by the activity classes. The maximum activity level from the landslide inventories of 2009, 2011 and 2013 were used to define the activity levels in this analysis. It can be seen from Figure 3.9 that the overall loss rate increases as the activity level rises although considerable uncertainties are observed in all activity classes. The uncertainties could be 
caused by a number of reasons: changes in vegetation, errors in the landslide inventories, and error in DEMs. It is clear that qualitative method of defining activity levels gives more uncertainty, and activity levels could be better defined using measured loss values from DEMs, when available.

\subsubsection{Landslide volume and the hidden slip surface}

The study aimed to calculate landslide volumes, but resulted in calculating only gain and loss volumes. The calculation by subtracting multi-temporal DEMs may not give the volume of the entire mobilized mass since part of the displaced landslide materials may still be located in the depletion area, on top of the failure surface. Ignoring this will cause a significant underestimation of the real landslide volume. Landslides with short runout distances are particularly sensitive to this problem. An example from one of the short runout distance landslides in the area is used to illustrate this concept (Figure 3.10). In this case the slope moved down as a block, causing a small elevation difference $(-2$ to $+3 \mathrm{~m})$ in the middle of the slope. A significant gain is observed at the landslide toe, with a maximum value close to $20 \mathrm{~m}$. The actual landslide body is the difference between the post-landslide elevation and the failure surface elevation, but with the DEM subtraction it was only possible to detect net gain and net loss areas. This means the depth measured by the DEMs is only trustworthy at the landslide toes, where the failure surface overlaps with the pre-landslide terrain surface. This would not be an issue for those landslides where the runout distance is so long that all landslide materials are transported out of the depletion zone.

In our trend analysis the post-seismic material loss was close to the volume gained by the co-seismic landslides. This does not mean, however, that the coseismic landslide materials are depleted. Only the materials deposited in the channels, where the measurements from the DEM subtraction gives the largest gain and realistic depth, were eroded in the years following the earthquake. The majority of the co-seismic landslide bodies are still remaining on the slopes after major debris flows, which being underestimated by comparing DEMs. The sliding surface is playing a major factor in measuring landslide volume, but is usually not addressed as it is not possible to measure this for many landslides over a large area. Obtaining the slip surface information requires measurement from boreholes or geophysics methods, which are expensive and not likely to be applied on a large number of targets. 


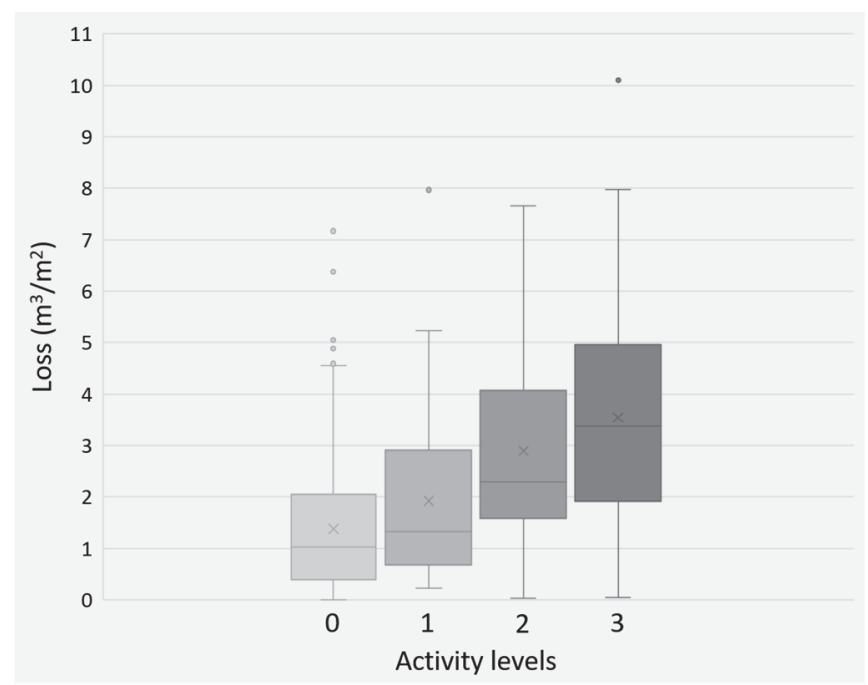

Figure 3.9: Volume loss per square meter of the activity levels interpreted from visual image interpretation. 0: dormant (measured from 430 landslides); 1: slightly active (64 landslides); 2: moderate active (64 landslides); 3: very active (172 landslides).

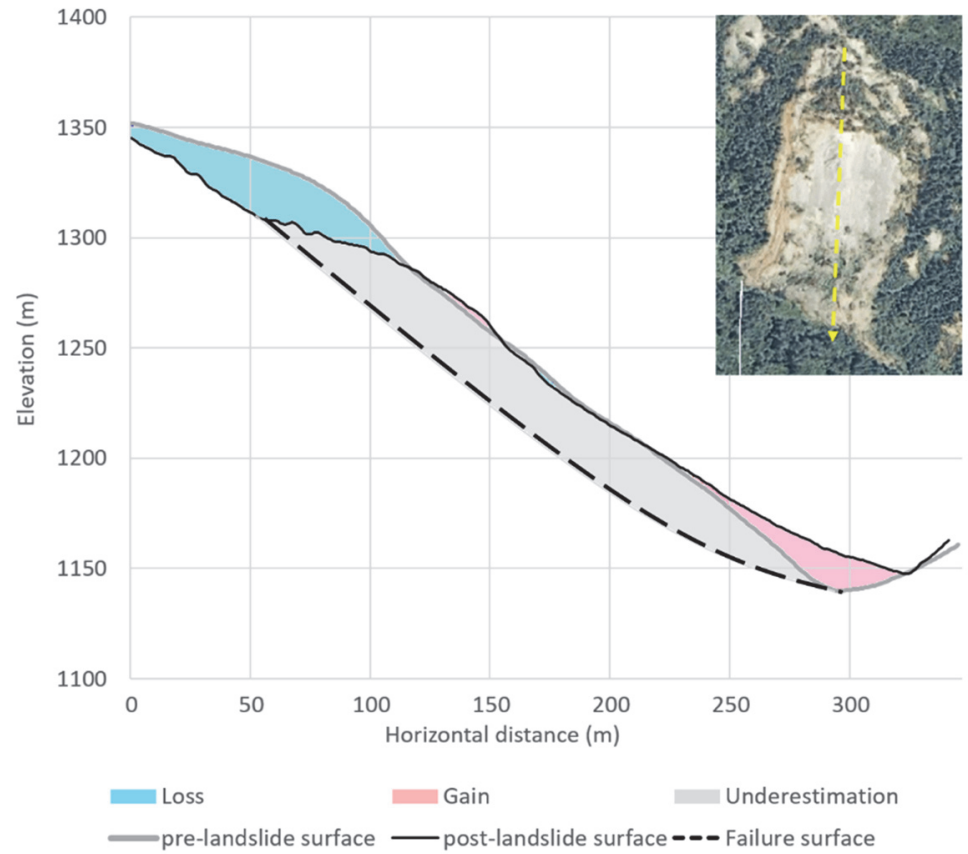

Figure 3.10: Concept of the unknown slip surface causing underestimation in volume. The volume loss of the landslide is $0.17 \times 106 \mathrm{~m}^{3}$ and the volume gain is $0.12 \times 10^{6} \mathrm{~m} 3$.

This issue should be investigated further to understand how to properly measure the actual volume of landslides. 


\subsubsection{Area-gain relation}

In order to analyse the empirical relation between area and volume we require information on the depth of the sliding surface for all landslides. That is why it is not possible to make an area-volume relationship for all landslides in the area. Instead, an area-gain relation of 483 co-seismic landslides is presented in Figure 3.11. The trend fits for an equation of $V=\alpha A^{\gamma}$ where $V$ is the volume gain and $A$ is the landslide area. $\alpha$ is a constant coefficient which ranges from 0.007 to 0.024 , and $\gamma$ is the scaling exponent within a range from 1.485 to 1.581. It should be noted that this equation only fits the volume gain calculated by DEM subtraction, which is not the actual landslide volume. The equation is only valid for the eastern side (Longchi) of our study area, as this is the only part with overlapping of the two LiDAR derived DEMs and the landslides in this region are much smaller than the side of Yingxiu (Figure 3.1). We present also the area-volume relationship of Guzzetti et al. (2009) for comparison. The loss and gain volume data is attached in the supplementary file.

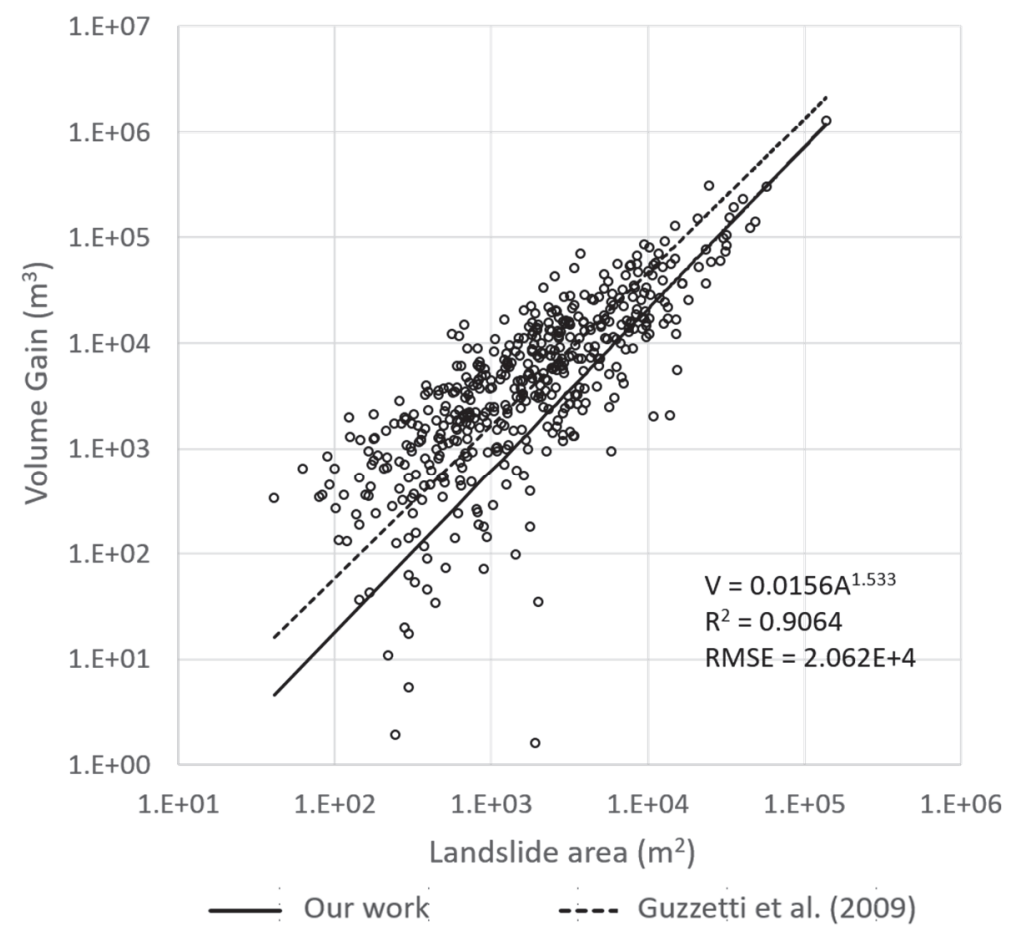

Figure 3.11: area-volume gain relation of co-seismic landslides.

\subsection{Conclusions}

This research has proven the potential of multi-temporal DEMs comparison in assisting relief and reconstruction panning after a major earthquake. We were only able to estimate the gain from the co-seismic landslides, which was an 
underestimation of the actual landslide volume due to the hidden failure surfaces. However this gain value is still very useful to predict the magnitude of the following debris flows as most of the erosion would take place in channels, where the landslide depth is measured correctly by DEM comparison. In the Wenchuan area the volumetric analysis was not carried out immediately after the earthquake, and this could be the reason that the government underestimated the threat before the debris flow disasters in 2010. The data security policy might be one of the reason as the LiDAR data of was collected by the government but not accessible to the specialists at that time. Nowadays commercial satellites such as Pleiades provide a good data source in case of similar events that might occur in future, with much less restrictions in countries with tight data sharing policies, despite their high cost and uncertainty in cloud coverage for successful data collection. Data collected by drones also have a large benefit to carry out a fast volumetric analysis in an area hit by an earthquake, in spite of its limited survey coverage and the necessity of including GCPs.

In this study we collected nine DEMs with different resolutions and from different sources, which were generated in different years, and covered different parts of the study area. We manually registered the DEMs both horizontally and vertically, which required a careful subjective judgment to choose the location of ground control points, tie points, and matching profiles. Due to the differences in sensors, spatial resolution, datum, and coordinate systems of the original DEMs, the matching of the DEMs could not be done perfectly. This is particularly observed at a few locations with steep and complex terrain, where even the best DSMs showed a relatively large difference even in areas where no disturbance was expected.

We strongly recommend to use DEMs from the same data source, or at least with similar level of accuracy, to study mobilized volume. However, this is often not possible as high resolution DEMs (e.g. derived from LiDAR or UAV) might not be available for the pre-event situation. The post event DEM should also be taken as soon as possible after the occurrence to minimize the disturbance caused by reactivations, vegetation growth or human activities. An ideal data set was shown by Tseng et al. (2013) where multi temporal LiDAR data could be used to estimate the volumes for landslides triggered by cyclone Morakot in Taiwan. Table 3.5 presents the overall conclusion on the nine DEMs used in this study. As can be seen Pleiades stereo images could be the best option to obtain good volume estimations over a very large area. However, LiDAR and UAV-based photogrammetry would be better to avoid the shadow problems related to the Pleiades DEMs. LiDAR data is preferable over UAV-based photogrammetry as it allow to generate DSMs and maps of vegetation and building height. But in many countries, the collection of LiDAR data as well as control points for generating photogrammetry-based DEMs may be hindered 
by tight data collection and sharing policies. In this study we used a preearthquake DTM and a post-earthquake DSM to obtain the elevation changes corresponding to the co-seismic landslides. Landcover did not have a large impact on the co-seismic landslides since they were removed by mass movements, but was affecting all the non-landslide areas when comparing LI2008 with LI1999. Another problem encountered in this study was that there has been a major co-seismic change in elevation due to uplifting, which was in the order of 6 meters vertically, and 4 meters horizontally (Xu et al., 2009). However, it was not possible to find suitable locations that did not have major changes in landcover to analyze the earthquake uplifting from the DEM difference.

Table 3.5: Summary of the main characteristics of the nine DEMs used in this study for estimating landslide volume. We did not register TAN2017 due to its large error.

\begin{tabular}{|c|c|c|c|c|c|}
\hline DEMs & $\begin{array}{c}\text { Terrain } \\
\text { features } \\
\text { ignored }\end{array}$ & $\begin{array}{c}\text { Registration } \\
\text { difficulty }\end{array}$ & $\begin{array}{c}\text { Potential } \\
\text { overage }\end{array}$ & Major problem & Access Policy \\
\hline LI2008 & No & Low & Regional & Limited coverage & Only Chinese state-own \\
organizations
\end{tabular}

To address this type of issue it is recommended to have a more organized data collection plan instead of only start collecting data after the occurrence of elevation changing events, especially for the tectonically active areas. 


\section{Modeling landslide failure surfaces from DEMs for volume estimation}

\subsection{Introduction}

The volume of a landslide is an important factor for the evaluation of possible runout areas and cascading hazards such as landslide dam breach floods and debris flows (Dade and Huppert, 1998; van Westen et al., 2006). The volume of a landslide can be considered in different ways, as initial volume or deposited volume. In the case of slide-type mass movements, the initial volume is the material volume between the original ground surface and the failure surface. Knowing the position and geometry of the failure surface (also referred to as slip surface) is required for landslide volume estimation. However, such information is usually difficult to obtain, particularly over large areas with many landslides, due to the uncertainty and complexity of the underground information. Three methods are usually applied to obtain volume information of landslides: comparison of Digital Elevation Models (DEM), empirical relations between area and volume, and field survey methods.

Field survey methods such as trenching, boreholes and geophysical methods are able to collect information of underground structures. They provide site specific information which is essential to reconstruct the slip surface of individual landslides. However, these methods are relatively expensive and their application over many landslides within an area is difficult, also due to accessibility. Generally these methods are restricted to specific landslides, for which mitigation measures are planned. In the area struck by the 2008 Wenchuan earthquake only a few dozen of the total of more than 60,000 coseismic landslides (Xu et al., 2013) were investigated using these methods. For example the Shaofang catchment landslide $\left(2 \times 10^{6} \mathrm{~m}^{3}\right)$, which created a debris flow and blocked the Minjiang River, was measured by geophysical surveys (Yang, 2010). The Lianhuaxin catchment landslide $\left(7.5 \times 10^{6} \mathrm{~m}^{3}\right)$ which produced more than ten debris flows, was investigated by drilling bore holes and trenching (Hao et al., 2011). The Wenjia catchment landslide $\left(81.6 \times 10^{6} \mathrm{~m}^{3}\right)$ which created a massive debris flow and destroyed a settlement, was measured by all three methods (Sichuan Province Geological Engineering Complex, 2010).

The field-based methods are not applicable for volume estimation for a large area, including many individual landslides. The most applied method for these situation is based on empirical relations between landslide area and volume (Guzzetti et al., 2009; Larsen et al., 2010; Li et al., 2014; Parker et al., 2011; Tang et al., 2012b). Whereas the empirical volume estimations for individual landslides may have a large uncertainty, it is more applicable for estimating 
the total landslide volume for a certain area, including many landslides. The quality of the estimation depends on the local geo-environmental setting, the landslide types, and the quality of the landslide inventory (Guzzetti et al., 2009). The method is based on the statistical analysis of area and volumes for a number of measured landslides, and from the source literature it is not always clear how the original landslide volumes were measured that were used to derive the empirical relations. For example the volume data from Wen et al. (2004) is cited from other works (Chai et al., 1995; Zhong and Ge, 1993; Zou and Shao, 1996) which have no description of the measurement method. Rice et al. (1969) indicate that they measured landslide volume of soil slips using field survey, but did not indicate how they reconstructed the landslide volume for many slides. Yamagishi and Iwahashi (2007) used field survey cards to record the geometry of the landslides, but they did not describe how depth was measured. Parker et al. (2011) analyzed area-volume relation of the Wenchuan-earthquake-induced landslides with 41 field measured landslides but did not describe the measurement method. Larsen et al. (2010) collected a global landslide dataset containing 42 million samples from varies sources, without a clear description of their volume measurement methods.

The best method for estimating landslides volumes over larger areas thus far, is the comparison of good quality pre- and post-event Digital Elevation Models (DEMs) (Chen et al., 2006; Tseng et al., 2013; van Westen and Lulie Getahun, 2003). There are several problems related with the estimation of landslide volumes from pre-and post-event DEMs. First of all, good quality Digital Elevation Models should be available for both pre-and post-event situations. Ideally such DEMs should be derived from LiDAR, allowing to generate bare surface models, without the disturbing effect of vegetation. Unfortunately many areas in the world are not yet mapped using such high resolution DEM data, and therefore in many instances the volume estimation after a landslide event may be hindered by this.

However, this method does not allow to calculate the volume of the entire landslide body as landslide material may still be located in the depletion area, where both volume gain and loss takes place. This concept is expressed by two examples in Figure 4.1, in which DEM comparison only detects the loss (light blue) and gain (pink), ignoring a large portion of the mobilized materials in the middle of the slope and leading to a considerable underestimation (light grey). This is an important issue for landslides with short run out distance, while for those with larger run out distances the landslide materials will be transported mostly out of the depletion zone, and the DEM comparison is able to measure the volume correctly. Several other approaches were proposed to address the unknown failure surface issue, without the use of field methods. Chen et al. (2014b) introduced a Mass Balance Line by vertically shifting the surface of a DEM to achieve a balance between material loss and gain. However making 
loss and gain equal to each other would not solve the underestimation by DEMs since the failure surface is still unknown. Chen et al. (2013b) proposed to construct the terrain below a rock fall body based on the surrounding landscape measured by a laser scanner, but did not investigate the possibility for implementation on a large numbers of targets. Reid et al. (2015) developed the Scoops3D model and analyzes landslide stability by simulating the failure surface through spheres in a three-dimensional environment. This method requires considerable input data, beside the elevation models, on soil parameters, hydrological conditions and earthquake loading, which are very difficult to obtain over large areas.

Estimating landslide volume based on elevation models of the terrain and of the failure surfaces without detailed field investigations is still a major challenge. Thus far, to the knowledge of the authors, no methods have been developed that allow to calculate the actual landslide volume over a large area, only based on remotely sensed data. In order to address this, we developed a model to simulate the geometry of failure surfaces with exposed scarps.
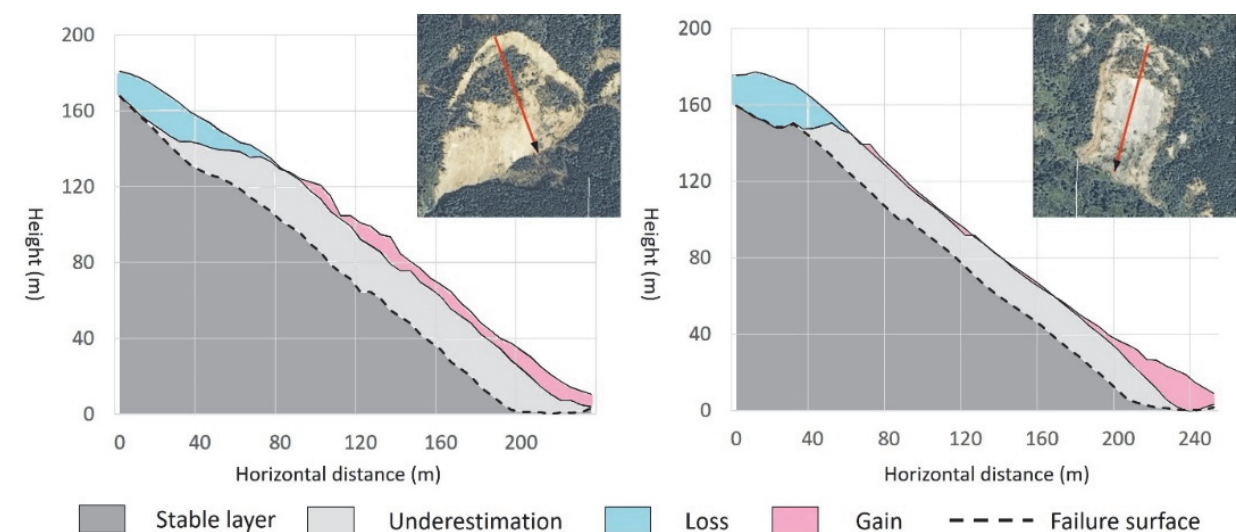

Figure 4.1: Two examples of volume underestimation by comparing two Digital Elevation Models. The arrows indicate the movement direction and the location of the cross sections. The actual landslide body should be either the blue area plus the grey area (initiation volume), or the pink area plus the grey area (depositional volume). However, with DEM comparison it is only possible to detect the pink area as gain and the blue area as loss.

To test our model, a series of analogue experiments were designed to acquire data for model testing in a controlled environment, before applying the model to real landslide cases.

\subsection{Model description}

A MATLAB model named "SLIPFITTER" was developed to model failure surfaces of multiple landslides in one run, using pre- and post-event DEMs. It models 
polynomial surfaces in with given input data (Table 4.1). The most important input data consist of the identification of the landslide scarps, and detailed DEMs showing the situation before and after the landslide event. Additional option data points can be included, showing the location of the failure surface, either resulting from boreholes, geophysical analysis or the geomorphological surface expression of the failure surface on the pre-event DEM.

Table 4.1: Input data for the modelling of landslide volumes using the proposed modeling approach

\begin{tabular}{|c|c|c|}
\hline Data & format & description \\
\hline \multicolumn{3}{|c|}{ Modeling polynomial surfaces in MATLAB } \\
\hline Scarp & \multirow{3}{*}{$\begin{array}{l}\text { ARCMAP } \\
\text { ASCII } \\
\text { raster }\end{array}$} & $\begin{array}{l}\text { Landslide scarp elevation points, extracted by } \\
\text { overlaying the mapped landslide scarps with the post- } \\
\text { landslide DEM. }\end{array}$ \\
\hline Additional point & & $\begin{array}{c}\text { Any other known elevation point representing the slip } \\
\text { surface which is not part of the backscarp (e.g. } \\
\text { depths from drillholes, geophysics, or } \\
\text { geomorphological expression of the scarp on the } \\
\text { surface) }\end{array}$ \\
\hline Landslide ID & & $\begin{array}{l}\text { A rasterized landslide inventory map where each } \\
\text { landslide has a unique number as identifier. }\end{array}$ \\
\hline \multicolumn{3}{|c|}{ Volume and error calculation in ARCMAP } \\
\hline $\begin{array}{l}\text { Modeled failure } \\
\text { surface }\end{array}$ & \multirow{3}{*}{ Raster file } & The output file from the MATLAB script. \\
\hline Pre-failure DEM & & A DEM represents the pre-landslide terrain. \\
\hline Post-failure DEM & & A DEM represents the post-landslide terrain. \\
\hline $\begin{array}{l}\text { Landslide } \\
\text { inventory }\end{array}$ & Shape file & $\begin{array}{l}\text { Landslide polygons with unique FID field in the } \\
\text { attribute table. It is used to extract the results } \\
\text { automatically. }\end{array}$ \\
\hline
\end{tabular}

A rasterized landslide inventory is needed to distinguish individual landslides (Landslide ID). The central part is a script created in MATLAB to carry out the surface fitting. A function is used to fit a polynomial surface to the provided data. The input for this consists of the elevation points of landslide scarps (Scarp), which are extracted by overlaying landslide scarp polygons with the post-landslide DEM. These are considered as the upper part of the failure surface, and the entire surface can be modelled by extending the uncovered part of the failure surface into the covered part. Whenever available also points 
of other known failure surfaces elevations (Additional point) are used. These two files composed the data points used for modeling and are subsequently used by the MATLAB script to carry out the fitting function. A function was made to multiply the number of elevation points from the Additional point file to be equal to the Scarp file, so that they have the same weight in the modelling. First to fifth polynomial order surfaces were tested in this study. A polynomial order higher than five would lead to a long runtime and large noise.

The analysis consisted of a number of steps (See Figure 4.2) which combine GIS operations with the modeling in MATLAB :

Step 1. A landslide inventory is created in GIS and converted into a raster map with a unique identifier for each landslide (Landslide ID).

Step 2. Landslide scarps are carefully checked with respect to the post-failure DEM and satellite images, and the boundaries are digitized to fit the scarps exactly on the post-failure DEM. The scarps are extracted (e.g. using the 'Extract by mask' tool in ARCMAP). The post-failure DEM is used as the input raster and the digitized scarp shape file as the mask.

Step 3. Whenever possible, it is advisable to add additional points that help to define the failure surface better. GIS can be used to extract the elevation points with evidence of the failure surface (Additional point). For example, if the assumption is that the failure surface outcrops at the foot of the slope, the prefailure DEM can be used as the input raster and the pre-landslide stream lines can be used as mask. If this is not the case, elevation points can be assigned manually in other locations, e.g. representing the depth to the failure surface from boreholes or geophysical surveys.

Step 4. The "SLIPFITTER" model is executed in MATLAB with the Landslide ID file, the Scarp data and Additional points containing failure surface elevation.

Step 5. The output will be an elevation model of the failure surface which is subsequently used in GI to separate the depletion and accumulation zones. Based on the same assumption of Step 3, GIS operations (e.g. the 'Intersect' tool in ARCMAP) can used to separate the landslide polygons from the stream lines. 


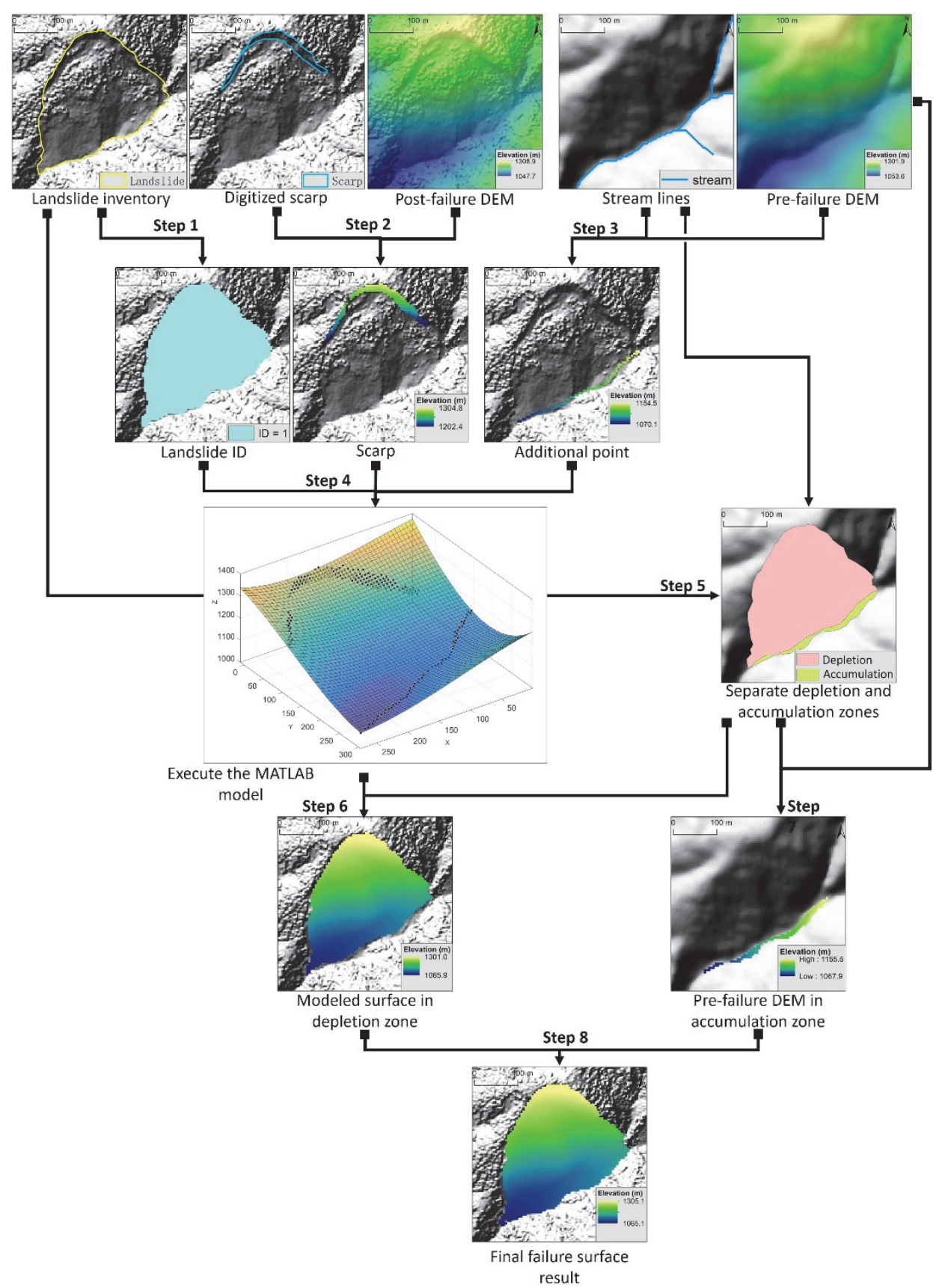

Figure 4.2: Flow chart of the volume estimation analysis.

Step 6. The depletion zone is extracted, using the modeled failure surface as the raster file and the depletion zone shapefile as the mask. The modeled 
failure surface is subtracted from the post-failure DEM and the resulting gain is calculated as the landslide volume in the depletion zone.

Step 7. The accumulation zone is extracted, using the pre-failure DEM as the raster file and the accumulation zone shapefile as the mask. The pre- and postfailure DEMs are subtracted in the accumulation zone to obtain the landslide volume in the accumulation zone.

Step 8. The output from Step 6 and Step $\mathbf{7}$ is combined to obtain the final failure surface result, and subtracting the result from the post-failure DEM to calculate landslide volume.

The results from the MATLAB script (step 4) were used in GIS (e.g. ARCMAP) to calculate errors and volumes. Root Mean Square Error (RMSE) was used to describe how accurate the surface was modeled and was calculated within the range of the failure surface (Figure 4.3).

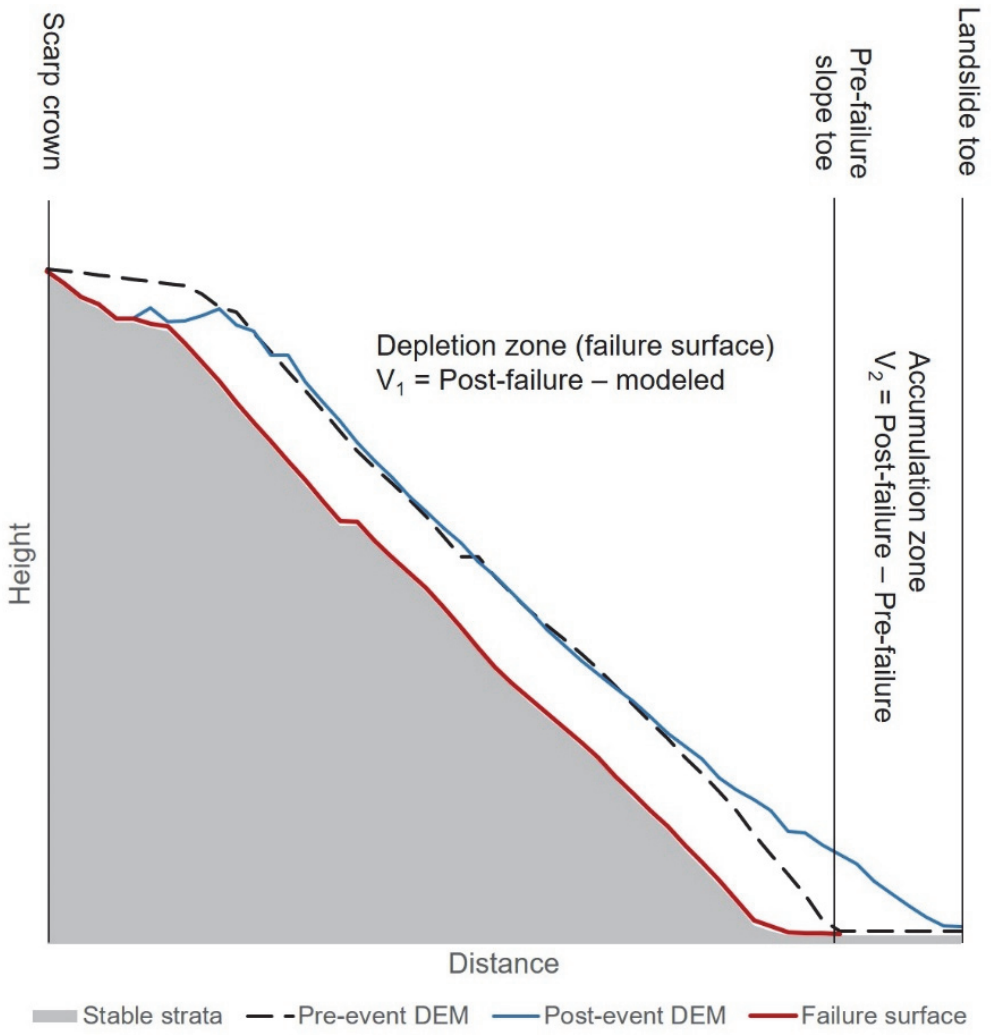

Figure 4.3: Volume estimation method for a modeled landslide. The total volume is calculated as $V_{1}+V_{2}$. 


\subsection{Model testing}

\subsubsection{Field experiments}

In order to test the method in a fully controlled environment, a field experiment was conducted on an outdoor sand pile where the pre- and post-failure situation could be mapped in detail and where also the failure surface could be excavated and mapped. The sand pile was moisturized before the experiment so that the material had some cohesion. The experiment consisted of three stages. In the pre-failure stage the slopes were chosen and prepared for the experiment. A number of ground control points (GCPs) around the sand pile were measured with a real-time kinematic GPS (RTK). A DJI phantom 3 drone was used to take $s$ set of vertical photos, which would be used later for generating a DEM. In the second stage the landslides were triggered and a new set of vertical photos was taken after failure to generate the post-failure DEM. Then the sand on top of the failure surface was carefully removed by hand and using a handheld shovel, exposing the failure surface. The difference in the material strength, above and below the failure surface, could be clearly felt by hand and care was taken to only remove the looser sand above the failure surface. After cleaning the failure surface a new set of vertical images was made using the drone. for each of the experiment stages. Later in the office, Pix4D software was used to generate digital elevation models (DEMs) with a cell size of half a centimeter. We tested three different slope failure types:

TEST A: A translational failure was initiated on a fresh sandpile with a relatively modest slope of 24 degrees, and low moisture content (Figure $4.4 \mathrm{~A} 1$ ). The failure was triggered using the vibrations of a shovel at the toe of the slope. The sandy slope produced a failure (Figure 4.4 A2) with a clearly visible backscarp, with a steep slope. After cleaning the landslide material the failure surface was exposed (Figure $4.4 \mathrm{~A} 3$ ). The length to width ratio of the failure was 17:10. The profile of the failure is shown in Figure 4.4 A4.

TEST B: Another translational failure was triggered on a small sand pile which had a relatively higher moisture content and a steeper slope (41.5 degrees). The toe of the slope was excavated (Figure $4.4 \mathrm{~B} 1$ ) after which the pre-failure situation was mapped using drone images. The failure was triggered by vibrations from shovels on both lateral sides of the slope (outside of the failure extent). The top part of the slope collapsed, creating a large scarp (Figure 4.4 B2). The failure surface of this test is almost flat (Figure $4.4 \mathrm{B3}$ ). The length to width ratio of the failure was $11: 10$. The profile of this experiment is shown in Figure 4.4 B4.

TEST C: To simulate a deep rotational failure, we triggered a failure by adding water to the slope. First we excavated a slope of the sandpile and covered the 
bottom of it with a waterproof tarpaulin to create an impermeable lower surface. Next sand was piled up in the hollow and compacted using shovels, and the pre-failure situation was mapped using the drone (Figure $4.4 \mathrm{C} 1$ ). In the next step water was added using a hose until failure occurred, as evidenced by the formation of a series of cracks on the upper lateral and lower part of the slope (Figure $4.4 \mathrm{C2}$ ). The failure surface had a curved shape and was relatively deeper than in the other tests. In the bottom of the slope the failure surface reached to the waterproof tarpaulin (Figure $4.4 \mathrm{C} 3$ ). The length to width ratio of the failure was 12:10. The profile of the test is shown Figure 4.4 C4.

The DEMs of the pre-, post- and failure surfaces were generated for the three tests, and the resulting losses and gains were calculated (Table 4.2). It can be seen from table 4.2 that direct comparisons of pre- and post-landslide DEMs are underestimating the actual volume. The volume calculated by the failure surfaces were 1.9 to 2.9 times of the volume gain estimated by subtracting DEMs.

Table 4.2: Area and volume results of the field experiments.

\begin{tabular}{|c|c|c|c|c|c|}
\hline & \multirow{3}{*}{$\begin{array}{l}\text { Planimetric } \\
\text { area }\left(\mathrm{cm}^{2}\right)\end{array}$} & \multicolumn{4}{|c|}{ Volume $\left(\mathrm{cm}^{3}\right)$} \\
\hline & & \multicolumn{2}{|c|}{ Post DEM - Pre DEM } & \multirow{2}{*}{$\begin{array}{l}\text { Pre DEM - } \\
\text { Failure } \\
\text { Surface DEM }\end{array}$} & \multirow{2}{*}{$\begin{array}{c}\text { Post DEM - } \\
\text { Failure } \\
\text { Surface DEM }\end{array}$} \\
\hline & & Loss & Gain & & \\
\hline $\begin{array}{c}\text { TEST } \\
\boldsymbol{A}\end{array}$ & 25,007 & 129,000 & 82,900 & 234,400 & 191,300 \\
\hline TEST B & 48,180 & 374,300 & 437,400 & 842,200 & 903200 \\
\hline TEST C & 6,917 & 29,500 & 35,100 & 68,900 & 92,500 \\
\hline
\end{tabular}

\subsubsection{Failure surface modeling}

The results from the field experiment were used to test the "SLIPFITTER" model. We tested the performance of first to fifth order polynomial surfaces in the MATLAB script under five scenarios with different configurations of additional points that indicate the depth to the failure surface (Figure 4.5). The following scenarios were used, that mimic actual availability of additional data points in real cases, e.g. through boreholes, geophysical surveys or geomorphological interpretation: (1) evenly distributed additional data points; (2) no additional data points; (3) additional data point along a profile, as would be available from a geophysical survey; (4) a single additional point, as would be available from a borehole, and (5) additional points along the toe of the 
slope, as would be available when there is geomorphological evidence that the failure surface outcrops there. The elevation of the scarp was extracted from the post-failure DEM.

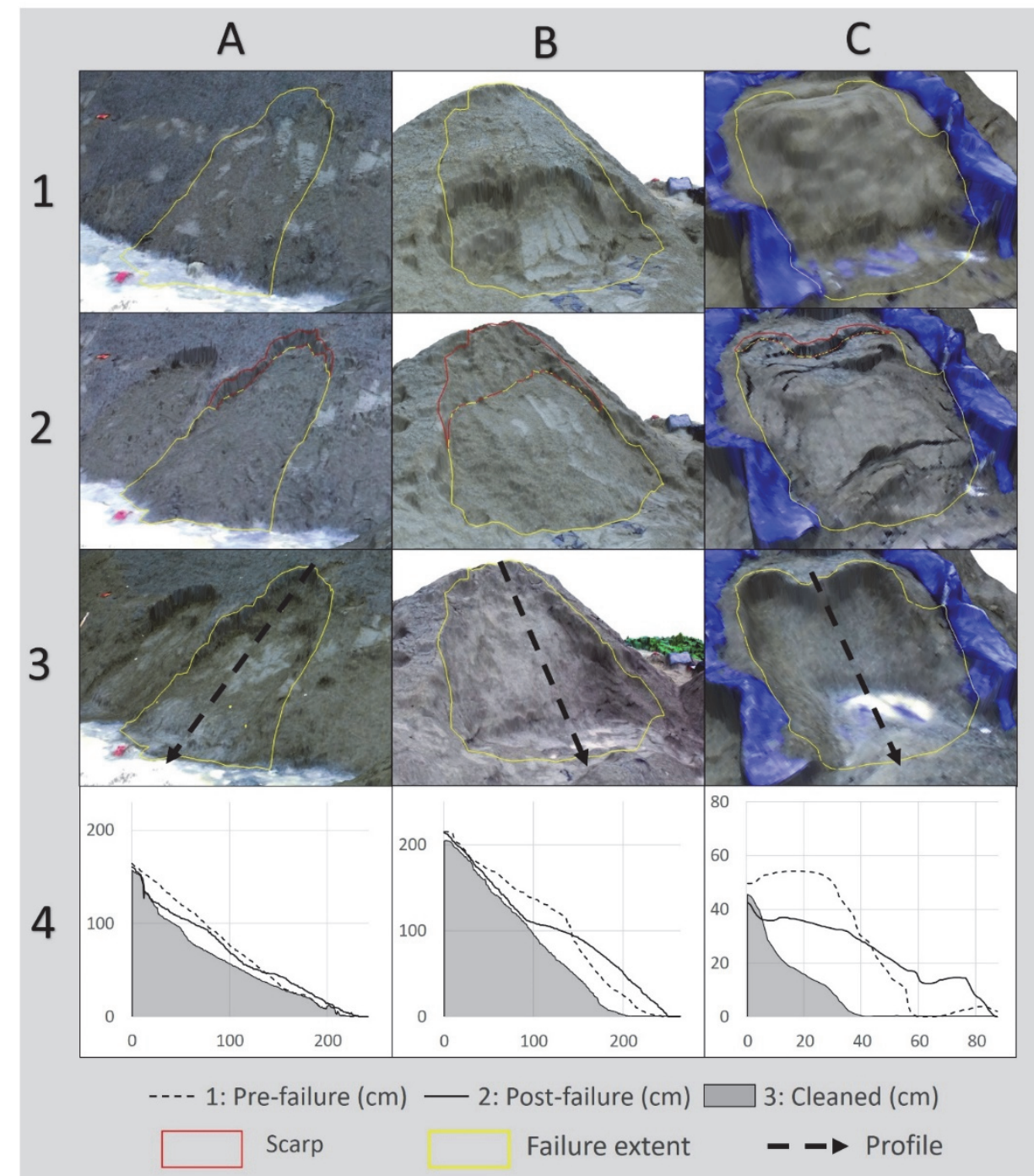

Figure 4.4: The three landslide tests with the situation before (1) and after (2) failure, and after cleaning the failure surface (3) and the three slope profiles (4). Test A: translational failure on modest slope; Test B: translational collapse on steeper slope; Test C: deep rotational failure. 

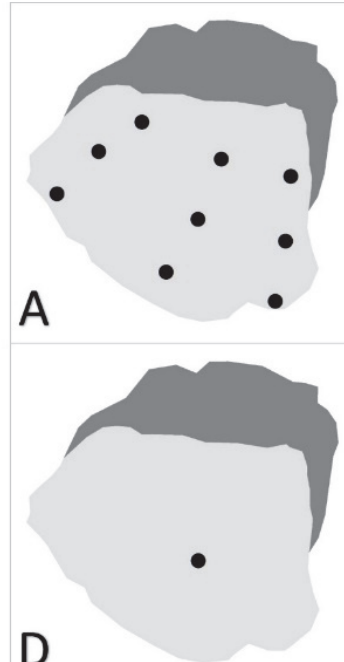

D
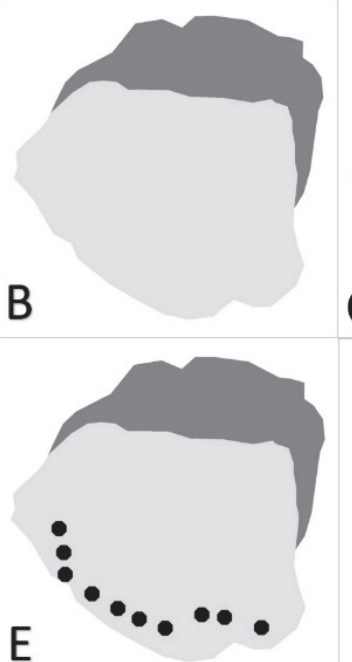

C

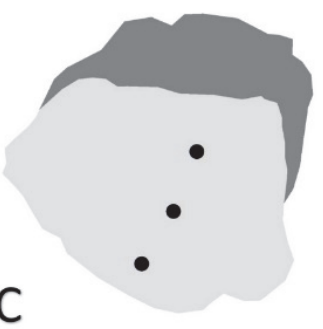

- $\quad$ Elevation point

Body

Scarp

Figure 4.5: Five scenarios with different configurations of additional points. A: Scenario I, additional points distributed evenly. B: Scenario II, no additional points. C: Scenario III, points along a profile. D: Scenario IV, one point in the center. E: Scenario V, points following the toe of pre-failure slope.

The additional points were extracted from the cleaned failure surface, except for the last scenario which used the pre-failure DEM. Both the scarp points and the additional elevation points were imported to the model to fit possible failure surfaces.

The results are presented in figure 4.6, where the errors are shown for all five scenarios of additional data points (Figure 4.5) and three landslides tests (Figure 4.4). The figure shows the RMSE values for the modelled failure surfaces in "SLIPFITTER" as compared to the observed failure surface for the five scenarios ( $A 1$ to $A 5$ ) and as the ratio between the modelled landslide volume and the measured volume for the same scenarios (B1 to B5).

Scenario I includes nine additional points distributed evenly on a landslide body (Figure $4.5 \mathrm{~A}$ ). The RMSE of the output surfaces was between 2.7 and $9.2 \mathrm{~cm}$ (Figure $4.6 \mathrm{~A} 1$ ) which was the lowest among all the scenarios. The error slightly decreased from first to fifth order polynomial functions for all the three tests. From third to fifth order TEST A and C showed a small increment in error. The lowest error was achieved with a third order polynomial in TEST A and C, and with a fifth order polynomial in TEST B. The largest variation in volume $(-29 \%$ of the measured volume) was obtained using the first order polynomial failure surface in TEST A, and the rest of the results showed a variation between $14 \%$ and $+14 \%$ (Figure 4.6 B1). 
In scenario II, no additional data points were used, and the failure surface was modelled using only backscarp elevation (Figure $4.5 \mathrm{~B}$ ). As can be expected this resulted in a large range of errors ( 8.4 to $522.4 \mathrm{~cm}$ ) and the error exceeded the maximum landslide depth for higher order polynomials (Figure 4.6 A2). TEST $C$ had a lower error than the other two tests. A large variation in volume was observed in TEST A and B when polynomial order was higher than one (Figure $4.6 \mathrm{~B} 2$ ), reaching extreme values. The volume variation of TEST $\mathrm{C}$ was between $-20 \%$ to $+24 \%$ from first to fourth order, increasing to $+121 \%$ for fifth order surface.

In scenario III several additional points were included that are located on a profile and that reflect the availability of geophysical information (Figure 4.5 C). the second order surface showed the lowest error in all the three tests (4.5 - $8.6 \mathrm{~cm})$. TEST A showed a large error $(26.9-41.5 \mathrm{~cm})$ with a polynomial order higher than two (Figure 4.6 A3). The error of TEST B and C showed an increase from second to fourth order, reaching up to $16.8 \mathrm{~cm}$. The estimated volume has a relatively large variation in TEST A $(-38 \%-+130 \%)$ and a moderate variation in TEST B and C $(-28 \%-+40 \%)$ (Figure 4.6 B3). All the modelled failure surface types resulted in underestimations in TEST B and overestimations in TEST C.

In scenario IV only one point was available at the center of the body that reflects the availability of a borehole (Figure $4.5 \mathrm{D}$ ). The error for TEST A was very large $(77-121 \mathrm{~cm})$ when polynomial order was higher than two (Figure 4.6 A4). TEST $B$ and $C$ had an increasing RMSE $(6.3-13.9 \mathrm{~cm})$ from first to fourth order surfaces, and a slight decrease occurred at fifth order polynomial $(12-12.3 \mathrm{~cm})$. The volume estimated in TEST A had a relatively large variation $(-44 \%-+82 \%)$ and was close to the measurement when applying fourth order polynomial despite a RMSE of $77.1 \mathrm{~cm}$ (Figure 4.6 B4). The volume estimation variation of TEST $B$ had a range of $\pm 14 \%$. TEST $C$ showed volume overestimation for all the surface types, ranging from $+21 \%$ to $47 \%$.

The last scenario $(\mathrm{V})$ is based on assumption that a failure surfaces outcrops when reaching the toe of a pre-failure slope, where the additional points could be extracted by a pre-failure DEM following the toe (Figure $4.5 \mathrm{E}$ ). The error of the modeled surfaces ranged from 4.4 to $11.8 \mathrm{~cm}$, which was the second lowest in the five scenarios. All the three tests showed a $<10 \mathrm{~cm}$ RMSE with polynomial orders higher than one (Figure 4.6 A5). The lowest RMSE was obtained with second order surface for TEST A, fifth order for TEST B and third order for TEST C. 

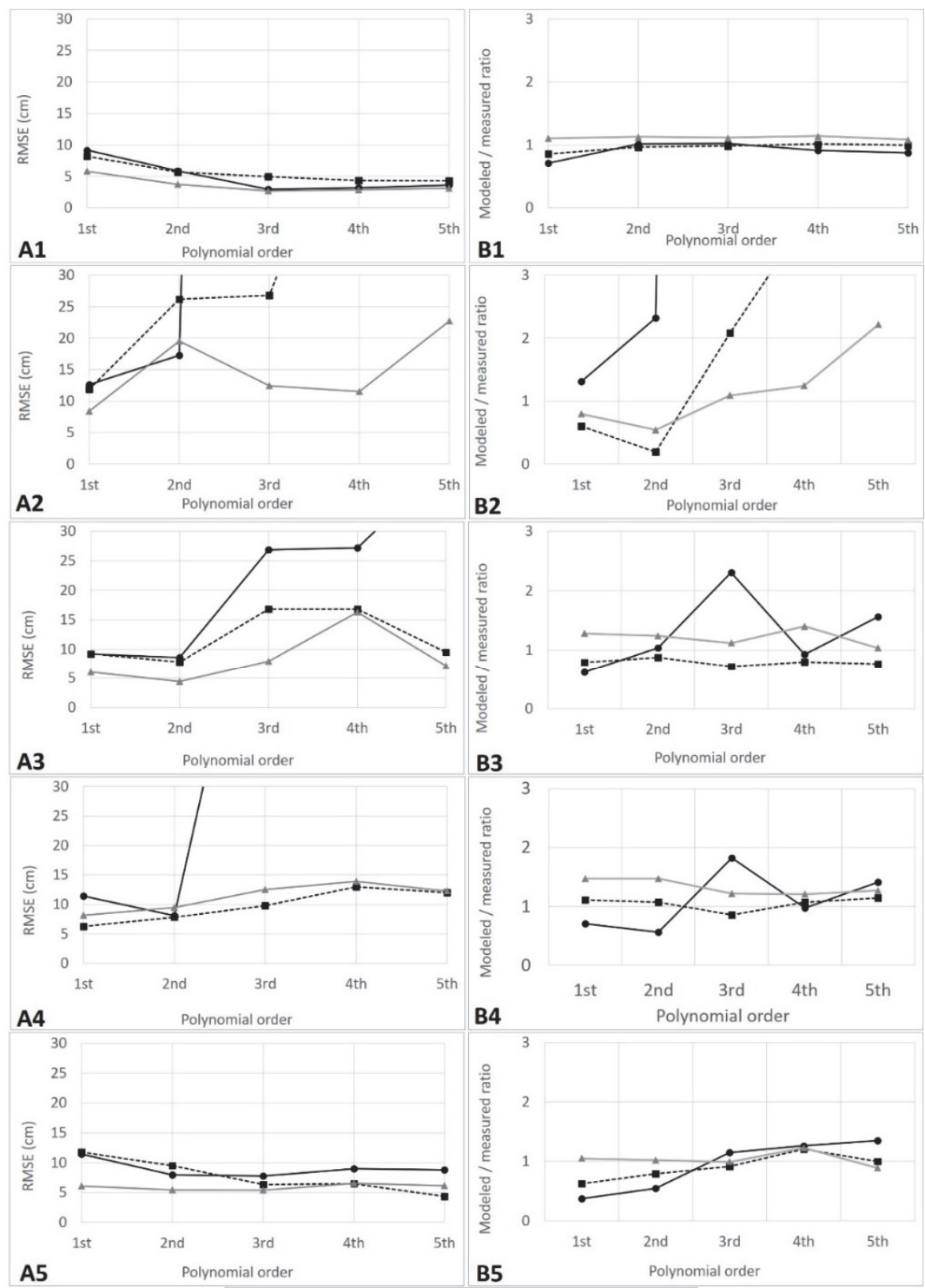

$\rightarrow$ Test A $\quad-$-Test B $\quad-$ Test C

Figure 4.6: Statistics of model testing with five scenarios. A1 - A5: Root Mean Square Errors (RMSE) of the modeled failure surfaces. B1 - B5: Ratios between the landslide volumes based on the modelled and observed failure surfaces. Test A: translational failure on modest slope; Test B: translational collapse on steeper slope; Test C: deep rotational failure. 
The most accurate volume estimation was obtained by applying a third order surface in TEST A and C (Figure 4.6 B5) and applying a fifth order surface in TEST B. It could be observed that the overall variation in error and volume were both low when using a third order polynomial. Results indicated that there is a large difference in RMSE and landslide volume for the five scenarios. The best performing scenario is where there are additional points available spread out over the entire landslide (Scenario I). The second-best option is scenario $V$, where points of the outcropping failure surface are used, although the volume tends to be underestimated. The scenarios that resemble the availability of a borehole (scenario IV) or geophysical profile (scenario III) gave larger errors, although the results differ considerably. As could be expected the scenario $(\mathrm{V})$ that did not use additional data points behaved worse than the others.

There were also significant differences between three landslides types as can be observed from figure 4.6. The best results were obtained for deep rotational failure where the modelled failure surface resembled the actual failure surface best, and where the landslide volumes were almost similar (at least for scenarios I and V). Translational failure surface showed large model errors, especially in the case of Test A (on modest slopes), in under scenarios II, III and IV.

\subsection{Volume estimation on earthquake induced landslides}

After testing the method on experimental data in a controlling experiment, the next step was to apply the model on real landslides, in the epicentral area of the 2008 Wenchuan earthquake, which triggered many landslides (Tang et al., 2016). We limited the study area to a section in the Longhi watershed where two LiDAR-derived elevation models were available. These included a preearthquake $5 \mathrm{~m}$ resolution LiDAR Digital Terrain Model (DTM) collected in 1999 and a post-earthquake $2.5 \mathrm{~m}$ resolution LiDAR Digital Surface Model (DSM) collected in 2008. The DSM was resampled to $5 \mathrm{~m}$ in order to accelerate the script processing. Unfortunately, the 2008 DSM could not be converted into a Digital Surface Model, due to the non-availability of the original point clouds, and therefore this model contains additional heights of vegetation and buildings. Remote sensing images were used to generate a multi-temporal landslide inventory (Tang et al., 2016). Due to the limited overlapping area of the two LiDAR DEMs, only a small area could be selected as test area. Ten of the co-seismic landslides were chosen as the study samples since had clearly visible scarps. A landslide inventory was created in ARCMAP and converted into a raster map with a unique identifier for each landslide. Landslide scarps were carefully checked with respect to the post-earthquake DSM and satellite images, and the boundaries were digitized to fit the scarps exactly on the post- 
earthquake DSM. The same procedure was followed as presented in Figure 4.2. The pre-earthquake DTM was used as the input raster and the pre-landslide stream lines were used as the mask, assuming that the failure surface was outcropping at the toe of the slope.

\subsubsection{Volume analysis from DEMS}

We modeled the failure surfaces for the nine landslides in the study area with second to fifth order polynomial surfaces and made a comparison with the volume estimated by DEM subtraction. First order polynomial was left out because it can only model flat surfaces. The samples contained two rock falls ( $B$ and $D$ ) and seven debris slides. A volume gain of $1.4 * 10^{6} \mathrm{~m}^{3}$ was estimated by DEM subtraction (Figure 4.7 A and Table 4.3). All the modelled failure surface types resulted a larger volume than the gain from DEM subtraction. The second order polynomial surface resulted in a similar total volume as the DEM subtraction gain (Figure $4.7 \mathrm{~B}$ and Table 4.3). However, four landslides ( $B, C, E$, and $G$ ) showed a volume less than DEM subtraction, which suggested that their failure surfaces were not properly modeled. Applying third, fourth, and fifth order polynomial surfaces resulted in similar volume for individual landslide and the total volume (Figure 4.8 C, D, E). For individual landslides the volume varied largely from $102 \%$ to $802 \%$, compared with the gain from DEM comparison. The average model result to DEM subtraction gain ratio was $270 \%$ which was a similar value as the measurement in TEST C. For the total volume, the $3^{\text {rd }}$ to $5^{\text {th }}$ order surfaces produced $404 \%$ to $441 \%$ of volume as the DEM subtraction. All the landslides resulted similar modeled volume other than landslide E. Based on what was observed in modeling field tests with Scenario V (Figure $4.6 \mathrm{~A} 5$ and B5), the results from $3^{\text {rd }}$ to $5^{\text {th }}$ order polynomial surfaces are likely to be reliable for volume estimation and $3^{\text {rd }}$ order surfaces are expected to have the most accurate result

\subsubsection{Comparison with Empirical methods}

We applied three empirical equations to compare with our volume estimation results. The first one is the power-law relation between area and volume proposed by Guzzetti et al. (2009), which was based on the measurements of 677 landslides collected around the world (Eq. 4.1). The second power-law relation was presented by Larsen et al. (2010), and was based on a global landslide inventory with 4231 landslides (Eq. 4.2). The third was a regression equation developed by Tang et al. (2012b) which was based on 49 fieldmeasured co-seismic landslides triggered by the Wenchuan earthquake (Eq. 4.3). 


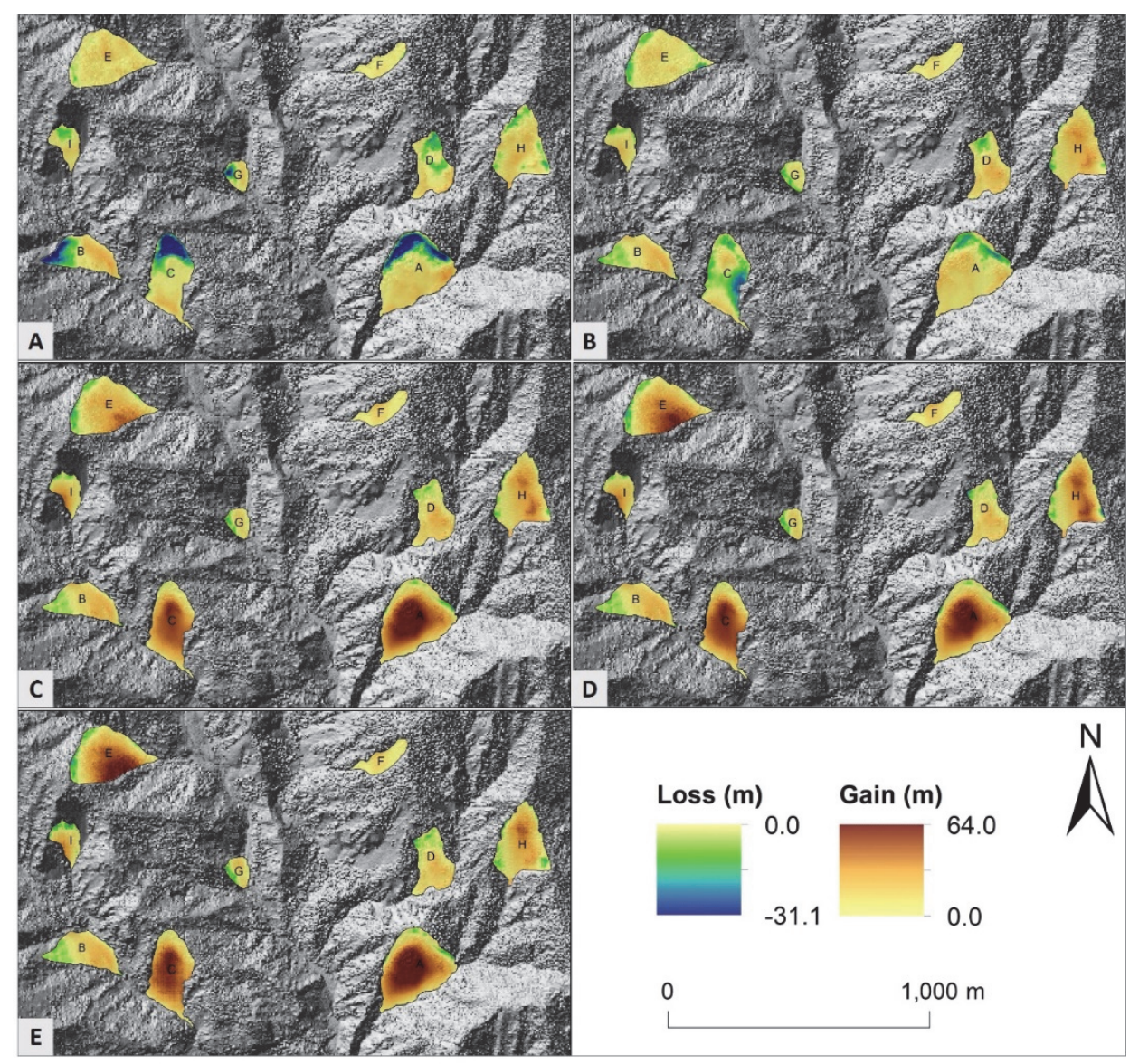

Figure 4.7: Landslide volumes estimated using different methods. (A) by DEM subtraction; (B) using second order polynomial failure surfaces; $(C)$ using third order polynomial failure surface; (D) using fourth order polynomial failure surfaces; $€$ using fifth order polynomial failure surfaces.

In the equations $V$ stands for volume of a landslide and the subscripts indicates the authors of the equations. $A$ is the planimetric area of a landslide.

$$
\begin{aligned}
& V_{G}=0.074 * A^{1.450} \\
& V_{L}=0.146 * A^{1.332} \\
& V_{T}=1.432 * \operatorname{Ln}(A)-4.985
\end{aligned}
$$

The total volumes computed from Eq. $1\left(2.4 * 10^{6} \mathrm{~m}^{3}\right)$ and Eq. $4.3\left(2.9 * 10^{6} \mathrm{~m}^{3}\right)$ were larger than the values resulting from the DEM subtraction. The application of Eq. 2 resulted in only four landslides with larger volumes than those calculated from DEMs, and the total volume was close to the gain estimated from DEM comparison (Table 4.3). 
All the empirical equations resulted in lower total volume than the result from $3^{\text {rd }}$ to $5^{\text {th }}$ order surfaces. Several similar volume estimation results between the modeled surfaces and the empirical equations were observed on individual landslides. The volumes estimated using the empirical relations of Guzzetti et al. (2009) and Tang et al. (2012b) were in the same order as those calculated using a third order polynomial failure surface for landslides B, D, E, and F. The equation by Tang et al. (2012b) also produced a similar volume for landslide $\mathrm{H}$. The equation of Larsen et al. (2010) only produced a close result for the third order polynomial surface for landslide $G$. The estimated volume was close to the results from the second order surfaces on landslides A, E, F, and I. Due to the limited data and landslide samples, it is not possible to evaluate the accuracy further.

Table 4.3: Volume estimation results. All values are in $10^{4} \mathrm{~m}^{3}$. Landslides A to $I$ are presented in Figure 4.7.

\begin{tabular}{|c|c|c|c|c|c|c|c|c|c|c|}
\hline \multirow{3}{*}{ Landslide } & \multirow{3}{*}{$\begin{array}{c}\text { Area } \\
\left(10^{4} \mathrm{~m}^{2}\right)\end{array}$} & \multicolumn{9}{|c|}{ Volume $\left(10^{4} \mathrm{~m}^{3}\right)$} \\
\hline & & \multirow{2}{*}{$\begin{array}{l}\text { DEM } \\
\text { LOSS }\end{array}$} & \multirow{2}{*}{$\begin{array}{l}\mathrm{DEM} \\
\text { gain }\end{array}$} & \multicolumn{4}{|c|}{ Polynomial surfaces } & \multicolumn{3}{|c|}{ Empirical equations } \\
\hline & & & & $\begin{array}{l}2^{\text {nd }} \\
\text { order }\end{array}$ & $\begin{array}{l}3^{\text {rd }} \\
\text { order }\end{array}$ & $\begin{array}{l}4^{\text {th }} \\
\text { order }\end{array}$ & $\begin{array}{l}5^{\text {th }} \\
\text { order }\end{array}$ & $\begin{array}{c}\text { Guzzetti } \\
2009\end{array}$ & \begin{tabular}{|c|} 
Larsen \\
2010
\end{tabular} & $\begin{array}{l}\text { Tang } \\
2012\end{array}$ \\
\hline A & 6.0 & 19.2 & 31.8 & 35.4 & 154.0 & 135.1 & 155.4 & 62.3 & 33.6 & 64.8 \\
\hline B & 2.8 & 8.9 & 18.6 & 18.4 & 22.8 & 23.4 & 22.6 & 20.8 & 12.3 & 27.4 \\
\hline C & 4.0 & 16.9 & 11.9 & 8.0 & 85.9 & 95.6 & 95.4 & 34.5 & 19.5 & 40.8 \\
\hline D & 2.7 & 3.8 & 9.8 & 21.6 & 21.0 & 18.5 & 17.7 & 19.9 & 11.8 & 26.5 \\
\hline E & 4.7 & 0.5 & 28.7 & 21.0 & 58.1 & 83.3 & 98.1 & 43.9 & 24.3 & 49.3 \\
\hline $\mathrm{F}$ & 1.3 & 0.1 & 4.4 & 5.4 & 7.6 & 8.3 & 7.1 & 6.7 & 4.4 & 11.2 \\
\hline G & 0.8 & 1.8 & 2.9 & 1.3 & 3.0 & 3.4 & 3.9 & 3.7 & 2.5 & 6.8 \\
\hline $\mathrm{H}$ & 4.2 & 2.5 & 23.7 & 45.3 & 53.6 & 62.4 & 47.8 & 36.9 & 20.8 & 43.0 \\
\hline I & 1.3 & 1.0 & 3.9 & 5.3 & 11.3 & 11.5 & 9.7 & 6.6 & 4.3 & 11.0 \\
\hline Sum & 28.9 & 59.9 & 140.2 & 163.8 & 420.6 & 444.4 & 459.7 & 241.0 & 137.0 & 290.3 \\
\hline
\end{tabular}

\subsection{Discussion \& conclusion}

The results from the field test showed that it is not possible to create the failure surface elevation models in a sufficiently accurate manner using only the scarps extracted from the post-failure DEM. Unfortunately many backscarps of landslides, especially those related to translational failures, are relatively small 
and steep, and the use of these alone for the modelling of the failure surface results in large errors. It is essential to use some additional elevation points, that could be obtained by overlaying the pre-and post-failure DEMs and trace the outcropping failure surface along the bottom of the slope.

When a landslide reaches the toe of the slope, the model is able to calculate the volume based on pre- and post-failure DEMs over a large area without taking additional field measurements, with the assumption that the failure surface outcrops at the foot of the pre-failure slope. The model can improve the results, when a few boreholes are available, forming a cross section on the lower part of the slope to better model the failure surface.

The application of the model in the Wenchuan test area showed that the most reliable model results were obtained by applying third order polynomial surfaces. The results gave a difference of up to $300 \%$ as compared to the total volume gain estimated by DEM subtraction, which is slightly higher than the results from the field experiment (206\% to $287 \%$ of the results from DEM subtraction). Based on these field experiments, the uncertainty in volume was $15 \%$ at maximum (Figure 4.6 B5). However the uncertainty should be investigated further since we only carried out tests for three landslide types.

The modeled third order polynomial failure surfaces resulted in a higher total volume than the empirical equations. This was probably caused by the small number of samples. The volume modeled by third order surfaces showed a consistency with the equations of Guzzetti et al. (2009) and Tang et al. (2012b) on several of the samples. The equation of Larsen et al. (2010) had a similar volume as the DEM subtraction in the test area in Wenchuan, probably because the equation was based on a very large numbers of global landslides with an average depth lower than our samples. Due to lack of data, a conclusion on the volume estimation accuracy could not be made. To obtain total landslide volume over a large area it is suggested to use empirical equations calibrated by local measurements. Our model is more suitable to obtain depth and volume information for individual landslides.

The model that integrates MATLAB and ARCMAP functions to estimate landslide volume based on failure surface geometry has also a number of limitations. It can only be applied when pre- and post-failure DEMs are available that have sufficient high quality. The resolution and DEM accuracy should be large enough to make backscarps clearly visible and provide correct information on elevations for data points. We could only find nine landslides that meet this requirement among the 350 co-seismic landslides in the selected area. This was because most of the landslides were small in size and did not have a clearly visible backscarp. Also many landslides did not reach to the toe of the slope, which was an important assumption in order to be able to use the additional 
points of the outcropping failure surface. It appears that the model is not suitable for small landslides, and the threshold of landslide size is depending on the resolution of the DEMs. For landslides that could not reach the foot of the slope, measured additional elevation points were required, which are generally not available.

Due to the unavailability of a bare surface model for the post-earthquake situation, there remained the issue of vegetation disrupting volume estimation result, as landslides A, C, D, F and I had some trees still located on the failed slopes. It was not possible to apply an automatic filter to remove the vegetation in the gridded Digital Surface Model, as the original point cloud was not available.

The total landslide volume obtained using the model showed a poor agreement with the results using empirical equations, and there were significant differences for both individual landslides as well as for the total volume. Due to lack of measurements from boreholes or geophysical investigations it is not possible to know which method is more accurate. Currently the scarps need to be extracted manually and many processes need to be carried out in ARCMAP, which limit the efficiency of modeling. The model should be further developed, which will involve fully automatic data extraction and calculating the resulting statistics. A database of field measured landslide volume and high-resolution elevation models should be collected in order to assess the model performance on more landslides in different areas. 


\section{Monitoring recovery in an earthquake affected mountain environment}

\subsection{Introduction}

\subsubsection{Background}

Large-scale disasters (e.g. earthquakes, cyclones, floods, volcanic eruptions and forest fires) cause wide-spread losses to society, leading to direct and indirect social and economic losses. Catastrophic earthquakes have caused severe damage to human societies in the past 20 years (e.g. 1999 Izmit Turkey, 1999 Chi-Chi Chinese Taipei, 2003 Bam Iran, 2004 Indian ocean, 2005 Pakistan, 2008 Wenchuan China, 2010 Haiti, 2011 Tōhoku Japan, 2015 Gorkha Nepal, and 2018 Palu Indonesia). The earthquakes caused heavy losses by damaging buildings due to ground shaking and several triggered secondary disasters like landslides and tsunamis. These events also have a large impact on the natural environment, and critically change the conditions related to vegetation, active processes and hydrology leading to new hazards or increased intensity and frequency of existing hazards. This aspect is often not fully considered in post-disaster reconstruction planning, leading to unfortunate new impacts and losses.

Earlier studies on post-earthquake recovery were carried out using field visits and statistics based on interviews (Bolin and Stanford, 1998; Sakamoto and Yamori, 2009; Wang et al., 2012; Wu and Lindell, 2004). Several studies on recovery monitoring used remote sensing methods (Burton, 2015; Platt et al., 2016; Yang et al., 2015b), however, few studies focused on multi-temporal monitoring of post-earthquake recovery in an environment affected by several multi-hazards. The aim of this study is to monitor the changing built-up environment in a mountainous region during the recovery process from the 2008 Wenchuan earthquake.

The $M_{w} 7.9$ Wenchuan earthquake occurred on 12 May 2008 in Sichuan province, affecting an area of $110,000 \mathrm{~km}^{2}$, most of which consisting of steep mountains with deeply incised valleys. The earthquake triggered a large number of landslides, and estimations varied between 48,000 and 200,000 (Dai et al., 2011; Tanyas et al., 2019; Xu et al., 2013). Around one third of the 87,537 casualties was estimated to have been caused by the landslides and not by ground shaking only (Wang et al., 2009a). The estimated losses from the earthquake were around 115 billion US dollar (Dai et al., 2011). After the relief stage the reconstruction began in 2009, and 19 of the Chinese provinces supported each one of the affected counties or cities in the recovery by using at least $1 \%$ of their annual provincial revenue for a period of 3 years 
(Dunford and Li, 2011; Huang et al., 2011; United Nations Office for Disaster Risk Reduction (UNISDR), 2010; Zuo et al., 2013). The provinces were requested to provide specialists in planning and design, as well as construction workers. A fast reconstruction progress was witnessed and the reconstruction was completed in 2012.

However, extreme rainfall events in the years following the earthquake triggered numerous mass movements, mostly in the form of debris flows, destroying many of the reconstructed buildings. One of the most devastating events occurred in Qingping village (Mianzhu County) on 13 August 2010, when two debris flows from the Wenjia watershed, destroyed the mitigation measures and buried most of the valley, including newly reconstructed villages and roads (Tang et al., 2012a). Another example of a major post-earthquake disaster was the debris flow that dammed the Minjiang River which flooded the nearby Yingxiu town on 14 August 2010 (Xu et al., 2012).

The increased debris flow activity lasted for five years, and a third major disaster occurred on 10 July 2013, when a debris flow formed by a breached landslide dam severely damaged the reconstructed buildings in Qipangou village, destroying most of the farmlands (Hu and Huang, 2017). The losses caused by these disasters have resulted from a lack of experience in postearthquake reconstruction planning.

Vegetation changes (mainly from vegetated to bare) which can be detected from high resolution remote sensing images are important indicators for landslide monitoring (Mondini et al., 2011; Saba et al., 2010; Stumpf and Kerle, 2011), and vegetation regrowth on landslide surfaces has been widely used to analyze the recovery of landslide surfaces (Khan et al., 2013; Li et al., 2016; Yang et al., 2017). In the epicentral area of the 2008 Wenchuan earthquake, the total area of active landslides has decreased linearly in the first five to eight years (Tang et al., 2016; Yang et al., 2017; Yang et al., 2018; Zhang et al., 2016). Similar recovery patterns of co-seismic landslide surface were also observed In the Mianyuanhe area of the Wenchuan earthquake affected region (Li et al., 2016).

The Wenchuan earthquake has initiated many studies related to assessing vulnerability and losses (Wang et al., 2009b; Wu et al., 2012), such as physical (Cui et al., 2013), social (Hu et al., 2010; Kun et al., 2009; Lo and Cheung, 2015; Wang et al., 2015; Yang et al., 2015a), environmental (Yang et al., 2017), institutional (Hu et al., 2010), and economic vulnerability (Wu et al., 2012; Zhang et al., 2013b). Household vulnerability was studied in particular by a number of studies (Sun et al., 2010a; Sun et al., 2010b; Zhang, 2016) which included subjective perceptions (Yang et al., 2015a), factor analysis on household vulnerability (Wang et al., 2015) and on household income (Sun et 
al., 2010b), and household vulnerability to poverty (Sun et al., 2010a). Recovery was studied by (Dalen et al., 2012) and (Wang et al., 2015).

In this study we generated seven inventories of elements-at-risk from satellite images covering a period of 13 years (2005 - 2018) and conducted several field surveys to study the recovery of Longchi valley, located close to the epicenter of the Wenchuan earthquake. Image interpretation was carried out based on a series of satellite images collected between 2005 and 2018. The study aims to demonstrate and analyze the process of post-disaster recovery in an unstable geo-environment disrupted by a major earthquake.

\subsubsection{Study area description}

The study was conducted in the Longxi watershed, located within $20 \mathrm{~km}$ from the epicenter of the 2008 Wenchuan earthquake in Sichuan province of China (Figure 5.1). The valley had 2306 permanent residents based on the national census in 2010 (Baidu Encyclopedia, 2016). The area of the watershed is about $89 \mathrm{~km}^{2}$ and the elevation ranges from 810 to $3200 \mathrm{~m}$. The main channel of the Longxi River, which is a tributary of the Minjiang River, has an average yearly discharge of $3.44 \mathrm{~m}^{3} / \mathrm{s}$ and the recorded maximum discharge was $300 \mathrm{~m}^{3} / \mathrm{s}$. The river flows through the Zipingpu hydropower reservoir which is also one of the major water sources of the province, providing drinking water to the large city of Chengdu (with 16.3 million inhabitants). The climate is sub-tropical, with an average annual precipitation of $1135 \mathrm{~mm}$, of which $80 \%$ occurs from May to September. The highest precipitation takes place in August with a maximum recorded intensity of $83.9 \mathrm{~mm} / \mathrm{h}$ (Sichuan Geology Engineering Reconnaissance Institute, 2010). One of the two major faults that ruptured during the earthquake passes through the area: the Yingxiu -Beichuan fault, which had a horizontal displacement of $4.5 \mathrm{~m}$ and a vertical displacement of $6.2 \mathrm{~m}$ (Gorum et al., 2011). The Guanxian - Jiangyou fault in the south was ruptured during the earthquake as well (Li et al., 2010). As shown in Figure 5.1 the surface ruptures splits into two branches in this region. At three kilometers the surface rupture continues in the eastern side of the watershed. Most of the area is underlain by granite, with some conglomerate distributed in the north, and carbonatite and sandstone in the south.

\subsubsection{History of the study area}

Longchi town was formerly called Longxichang and was located at the outlet of the Longxi watershed. It was founded in 251 B.C. as the first relay station in the mountains on the $320 \mathrm{~km}$ long Ranmang mountain path which connected the Chengdu Plain (Figure 5.1) with the counties in the mountainous region. It developed into a booming businesses area. The 1933 Diexi earthquake induced 11 landslide dams, which resulted in a catastrophic dam-breach flood, which killed at least 2500 people along the Minjiang River and damaged the irrigation 
system of Dujiangyan. Although not documented, the village of Longxichang was heavily damaged during this event, as it was located along the Minjiang River. In 1940 the Republic of China assigned it township with nine villages under its jurisdiction and the name of Longchi town was formally used. It lost its function as a relay station in 1955 when an asphalt road connecting the mountainous region and the Chengdu Plain was constructed. Being a habitat of many wild animals including pandas and densely covered by forests, the northern part of the watershed was designated as a national forest park by the Chinese government in 1992, with the Longchi artificial Lake as its major attraction (Figure 5.1). In May 1998 the Zipingpu hydropower reservoir was built and the town residences was moved into the watershed, 400 meters west to the current location on the northern side of the river, with a newly built tunnel as the only road access (Figure 5.1, Access 1). Subsides were distributed to the residences to build new houses. Forestry was an important economic activity in the heavily forested watershed of the Longchi River, with trees producing medicines, nuts and building materials. Agriculture and tourism were almost equally important, generating a gross output value of 6.9 million US dollar for the year of 1999. In 2006 to 2007 the government invested in building a new settlement at current location with apartment buildings. After the earthquake the location of the new settlement was used as the current town center location (Figure 5.1).

The 2008 earthquake resulted in only a few casualties in this valley, as it occurred at 14:28 when most of the inhabitants were working outdoors. The earthquake triggered a total of 1597 landslides, which crashed four hostels, killing ten persons. The national park was closed due to high landslide threat. After the relief operations, the city of Shanghai was assigned responsibility to execute the recovery activities of the nearby Dujiangyan city, and the surrounding area, including the Longchi valley. In May 2009 the $7.3 \mathrm{~km}$ long Longxi tunnel (Figure 5.1) was completed for the Duwen Highway, which greatly helped disaster relief and reconstruction by reducing travel time greatly. A new tunnel was made to connect the Longxi watershed and the highway as an alternative access (Figure 5.1, access 2). Most of the reconstruction was finished by 2010 , when in the same year a storm triggered debris flows from most of the sub-catchments, severely damaging the newly constructed buildings. 


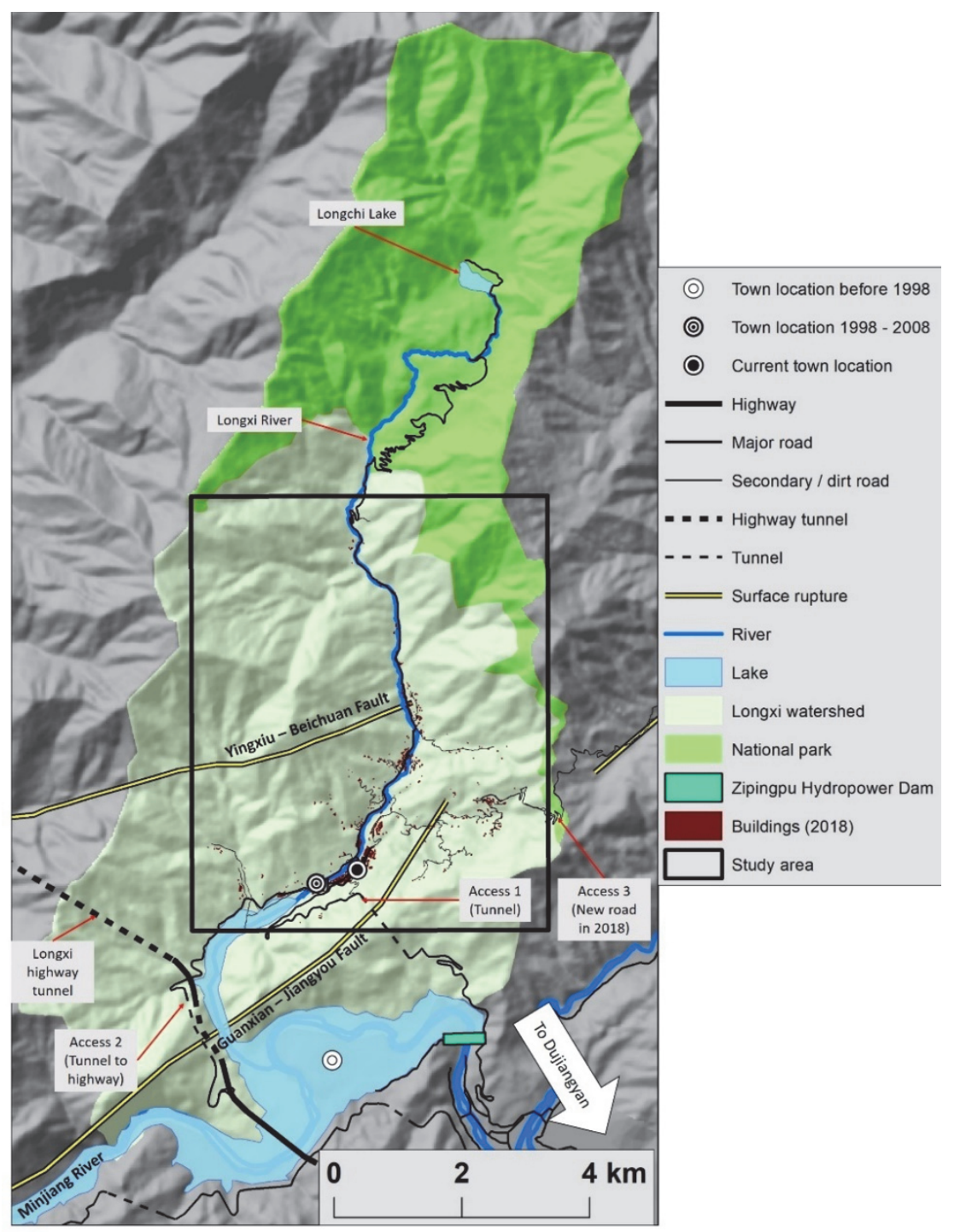

Figure 5.1: The location of the study area. The roads and buildings reflect the situation in 2018. Buildings outside the study area polygon were not mapped.

The reconstruction was finished in 2012. In 2014, the government assigned two towns in neighboring watersheds under the jurisdiction of the Longchi township. In 2015 the tunnel connecting the Highway (Figure 5.1, access 2) was closed due to water leakage and there was no plan to repair it due to a low economic interest caused by the closing of the national park. In 2018, a new road was made to connect the neighboring watershed (Figure 5.1, access 3 ). Till the beginning of 2019 , there was no official announcement about the time to reopen the national park and repair the access to the highway. 


\subsection{Data \& methodology}

In order to monitor the changes in the post-earthquake period, we acquired a series of ten high $(5-10 \mathrm{~m})$ to very high $(0.5-2.5 \mathrm{~m})$ resolution satellite images covering the period between 2005 and 2018 (Table 5.1).

Table 5.1. Data used for interpretation (Pan= panchromatic image, $M u l=$ multi-spectral image, $R G B=$ Red/Green/Blue: color composite).

\begin{tabular}{|c|c|c|c|c|}
\hline Data type & Data source & Collection date & $\begin{array}{l}\text { Cell size Pan / Mul } \\
(\mathbf{m})\end{array}$ & Band \\
\hline \multirow{10}{*}{$\begin{array}{l}\text { Satellite } \\
\text { images }\end{array}$} & Quickbird & JUL 2005 & 2.4 & Mul \\
\hline & IKONOS & SEP 2007 & 1 & RGB \\
\hline & Aerial photographs & JUN 2008 & 1 & RGB \\
\hline & Spot 5 & FEB 2009 & $2.5 / 10$ & Pan + Mul \\
\hline & Worldview-2 & MAR 2010 & $0.5 / 2$ & Pan + Mul \\
\hline & Worldview-2 & APR 2011 & $0.5 / 2$ & Pan + Mul \\
\hline & Pleiades & APR 2013 & $0.5 / 2$ & Pan + Mul \\
\hline & Pleiades & DEC 2014 & $0.5 / 2$ & Pan + Mul \\
\hline & Spot 6 & APR 2015 & 1.5 & RGB \\
\hline & Pleiades & JUN 2018 & $0.5 / 2$ & Pan + Mul \\
\hline DTM & Aerial LiDAR & 1999 & 5 & - \\
\hline \multirow{2}{*}{$\begin{array}{l}\text { Landslide } \\
\text { inventory }\end{array}$} & Chapter 2 & 2016 & \multicolumn{2}{|c|}{$\begin{array}{l}\text { Polygon-based vector data with landslide } \\
\text { activity mapped for } 5 \text { periods (2008 - } \\
\text { 2015) }\end{array}$} \\
\hline & This study & 2018 & \multicolumn{2}{|c|}{$\begin{array}{l}\text { Polygon-based inventory based on image } \\
\text { from June } 2018\end{array}$} \\
\hline
\end{tabular}

The images were georeferenced with Erdas IMAGINE Autosync Workstation and ARCMAP Geo-referencing Tool. A LiDAR DTM provided by the National Bureau of Surveying and Mapping of China was used to visualize images in a 3D environment in ArcScene software to assist interpretation. The multi-temporal landslide inventories reported in chapter 2 (Tang et al., 2016) were used to identify the active landslides over time. An additional landslide inventory was made for 2018 , to match with the mapping of the buildings, roads and landside in this study using the Pleiades image from June 2018. 
Table 5.2. Attributes of the element-at-risk inventories, and the main methods of collection (Image = Image interpretation, Mapping = field mapping, Interview= Interviews with local people, Literature = various published and unpublished sources, Calculated $=$ calculated from other attributes

\begin{tabular}{|c|c|c|c|c|c|c|}
\hline \multirow[b]{2}{*}{ Attributes } & \multirow[b]{2}{*}{ Varieties / descriptions } & \multicolumn{5}{|c|}{ Source } \\
\hline & & 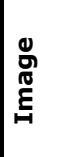 & $\frac{0}{\frac{0}{2}}$ & 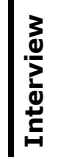 & 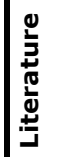 & $\begin{array}{l}\frac{d}{d} \\
\frac{\pi}{3} \\
\frac{\tilde{J}}{\pi} \\
0\end{array}$ \\
\hline \multicolumn{7}{|c|}{ Buildings } \\
\hline $\begin{array}{c}\text { Construction } \\
\text { types }\end{array}$ & $\begin{array}{l}\text { Permanent buildings: RC frame structure } \\
\text { Reinforced masonry / Wood \& brick / Wooden } \\
\text { Temporary buildings: Pre-fabricated metal } \\
\text { houses / Tents \& shacks }\end{array}$ & $x$ & $\mathrm{x}$ & $x$ & & \\
\hline Function & $\begin{array}{l}\text { Residence / Hostel / Institutional/ Commercial / } \\
\text { Agricultural building / Shelter }\end{array}$ & & $x$ & $x$ & & \\
\hline Builder & Self-constructed / government-build & & $x$ & $x$ & & \\
\hline Unit price & $\begin{array}{l}150-2700 \text { Chinese yuan per } \mathrm{m}^{2} \text {, depending on } \\
\text { Construction types }\end{array}$ & & & $x$ & $x$ & \\
\hline Building floors & $\begin{array}{l}\text { Floors of a building. A maximum of } 4 \text { floors was } \\
\text { allowed. }\end{array}$ & & $\mathrm{x}$ & & & \\
\hline Floor space & Building area $*$ building floors & & & & & $x$ \\
\hline Value & Floor space $*$ unit price & & & & & $x$ \\
\hline \multicolumn{7}{|c|}{ Roads } \\
\hline Type & Major road / Secondary road / Dirt road / tunnel & $x$ & $x$ & & & \\
\hline \multicolumn{7}{|c|}{ Farmlands } \\
\hline Type & Food crops / Commercial crops & $x$ & $x$ & & & \\
\hline \multicolumn{7}{|c|}{ Mitigation works } \\
\hline Type & $\begin{array}{l}\text { Check dam / Drainage channel / Embankment } \\
\text { Reinforced slopes }\end{array}$ & $\mathrm{x}$ & $\mathrm{x}$ & & & \\
\hline \multicolumn{7}{|c|}{ all elements-at-risk } \\
\hline Damage level & $\begin{array}{l}\text { No damage / Moderately damaged / severely } \\
\text { damaged / Destroyed }\end{array}$ & $x$ & $\mathrm{x}$ & & & \\
\hline Damage type & $\begin{array}{l}\text { Earthquake / Slides / Debris flows / Flood / No } \\
\text { damage }\end{array}$ & $x$ & $x$ & $x$ & & \\
\hline Usage status & Normal / Abandoned / Empty & $x$ & $x$ & & & \\
\hline Geometry & Auto calculated in ArcMap & & & & & $x$ \\
\hline
\end{tabular}

Before interpreting built-up areas, we also consulted OpenStreetMap, in order to evaluate if data from this platform could be used. Unfortunately, the information in OpenStreetMap was very general for the Wenchuan earthquakeaffected area, and was limited to the main roads, and general polygons of settlements. Given the current difficulty to digitize and store data in OpenStreetMap from different time periods we decided to generate our database outside of the platform. 
We used the above mentioned data to interpret and digitized manmade features, including buildings, farmlands, plantations, roads and mitigation works. Inventories were made for the following years: 2007, 2008, 2010, $2011,2013,2015$ and 2018. The inventory of 2007 was made first, then the 2008 inventory was created based on modifying the earlier inventory using the aerial photograph of 2008. The inventory of 2010 was derived by modifying the inventory of 2008 using the Wolrdview-2 image from 2010, and the inventory of 2011 was derived from the 2010 inventory, and so on. Digitizing in such a manner allowed us to keep consistency among the multi-temporal inventories. A series of attributes listed in Table 5.2 were acquired for the digitized features through image interpretation, field mapping, and interviews.

Institutional buildings refer to public service buildings like schools, hospitals and water pumping stations. Commercial buildings accommodate shops and local companies. Agricultural buildings are used for storage of livestock, agricultural products and farming equipment. Shelters are temporary residences, including pre-fabricated houses, tents and shacks.

Farmlands were classified into crops for food or commercial crops. Commercial crops are several local plant species, including kiwifruit, tea, and magnolia officinalis, that were widely cultivated and exported to benefit the local economy. Crops for food are the vegetables grown for local consumption.

Roads were categorized into: major road, which were wide and built by the national government; secondary road, which is narrower than the major road and could be either local-build or constructed with help from the government; dirt roads are roads without asphalt or concrete layer. Several bridges and tunnels were mapped as well.

Mitigation works were mapped, and were classified into: check dams, which block debris flow runout and slow down erosion; drainage channels are used to redirect runout of debris flows and floods into river directly, avoiding flow through built up areas; embankments are built to shield of debris flow and flood runout; reinforced slopes are stabilized with reinforcement measures and sometimes combined with drainages. 


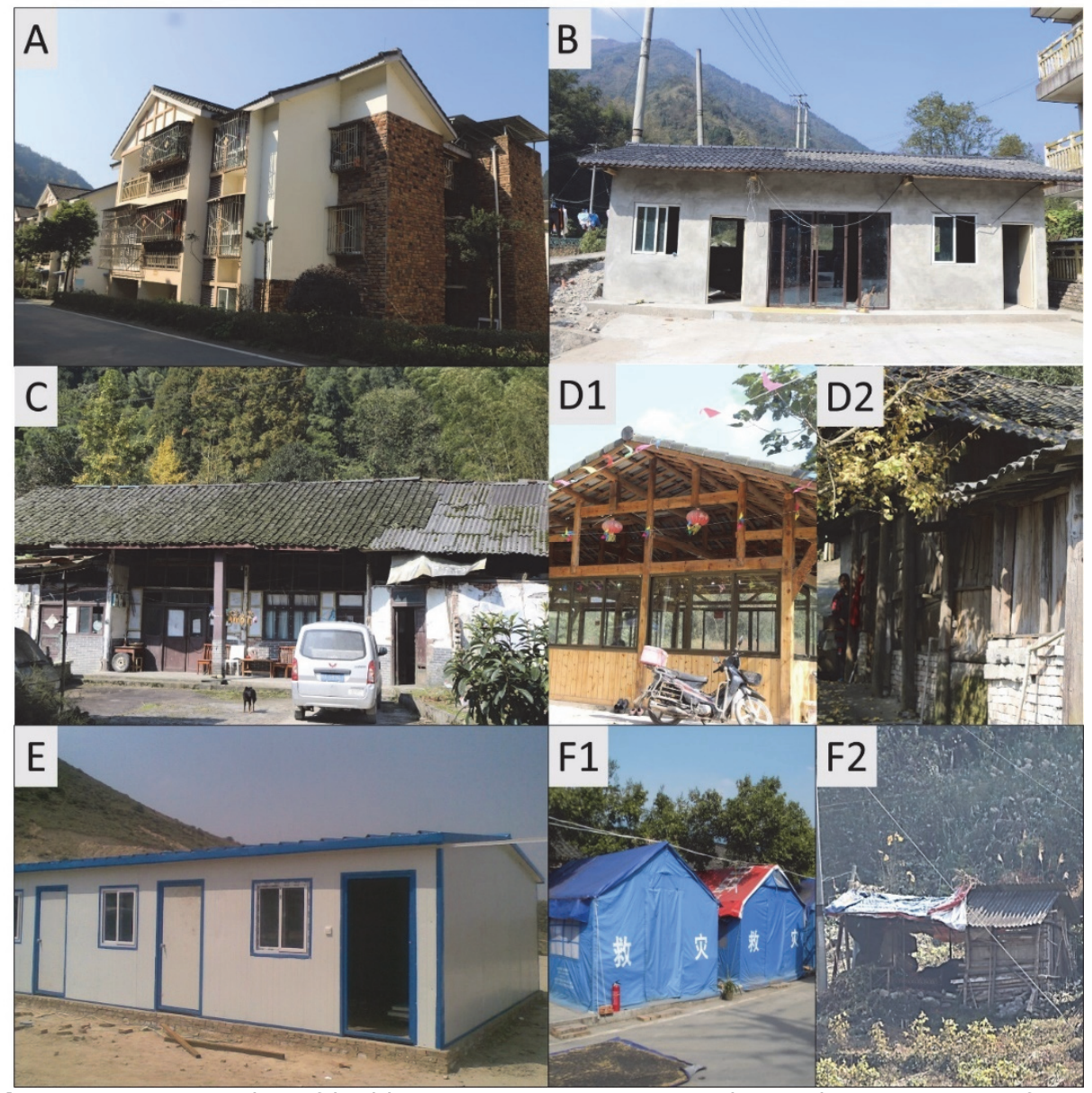

Figure 5.2: Examples of building construction types in the study area. $A$ : RC frame (RCF) structure residences built by the reconstruction teams from Shanghai city. B: reinforced masonry (RCM) building of a hostel. C: wood and brick residence (WB). D1: wooden structure $(W)$ serving as restaurant. D2: wooden residence with walls made by wooden plates and bricks. E: pre-fabricated metal (PFM) temporary houses. F1: tents distributed by the government. F2: a shack made from wood, asbestos tiles and waterproof cloth.

The status of a building is determined by the attributes of damage level, damage type and usage status. The damage level indicates the magnitude of damage a building receives and was assigned based on both image observation and interviewing local people and authorities. If a building is not damaged, level 0 is assigned.

Moderately damaged (level 1) means a disaster-affected building was damaged and restored its function after repair. 
If a building was damaged beyond repair and not collapsed, it was considered as severely damaged (level 2). If a building collapsed, it was classified as destroyed (Level 3). The damage type shows what type of hazard feature affected the building, such as ground shaking, landslide, debris flow and flooding. Under certain circumstances a building could be affected by more than one hazard type, for instance by ground shaking and landslide impact at the same time. The usage status indicates if a feature is functioning normally, is temporary not been used, or completely abandoned. It is assigned based on field mapping and interviews. The geometrical attributes (area or length) were calculated automatically in ArcMap, based on the polygon (buildings or land parcels) or line (road) features. Floor space was calculated by multiplying the number of building floors with the footprint area. The unit price is the cost to construct buildings per square meter and was obtained through interviews, and literature study. The replacement value of a building was estimated by multiplying the unit price with the floor space. All the economic values in this study were converted to US dollar (USD) with a 10-years-average exchange rate of 1 dollar $=6.51$ Chinese Yuan.

We investigated economic recovery by interviewing the local inhabitants and village authorities. Unfortunately, most of them were not willing to share information regarding their income, thus we could only make a descriptive analysis. Each of the interviewees represents one family in the analysis. A total of 113 persons were interviewed in 2018.

\subsection{Monitoring reconstruction}

In this section we analyze the changes of the built-up environment caused by human activities and disasters from 2007 to 2018. The statistics of each year are shown in Table 5.3.

\subsubsection{Pre-earthquake (2007)}

We created the 2007 inventory based on a Quickbird image from 2005 and an IKONOS image from 2007. The attributes of the inventory were based on the memories of our interviewees. 417 buildings were identified from the images (Figure 5.3). Many buildings were constructed along the river due to easy access to the main road. Most of the buildings were self-built residences (304), and more than half of them used WB structure (186). Buildings with a tourism function were the second class in terms of number (87), and most of them consisted of RCM types (75). Only 16 buildings were constructed by the government, including 12 RCM apartment buildings and 4 RCF institutional buildings (Table 5.3 ). 
Most of the buildings were not properly designed to withstand a major earthquake, because most construction was informal and no earthquake resistant building practices were applied by local people. The last major earthquake in this area dates back from 1933 (Deixi earthquake), and there were no eye witnesses alive of that event anymore in 2007. Even though there were many RCM buildings, it appears that only the ones built by the government applied a certain standard against ground shaking, as none of them collapsed during the 2008 earthquake.

\subsubsection{The impact of the earthquake (2008)}

From 2007 to 2008, prior to the earthquake, 6 buildings were removed and 33 buildings were constructed by the local residents. A total of 444 buildings were affected by the earthquake, of which 142 buildings were completed destroyed. Based on the 2009 SPOT image and the 2010 Worldview-2 images a total of 221 buildings were severely damaged and subsequently removed. 


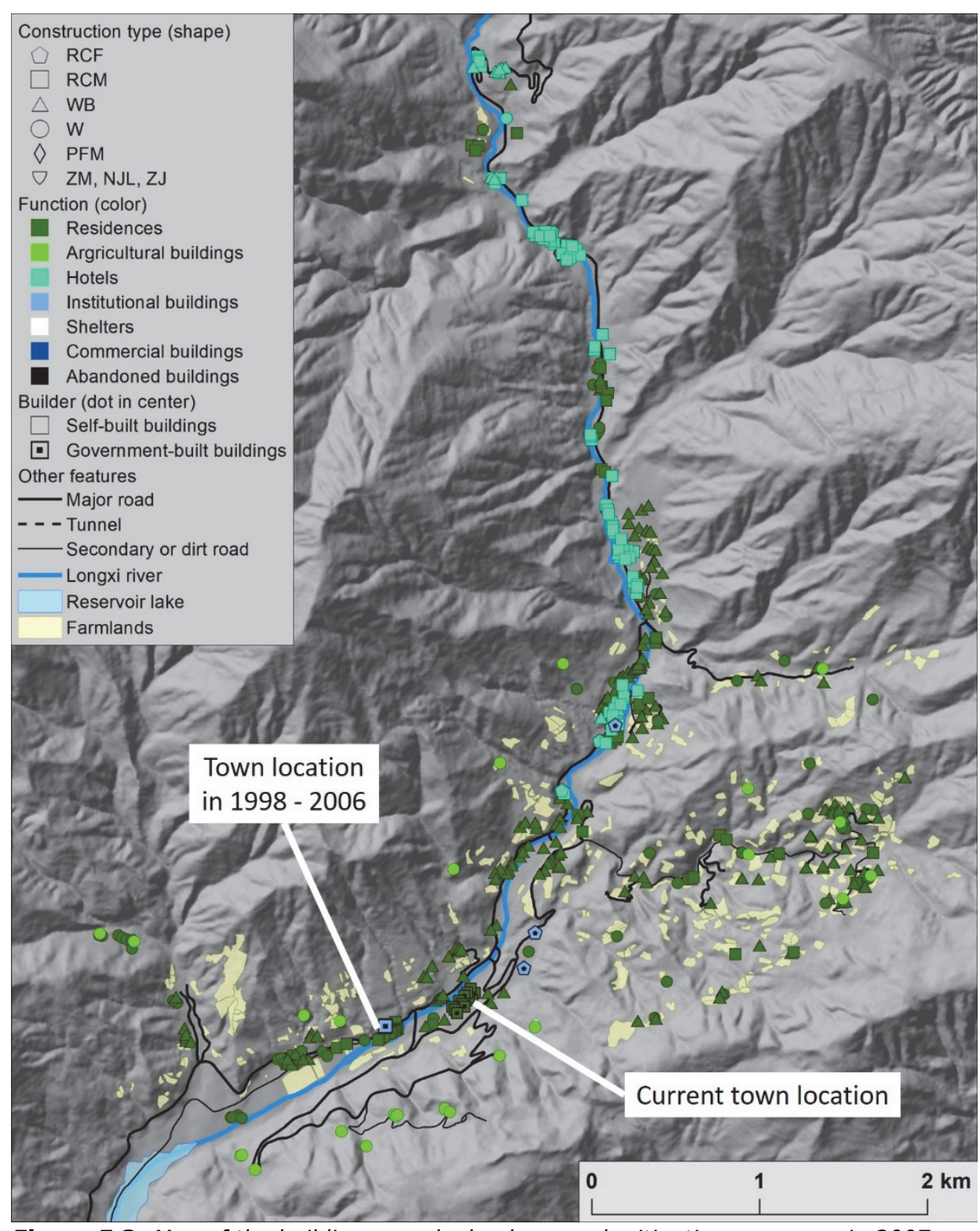

Figure 5.3: Map of the buildings, roads, land use and mitigation measures in 2007.

The remaining 81 buildings were repaired and functioned normally in 2009 and 2010, thus were classified as moderately damaged (Figure 5.4). A total of 1597 landslides were induced by the earthquake in the study area, and 29 of the 142 destroyed buildings were hit by co-seismic landslides. A summary of the building damage is shown in Table 5.4 . 
Table 5.3: Number of functioning buildings per construction type and land use for the seven time periods considered. The numbers before the brackets indicate the total number and the numbers in the brackets indicate the building numbers built by government. *Sum of all buildings.

\begin{tabular}{|c|c|c|c|c|c|c|c|c|}
\hline \multirow[t]{2}{*}{ Period } & \multirow[t]{2}{*}{ Land use } & \multicolumn{6}{|c|}{ Construction type } & \multirow[b]{2}{*}{ Total } \\
\hline & & RCF & RCM & WB & $\mathbf{w}$ & PFM & TSs & \\
\hline \multirow{5}{*}{ 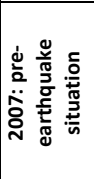 } & Residences & 0 & $66(12)$ & 186 & 51 & 0 & 0 & $304(12)$ \\
\hline & Hotels & 1 & 75 & 10 & 0 & 1 & 0 & 87 \\
\hline & Institutional building & $3(3)$ & $1(1)$ & 0 & 0 & 0 & 0 & $4(4)$ \\
\hline & Agricultural & 0 & 0 & 0 & 23 & 0 & 0 & 23 \\
\hline & total & $4(3)$ & $142(13)$ & 196 & 74 & 1 & 0 & *417(16) \\
\hline \multirow{6}{*}{ 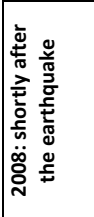 } & Residences & 0 & 24 & 40 & 5 & 0 & 0 & 69 \\
\hline & Hotels & 0 & 9 & 0 & 0 & 0 & 0 & 9 \\
\hline & Institutional building & $2(2)$ & 0 & 0 & 0 & 0 & 0 & $2(2)$ \\
\hline & Agricultural & 0 & 0 & 0 & 1 & 0 & 0 & 1 \\
\hline & Shelters & 0 & 0 & 0 & 0 & $82(82)$ & 227 & $309(82)$ \\
\hline & Total & $2(2)$ & 33 & 40 & 6 & $82(82)$ & 227 & *390(84) \\
\hline \multirow{7}{*}{ 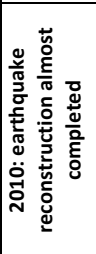 } & Residences & $126(118)$ & 78 & 237 & 42 & 0 & 0 & $483(118)$ \\
\hline & Hotels & 77 & 18 & 2 & 3 & 0 & 0 & 100 \\
\hline & Institutional building & $25(25)$ & $1(1)$ & 0 & 0 & 0 & 0 & $26(26)$ \\
\hline & Agricultural & 0 & 1 & 1 & 86 & 0 & 0 & 88 \\
\hline & Commercial & $36(32)$ & 2 & 0 & 1 & 0 & 0 & $39(32)$ \\
\hline & Shelters & 0 & 0 & 0 & 0 & 116(116) & 21 & $137(116)$ \\
\hline & Total & $266(175)$ & 99(1) & 239 & 132 & $116(116)$ & 21 & $873(292)$ \\
\hline \multirow{7}{*}{ 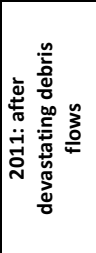 } & Residences & $124(116)$ & 65 & 236 & 40 & 2 & 0 & $467(116)$ \\
\hline & Hotels & 59 & 12 & 1 & 3 & 0 & 0 & 75 \\
\hline & Institutional building & $25(25)$ & $1(1)$ & 0 & 0 & 0 & 0 & $26(26)$ \\
\hline & Agricultural & 0 & 1 & 7 & 86 & 0 & 0 & 94 \\
\hline & Commercial & $36(32)$ & 2 & 0 & 1 & 0 & 0 & $39(32)$ \\
\hline & Shelters & 0 & 0 & 0 & 0 & $50(50)$ & 3 & $53(50)$ \\
\hline & Total & $244(173)$ & $76(1)$ & 229 & 127 & $52(50)$ & 3 & "712(224) \\
\hline \multirow{6}{*}{ 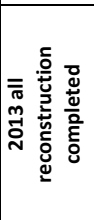 } & Residences & $143(132)$ & 56 & 206 & 42 & 3 & 0 & $450(132)$ \\
\hline & Hotels & 68 & 17 & 1 & 3 & 0 & 0 & 89 \\
\hline & Institutional building & $20(20)$ & 1(1) & 0 & 0 & 0 & 0 & $21(21)$ \\
\hline & Agricultural & 0 & 1 & 2 & 76 & 0 & 0 & 79 \\
\hline & Commercial & $36(32)$ & 2 & 0 & 1 & 0 & 0 & $39(32)$ \\
\hline & Total & $267(184)$ & $77(1)$ & 209 & 122 & 3 & 0 & "678(185) \\
\hline \multirow{6}{*}{ 望 } & Residences & $142(132)$ & 68 & 199 & 45 & 3 & 0 & $457(132)$ \\
\hline & Hotels & 69 & 13 & 1 & 3 & 0 & 0 & 86 \\
\hline & Institutional building & 19(19) & $1(1)$ & 0 & 0 & 0 & 0 & $20(20)$ \\
\hline & Agricultural & 0 & 1 & 6 & 78 & 0 & 0 & 85 \\
\hline & Commercial & $36(32)$ & 2 & 6 & 1 & 0 & 0 & $45(32)$ \\
\hline & Total & $272(183)$ & $85(1)$ & 208 & 127 & 3 & 0 & "693(184) \\
\hline \multirow{6}{*}{$\stackrel{\infty}{\stackrel{N}{N}}$} & Residences & $142(132)$ & 68 & 199 & 49 & 3 & 0 & $461(132)$ \\
\hline & Hotels & 71 & 13 & 1 & 3 & 0 & 0 & 88 \\
\hline & Institutional building & 19(19) & $2(2)$ & 0 & 0 & 0 & 0 & $21(21)$ \\
\hline & Agricultural & 0 & 1 & 8 & 77 & 0 & 0 & 86 \\
\hline & Commercial & $36(32)$ & 2 & 4 & 1 & 0 & 0 & $43(32)$ \\
\hline & Total & $268(183)$ & $86(2)$ & 212 & 130 & 3 & 0 & "699(185) \\
\hline
\end{tabular}




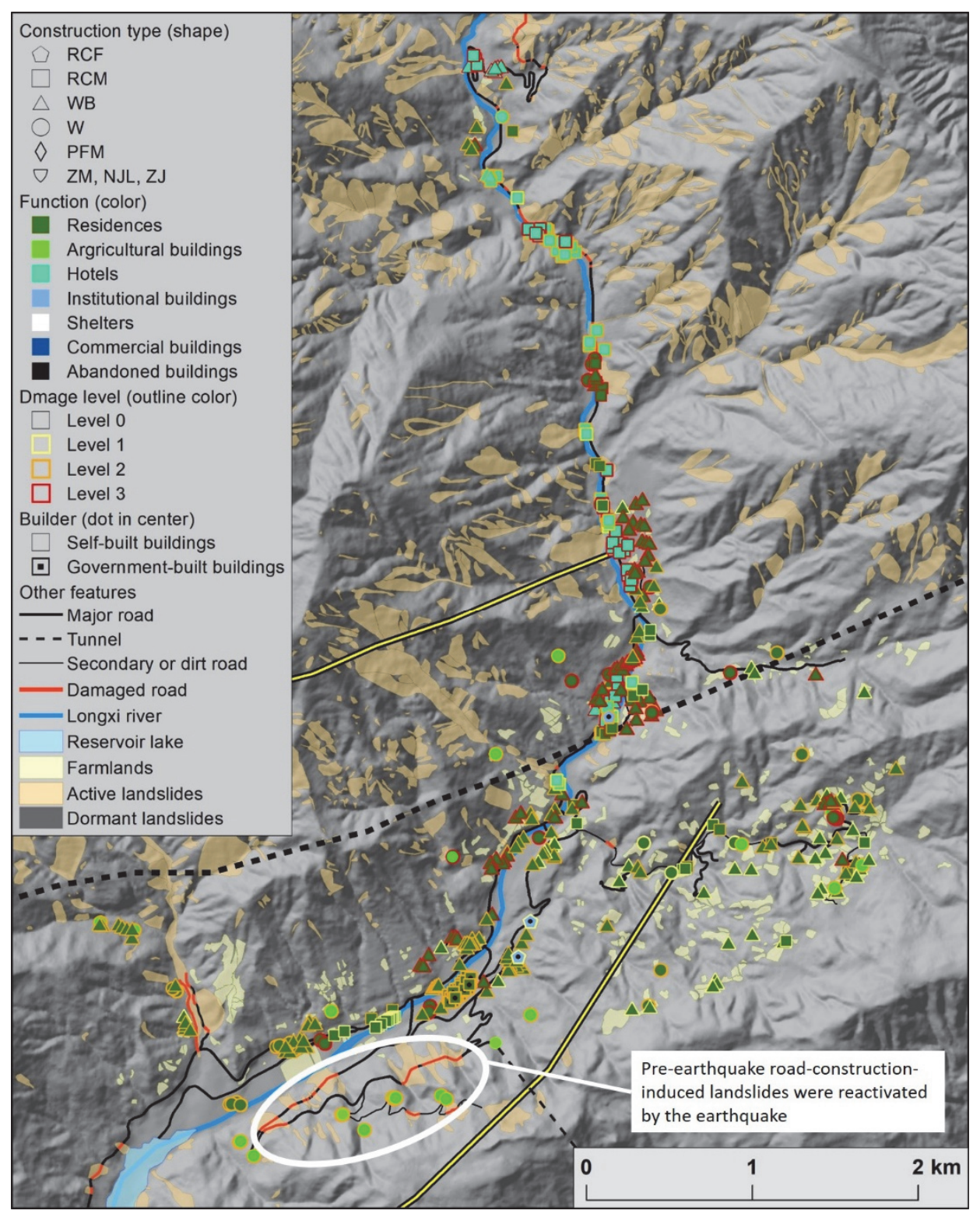

Figure 5.4: The damage map and the co-seismic landslide inventory.

Relatively more single floor buildings were destroyed by the earthquake than 2 -floor buildings. The significance in building floors is very obvious for the RCM construction type, as $35 \%$ of the 1 -floor buildings survived the earthquake while only $13 \%$ of the 2 -floor buildings were repairable.

No significant difference in damage levels related with different construction types was observed. 
Table 5.4: Statistics of building damages caused by the earthquake. The percentage in the brackets was calculated by the number in the cell divided by the total numbers of the row. *Sum of all affected buildings.

\begin{tabular}{|c|c|c|c|c|c|}
\hline \multirow{2}{*}{ Construction type } & \multirow{2}{*}{ Floors } & \multicolumn{3}{|c|}{ Damage levels } & \multirow{2}{*}{$\begin{array}{c}\text { Sum by floors and } \\
\text { construction type }\end{array}$} \\
\cline { 3 - 6 } & & Level 1 & Level 2 & Level 3 & 2 \\
\hline \multirow{2}{*}{ RCF } & 1 floor & 2 & 0 & 0 & 2 \\
\cline { 2 - 6 } & 2 floors & 0 & 2 & 0 & 63 \\
\hline \multirow{2}{*}{ RCM } & 1 floor & $22(35 \%)$ & $19(30 \%)$ & $22(35 \%)$ & 82 \\
\cline { 2 - 6 } & 2 floors & $11(13 \%)$ & $51(63 \%)$ & $20(24 \%)$ & 160 \\
\hline \multirow{2}{*}{ WB } & 1 floor & $34(21 \%)$ & $70(44 \%)$ & $56(35 \%)$ & 69 \\
\cline { 2 - 6 } & 2 floors & $6(9 \%)$ & $38(55 \%)$ & $25(36 \%)$ & 61 \\
\hline \multirow{2}{*}{ W } & 1 floor & $6(10 \%)$ & $38(60 \%)$ & $19(30 \%)$ & 3 \\
\cline { 2 - 6 } & 2 floors & 0 & 3 & 0 & 288 \\
\hline \multirow{2}{*}{ Sum by building floors } & 1 floor & $64(22 \%)$ & $127(44 \%)$ & $97(34 \%)$ & 156 \\
\cline { 2 - 6 } & 2 floors & $17(11 \%)$ & $94(60 \%)$ & $45(29 \%)$ & 142 \\
\hline \multicolumn{2}{|c|}{ Sum by damage level } & 81 & 221 & & 244 \\
\hline
\end{tabular}

The damage ratios of the three major types ( $R C M, W B$ and $W)$, are shown in Figure 5.5.

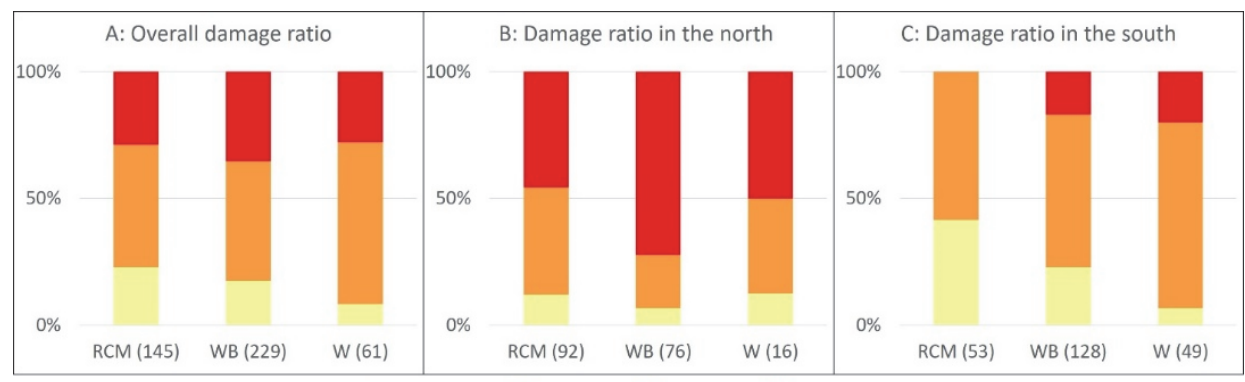

Damage level: $\square$ Level $1 \square$ Level $2 \square$ Level 3

Figure 5.5: Damage ratio statistics of the three major structural types. The numbers in brackets under the $x$ axis indicate the total numbers of buildings. A: damage ratio of all the earthquake-affected buildings. $B$ : damage ratio on the northern side of the dotted line in Figure 5.4 C: damage ratio on the southern side of the dotted line in Figure 5.4

A damage pattern controlled by fault rupture was found, and building damage was more serious on the hanging wall or within one-kilometer distance of the Yingxiu - Beichuan fault rupture (indicated by a thick dotted line in Figure 5.4 and 5.6). The landslide area density was much higher in this zone as well. Both sides showed a clear difference in damage level, as the ratio of buildings being destroyed in the north was much higher (Figure 5.5 B and C) than in the south. The damage was not influenced by the construction types in the north, because the shaking was so strong that it exceeded the resistance of all types (Figure $5.5 \mathrm{~B}$ ). The southern side showed a significance difference in damage for the 
construction types, as the loss of RCM buildings had the lowest loss ratio and wooden buildings had the highest (Figure $5.5 \mathrm{C}$ ).

Road stretches with a combined length of $3.7 \mathrm{~km}$, which was $11 \%$ of the road network of $33.5 \mathrm{~km}$, were blocked by co-seismic landslides (Figure 5.4). The earthquake reactivated human-induced landslides which were caused by road construction in the south. Fresh bare surfaces of the landslides could be observed from the 2005 image and they were almost fully covered by vegetation in the image of 2007.

None of the farmlands were directly affected by the co-seismic landslides, because most of them were located on gentle slopes or flat lands in the southern part.

The aerial photos of 2008 and the SPOT image of 2009 were used to map shelters. Before the government could bring in pre-fabricated houses the survivors set up 229 shelters by building shacks and using tents provided by the government. Before the winter of 2008 four temporary settlements were made with 82 pre-fabricated buildings, which housed multiple families (Figure 5.6 and table 5.3). A total of 81 buildings survived the earthquake, of which 64 were located more than one-kilometer distance to the South of the Yingxiu - Beichuan fault (Figure 5.5). Most of the survived buildings were self-built residences and no significance in the construction types was found. The government had problems in identifying suitable locations for the shelter settlements. The lack of awareness of the possible areas endangered by postearthquake landslide and debris flow played an important role in this. The local residents mostly constructed the shelters next to their destroyed houses, even when this was very close to co-seismic landslides. The largest planned settlement with pre-fabricated buildings along with some native shacks was sited on the lower part of the alluvial fan of one of the largest sub-watersheds, the Bayi catchment, which later posed a high debris flow threat, as $29 \%$ of its watershed area was covered by co-seismic landslides (Figure $5.4 \mathrm{~B}$ ).

It was difficult to estimate the accommodation status of the survivors since many of them went to relatives outside the area and many workers and soldiers stayed in the area to carry out the relief. 


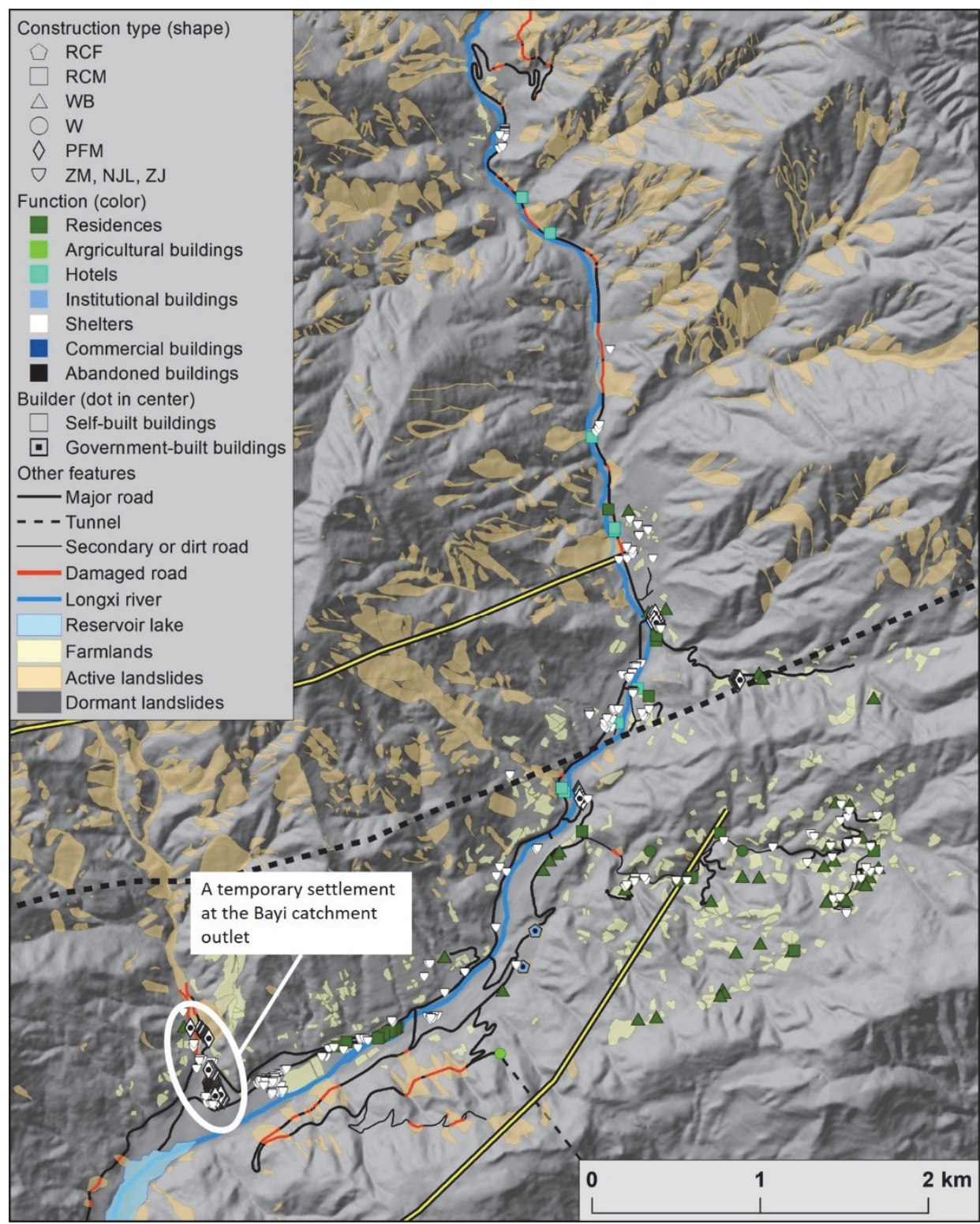

Figure 5.6: Map of the buildings that survived the earthquake and location of temporary shelters.

\subsubsection{Early reconstruction stage (2009 - 2010)}

The SPOT image of 2009 and the Worldview-2 image of 2010 were used to map the buildings, roads, and mitigation measures for 2010, which illustrates the changes brought by reconstruction. During this period all rubble was removed as well as most of the tents and shacks. 
The new inventory contains 873 buildings, out of which 706 were newly constructed, including new shelters. Among the 655 reconstructed permanent buildings, 481 were built by the residents themselves and 174 by the government, mostly concentrated in the center of Longxi town, where a number of apartment buildings were made. An extra 34 pre-fabricated buildings, 17 TSs shelters and 6 mitigation works were constructed in this period (Table 5.3). Eighty-one buildings that survived the earthquake were still functioning in 2010. All the damaged roads were repaired and a new highway entrance was made in May 2009, which contributed to the fast reconstruction (Figure 5.1, access 2 and Figure 5.8).

The Chinese government implemented a policy to avoid losses in future earthquakes and applied framed structures for $99 \%$ of the reconstructed buildings. The government chose to place most of the new apartment buildings together at the central location in Longchi town (Figure 5.8). An example of such a government-built apartment building is shown in Figure $5.2 \mathrm{~A}$. Three potentially dangerous slopes near Longchi town were stabilized during the reconstruction process (Figure $5.7 \mathrm{C}$ ). Some of the residents chose to rebuild their houses on the original location of their old houses since the governmentbuilt apartments were far away from their farmlands. The earthquake did not significantly change their preferences of construction types, and most of them (278) rebuild their house with locally available wood (WB and W construction types). A notable increase in using frame structures among the hostels was observed (Table 5.3), many of which were rebuild near the original locations along the Longxi River. During an extreme rainfall events in 2009 a total of 164 landslides were activated, and a debris flow destroyed nine pre-fabricated buildings and covered 619 meters of road at the outlet of the Bayi subwatershed. After the debris flow two relatively weak check dams were installed in the upper catchment and a drainage channel was made near the outlet (Figure 5.7 B \& C).

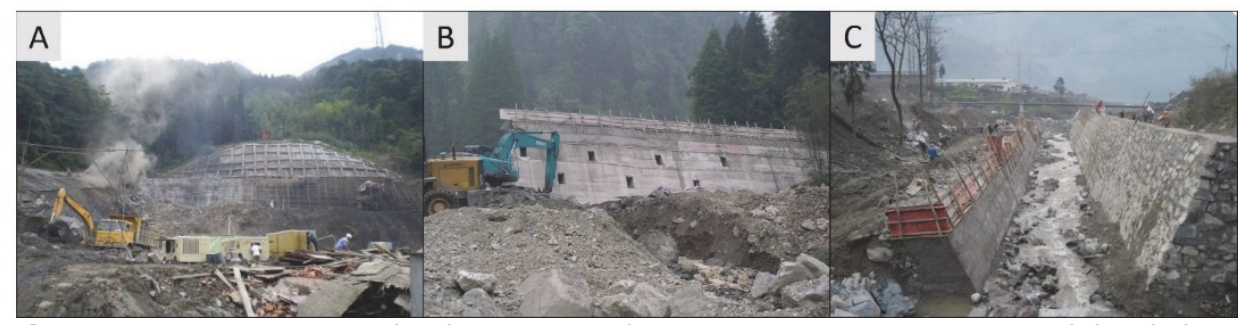

Figure 5.7: Mitigation works that were under construction in 2010. A: stabilized slope near the newly built primary school in Longchi town. B: check dam being built in the Bayi sub-catchment after a debris flow in 2009. C: drainage channel being built at the outlet of the Bayi catchment after the debris flow in 2009. 


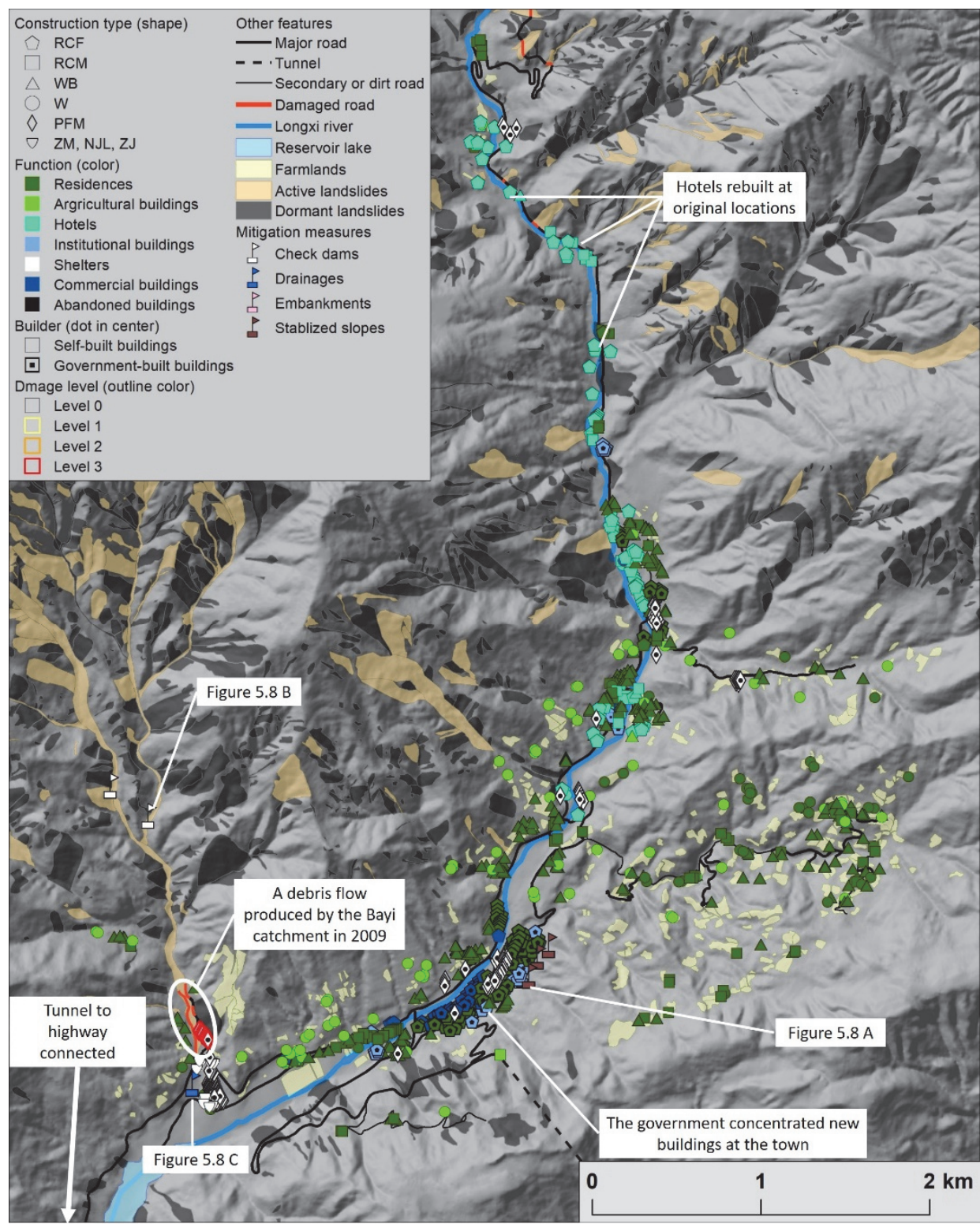

Figure 5.8: The inventory of the situation in 2010, showing the buildings, roads, and remedial measures for the period between 2008 and 2010. Overlain are the active landslides in 2009.

\subsubsection{The August 2010 debris flows}

The Worldview-2 image from 2011 was used to map the changes caused by the large debris flow disaster that occurred in August 2010 (Figure 5.9). The most catastrophic debris flow event was triggered by a storm on 14 Aug 2010 
with a maximum recorded rainfall intensity of $75 \mathrm{~mm} / \mathrm{h}$ measured by rain gauges in the town (Xu et al., 2012). About 341 new landslides were triggered and 1151 of the co-seismic landslides were reactivated in this study area during this event, producing several massive debris flows which joined in the valley of the Longxi River (Yu et al., 2011), reaching the Zipingpu lake. Sedimentation was $5-7 \mathrm{~m}$ at about 300 meters upstream of the town (Figure 5.9) (Sichuan Geology Engineering Reconnaissance Institute, 2011). Nearly one-fourth of all buildings in the study are were impacted by debris flows and subsequent floods. The losses were largest for those buildings located either close to the river or near sub-catchment outlets (Figure 5.9). Among all the 213 affected buildings, 70 were destroyed, 41 were severely damaged and 102 were moderately damaged. The most severe loss occurred at the outlet of the Bayi sub-catchment, where 64 shelters were completely razed and 4 shelters were moderately damaged by a large debris flow (Figure 5.10 A \& B). The drainage and the poorly constructed check dams in Bayi sub-catchment constructed in earlier years by the government did not prove to be adequate and were destroyed (Figure $5.10 \mathrm{C}$ ). The total number of buildings in the area reduced to 712 (Table 5.3). Two government offices, a water treatment plant and a water pumping station were affected, with 9 RCF buildings moderately damaged. The debris flows and floods also damaged $35,000 \mathrm{~m}^{2}$ of farmlands and $7.5 \mathrm{~km}$ of roads were destroyed (Figure 5.9).

Residences and hostels were the most affected building occupancy types (60\% of all affected buildings). This was because the local people reconstructed many of their residences on historical debris flow deposits, which presented relatively flat lands at sub-catchment outlets (Figure 5.10 A \& D), and most of the hostels were reconstructed beside the Longxi River in order to attract tourists (Figure $5.10 \mathrm{E}$ ). A few government-built apartment buildings were also being placed on similar locations (Figure 5.10 D and F).

\subsubsection{The late reconstruction stage (2010-2013)}

The WorldView image of 2011 and the Pleiades image collected in April 2013 were used to map the changes between 2011 and 2013, which represents the situation shortly after the post-debris-flow reconstruction was completed in 2012. All the temporary buildings were removed by 2012. A total of 38 buildings, that were threatened by debris flows or floods, were abandoned. The government constructed another 25 buildings to replace these (Figure 5.11) and also local people constructed 67 new buildings. 


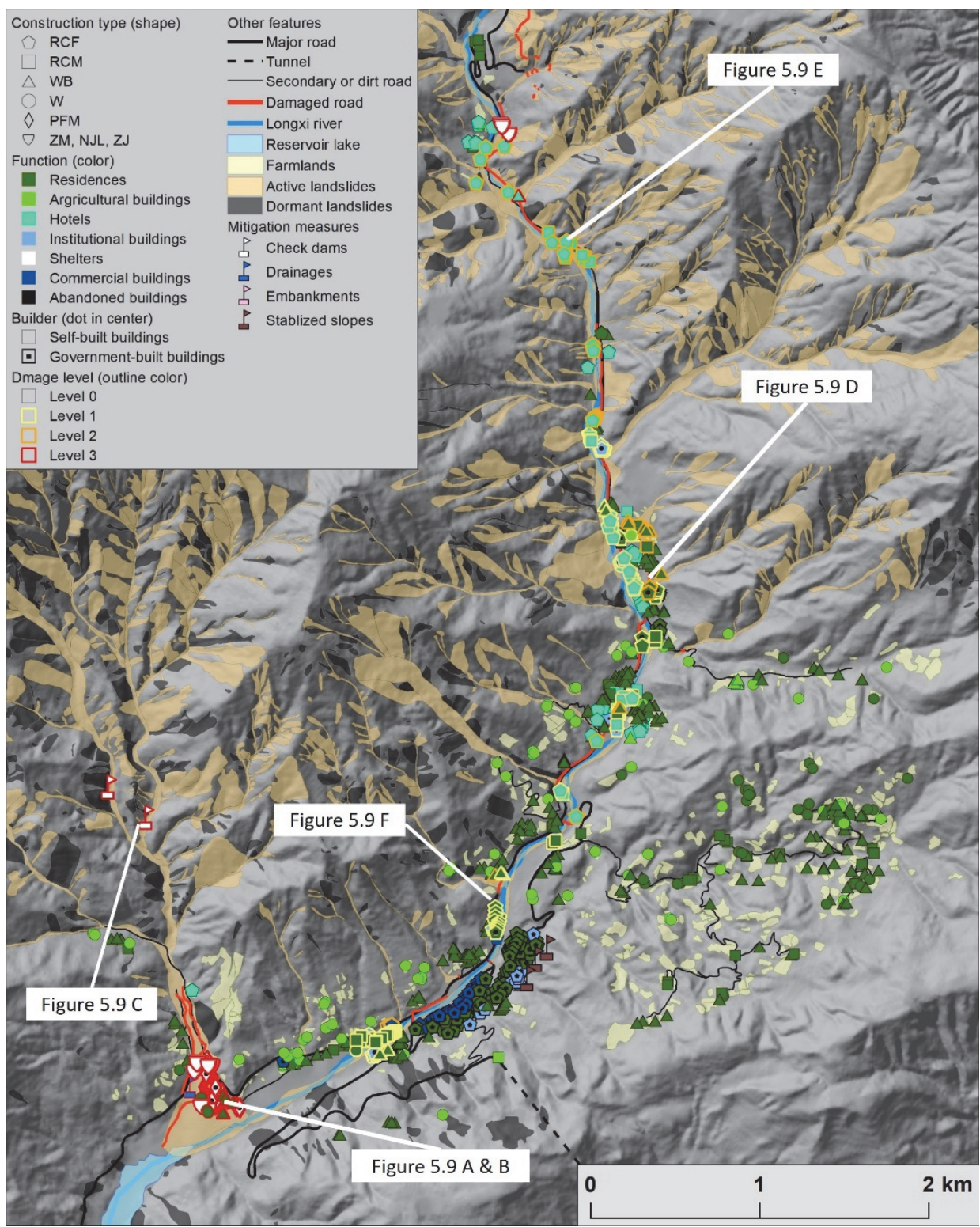

Figure 5.9: The 2011 inventory and the active landslides in 2010.

Some self-built buildings were removed during the construction process. The total numbers of functioning buildings were reduced to 678 (Table 5.3). Many mitigation measures, such as check dams, sediment retention basins, and debris flow early warning systems, were implemented in the three most dangerous sub-catchment and concrete embankments were installed along parts of the river (Figure 5.11). 


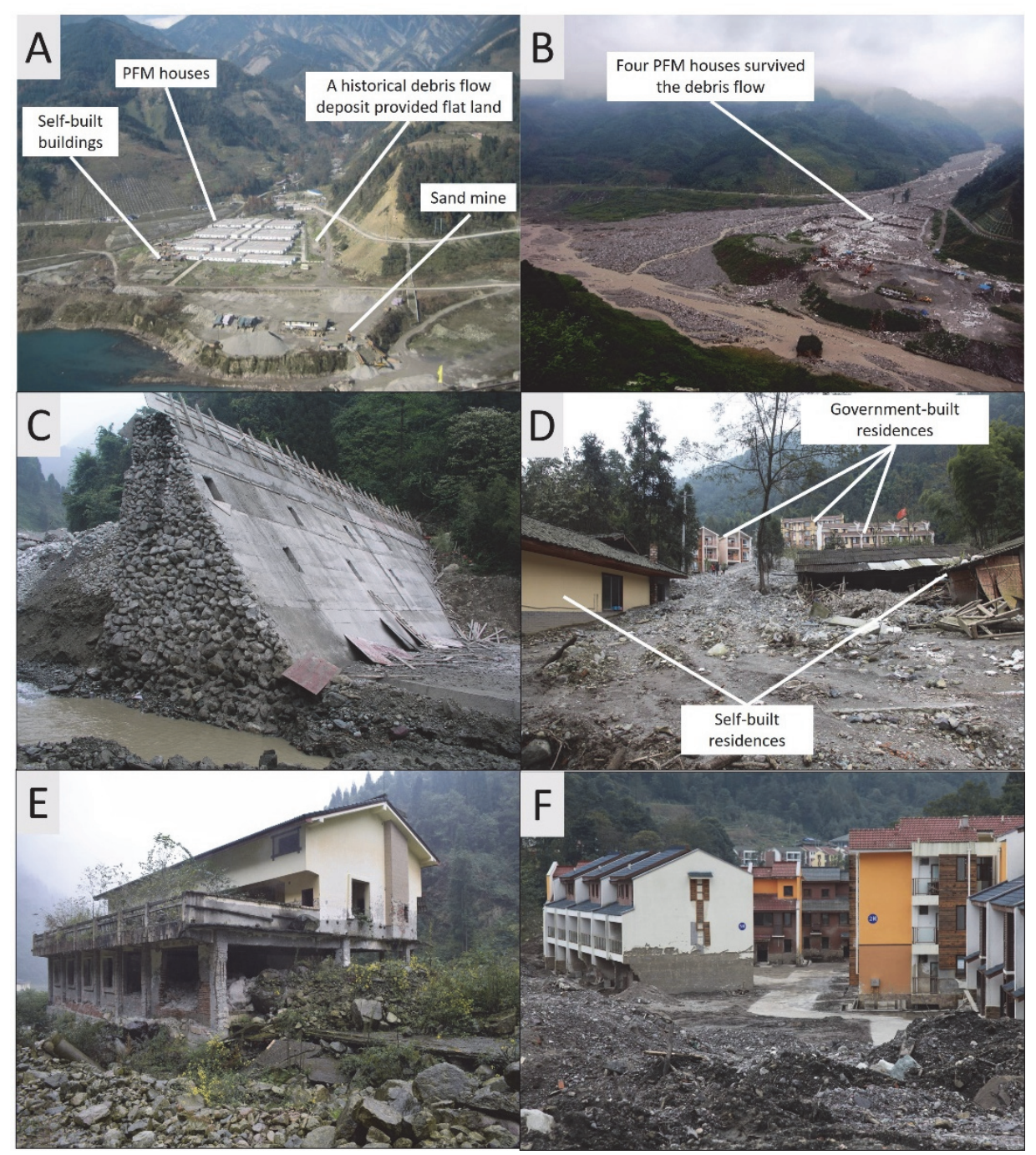

Figure 5.10: Losses caused by the Aug 14, 2010 debris flows. The locations of the examples are shown in Figure 8. A: The temporary settlement at the Bayi sub-catchment outlet in 2009 (Luo et al., 2010); B: The shelters destroyed by a debris flow from the Bayi sub-catchment (Luo et al., 2010); C: One of the two under designed check dams in Bayi sub-catchment which were destroyed (Liu, 2010); D: Residences reconstructed on old debris flow deposits were damaged; E: A hotel beside the Longxi River was struck; F: government-built apartment buildings beside the river were damaged.

The debris flow warning is based on the accumulative rainfall and rainfall intensity recorded by rain gauges installed in the watershed. A camera was installed in the upper stream, near the location of the damaged hotel shown in Figure $5.10 \mathrm{E}$, to monitor debris flow and flood activities in the Longxi River. Due to the construction of the mitigation works the total road length increased to $38.1 \mathrm{~km}$. 


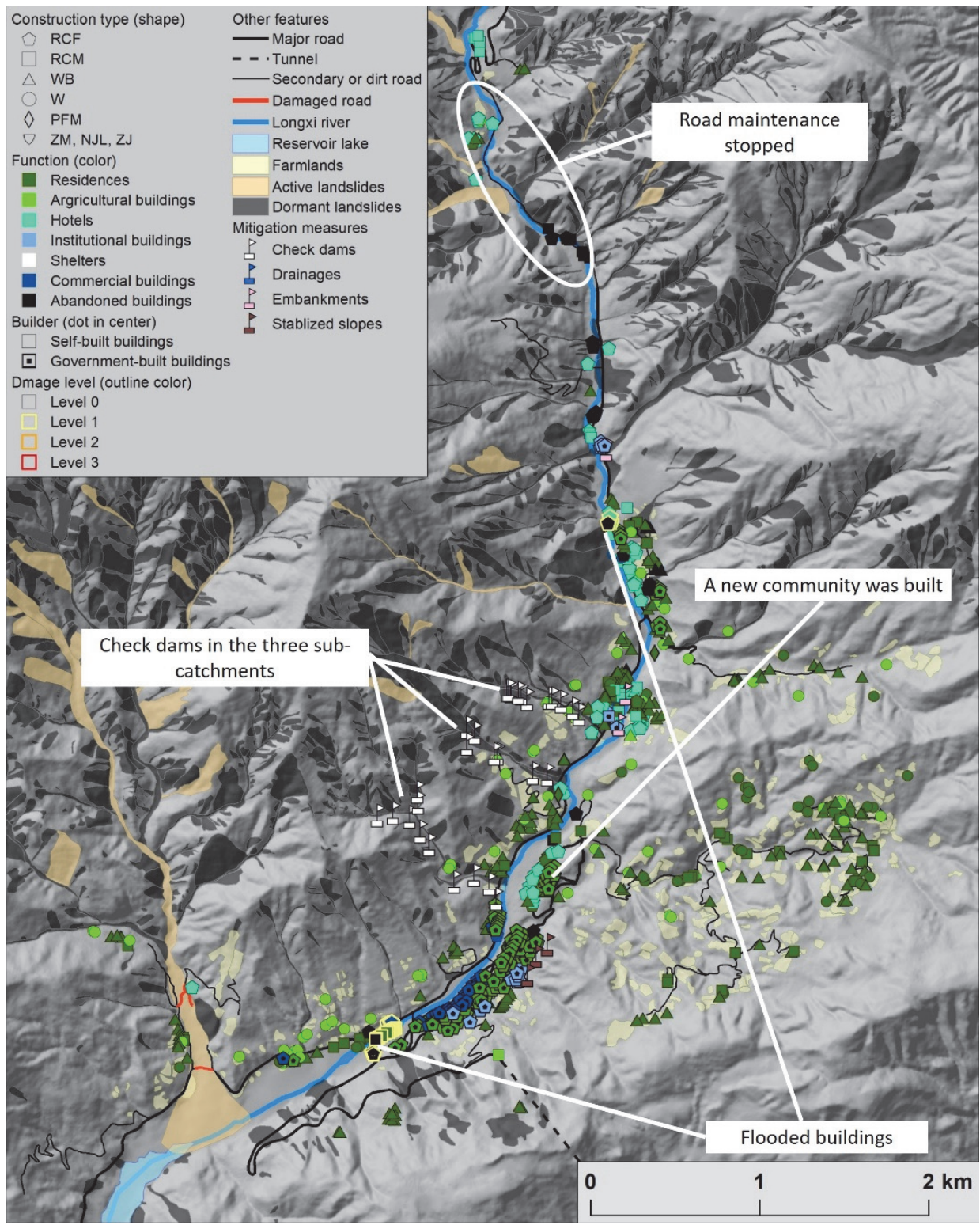

Figure 5.11: The inventory of 2013 and active landslides in 2013.

From August 2010 to April 2013 the debrisflow activity of most of the subcatchments reduced except for the Bayi sub-catchment. A flashflood took place in 2013 which damaged 20 buildings. A major cause of the floods was the dramatic raise of the riverbed (Yu et al., 2011) brought by debris flows. Because it was not possible to reopen the Longxi national park due to high landslide threat along the access road, the government decided to stop maintaining the damaged access road to the park in the north. A dirt road was 
made as a replacement. This did not affect the economy much directly as the tourism was low and most of the farmlands and forestry are in the south of the watershed.

\subsubsection{Post-reconstruction period (2013 - 2018)}

The last two change maps were made by interpreting the 2015 SPOT 6 image and the 2018 Pleiades image. From 2013 to 2018 the Longchi society developed in a stable manner without any major disruption, thus we only described the inventory of 2018 (Figure 5.12). In this period 21 new buildings were constructed by local people. The total number of buildings in the area grew to 699 (Table 5.3). The road length increased to $46.2 \mathrm{~km}$, as many dirt roads were made to access farmlands. The tunnel connecting the highway was closed due to water leakage (Figure 5.1, access 2). The government decided to stop its maintenance, probably because of a low economic interest caused by the loss of tourism. Only the old tunnel (Figure 5.1, access 1 ) could be used, which caused a delay in traveling to Dujiangyan city by car of 40 minutes. A secondary road was made in 2018 connecting the neighboring catchment and provided a second access road for the Longxi watershed (Figure 5.12).

Landslides and floods did not cause any major loss since 2013. A few debris flow watersheds were treated with mitigation structures (Figure 5.12). Two elevated drainage channels were installed in 2015 in the southern part to redirect floods produced by two small catchments into the river directly. The Bayi catchment produced floods that damaged dirt roads in almost every summer during this period.

\subsection{Analysis of economic values}

In this section the economic values of the built-up features were estimated in US dollar. The total value of the buildings was estimated by multiplying floor space with the unit price for construction. The values and the exposure in the seven investigated periods were evaluated. 


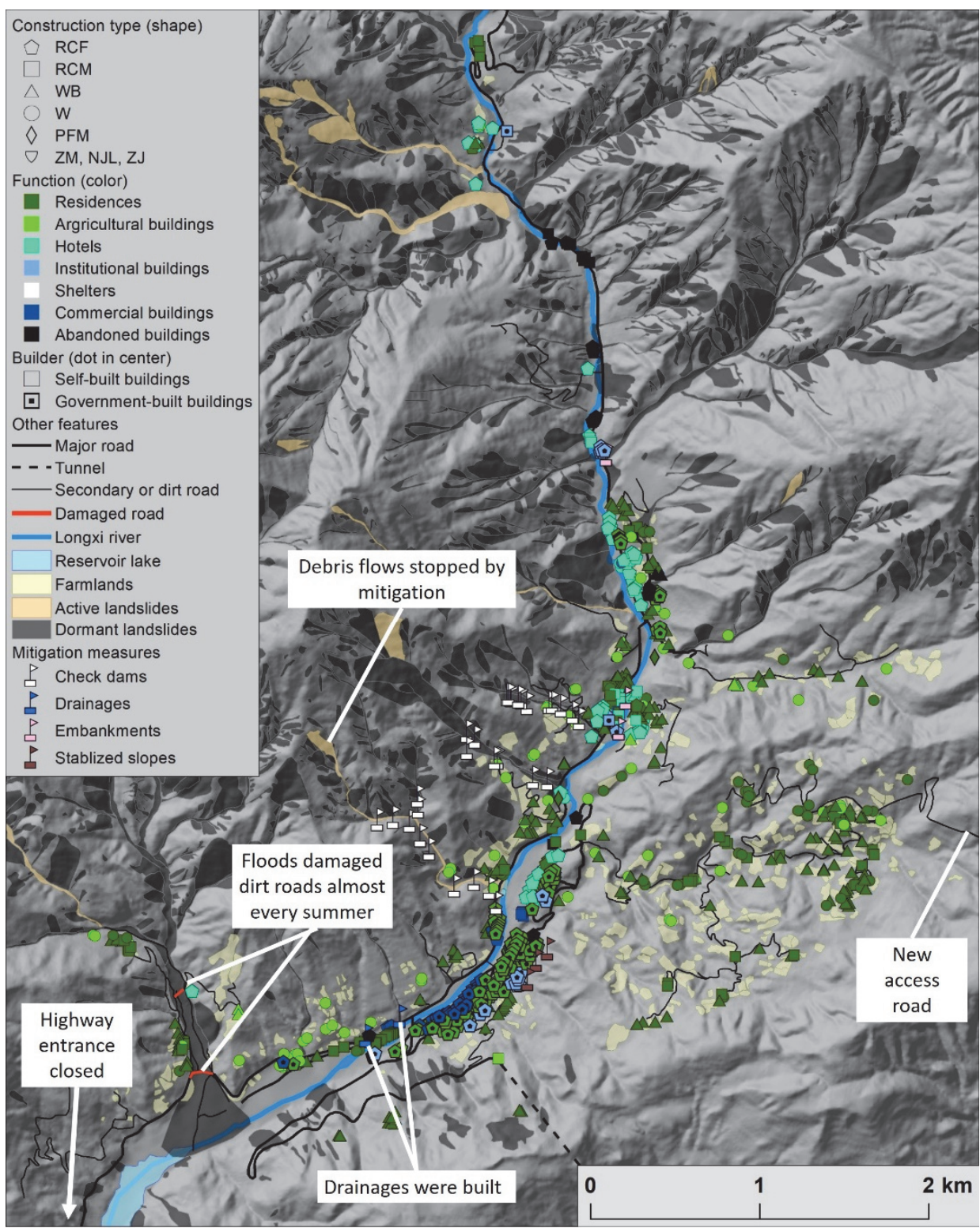

Figure 5.12: The inventory of 2018 and active landslides in 2018.

\subsubsection{Value estimation}

The unit prices for different building types and roads were acquired through interviews with local builders and local government officers (Table 5.5). The unit prices of buildings increased after the earthquake due to several reasons: higher building standards, large consumption of building materials in the earthquake-hit areas, and currency devaluation. The price of mitigation 
structures were estimated based on the mitigation design of a catchment in the neighboring watershed ( $\mathrm{Li}$ et al., 2011). The mitigation structures of the three sub-catchments (Figure 5.11) built after 2010 have a worth of approximately 30 million Yuan (Chengdu Bureau of Land and Resources, 2018). We were not able to acquire prices of farmlands, forests and other indirect factors. Therefore the analysis was limited to economic value, investment and direct loss caused by hazards. Severely damaged and destroyed buildings were counted as direct economic loss.

Table 5.5: Unit price of built-up features. All values were adjusted to the situation of 2012 by inflation rate of Chinese Yuan. *Calculated based on mitigation design of a nearby catchment.

\begin{tabular}{|c|c|c|c|}
\hline \multicolumn{2}{|l|}{ Type } & \multicolumn{2}{|c|}{ Value } \\
\hline Construction type & Code & $\begin{array}{c}\text { Unit price before } \\
2008 \\
\left(\text { USD } / \mathrm{m}^{2}\right) \\
\end{array}$ & $\begin{array}{l}\text { Unit price } 2008- \\
2012\left(\text { USD } / \mathrm{m}^{2} \text { ) }\right.\end{array}$ \\
\hline $\mathrm{RC}$ frame structure & $\mathrm{RCF}$ & 217 & 415 \\
\hline Reinforced masonry & $\mathrm{RCM}$ & 144 & 200 \\
\hline Wood \& brick & WB & 54 & 77 \\
\hline Wooden & W & 27 & 46 \\
\hline $\begin{array}{c}\text { Pre-fabricated metal } \\
\text { houses }\end{array}$ & PFM & - & 154 \\
\hline Tents \& shacks & TSs & - & 6 \\
\hline \multicolumn{2}{|c|}{ Reinforced slopes } & - & $* 205$ \\
\hline \multicolumn{2}{|c|}{ Drainage channels } & - & $* 103$ \\
\hline \multicolumn{2}{|c|}{ Embankments } & - & $* 362$ \\
\hline \multicolumn{4}{|c|}{ Road (USD / m) } \\
\hline \multicolumn{2}{|c|}{ Major road (6 m wide) } & \multicolumn{2}{|c|}{207} \\
\hline \multicolumn{2}{|c|}{ Secondary road ( $3 \mathrm{~m}$ wide) } & \multicolumn{2}{|c|}{23} \\
\hline \multicolumn{2}{|c|}{ Bridge (5 m wide) } & \multicolumn{2}{|c|}{828} \\
\hline \multicolumn{2}{|c|}{ Tunnel ( $6 \mathrm{~m}$ wide road) } & \multicolumn{2}{|c|}{5069} \\
\hline \multicolumn{4}{|c|}{ Others } \\
\hline \multicolumn{2}{|c|}{$\begin{array}{l}\text { Mitigation works of the three sub- } \\
\text { catchments (Figure 5.11) }\end{array}$} & \multicolumn{2}{|c|}{4.6 million USD in total } \\
\hline
\end{tabular}

The total value of all buildings was estimated to be about 19.5 million USD in 2007 (Figure $5.13 \mathrm{~A}$ ). The earthquake caused 8.2 million USD direct loss in 2008 , which was $42 \%$ of the value in the previous year. The temporary shelters in 2008 were worth 2.2 million USD, making the total building value in 2008 reaching 14.5 million USD. A 0.1 million USD loss was caused by the debris flow in 2009. As a result of the fast reconstruction, the total value increased rapidly to 96 million USD in 2010, which was nearly 5 times the value in 2007. 


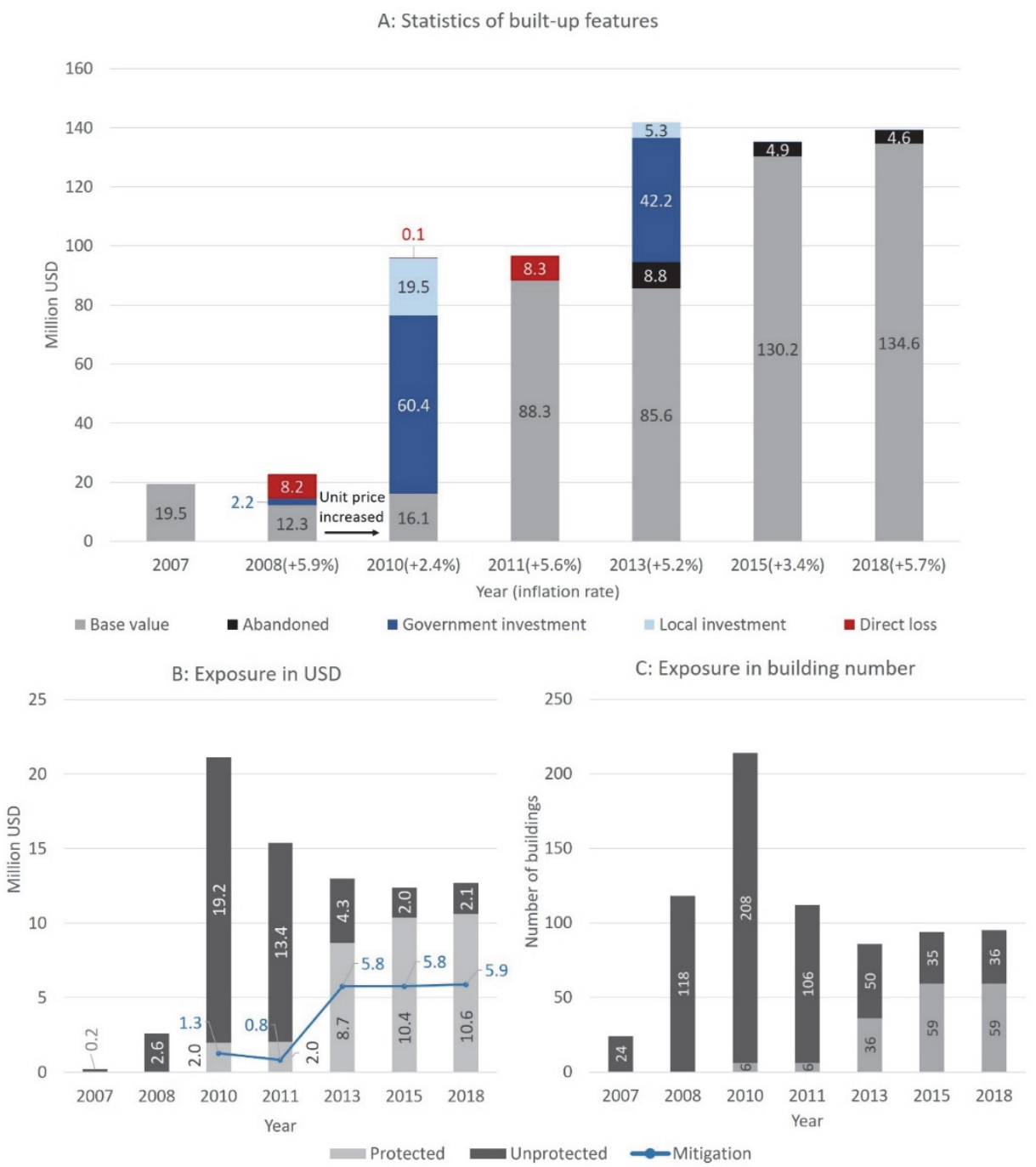

Figure 5.13: $A$ : the total built-up values, investments and direct economic losses over the period between 2007 and 2018 in the Longxi area. B: The total building value that was at risk of being impacted by debris flows and floods. The values were adjusted with the inflation rate. C: The total number of buildings that was at risk of being impacted by debris flows and floods.

This was caused by the increase in the number of apartment buildings and the overall improvement in construction type, particularly the RCF buildings accounted for $75 \%$ of the total value. The disaster in August 2010 caused a loss of 8.3 million USD, making the building value dropped to 88.3 million USD in 2011. It is notable that the direct loss in 2010 was slightly more than the loss caused by the Wenchuan earthquake. New buildings and the mitigation structures raised the total value to 133.1 million USD in the 2013 inventory. A 
gradually small increase in the total values was observed from 2013 to 2018, which was caused by currency inflation and new buildings.

A total of 130.3 million USD was invested in the reconstruction and hazard mitigation. The government invested 104.9 million USD, which was almost four times the private investment ( 25.3 million USD), and a large portion of the private investment came from government subsidies. Over all investigated period the total direct loss was 16.5 million USD, out of which 8.4 Million was government losses and 8.1 million USD private losses. The risk was only analyzed by the value of potential exposed assets since we could not quantify the return period of the hazards, as this was changing from year to year due to the changing landslide activity. The post-earthquake environment was highly dynamic due to the constantly changing amount of loose material and vegetation regrowth, making the triggering rainfall threshold and magnitude of disasters different in each of the years. The potential exposure described in this section includes buildings under threat of landslides and floods. The hazard extent was determined by the maximum extent of landslide and historical floods. Any building located in the hazard extent was considered to have a potential exposure to the post-seismic hazards.

The exposure in 2007 was 0.2 million USD (Liu et al., 2007), since the area did not present any major active landslide or debris flow areas, and was nearly completed forested before 2008. This changed dramatically after the earthquake. The landslide frequency and magnitude were high in the first three years in this area based on our previous work of monitoring post-earthquake landslide activities (Tang et al., 2016). In 2008 the total value of the exposed elements-at-risk was only 2.6 million USD as many of the buildings were destroyed by the earthquake and reconstruction had not commenced (Figure 5.13 B). By 2010 the value of potential exposed buildings had increased enormously to 21.2 million USD as many buildings were reconstructed in the danger zone. A total of 1.3 million USD was invested in mitigation works. There were 2 million USD worth of buildings protected by the reinforced slopes shown in Figure 5.7 A and Figure 5.8. The check dams and the drainage at the catchment outlet did not count as protection due to their poor quality (Figure 5.7 B \& C and Figure 5.8). After the 2010 debris flow disaster the landslide activity decayed significantly (Tang et al., 2016). In 2011 the total value of potential exposed buildings reduced to 15.4 million USD because of the loss caused by the 2010 disaster. The mitigation value reduced to 0.8 million USD because of the destroyed check dams and drainage. In 2013 the total value of the potentially exposed buildings was 13 million USD, and 8.7 million USD was under the protection of 5.8 million worth mitigation structures. The potentially exposed value remained stable at 12.4 to 12.7 million USD from 2015 to 2018, with 12 to 12.1 million USD protected. The total spending on mitigation works increased to 5.9 million USD. It is difficult to predict the future situation as the 
number of assets would increase if the Longchi National Park reopens, and hazard activity could further diminish as the environment recovers completely and reaches the pre-earthquake condition.

\subsection{Economy}

The economy prior to the earthquake relied mostly on farming, tourism, and working outside of the town. The farmlands generated about half of the profit (Baidu Encyclopedia, 2016), occupying an area of 76 hectares and were used mainly for growing commercial crops (74\%). The 87 hotel buildings in 2007 indicated that tourism played an important role in the local economy. Employment outside the study area (Mainly in the cities of Dujiangyan and Chengdu) had a significant contribution as well, as $20 \%$ of the interviewees stated it was one of the major income sources.

The earthquake lead to an unemployment of $19 \%$ of the population. The tourism activities came to a complete stop, but agriculture did not take much direct damage from the earthquake. The government distributed subsidies to the residents based on the reported property damage. They also organized several companies to employ the local people, causing an extra of $9 \%$ of the families that relied on working outside of the area.

After the relief efforts in 2008 and 2009 both the government and the local population were expecting the recovery of the tourism sector brought by the national park. Judged from the reconstructed hostels, there was a plan to restore economy by tourism. Entrepreneurial local people built more hostels than there were 2007 and the floor space was almost doubled. The government connected the town with the major highway to Wenchuan, which was already planned before the earthquake but which was executed at record speed after the disaster, and which was completed in May 2019. Agriculture was strongly encouraged by the government. The area of farmlands increased during 2008 to 2010 ( +6 hectares) and commercial crops had a higher ratio ( $+9 \%$ ) than in 2007. Sixty-five new agriculture buildings were built in 2010, as the local farmers started to raise domestic animals such as chicken, ducks and goats. The unemployment rate was reduced to $3 \%$. The debris flows that occurred on August 14, 2010 had a large impact on the local economy since the Longxi National Park had to be closed for indefinite period due to the increased landslide threat, and the destruction of the access road and most of the tourist infrastructure. As a result, in 2011 the government stopped the road maintenance in the northern part which connects the settlements with the national park. A total of 12 hotels were closed and waited for the reopening of the national park. The economy could only rely on agriculture and working outside. A fast increase in farmland area was observed during 2010 to 2013 (+9 hectares). 
Farmlands continued to expand from 2010 to 2018, reaching 98 hectares, which was 15 hectares more than in 2010. Since the temperature in the Longchi valley is always lower in summer than the nearby cities (Dujiangyan and Chengdu) and most of the landslides were stabilized, the tourism started to recover since 2015. The closure of the tunnel connecting Longchi town with the highway increased the fuel cost to transport goods and reduce potential tourism. Till the end of 2018, the government did not announce any plan to repair the tunnel. The economy of the Longchi watershed is not likely to be fully recovered before the reopening of the nation park.

\subsection{Discussion \& conclusions}

We monitored the changes in the Longxi valley during a ten year period after the Wenchuan earthquake and the subsequent recovery process, with seven inventories from different years containing buildings, roads, land use and mitigation measures. Most of the stronger building construction types were only implemented after the earthquake, and mitigation structures were only installed after being impacted by debris flows and floods. A greater awareness to avoid living in hazard prone areas was observed after the 2010 debris flows. Despite the extensive and repeated damage, the earthquake, and subsequent landslides, debris flows and floods gave Longchi town a chance to increase its resistance to these hazards in future, and to improve economically.

Due to the direct involvement of the Government of the city of Shanghai, who supported Longxi town financially and with expertise, the recovery was fast, considering the large loss and the mountainous terrain in the area impacted by the Wenchuan earthquake. The lack of experience of dealing with postearthquake landslides was the largest flaw in the recovery planning. The damage caused by post-seismic landslides was not only restricted to Longxi, but was reported across the entire earthquake affected region. The postearthquake disasters did not significantly slow down the reconstruction process because of the strong economy of China, and the large amount of funding that was invested in reconstruction and protection using mitigation structures. However, recovering the economy through tourism was a failure in Longchi town, because post-seismic debris flow activity was underestimated. Many resources were wasted, for example the destroyed and abandoned hostels, the destroyed main road, and the revoked highway entrance. Similarly many unused and often destroyed tourism facilities can be seen all over the earthquake affected area. Among all the towns that had planned tourism, Longchi had one of the worst failures, because its biggest attraction was the national park which could not be reopened. The recovery would have been much more efficient if it included the awareness of dealing with post-seismic hazards. However, the question remains if these reactivations could have been predicted and mitigated properly. 
The Longxi valley shows a typical example of the concept of dynamic risk, as both hazard and element at risk were constantly changing. Post-seismic landslides were controlled by the available amount of co-seismic loose materials and vegetation growth (Fan et al., 2018a; Tang et al., 2019; Tang et al., 2016; Yang et al., 2018), which were different from time to time. Floods were closely related to landslide activities as they could dam rivers in the short term and caused raising of the riverbeds in the long term. The reconstruction made the total value of the built-up features nearly 4 times higher than it was in 2007, and many of them were reconstructed in the hazard prone zones. The risk was very high in 2010 as the reconstruction created many potentially exposes buildings and there had not been a major event to deplete the coseismic landslide materials. The direct economic loss caused by the debris flows alone was more than that caused by the earthquake. It is recommended to update hazard and risk map in an earthquake-hit region frequently, depending on the occurrence of hazards, human activities and environment recovery.

It is important to take multi-hazard effects into consideration in planning recovery. The Longxi watershed experienced an earthquake, slope failures, debris flows, and floods. The four disasters showed directly or indirectly interactions, which caused a high difficulty for hazard assessment. In such a mountainous region it is recommended not to re-build near the outlet of catchments containing many co-seismic landslides. Avoiding reconstruction too close to rivers is also recommended to avoid the floods caused by riverbed raising and landslide dams. However, in a mountainous region the flat lands are most likely created by historical landslides and river terraces, leaving very limited options to planners. One possible solution could be to delay reconstruction and wait for environment to recover to an acceptable point. Careful monitoring and analysis of post-earthquake hazards and risk is essential. 


\section{A catchment-based (semi) quantitative approach to estimate potential losses caused by post-earthquake debris flows}

\subsection{Introduction}

Debris flows often cause large losses to settlements in mountainous regions. The initiation mechanisms can be diverse, such as individual or multiple landslides transforming into flow, accelerated erosion of loose materials by concentrated surface runoff, rapid melting of snow and or ice masses, and break-out of natural or man-made lakes (Papa et al., 2012; Tang et al., 2011b; van Asch et al., 2013; Zhang et al., 2012). Co-seismic landslides triggered by large earthquakes create substantial amounts of loose materials, which can be subsequently reactivated or entrained by surface flows, decreasing the rainfall threshold required to trigger debris flows drastically (Chen, 2011; Guo et al., 2016; Lin et al., 2004; van Asch et al., 2013; Zhou and Tang, 2013). For example, several catastrophic debris flows were witnessed after the 1999 Chichi earthquake and the 2008 Wenchuan earthquake, causing many casualties and massive property damage (Chen et al., 2004; Dong et al., 2011; Hu and Huang, 2017; Tang et al., 2012a). Since large earthquakes in mountains may alter the vegetation, topography and volume of loose materials significantly, this also changes the nature of the hazards, and pre-earthquake hazard and risk maps would not be adequate anymore. Without sufficient knowledge on the changing risk situation, post-earthquake reconstruction planning has proven to be very difficult, as witnessed by debris flow disasters in several towns that were reconstructed after the 2008 Wenchuan earthquake.

Risk depends on the components of hazard (temporal, spatial, intensity probability), elements-at-risk (location, land use, construction type, economic value, number people) and vulnerability (physical, social, environmental, systemic) (Fell, 1994; van Westen et al., 2006; Varnes, 1984). Risk assessment aims to assess the probability of losses, and can be analyzed quantitatively (Lee and Chi, 2011; Remondo et al., 2005; Zêzere et al., 2008), semi-quantitatively (Finlay et al., 1999; Gentile et al., 2008) or qualitatively (Abella and Van Westen, 2007; Akgun et al., 2012). Risk is dynamic as hazard components and elements-at-risk characteristics will change over time (Guzzetti et al., 2005; Rautela and Lakhera, 2000; van Westen and Greiving, 2017). Due to the constantly changing post-earthquake environment, in terms of vegetation recovery, landslide activity, and reconstruction activities, hazard and risk change continuously. The quantification of these changing risk remains a major scientific and societal challenge (van Westen and Greiving, 2017). 
In this chapter an attempt is made to quantify losses caused by debris flows at watershed level for post-earthquake situations. An indicative and evidencebased debris flow occurrence probability assessment was carried out, which was combined with an exposure analysis of economic values to quantify loss. Due to lack of data to model or map the actual debris flow intensity, and assess the physical vulnerability, a complete risk analysis could not be achieved, and results are limited to potential loss assessment. A total of 66 first order catchments in the epicentral zone of the Wenchuan earthquake (with an area larger than $0.1 \mathrm{~km}^{2}$ ) were selected (Figure 6.1), and the exposed economic value was calculated for seven time periods: June 2008, May 2009, premonsoon of 2010, April 2011, April 2013, April 2015, and April 2018.

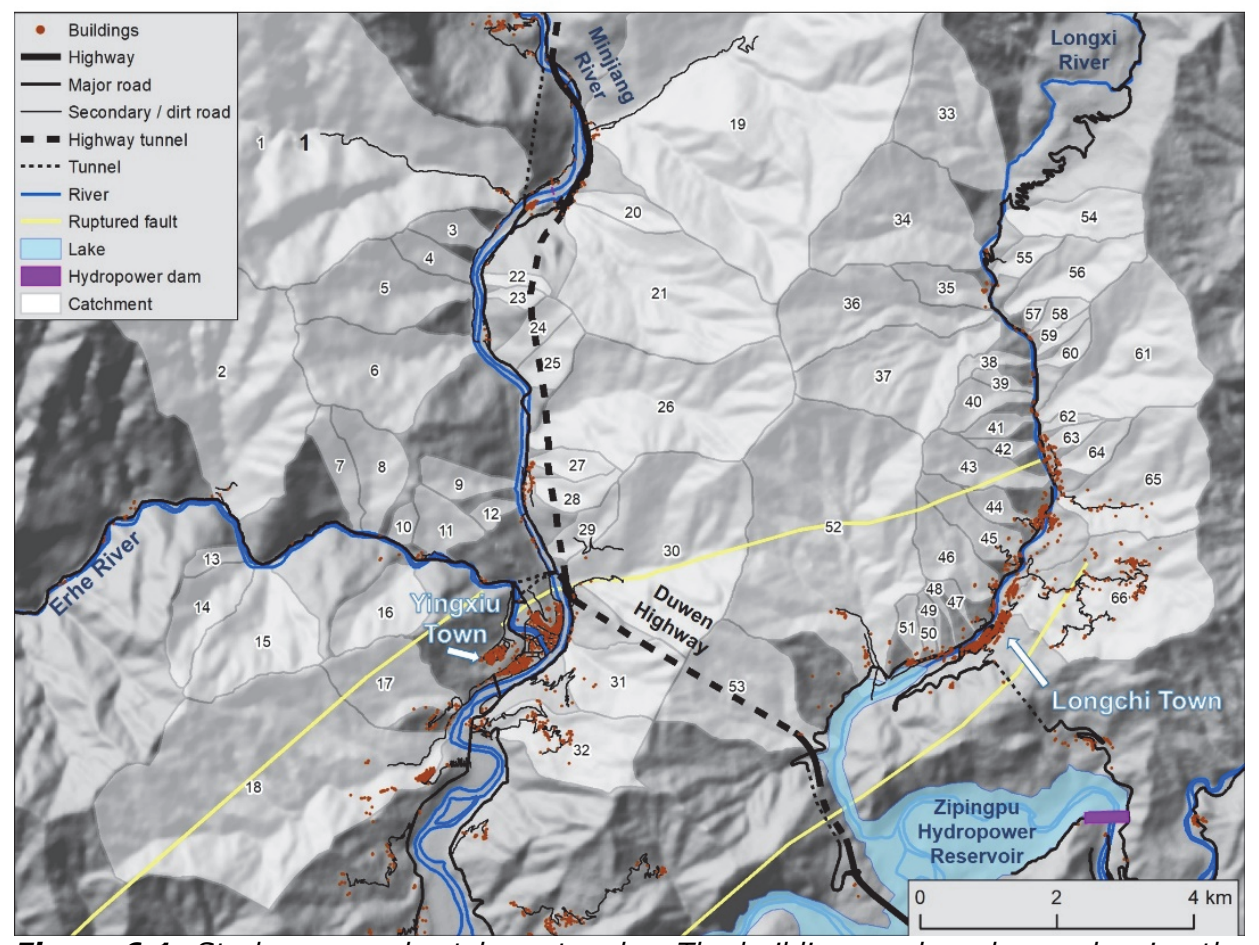

Figure 6.1: Study area and catchment codes. The buildings and roads are showing the situation of 2014. Numbers in the catchment polygons indicate catchment ID used later in this chapter.

\subsection{Data description}

Table 6.1 provides and overview of the data used in the study. 
Table 6.1. Data used for this study (pan= panchromatic image, Mul = multi-spectral image, $R G B=$ Red/Green/Blue: color composite). Usage: (1) Identifying debris flow occurrence, (2) Deriving factors for analysis. (3) Mapping exposure, (4) Investigating prices. NASG = National Administration of Surveying, Mapping and Geo-information of China, SGMC = Station of Geo-environment Monitoring of Chengdu (SGMC), SKLGP = State Key Laboratory of Geo-hazard Prevention and Geo-environment Protection, Chengdu University of Technology, IMHE = Institute of Mountain Hazards and Environment, Chinese Academy of Science.

\begin{tabular}{|c|c|c|c|c|c|c|c|c|}
\hline \multirow{2}{*}{$\begin{array}{l}\text { Data } \\
\text { type }\end{array}$} & \multirow[b]{2}{*}{ Data source } & \multirow[b]{2}{*}{ Collection date } & \multirow{2}{*}{$\begin{array}{c}\text { Cell size } \\
\text { pan/Mul }(\mathrm{m})\end{array}$} & \multirow[b]{2}{*}{ Band } & \multicolumn{4}{|c|}{ Usage } \\
\hline & & & & & (1) & (2) & (3) & (4) \\
\hline \multirow{8}{*}{ 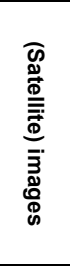 } & Aerial photograph & JUN 2008 & 1 & RGB & $x$ & $x$ & $x$ & \\
\hline & SPOT 5 & FEB 2009 & $2.5 / 10$ & Pan + Mul & $x$ & $\mathrm{X}$ & $\mathrm{X}$ & \\
\hline & SPOT 5 & MAY 2009 & 2.5 & Pan & $x$ & $\mathrm{X}$ & $x$ & \\
\hline & Worldview-2 & APR 2011 & $0.5 / 2$ & Pan + Mul & $x$ & $\mathrm{X}$ & $x$ & \\
\hline & Pleiades & APR 2013 & $0.5 / 2$ & Pan + Mul & $x$ & $x$ & $x$ & \\
\hline & Pleiades & DEC 2014 & $0.5 / 2$ & Pan + Mul & $x$ & $\mathrm{X}$ & $\mathrm{x}$ & \\
\hline & Spot 6 & APR 2015 & 1.5 & RGB & $x$ & $\mathrm{X}$ & $x$ & \\
\hline & Pleiades & JUN 2018 & $0.5 / 2$ & Pan + Mul & $x$ & $\mathrm{X}$ & $\mathrm{X}$ & \\
\hline \multirow{2}{*}{ 목 } & $\begin{array}{l}\text { Aerial LiDAR based } \\
\text { contour from NASG }\end{array}$ & 1999 & 5 & $\begin{array}{l}\text { An aerial LiDAR based DTM } \\
\text { covering the Longchi area }\end{array}$ & & $\mathrm{X}$ & & \\
\hline & $\begin{array}{l}10 \text { m interval contour } \\
\text { from NASG }\end{array}$ & 2010 & 5 & $\begin{array}{l}\text { A contour generated DTM } \\
\text { covering the Yingxiu area }\end{array}$ & & $\mathrm{X}$ & & \\
\hline \multirow{4}{*}{ 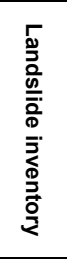 } & Chapter 2 & 2016 & \multicolumn{2}{|c|}{$\begin{array}{l}\text { Polygon based vector data with landslide } \\
\text { activity mapped for } 5 \text { periods }(2008-2015)\end{array}$} & $x$ & $\mathrm{X}$ & & \\
\hline & Chapter 5 & 2018 & \multicolumn{2}{|c|}{$\begin{array}{c}\text { Polygon-based inventory based on image } \\
\text { from June } 2018\end{array}$} & $x$ & & & \\
\hline & Xu et al. (2013) & 2013 & \multicolumn{2}{|c|}{$\begin{array}{c}\text { Polygon-based co-seismic landslide } \\
\text { inventory }\end{array}$} & $x$ & $x$ & & \\
\hline & Fan et al. (2019a) & 2018 & \multicolumn{2}{|c|}{$\begin{array}{l}\text { Polygon based vector data with landslide } \\
\text { activity mapped for } 6 \text { periods }(2005-2015)\end{array}$} & $x$ & & & \\
\hline \multirow{3}{*}{ 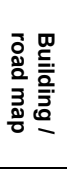 } & NASG & 2010 & \multirow{2}{*}{\multicolumn{2}{|c|}{$\begin{array}{c}\text { Official building and road shapefiles mapped } \\
\text { by NASG in Yingxiu }\end{array}$}} & & & $x$ & $x$ \\
\hline & NASG & 2014 & & & & & $x$ & $x$ \\
\hline & Chapter 5 & 2018 & $\begin{array}{l}\text { Polygon-bas } \\
\text { mapped for }\end{array}$ & $\begin{array}{l}\text { sed built-up feature inventory } \\
7 \text { periods ( } 2007-2018) \text { in the } \\
\text { Longchi area }\end{array}$ & & & $x$ & $x$ \\
\hline \multirow{4}{*}{ 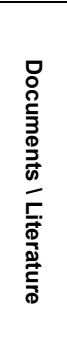 } & $\begin{array}{l}\text { Official hazard } \\
\text { investigation reports. }\end{array}$ & - & \multicolumn{2}{|c|}{$\begin{array}{c}\text { Sichuan Geological Survey institute (2010), } \\
\text { Sichuan Geology Engineering } \\
\text { Reconnaissance Institute (2011), Yang } \\
\text { (2010), Hao et al. (2011), Li et al. (2011) }\end{array}$} & $x$ & & & $x$ \\
\hline & Zhao and Liu (2005) & - & \multicolumn{2}{|c|}{$\begin{array}{c}\text { Describes risk assessment method and } \\
\text { property prices in Sichuan province in } 2005 .\end{array}$} & & & & $x$ \\
\hline & Field investigation & 2018 & \multicolumn{2}{|c|}{$\begin{array}{c}\text { Field investigations and interviews were } \\
\text { carried out to identify building types and unit } \\
\text { prices }\end{array}$} & $x$ & & $\mathrm{x}$ & $x$ \\
\hline & Rainfall data & $2008-2018$ & \multicolumn{2}{|c|}{ Provided by SGMC, SKLGP, IMHE } & & $x$ & & \\
\hline
\end{tabular}

All the mapping and analysis were done within the area covered by catchment boundaries combined with debris-flow-affected zones. The latter were obtained by using the four available landslide inventories (Table 6.1). Areas which had a clear debris flows hazard but didn't contain any events in the inventories were mapped based on the descriptions in the official hazard investigation reports. A total of four tasks were carried out in order to reach the loss analysis: (1) Identifying debris flow occurrences between time instances and assessing the affecting area; (2) Deriving factors that were used to assess 
indicative debris flow probability; (3) Mapping exposure; (4) Investigating unit prices of built-up features and estimate the economic value of exposure.

\subsection{Indicative hazard probability estimation}

The probability of debris flow occurrence was assessed through a semiquantitative approach. First a hazard score system was applied and then the scores were analyzed with the historical debris flows to estimate probability.

\subsubsection{Data preparation}

Debris flow activities were identified by observing satellite images, engineering/investigation reports (Hao et al., 2011; Li et al., 2011; Sichuan Geological Survey institute, 2010; Sichuan Geology Engineering Reconnaissance Institute, 2011; Yang, 2010), landslide inventories, and field surveys (Table 6.1). Debris flows that stopped within catchments, not reaching the locations of exposed elements-at-risk, were not taken into account. When check dams were installed, the occurrence was judged by whether the dams were filled with debris flow materials. Unfortunately, there was not enough data available to reconstruct the actual debris flow dates. In most instances, it was only possible to indicate that a debris flow had occurred between two times periods for which images were available, or when fieldwork was carried out. As there were no continuous monitoring devices installed in most of the watersheds, the exact times of debris flow occurrence could not be obtained. The debris flow occurrence was saved in a Boolean format in the polygon-based catchment shapefile ( 1 is occurrence, and 0 non-occurrence).

Factors that related with loose materials, vegetation, terrain and mitigation works were derived in order to be analyzed with historical debris flow occurrence. A total of 7 factors were derived:

Co-seismic landslides area: Co-seismic landslides were the major source for post-earthquake debris flows. The total co-seismic landslide area was calculated per watershed. The co-seismic landslide inventory mapped in Chapter 2 was used, and when a catchment extended out of the mapping area, the inventories of Xu et al. (2013) and Fan et al. (2018a) were used.

Presence of stream blockage: Stream blockage provided large volumes of materials that could be entrained and in these watersheds the debris flow magnitude when breached will be higher. So in these cases the potential hazard intensity is increased by stored material in the stream channel. This factor was derived manually by visual interpretation of the available images. Three classes were used: full blockage, partial blockage and no blockage. Partial blockage resulted in situations where landslides filled up valleys without damming the 
river completely, and the remaining sediments could be eroded by streams or entrained by debris flows.

Presence of large landslides: Large landslides provide more loose materials and are important for producing debris flows, as observed in Chapter 2. We selected the largest $1 \%$ of the landslides from the co-seismic landslide inventories made in Chapter 2 and from Fan et al. (2018a), with a minimum size of $100,000 \mathrm{~m}^{2}$. The categories are absence and presence.

Vegetation regrowth rate: A supervised classification was carried out to extract vegetation from satellite images using NDVI. The images of February 2009, April 2011, April 2013 and June 2018 were used. Since the Pleiades image of December 2014 has heavy shadows as described in Chapter 3, red band of the 2015 Spot 6 image was used. vegetation regrowth rate was estimated by:

$$
V_{r}=\frac{A_{v}}{A_{b}} * 100 \%
$$

Where $V_{r}$ was the vegetation regrowth rate in percentage per catchment, $A_{v}$ was the vegetation cover within landslides at a particular time period and $A_{b}$ was the maximum bare surface area in all period(s) prior to the time when $A_{v}$ was estimated. In most cases $A_{b}$ equals to co-seismic landslide area. If a catchment is partially out of the image boundaries or partially covered by clouds, the value was calculated based on the visible areas.

Mitigation measures: Varies types of mitigation measures were applied in this area, such as check dams, drainages, embankments and sediment retention basins. They were mapped manually from the images. The mitigation measures were classified into two categories: (1) "mitigated", which means mitigation structures were installed and debris flows are not likely to cause damage and (2) "No mitigation". If a catchment was fully mitigated, it was assumed that its probability to create debris flow was reduced to zero. For other catchments the value of 1 was used.

Catchment area: The size of a catchment is indicative for the amount of precipitation and runoff. It was calculated using GIS.

Catchment slope: The average slope within a catchment was calculated based on the available digital terrain models (See Table 6.1).

\subsubsection{Debris flow history}

Table 6.2 provides a summary of post-seismic debris flow history for the 66 catchments. In the table the debris flow occurrences are indicated by orange cells for a given time period. After the earthquake and before the monsoon of 
2008 , three catchments produced debris flows with a maximum rain intensity of $9 \mathrm{~mm} / \mathrm{h}$. During the monsoon of 2008, 11 out of the 66 watersheds produced debris flows (Table 6.2). Although substantial volumes of the co-seismic loose materials were remobilized (Chapter $2 \& 3$; Tang et al. 2016; Tang et al. 2019), the maximum rain intensity of $31 \mathrm{~mm} / \mathrm{h}$, which was recorded $12 \mathrm{~km}$ away from the area, was not high enough to trigger catastrophic events. Debris flows occurred during the monsoon of 2009 but were limited in volume based on the reports (Hao et al., 2011; Li et al., 2011; Sichuan Geological Survey institute, 2010; Sichuan Geology Engineering Reconnaissance Institute, 2011; Yang, 2010) and the recorded rainfall that triggered debris flows was only $19.4 \mathrm{~mm} / \mathrm{h}$ at maximum. We do not have an image to identify debris flow activities in the monsoon of 2009, therefore the data of Fan et al. (2019a) was used, which recorded activity in three watersheds. Due to lack of data stream blockage was assumed to be unchanged. Average vegetation regrowth rate of 2009 and 2011 was used for this period. The rain gauges were repaired or newly installed in this region by the end of 2009. The monsoon of 2010 was much more severe, and the largest rainfall event had a recorded intensity of $75 \mathrm{~mm} / \mathrm{h}$ near the town of Longchi, triggering debris flows in 59 watersheds. Interpretation of the Pleiades image of April 2013 revealed the cumulative effect brought by the monsoons of 2011 and 2012. Debris flows were observed in fifteen watersheds, triggered by an event with a maximum rainfall intensity of $41.7 \mathrm{~mm} / \mathrm{h}$. From the end of 2012 till April 2015, only 12 watersheds produced debris flows. The maximum rainfall intensity during this period was $35.6 \mathrm{~mm} / \mathrm{h}$. The last available image was from April 2018, which allowed to evaluate the cumulative effects of three monsoon periods (2015, 2016 and 2017). During these three years, the maximum recorded rainfall intensity was $61 \mathrm{~mm} / \mathrm{h}$, and debris flows occurred in only six watersheds.

Seven watersheds never produced any debris flow. Five of these had a low coseismic landslide area density $(1 \%-12 \%)$. The two other watersheds (ID 15 \& 24) were affected by large rockslides that filled valleys along streams, and the dams were not breached during the 10 years following the earthquake. No barrier lake was observed behind the blockages. 
Table 6.2: Summary of post-seismic debris flow history. Cells with an orange color indicate debris flow occurrence. $C S L=$ co-seismic landslide area and $V_{r}=$ vegetation recovery (See equation 6.1). The columns with blockage contain the following information:(B) full blockage; $(P)$ partial blockage; $(M)$ mitigated. The last three rows list the information of the rainfall with the highest intensity of the periods. Max rain intensity, cumulative rain and rainfall date are recorded from same events. Except for the rain measured for last two periods, the others were confirmed to be related with debris flow occurrence. * The largest rain recorded was from JAN to OCT 2018.

\begin{tabular}{|c|c|c|c|c|c|c|c|c|c|c|c|c|c|c|c|c|c|c|c|c|c|c|c|c|c|}
\hline \multirow[b]{2}{*}{$\tilde{\sigma}$} & \multirow{2}{*}{. } & \multirow{2}{*}{ 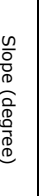 } & \multirow{2}{*}{$\begin{array}{l}\text { On } \\
\stackrel{5}{c} \\
\text { 点 } \\
\text { 思 }\end{array}$} & \multirow{2}{*}{ 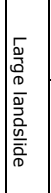 } & \multicolumn{3}{|c|}{$\begin{array}{c}\text { Monsoon } \\
2008\end{array}$} & \multicolumn{3}{|c|}{$\begin{array}{c}\text { Monsoon } \\
2009 \\
\end{array}$} & \multicolumn{3}{|c|}{$\begin{array}{c}\text { Monsoon } \\
2010\end{array}$} & \multicolumn{3}{|c|}{$\begin{array}{c}\text { Monsoons } \\
2011 \& 2012 \\
\end{array}$} & \multicolumn{3}{|c|}{$\begin{array}{c}\text { Monsoon } \\
2013 \& 2014 \\
\end{array}$} & \multicolumn{3}{|c|}{$\begin{array}{c}\text { Monsoons } \\
2015-2017 \\
\end{array}$} & \multicolumn{3}{|c|}{$\begin{array}{l}\text { Monsoons } \\
2018 \text { - ? }\end{array}$} \\
\hline & & & & & 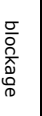 & 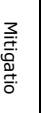 & $\leqq$ & 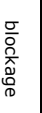 & 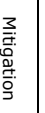 & $\leqq$ & 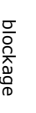 & 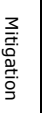 & $\leqq$ & 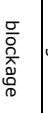 & 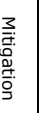 & $\leqq$ & 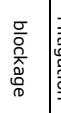 & 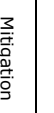 & $\leqq$ & 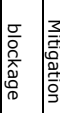 & & $\leqq$ & 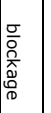 & 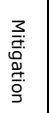 & $\leqq$ \\
\hline 1 & 40 & 42 & 17374 & $\mathrm{x}$ & B & & \begin{tabular}{|l|}
$0 \%$ \\
\end{tabular} & B & & $5 \%$ & B & & $14 \%$ & B & & $22 \%$ & $\mathrm{P}$ & & $34 \%$ & $P$ & & $85 \%$ & $P$ & & $87 \%$ \\
\hline 2 & 7.2 & \begin{tabular}{|l|}
46 \\
\end{tabular} & \begin{tabular}{|l|}
3503 \\
\end{tabular} & $\mathrm{x}$ & B & & $0 \%$ & B & & $5 \%$ & B & & $12 \%$ & $P$ & & $19 \%$ & $P$ & & $2 \%$ & $P$ & & $77 \%$ & $P$ & & $77 \%$ \\
\hline 3 & 0.5 & 42 & 385 & $x$ & $B$ & & $0 \%$ & $B$ & & $7 \%$ & B & & $39 \%$ & B & & $70 \%$ & $P$ & & $82 \%$ & $P$ & & $90 \%$ & $P$ & & $86 \%$ \\
\hline 4 & 0.5 & 43 & 225 & & B & & $0 \%$ & B & & $0 \%$ & B & & $35 \%$ & B & & $69 \%$ & $P$ & & $79 \%$ & $P$ & & $92 \%$ & & & $96 \%$ \\
\hline 5 & 2.1 & 45 & 1221 & $x$ & B & & $0 \%$ & B & & $0 \%$ & $B$ & & $20 \%$ & $B$ & & $40 \%$ & $B$ & & $51 \%$ & $P$ & & $80 \%$ & $\mathrm{P}$ & & $83 \%$ \\
\hline 6 & 2.8 & \begin{tabular}{|l|} 
\\
\end{tabular} & $\mid 1064$ & & B & & $0 \%$ & B & & $0 \%$ & $B$ & & $22 \%$ & & & $43 \%$ & & & $54 \%$ & & & $86 \%$ & & & $86 \%$ \\
\hline 7 & 1.7 & 39 & 1034 & $x$ & $\mathrm{~B}$ & & $0 \%$ & $\mathrm{~B}$ & & $6 \%$ & B & & $33 \%$ & $P$ & & $60 \%$ & $\mathrm{P}$ & & $64 \%$ & $P$ & & $78 \%$ & $P$ & & $80 \%$ \\
\hline 8 & 1.7 & 42 & 1066 & $x$ & B & & $0 \%$ & $\mathrm{P}$ & & $0 \%$ & $\mathrm{P}$ & & $24 \%$ & $P$ & & $48 \%$ & $P$ & & $66 \%$ & $P$ & & $74 \%$ & $P$ & & $75 \%$ \\
\hline 9 & 0.5 & 38 & 364 & & B & & $0 \%$ & B & & $2 \%$ & $B$ & & $38 \%$ & $B$ & & $74 \%$ & B & & $85 \%$ & B & & $97 \%$ & $B$ & & $97 \%$ \\
\hline 10 & 0.2 & 45 & 192 & $x$ & $B$ & & $0 \%$ & $B$ & & $9 \%$ & B & & $47 \%$ & B & & $85 \%$ & $B$ & & $90 \%$ & & & $94 \%$ & & & $99 \%$ \\
\hline 11 & 0.7 & 38 & 528 & & B & & $0 \%$ & B & & $6 \%$ & B & & $38 \%$ & $P$ & & $70 \%$ & $P$ & & $81 \%$ & $P$ & & $81 \%$ & $P$ & & $87 \%$ \\
\hline 12 & 0.2 & 41 & 94 & & B & & $0 \%$ & B & & $11 \%$ & B & & $45 \%$ & & & $78 \%$ & & & $71 \%$ & & & $98 \%$ & & & $96 \%$ \\
\hline 13 & 0.2 & 49 & 220 & & B & & $0 \%$ & B & & $4 \%$ & B & & $30 \%$ & $P$ & & $55 \%$ & $P$ & & $62 \%$ & $P$ & & $89 \%$ & $P$ & & $90 \%$ \\
\hline 14 & 1.1 & 46 & 710 & $x$ & $B$ & & $0 \%$ & $\mathrm{P}$ & & $1 \%$ & $P$ & & $17 \%$ & $P$ & & $32 \%$ & $\mathrm{P}$ & & $44 \%$ & $P$ & & $84 \%$ & $P$ & & $83 \%$ \\
\hline 15 & 2.2 & 41 & 759 & & B & & $0 \%$ & B & & $10 \%$ & $B$ & & $8 \%$ & $B$ & & $6 \%$ & $B$ & & $17 \%$ & B & & $95 \%$ & $B$ & & $94 \%$ \\
\hline 16 & 1.2 & \begin{tabular}{|l|}
39 \\
\end{tabular} & 439 & & B & & $0 \%$ & B & & $5 \%$ & B & & $41 \%$ & $P$ & & \begin{tabular}{|l}
$77 \%$ \\
\end{tabular} & $P$ & & $85 \%$ & $P$ & & $95 \%$ & $P$ & & $96 \%$ \\
\hline 17 & \begin{tabular}{|l|}
1.6 \\
\end{tabular} & 36 & 632 & & B & & $0 \%$ & B & & $0 \%$ & $B$ & & $35 \%$ & $P$ & & $69 \%$ & $P$ & \begin{tabular}{l|l} 
M & 8
\end{tabular} & $85 \%$ & $P$ & \begin{tabular}{l|l} 
M & 8 \\
\end{tabular} & $87 \%$ & $P$ & $M$ & $96 \%$ \\
\hline 18 & 10.6 & \begin{tabular}{|l|}
39 \\
\end{tabular} & 5050 & \begin{tabular}{|l|}
$x$ \\
\end{tabular} & $B$ & & \begin{tabular}{|l|}
$0 \%$ \\
\end{tabular} & $\mathrm{~B}$ & & $0 \%$ & $B$ & & $24 \%$ & B & & $47 \%$ & $P$ & \begin{tabular}{l|l}
$M$ & 6
\end{tabular} & $63 \%$ & $P$ & $\begin{array}{l}\text { M } 7 \\
\end{array}$ & $77 \%$ & $P$ & M & $77 \%$ \\
\hline 19 & 26.8 & \begin{tabular}{|l|}
37 \\
\end{tabular} & \begin{tabular}{|l}
9420 \\
\end{tabular} & \begin{tabular}{|l|} 
\\
\end{tabular} & $B$ & & $0 \%$ & $\mathrm{P}$ & & $10 \%$ & $\mathrm{P}$ & & $30 \%$ & $P$ & & $49 \%$ & $\mathrm{P}$ & & $47 \%$ & $P$ & & $86 \%$ & $P$ & & $86 \%$ \\
\hline 20 & 0.5 & 38 & 230 & & $B$ & & $0 \%$ & $\mathrm{~B}$ & & $11 \%$ & $B$ & & $36 \%$ & $P$ & & $60 \%$ & $P$ & & $75 \%$ & $P$ & & $96 \%$ & $P$ & & $90 \%$ \\
\hline 21 & 4.7 & 33 & 261 & & B & & $0 \%$ & $\mathrm{~B}$ & & $13 \%$ & $B$ & & $29 \%$ & & & $45 \%$ & & & $14 \%$ & & & $94 \%$ & & & $83 \%$ \\
\hline 22 & 0.2 & 38 & 74 & & B & & $0 \%$ & B & & $0 \%$ & $B$ & & $36 \%$ & $P$ & & $71 \%$ & & & $76 \%$ & & \begin{tabular}{l|l} 
M & 9 \\
\end{tabular} & $99 \%$ & & $M$ & $94 \%$ \\
\hline 23 & 0.2 & 41 & 167 & & B & & $0 \%$ & $\mathrm{P}$ & M & $6 \%$ & $P$ & M & $36 \%$ & $P$ & M & $66 \%$ & $P$ & M 7 & $70 \%$ & $\mathrm{P}$ & $\begin{array}{lll}\text { M } & 9 \\
\end{array}$ & $99 \%$ & $\mathrm{P}$ & M & $86 \%$ \\
\hline 24 & 1.1 & 34 & 986 & \begin{tabular}{|l|} 
\\
\end{tabular} & $B$ & & $0 \%$ & B & & $4 \%$ & $B$ & & $31 \%$ & $B$ & & $57 \%$ & $B$ & & $76 \%$ & $B$ & & $90 \%$ & B & M & $75 \%$ \\
\hline 25 & 1.1 & 42 & 898 & $\mathrm{x}$ & $B$ & & $0 \%$ & B & & $10 \%$ & $B$ & & $37 \%$ & $P$ & & $63 \%$ & $P$ & & $71 \%$ & $\mathrm{P}$ & & $80 \%$ & $P$ & M & $77 \%$ \\
\hline 26 & 5.2 & 39 & 1693 & $x$ & B & & $0 \%$ & B & & $16 \%$ & B & & $30 \%$ & $P$ & & $44 \%$ & $P$ & & $52 \%$ & $P$ & & $92 \%$ & $P$ & $M$ & $82 \%$ \\
\hline 27 & 0.5 & \begin{tabular}{|l|} 
\\
\end{tabular} & 210 & & B & & $0 \%$ & B & & $25 \%$ & B & & $47 \%$ & & & $69 \%$ & & M & $79 \%$ & & \begin{tabular}{l|l} 
M & 9 \\
\end{tabular} & $99 \%$ & & M & $98 \%$ \\
\hline 28 & 0.4 & 38 & 190 & & B & & $0 \%$ & B & & $5 \%$ & $B$ & & $36 \%$ & & & $66 \%$ & & $\begin{array}{ll}M & 8\end{array}$ & $80 \%$ & & M 9 & $97 \%$ & & $\mathrm{M}$ & $100 \%$ \\
\hline 29 & 0.5 & 38 & 389 & $x$ & B & & $0 \%$ & $\mathrm{~B}$ & & $7 \%$ & $B$ & & $34 \%$ & & & $61 \%$ & & M & $67 \%$ & & \begin{tabular}{|l|l} 
M & 8 \\
\end{tabular} & $81 \%$ & & M & $85 \%$ \\
\hline 30 & 5.3 & 37 & 1691 & $x$ & $B$ & & $0 \%$ & B & & $12 \%$ & $B$ & & $31 \%$ & & M & $50 \%$ & & M & $66 \%$ & & \begin{tabular}{|l|l} 
M & 8 \\
\end{tabular} & $81 \%$ & & M & $84 \%$ \\
\hline 31 & 1.6 & 34 & 295 & & & & $0 \%$ & & & $36 \%$ & & & $66 \%$ & & & $95 \%$ & & & $94 \%$ & & & $98 \%$ & & & $98 \%$ \\
\hline 32 & 2.0 & 27 & 101 & & & & $0 \%$ & & & $18 \%$ & & & $19 \%$ & & & $20 \%$ & & & $93 \%$ & & & 100 & & & $100 \%$ \\
\hline 33 & 2.6 & 38 & 483 & & $B$ & & $0 \%$ & B & & $6 \%$ & $B$ & & $6 \%$ & $P$ & & $0 \%$ & & & $15 \%$ & & & $73 \%$ & & & $79 \%$ \\
\hline 34 & 3.2 & \begin{tabular}{|l|}
38 \\
\end{tabular} & 554 & & B & & $0 \%$ & B & & $0 \%$ & B & & $13 \%$ & & & $25 \%$ & & & $42 \%$ & & & $81 \%$ & & & $85 \%$ \\
\hline 35 & 0.6 & 37 & 180 & & B & & $0 \%$ & B & & $0 \%$ & $B$ & & $14 \%$ & $P$ & & $28 \%$ & $P$ & & $52 \%$ & $\mathrm{P}$ & & $70 \%$ & $P$ & & $80 \%$ \\
\hline 36 & 2.5 & \begin{tabular}{|l|}
38 \\
\end{tabular} & 383 & & B & & $0 \%$ & B & & $0 \%$ & B & & $10 \%$ & & & $19 \%$ & & & $24 \%$ & & & $82 \%$ & & & $89 \%$ \\
\hline 37 & 2.8 & 37 & 261 & & & & $0 \%$ & & & $0 \%$ & & & $5 \%$ & & & $10 \%$ & & & $50 \%$ & & & $90 \%$ & & & $92 \%$ \\
\hline 38 & 0.2 & 28 & 9 & & & & $0 \%$ & & & $28 \%$ & & & $27 \%$ & & & $25 \%$ & & & $73 \%$ & & & $96 \%$ & & & $100 \%$ \\
\hline 39 & 0.2 & 29 & 4 & & & & $0 \%$ & & & $69 \%$ & & & $54 \%$ & & & $38 \%$ & & & $62 \%$ & & & $75 \%$ & & & $97 \%$ \\
\hline
\end{tabular}




\begin{tabular}{|c|c|c|c|c|c|c|c|c|c|c|c|c|c|c|c|c|c|c|c|c|c|}
\hline 40 & 0.5 & 36 & 46 & & & $0 \%$ & & $49 \%$ & & $57 \%$ & & $65 \%$ & & & $64 \%$ & & & $89 \%$ & & & $96 \%$ \\
\hline 41 & 0.3 & 39 & 63 & & $\mathrm{~B}$ & $0 \%$ & $P$ & $16 \%$ & $P$ & $40 \%$ & & $63 \%$ & & & $79 \%$ & & & $99 \%$ & & & $99 \%$ \\
\hline 42 & 0.2 & 39 & 39 & & & $0 \%$ & & $1 \%$ & & $30 \%$ & & $59 \%$ & & & $66 \%$ & & & $99 \%$ & & & $100 \%$ \\
\hline 43 & 0.9 & 37 & 170 & & & $0 \%$ & & $18 \%$ & & $46 \%$ & & $74 \%$ & & & $85 \%$ & & & $90 \%$ & & & $99 \%$ \\
\hline 44 & 0.3 & 34 & 61 & & B & $0 \%$ & B & $0 \%$ & B & $23 \%$ & & $46 \%$ & & M & $68 \%$ & & $\mathrm{M}$ & $77 \%$ & & M & $97 \%$ \\
\hline 45 & 0.8 & 35 & 328 & $x$ & B & $0 \%$ & B & $0 \%$ & B & $31 \%$ & $\mathrm{P}$ & $61 \%$ & $\mathrm{P}$ & M & $71 \%$ & $\mathrm{P}$ & $\mathrm{M}$ & $75 \%$ & $\mathrm{P}$ & M & $86 \%$ \\
\hline 46 & 1.0 & 36 & 175 & & B & $0 \%$ & B & $0 \%$ & B & $18 \%$ & & $35 \%$ & & M & $63 \%$ & & M & $83 \%$ & & M & $97 \%$ \\
\hline 47 & 0.2 & 35 & 4 & & & $0 \%$ & & $0 \%$ & & $13 \%$ & & $25 \%$ & & & $74 \%$ & & & $86 \%$ & & & $100 \%$ \\
\hline 48 & 0.1 & 36 & 12 & & & $0 \%$ & & $31 \%$ & & $48 \%$ & & $65 \%$ & & & $95 \%$ & & M & $92 \%$ & & $M$ & $100 \%$ \\
\hline 49 & 0.2 & 34 & 11 & & & $0 \%$ & & $7 \%$ & & $31 \%$ & & $54 \%$ & & & $65 \%$ & & M & $83 \%$ & & M & $84 \%$ \\
\hline 50 & 0.1 & 27 & 2 & & & $0 \%$ & & $61 \%$ & & $61 \%$ & & $0 \%$ & & & $88 \%$ & & & $93 \%$ & & & $98 \%$ \\
\hline 51 & 0.3 & 34 & 7 & & & $0 \%$ & & $0 \%$ & & $45 \%$ & & $89 \%$ & & & $97 \%$ & & & $98 \%$ & & & $99 \%$ \\
\hline 52 & 8.6 & 38 & 2610 & $x$ & B & $0 \%$ & B & $0 \%$ & B & $5 \%$ & P & $9 \%$ & $P$ & & $82 \%$ & $P$ & & $86 \%$ & $\mathrm{P}$ & & $85 \%$ \\
\hline 53 & 2.8 & 33 & 47 & & & $0 \%$ & & $0 \%$ & & $37 \%$ & & $73 \%$ & & & $63 \%$ & & & $67 \%$ & & & $100 \%$ \\
\hline 54 & 1.2 & 33 & 186 & & B & $0 \%$ & B & $49 \%$ & B & $49 \%$ & & $0 \%$ & & & $37 \%$ & & & $90 \%$ & & & $96 \%$ \\
\hline 55 & 0.4 & 36 & 80 & & B & $0 \%$ & B & $9 \%$ & B & $10 \%$ & & $10 \%$ & & & $39 \%$ & & & $87 \%$ & & & $91 \%$ \\
\hline 56 & 1.3 & 38 & 261 & & B & $0 \%$ & B & $13 \%$ & B & $12 \%$ & & $10 \%$ & & & $51 \%$ & & & $92 \%$ & & & $98 \%$ \\
\hline 57 & 0.1 & 38 & 24 & & B & $0 \%$ & B & $17 \%$ & B & $29 \%$ & & $40 \%$ & & & $81 \%$ & & & $99 \%$ & & & $84 \%$ \\
\hline 58 & 0.2 & 42 & 95 & & B & $0 \%$ & B & $11 \%$ & B & $34 \%$ & $\mathrm{P}$ & $57 \%$ & P & & $81 \%$ & $P$ & & $99 \%$ & $\mathrm{P}$ & & $98 \%$ \\
\hline 59 & 0.2 & 41 & 38 & & B & $0 \%$ & B & $32 \%$ & B & $49 \%$ & & $65 \%$ & & & $87 \%$ & & & $99 \%$ & & & $100 \%$ \\
\hline 60 & 0.2 & 41 & 89 & & B & $0 \%$ & B & $16 \%$ & B & $34 \%$ & & $52 \%$ & & & $86 \%$ & & & $98 \%$ & & & $99 \%$ \\
\hline 61 & 3.5 & 36 & 598 & & B & $0 \%$ & B & $16 \%$ & B & $33 \%$ & $\mathrm{P}$ & $50 \%$ & $\mathrm{P}$ & & $81 \%$ & $P$ & & $91 \%$ & $\mathrm{P}$ & & $96 \%$ \\
\hline 62 & 0.1 & 30 & 14 & & B & $0 \%$ & B & $0 \%$ & B & $47 \%$ & & $93 \%$ & $\mathrm{P}$ & & $98 \%$ & & & $96 \%$ & & & $100 \%$ \\
\hline 63 & 0.2 & 30 & 22 & & B & $0 \%$ & B & $0 \%$ & B & $22 \%$ & $\mathrm{P}$ & $44 \%$ & $\mathrm{P}$ & & $90 \%$ & $P$ & & $76 \%$ & $\mathrm{P}$ & & $87 \%$ \\
\hline 64 & 0.5 & 35 & 43 & & B & $0 \%$ & B & $21 \%$ & B & $45 \%$ & & $68 \%$ & & & $90 \%$ & & & $92 \%$ & & & $95 \%$ \\
\hline 65 & 2.8 & 33 & 246 & & & $0 \%$ & & $0 \%$ & & $29 \%$ & & $58 \%$ & & & $58 \%$ & & & $81 \%$ & & & $96 \%$ \\
\hline 66 & 4.1 & 28 & 41 & & & $0 \%$ & & $0 \%$ & & $50 \%$ & & $100 \%$ & & & $100 \%$ & & & 100 & & & $100 \%$ \\
\hline AVG & 2.5 & 37 & 889 & - & & $0 \%$ & - & $11 \%$ & . & $31 \%$ & & $50 \%$ & & - & $65 \%$ & & - & $89 \%$ & & - & $92 \%$ \\
\hline \multicolumn{5}{|c|}{ Max rain intensity $(\mathrm{mm} / \mathrm{h})$} & \multicolumn{2}{|r|}{31} & \multicolumn{2}{|r|}{19.4} & \multicolumn{2}{|c|}{75} & \multicolumn{2}{|r|}{41.7} & \multicolumn{3}{|c|}{35.6} & \multicolumn{3}{|c|}{61.5} & \multicolumn{3}{|c|}{$* 37.7$} \\
\hline \multicolumn{5}{|c|}{ Cumulative rain $(\mathrm{mm})$} & \multicolumn{2}{|r|}{94.7} & \multicolumn{2}{|r|}{39.6} & \multicolumn{2}{|c|}{237.2} & \multicolumn{2}{|r|}{223.5} & \multicolumn{3}{|c|}{328.5} & \multicolumn{3}{|c|}{146.8} & \multicolumn{3}{|c|}{ *285.1 } \\
\hline \multicolumn{5}{|c|}{ Rainfall date } & \multicolumn{2}{|c|}{ SEP 222008} & \multicolumn{2}{|c|}{ AUG 262009} & \multicolumn{2}{|c|}{ AUG 132010} & \multicolumn{2}{|c|}{ Aug 182012} & \multicolumn{3}{|c|}{ JUL 102013} & \multicolumn{3}{|c|}{ JUL 162017} & & JN 25 & 2018 \\
\hline
\end{tabular}

\subsubsection{Hazard scores}

The debris flow occurrences were analyzed together with the contributing factors and a hazard scoring system was created. The score values for each of the factors were calculated by average occurrence time and are shown in Table 6.3. For example, if catchments $A$ and $B$ belong to the same group characterized by the presence of a certain indicator (e.g. large landslides), their average occurrence time was calculated as $(1+3) / 2=2$ times per catchment. If catchments $C$ and $D$ belonged to another category (e.g. absence of a certain indicator like large landslides), their average occurrence time was $(0+2) / 2=1$ time per catchment. The hazard score of the presence of the indicator was calculated by subtracting the score for the absence class from the score of the presence class, which was $2-1=1$ in the example.

For the presence of large landslides, the calculation of the score was based on the absence and presence categories. The result showed that catchments with large landslides had an average 2.6 debris flow events and those without large landslide had 1.3. The final score was obtained by subtracting the occurrence 
rate of the absence category from the one of the presence categories, which resulted in a score of 1.3 (See Table 6.3).

The scores for stream blockages were analyzed taking into account the debris flow activity of the following years. For example, the score for a catchment with a new blockage in 2008 was related with debris flow activity in 2009. The resulting average occurrence rates for absence, partial and full blockage were $1,1.9$ and 3.2 , therefore the hazard scores were calculated as 0.9 for partial blockage $(1.9-1)$ and $2.2(3.2-1)$ for full blockage.

For quantitative factors (co-seismic landslide area, catchment area \& slope), a classification was carried out. Box plots were generated for catchments with varying numbers of time periods with debris flows $(0,1,2$, and 3 or more times) during the entire investigated period. The classification thresholds were determined by the maximum values in the box plot, excluding outliers. For the co-seismic landslide area, for example, the maximum values are $101,000 \mathrm{~m}^{2}$ (related to 0 debris flow occurrences), 439,000 m² (1 occurrence), 1,066,000 $\mathrm{m}^{2}$ ( 2 occurrences) and $5,050,000 \mathrm{~m}^{2}$ (for 3 or more debris flow occurrences) (See Figure 6.2). The average occurrence rate was calculated per class and the results were $1,1.6,1.8$ and 3.6. The hazard scores for the classes of co-seismic landslide area were $0.6(1.6-1)$ for the class of 101,000 to $439,000 \mathrm{~m}^{2}$ of coseismic landslide area per catchment, $0.8(1.8-1)$ for the class of 439,000 to $1,066,000 \mathrm{~m}^{2}$, and $2.6(3.6-1)$ for the largest co-seismic landslide area class $\left(>1,066,000 \mathrm{~m}^{2}\right)$.

A similar approach was carried out for the other quantitative factors (catchment area and slope steepness). The resulting hazard scores are shown in Table 6.3. 


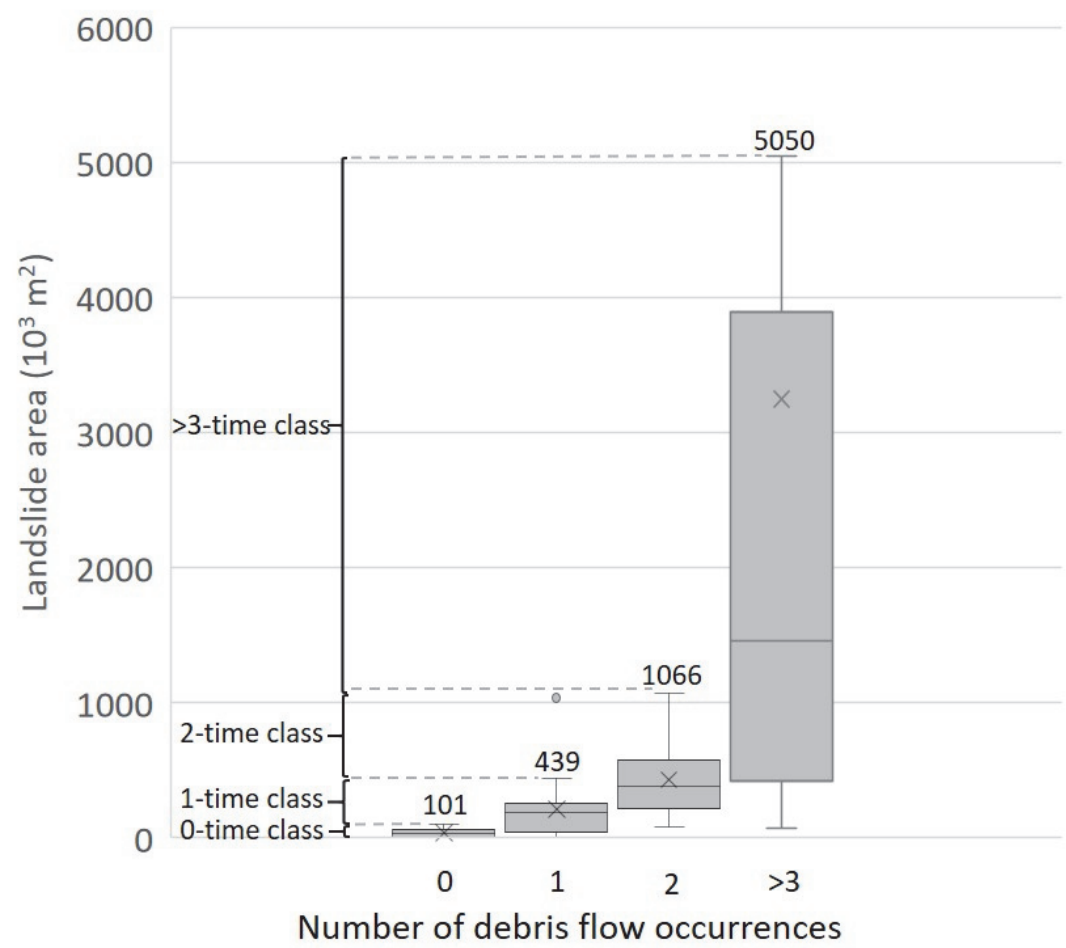

Figure 6.2: Example of classifying co-seismic landslide area per catchment according to the number of debris flow occurrences within the 7 time periods.

The following equation was used to combine the individual scores into an overall hazard score per catchment:

$$
\text { Hazard score }(S)=S_{a}+S_{s}+\left(\left(S_{C l s}+S_{b}+S_{L l p}\right) *\left(100 \%-V_{r}\right)\right) \quad \text { [Eq. 6.2] }
$$

Where $S_{a}$ is the catchment area score, $S_{s}$ is the catchment slope score, $S_{C l s}$ is the co-seismic landslide score, $S_{b}$ is the channel blockage score, $S_{L l p}$ is score for the presence of large co-seismic landslides. The addition of the last three scores gives an indication of the loose material availability in a catchment. The vegetation regrowth rate $\left(V_{r}\right)$ (See Equation 6.1) was subtracted from $100 \%$, to indicate the fraction of bare soil in a catchment and multiplied with the loosematerial-related factors in order to simulate dynamic hazard decay. If $\mathrm{Vr}$ reaches $100 \%$ (full regrowth), the loose-material score will be zero.

The hazard scores (S) for the 66 catchments are listed in Table 6.4. The related debris flow activation in the following period was marked in orange color. 
Table 6.3. Factor categories and scores used to generate the hazard scores for the 66 catchments.

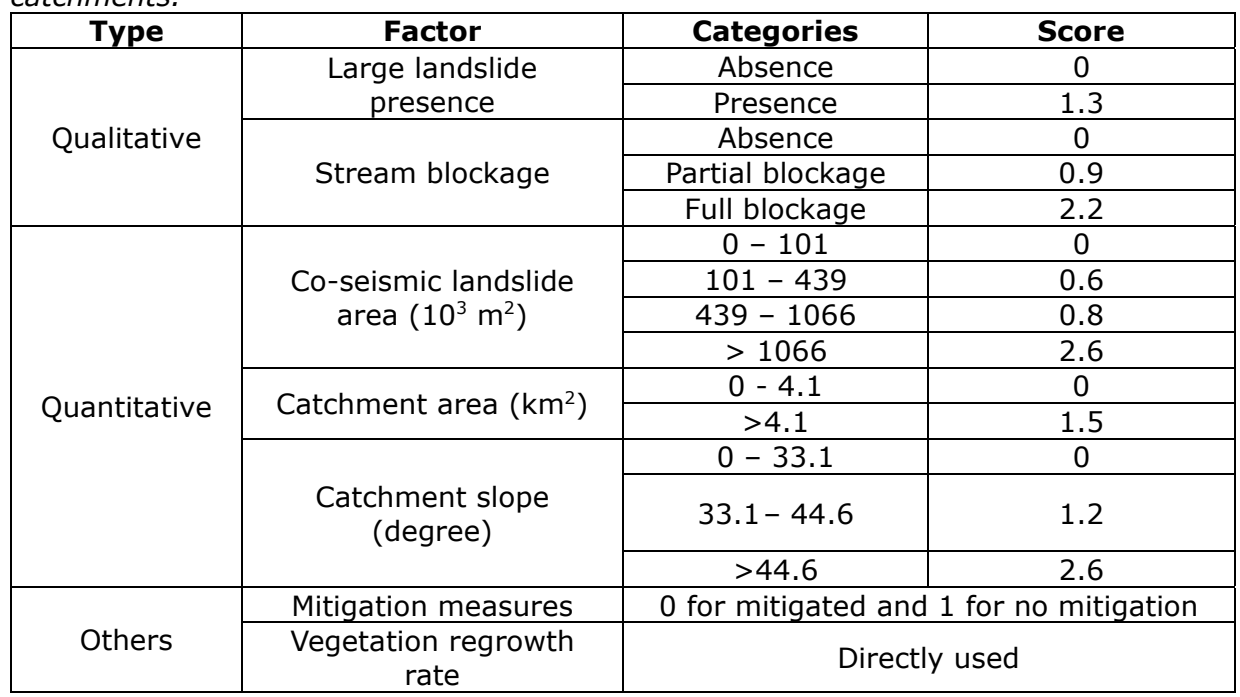

The highest score (10.2) was calculated for catchment ID 2 for the monsoon of 2010. The average hazard scores show a gradual decrease from 4.0 to 1.5 from 2008 to 2018. Catchment IDs 38 and 39 produced an abnormal situation, as they had debris flow activity in 2011 with a hazard score of zero in the previous period. This was caused by the fact that the rainfall event triggered new landslides instead of reactivating the co-seismic landslides. For such a situation the hazard scoring system is not applicable.

\subsubsection{Calculating indicative debris flow probability}

Indicative debris flow probability was analyzed based on the hazard scores and debris flow occurrence rates in groups that categorized by hazard score. The occurrence rate was calculated as the number of time periods with debris flows divided by total time periods (7). For a number of catchments belonging to the same group the average occurrence rate was calculated as the total number of time periods with debris flow activity in all catchments belonging to that group, divided by the number of catchments in that group multiplied by 7 (maximum number of time periods). For example, if catchment $A$ was active in one period, catchment $B$ was active in three periods, catchment $C$ had no activation, and catchment $D$ was active for two times, the occurrence rate is calculated as (1 $+3+0+2) /(4 * 7)$. Average hazard scores and debris flow occurrence rates were calculated for catchments in each score group, and the groups were categorized by a range of 1 and increment of 0.5 . 
Table 6.4. List of calculated hazard scores (S) and indicative debris flow occurrence probability $(P)$ for the 66 catchments. Cells with an orange color indicate that debris flows would occur in the next time period. Thick green outlines indicate catchments and periods where mitigation measures were installed.

\begin{tabular}{|c|c|c|c|c|c|c|c|c|c|c|c|c|c|c|}
\hline \multirow{3}{*}{ ID } & \multicolumn{14}{|c|}{ Time periods } \\
\hline & \multicolumn{2}{|c|}{$\begin{array}{c}\text { Monsoon } \\
2008\end{array}$} & \multicolumn{2}{|c|}{$\begin{array}{c}\text { Monsoon } \\
2009\end{array}$} & \multicolumn{2}{|c|}{$\begin{array}{c}\text { Monsoon } \\
2010\end{array}$} & \multicolumn{2}{|c|}{$\begin{array}{c}\text { Monsoons } \\
2011 \& 2012\end{array}$} & \multicolumn{2}{|c|}{$\begin{array}{c}\text { Monsoon } \\
2013 \& 2014\end{array}$} & \multicolumn{2}{|c|}{$\begin{array}{c}\text { Monsoons } \\
2015-2017\end{array}$} & \multicolumn{2}{|c|}{$\begin{array}{l}\text { Monsoons } \\
2018 \text { - ? }\end{array}$} \\
\hline & $S$ & $P$ & $S$ & $P$ & $S$ & $P$ & $S$ & $P$ & $S$ & $P$ & S & $P$ & $S$ & $P$ \\
\hline 1 & 8.8 & $81 \%$ & 8.5 & $79 \%$ & 8.0 & $75 \%$ & 7.5 & $71 \%$ & 5.9 & $58 \%$ & 3.4 & $38 \%$ & 3.3 & $37 \%$ \\
\hline 2 & 10.2 & $92 \%$ & 9.9 & $89 \%$ & 9.5 & $86 \%$ & 8.0 & $75 \%$ & 8.8 & $81 \%$ & 5.2 & $53 \%$ & 5.2 & $53 \%$ \\
\hline 3 & 5.3 & $54 \%$ & 5.0 & $51 \%$ & 3.7 & $40 \%$ & 2.4 & $28 \%$ & 1.7 & $21 \%$ & 1.5 & $19 \%$ & 1.6 & $20 \%$ \\
\hline 4 & 4.0 & $43 \%$ & 4.0 & $43 \%$ & 3.0 & $34 \%$ & 2.1 & $25 \%$ & 1.5 & $19 \%$ & 1.3 & $17 \%$ & 1.2 & $16 \%$ \\
\hline 5 & 8.7 & $81 \%$ & 8.7 & $81 \%$ & 7.5 & $71 \%$ & 6.3 & $62 \%$ & 5.6 & $56 \%$ & 3.6 & $39 \%$ & 3.4 & $38 \%$ \\
\hline 6 & 4.2 & $44 \%$ & 4.2 & $44 \%$ & 3.6 & $39 \%$ & 1.7 & $21 \%$ & 1.6 & $20 \%$ & 1.3 & $17 \%$ & 1.3 & $17 \%$ \\
\hline 7 & 5.5 & $55 \%$ & 5.2 & $53 \%$ & 4.1 & $43 \%$ & 2.4 & $28 \%$ & 2.3 & $27 \%$ & 1.9 & $23 \%$ & 1.8 & $22 \%$ \\
\hline 8 & 7.3 & $70 \%$ & 6.0 & $59 \%$ & 4.8 & $50 \%$ & 3.7 & $40 \%$ & 2.8 & $32 \%$ & 2.4 & $29 \%$ & 2.4 & $28 \%$ \\
\hline 9 & 4.0 & $43 \%$ & 3.9 & $42 \%$ & 2.9 & $33 \%$ & 1.9 & $24 \%$ & 1.6 & $20 \%$ & 1.3 & $17 \%$ & 1.3 & $17 \%$ \\
\hline 10 & 6.7 & $65 \%$ & 6.3 & $62 \%$ & 4.8 & $49 \%$ & 3.2 & $36 \%$ & 3.0 & $34 \%$ & 2.7 & $31 \%$ & 2.6 & $30 \%$ \\
\hline 11 & 4.2 & $44 \%$ & 4.0 & $43 \%$ & 3.1 & $34 \%$ & 1.7 & $21 \%$ & 1.5 & $19 \%$ & 1.5 & $19 \%$ & 1.4 & $18 \%$ \\
\hline 12 & 3.4 & $37 \%$ & 3.2 & $35 \%$ & 2.4 & $28 \%$ & 1.2 & $16 \%$ & 1.2 & $16 \%$ & 1.2 & $16 \%$ & 1.2 & $16 \%$ \\
\hline 13 & 5.4 & $55 \%$ & 5.3 & $54 \%$ & 4.6 & $48 \%$ & 3.3 & $36 \%$ & 3.2 & $35 \%$ & 2.8 & $32 \%$ & 2.8 & $31 \%$ \\
\hline 14 & 6.9 & $67 \%$ & 5.6 & $56 \%$ & 5.1 & $52 \%$ & 4.6 & $48 \%$ & 4.3 & $45 \%$ & 3.1 & $34 \%$ & 3.1 & $35 \%$ \\
\hline 15 & 4.2 & $44 \%$ & 3.9 & $42 \%$ & 4.0 & $42 \%$ & 4.0 & $43 \%$ & 3.7 & $40 \%$ & 1.4 & $18 \%$ & 1.4 & $18 \%$ \\
\hline 16 & 4.0 & $43 \%$ & 3.9 & $41 \%$ & 2.9 & $32 \%$ & 1.5 & $20 \%$ & 1.4 & $18 \%$ & 1.3 & $17 \%$ & 1.3 & $17 \%$ \\
\hline 17 & 4.2 & $44 \%$ & 4.2 & $44 \%$ & 3.2 & $35 \%$ & 1.7 & $22 \%$ & 1.5 & $19 \%$ & 1.4 & $0 \%$ & 1.3 & $0 \%$ \\
\hline 18 & 8.8 & $81 \%$ & 8.8 & $81 \%$ & 7.4 & $70 \%$ & 5.9 & $59 \%$ & 4.5 & $0 \%$ & 3.8 & $0 \%$ & 3.8 & $0 \%$ \\
\hline 19 & 8.8 & $81 \%$ & 7.0 & $68 \%$ & 6.1 & $60 \%$ & 5.1 & $52 \%$ & 5.2 & $53 \%$ & 3.4 & $37 \%$ & 3.4 & $37 \%$ \\
\hline 20 & 4.0 & $43 \%$ & 3.7 & $40 \%$ & 3.0 & $34 \%$ & 1.8 & $22 \%$ & 1.6 & $20 \%$ & 1.3 & $17 \%$ & 1.4 & $18 \%$ \\
\hline 21 & 5.5 & $55 \%$ & 5.1 & $52 \%$ & 4.7 & $49 \%$ & 3.0 & $34 \%$ & 3.2 & $36 \%$ & 2.7 & $31 \%$ & 2.8 & $32 \%$ \\
\hline 22 & 3.4 & $37 \%$ & 3.4 & $37 \%$ & 2.6 & $30 \%$ & 1.5 & $19 \%$ & 1.2 & $16 \%$ & 1.2 & $16 \%$ & 1.2 & $0 \%$ \\
\hline 23 & 4.0 & $43 \%$ & 2.6 & $0 \%$ & 2.2 & $0 \%$ & 1.7 & $0 \%$ & 1.7 & $0 \%$ & 1.2 & $0 \%$ & 1.4 & $0 \%$ \\
\hline 24 & 5.5 & $55 \%$ & 5.3 & $54 \%$ & 4.2 & $44 \%$ & 3.0 & $34 \%$ & 2.2 & $27 \%$ & 1.6 & $21 \%$ & 2.3 & $0 \%$ \\
\hline 25 & 5.5 & $55 \%$ & 5.1 & $52 \%$ & 3.9 & $42 \%$ & 2.8 & $32 \%$ & 2.4 & $29 \%$ & 2.1 & $25 \%$ & 2.2 & $0 \%$ \\
\hline 26 & 8.8 & $81 \%$ & 7.8 & $74 \%$ & 7.0 & $67 \%$ & 5.4 & $54 \%$ & 5.0 & $51 \%$ & 3.1 & $35 \%$ & 3.6 & $0 \%$ \\
\hline 27 & 4.0 & $43 \%$ & 3.3 & $36 \%$ & 2.7 & $31 \%$ & 1.4 & $18 \%$ & 1.3 & $0 \%$ & 1.2 & $0 \%$ & 1.2 & $0 \%$ \\
\hline 28 & 4.0 & $43 \%$ & 3.9 & $41 \%$ & 3.0 & $34 \%$ & 1.4 & $18 \%$ & 1.3 & $0 \%$ & 1.2 & $0 \%$ & 0.0 & $0 \%$ \\
\hline 29 & 5.3 & $54 \%$ & 5.0 & $51 \%$ & 3.9 & $42 \%$ & 2.8 & $32 \%$ & 1.8 & $0 \%$ & 1.6 & $0 \%$ & 1.5 & $0 \%$ \\
\hline 30 & 8.8 & $81 \%$ & 8.1 & $76 \%$ & 6.9 & $67 \%$ & 5.8 & $0 \%$ & 4.8 & $0 \%$ & 3.9 & $0 \%$ & 3.7 & $0 \%$ \\
\hline 31 & 1.8 & $22 \%$ & 1.6 & $20 \%$ & 1.4 & $18 \%$ & 1.2 & $16 \%$ & 1.2 & $16 \%$ & 1.2 & $16 \%$ & 1.2 & $16 \%$ \\
\hline 32 & 0.0 & $0 \%$ & 0.0 & $0 \%$ & 0.0 & $0 \%$ & 0.0 & $0 \%$ & 0.0 & $0 \%$ & 0.0 & $0 \%$ & 0.0 & $0 \%$ \\
\hline 33 & 4.2 & $44 \%$ & 4.0 & $43 \%$ & 4.0 & $43 \%$ & 2.9 & $33 \%$ & 1.9 & $23 \%$ & 1.4 & $18 \%$ & 1.4 & $18 \%$ \\
\hline 34 & 4.2 & $44 \%$ & 4.2 & $44 \%$ & 3.8 & $41 \%$ & 1.8 & $22 \%$ & 1.7 & $21 \%$ & 1.4 & $18 \%$ & 1.3 & $17 \%$ \\
\hline 35 & 4.0 & $43 \%$ & 4.0 & $43 \%$ & 3.6 & $39 \%$ & 2.3 & $27 \%$ & 1.9 & $23 \%$ & 1.7 & $21 \%$ & 1.5 & $19 \%$ \\
\hline 36 & 4.0 & $43 \%$ & 4.0 & $43 \%$ & 3.7 & $40 \%$ & 1.7 & $21 \%$ & 1.7 & $21 \%$ & 1.3 & $17 \%$ & 1.3 & $17 \%$ \\
\hline 37 & 1.8 & $22 \%$ & 1.8 & $22 \%$ & 1.8 & $22 \%$ & 1.7 & $22 \%$ & 1.5 & $19 \%$ & 1.3 & $17 \%$ & 1.2 & $16 \%$ \\
\hline 38 & 0.0 & $0 \%$ & 0.0 & $0 \%$ & 0.0 & $0 \%$ & 0.0 & $0 \%$ & 0.0 & $0 \%$ & 0.0 & $0 \%$ & 0.0 & $0 \%$ \\
\hline 39 & 0.0 & $0 \%$ & 0.0 & $0 \%$ & 0.0 & $0 \%$ & 0.0 & $0 \%$ & 0.0 & $0 \%$ & 0.0 & $0 \%$ & 0.0 & $0 \%$ \\
\hline 40 & 1.2 & $16 \%$ & 1.2 & $16 \%$ & 1.2 & $16 \%$ & 1.2 & $16 \%$ & 1.2 & $16 \%$ & 1.2 & $16 \%$ & 1.2 & $16 \%$ \\
\hline
\end{tabular}




\begin{tabular}{|c|c|c|c|c|c|c|c|c|c|c|c|c|c|c|}
\hline 41 & 3.4 & $37 \%$ & 3.0 & $34 \%$ & 2.5 & $29 \%$ & 1.2 & $16 \%$ & 1.2 & $16 \%$ & 1.2 & $16 \%$ & 1.2 & $16 \%$ \\
\hline 42 & 1.2 & $16 \%$ & 1.2 & $16 \%$ & 1.2 & $16 \%$ & 1.2 & $16 \%$ & 1.2 & $16 \%$ & 1.2 & $16 \%$ & 0.0 & $0 \%$ \\
\hline 43 & 1.8 & $22 \%$ & 1.7 & $21 \%$ & 1.5 & $19 \%$ & 1.4 & $18 \%$ & 1.3 & $17 \%$ & 1.3 & $17 \%$ & 1.2 & $16 \%$ \\
\hline 44 & 3.4 & $37 \%$ & 3.4 & $37 \%$ & 2.9 & $33 \%$ & 1.2 & $16 \%$ & 1.2 & $0 \%$ & 1.2 & $0 \%$ & 1.2 & $0 \%$ \\
\hline 45 & 5.3 & $54 \%$ & 5.3 & $54 \%$ & 4.0 & $43 \%$ & 2.3 & $27 \%$ & 2.0 & $0 \%$ & 1.9 & $0 \%$ & 1.6 & $0 \%$ \\
\hline 46 & 4.0 & $43 \%$ & 4.0 & $43 \%$ & 3.5 & $38 \%$ & 1.6 & $20 \%$ & 1.4 & $0 \%$ & 1.3 & $0 \%$ & 1.2 & $0 \%$ \\
\hline 47 & 1.2 & $16 \%$ & 1.2 & $16 \%$ & 1.2 & $16 \%$ & 1.2 & $16 \%$ & 1.2 & $16 \%$ & 1.2 & $16 \%$ & 0.0 & $0 \%$ \\
\hline 48 & 1.2 & $16 \%$ & 1.2 & $16 \%$ & 1.2 & $16 \%$ & 1.2 & $16 \%$ & 1.2 & $16 \%$ & 1.2 & $0 \%$ & 0.0 & $0 \%$ \\
\hline 49 & 1.2 & $16 \%$ & 1.2 & $16 \%$ & 1.2 & $16 \%$ & 1.2 & $16 \%$ & 1.2 & $16 \%$ & 1.2 & $0 \%$ & 1.2 & $0 \%$ \\
\hline 50 & 0.0 & $0 \%$ & 0.0 & $0 \%$ & 0.0 & $0 \%$ & 0.0 & $0 \%$ & 0.0 & $0 \%$ & 0.0 & $0 \%$ & 0.0 & $0 \%$ \\
\hline 51 & 1.2 & $16 \%$ & 1.2 & $16 \%$ & 1.2 & $16 \%$ & 1.2 & $16 \%$ & 1.2 & $16 \%$ & 1.2 & $16 \%$ & 1.2 & $16 \%$ \\
\hline 52 & 8.8 & $81 \%$ & 8.8 & $81 \%$ & 8.5 & $79 \%$ & 7.1 & $68 \%$ & 3.6 & $39 \%$ & 3.4 & $37 \%$ & 3.4 & $38 \%$ \\
\hline 53 & 0.0 & $0 \%$ & 0.0 & $0 \%$ & 0.0 & $0 \%$ & 0.0 & $0 \%$ & 0.0 & $0 \%$ & 0.0 & $0 \%$ & 0.0 & $0 \%$ \\
\hline 54 & 4.0 & $43 \%$ & 2.6 & $30 \%$ & 2.6 & $30 \%$ & 1.8 & $22 \%$ & 1.6 & $20 \%$ & 1.4 & $18 \%$ & 1.3 & $17 \%$ \\
\hline 55 & 3.4 & $37 \%$ & 3.2 & $36 \%$ & 3.2 & $36 \%$ & 1.2 & $16 \%$ & 1.2 & $16 \%$ & 1.2 & $16 \%$ & 1.2 & $16 \%$ \\
\hline 56 & 4.0 & $43 \%$ & 3.6 & $39 \%$ & 3.7 & $40 \%$ & 1.7 & $22 \%$ & 1.5 & $19 \%$ & 1.2 & $16 \%$ & 1.2 & $16 \%$ \\
\hline 57 & 3.4 & $37 \%$ & 3.0 & $34 \%$ & 2.8 & $32 \%$ & 1.2 & $16 \%$ & 1.2 & $16 \%$ & 1.2 & $16 \%$ & 1.2 & $16 \%$ \\
\hline 58 & 3.4 & $37 \%$ & 3.2 & $35 \%$ & 2.7 & $31 \%$ & 1.6 & $20 \%$ & 1.4 & $18 \%$ & 1.2 & $16 \%$ & 1.2 & $16 \%$ \\
\hline 59 & 3.4 & $37 \%$ & 2.7 & $31 \%$ & 2.3 & $27 \%$ & 1.2 & $16 \%$ & 1.5 & $19 \%$ & 1.2 & $16 \%$ & 0.0 & $0 \%$ \\
\hline 60 & 3.4 & $37 \%$ & 3.0 & $34 \%$ & 2.7 & $31 \%$ & 1.2 & $16 \%$ & 1.2 & $16 \%$ & 1.2 & $16 \%$ & 1.2 & $16 \%$ \\
\hline 61 & 4.2 & $44 \%$ & 3.7 & $40 \%$ & 3.2 & $36 \%$ & 2.7 & $31 \%$ & 1.5 & $19 \%$ & 1.4 & $18 \%$ & 1.3 & $17 \%$ \\
\hline 62 & 2.2 & $26 \%$ & 2.2 & $26 \%$ & 1.2 & $16 \%$ & 0.1 & $1 \%$ & 0.0 & $1 \%$ & 0.0 & $1 \%$ & 0.0 & $0 \%$ \\
\hline 63 & 2.2 & $26 \%$ & 2.2 & $26 \%$ & 1.7 & $21 \%$ & 0.5 & $8 \%$ & 0.1 & $2 \%$ & 0.2 & $4 \%$ & 0.1 & $2 \%$ \\
\hline 64 & 3.4 & $37 \%$ & 2.9 & $33 \%$ & 2.4 & $28 \%$ & 1.2 & $16 \%$ & 1.2 & $16 \%$ & 1.2 & $16 \%$ & 1.2 & $16 \%$ \\
\hline 65 & 1.8 & $22 \%$ & 1.8 & $22 \%$ & 1.6 & $20 \%$ & 1.5 & $19 \%$ & 1.5 & $19 \%$ & 1.3 & $17 \%$ & 1.2 & $16 \%$ \\
\hline 66 & 0.0 & $0 \%$ & 0.0 & $0 \%$ & 0.0 & $0 \%$ & 0.0 & $0 \%$ & 0.0 & $0 \%$ & 0.0 & $0 \%$ & 0.0 & $0 \%$ \\
\hline AVG & 4.0 & $41 \%$ & 3.8 & $39 \%$ & 3.2 & $34 \%$ & 2.2 & $24 \%$ & 2.0 & $19 \%$ & 1.6 & $15 \%$ & 1.5 & $13 \%$ \\
\hline
\end{tabular}

For example, group one has a range of hazard score $0-1,0.5-1.5$ for group two, $1-2$ for group three, $1.5-2.5$ for group four, till the upper limit reaches the maximum score. A scatter plot was made (Figure $6.3 \mathrm{~A}$ ). Several trend lines were analyzed (linear, polynomial. logarithmic, exponential), of which a power trend line had the highest $\mathrm{R}$ square. The equation to covert hazard scores $(\mathrm{S})$ to occurrence probability $(P)$ is:

$$
P=\left(1-S_{m}\right) * 0.1377 * S^{0.8163} * 100 \% \quad(0 \leq P \leq 1)
$$

Where $S_{m}$ refers to the presence of mitigation measures $(1=$ present, and $0=$ absent), which reduces the probability to zero if mitigation measures are protecting a catchment from debris flows. $S$ is the hazard score (See Table 6.4). The occurrence rate $(P)$ was used for each time period as an indication of the likelihood of debris flows in the following monsoon(s), given a normal rainfall situation. The probability cannot represent situations with very high or low precipitation. The average calculated rate was compared to the actual occurrence rate, which was calculated per period. The occurrence rates were plotted with maximum rain intensity, as shown in Figure $6.3 \mathrm{~B}$. It can be seen that the calculated occurrence rate was $25 \%$ higher than the actual rate in 
2008 monsoon, which had a maximum rain intensity of $31 \mathrm{~mm} / \mathrm{h}$ and a low cumulative rainfall $(94.7 \mathrm{~mm})$. Relatively accurate calculated rates were observed for the monsoon of 2011 to 2017 , with a difference of $3 \%-7 \%$ with the actual rate. The monsoon of 2010 showed the largest difference, with the actual rate $55 \%$ higher than the calculated rate because of a maximum intensity of $75 \mathrm{~mm} / \mathrm{h}$. This rain event was determined to have a 100 -years return period (Li et al., 2011; Yang, 2010).
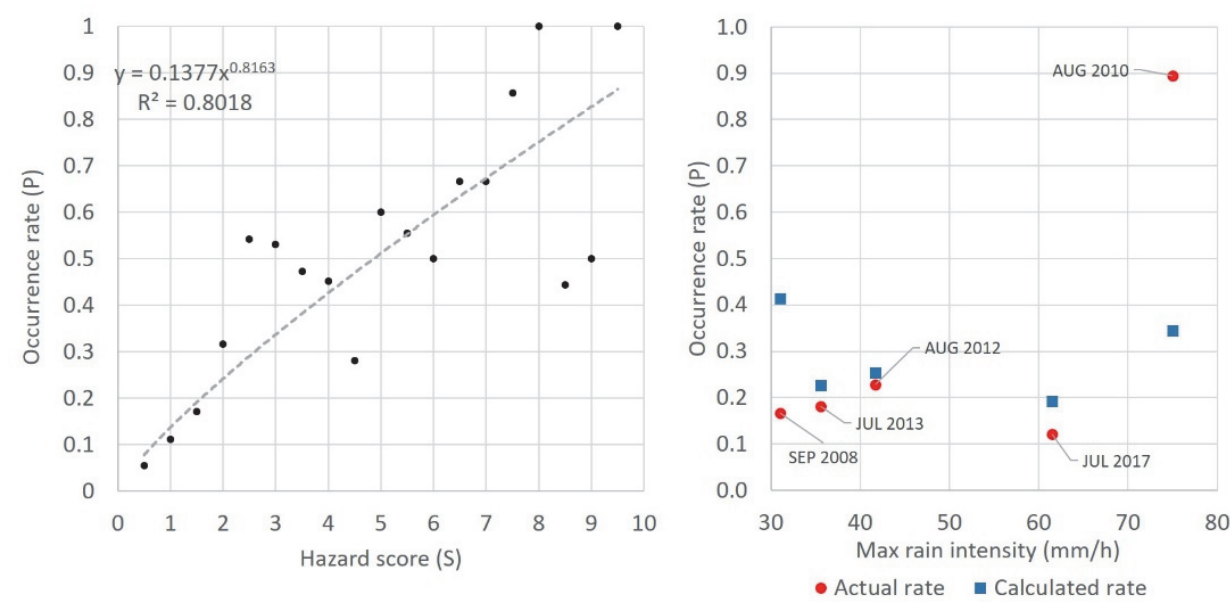

Figure 6.3: A: Scatter plot of the relation between debris flow occurrence rate $(P)$ and hazard score (S). B: Difference in actual occurrence rate and calculated occurrence rate of monsoons of 2008, 2010, 2011, 2013 and 2015 plotted with maximum rainfall intensity

The debris flow occurrence rate $(P)$ can be displayed per catchment for each of the investigated time periods (Figure 6.4). It can be seen that the overall probability was very high in 2008 and 2009, as many catchments experienced stream blockages which were not breached and vegetation regrowth rate was low. After the debris flows in 2010, the probability decayed fast due to a rapid vegetation regrowth and construction of mitigation measures. In 2018, the probability in 26 watersheds had reduced to 0 , because of fully recovered vegetation (10) and mitigation measures (16). The average probability decayed from $41 \%$ in 2008 to $13 \%$ in 2018 (Table 6.4). 


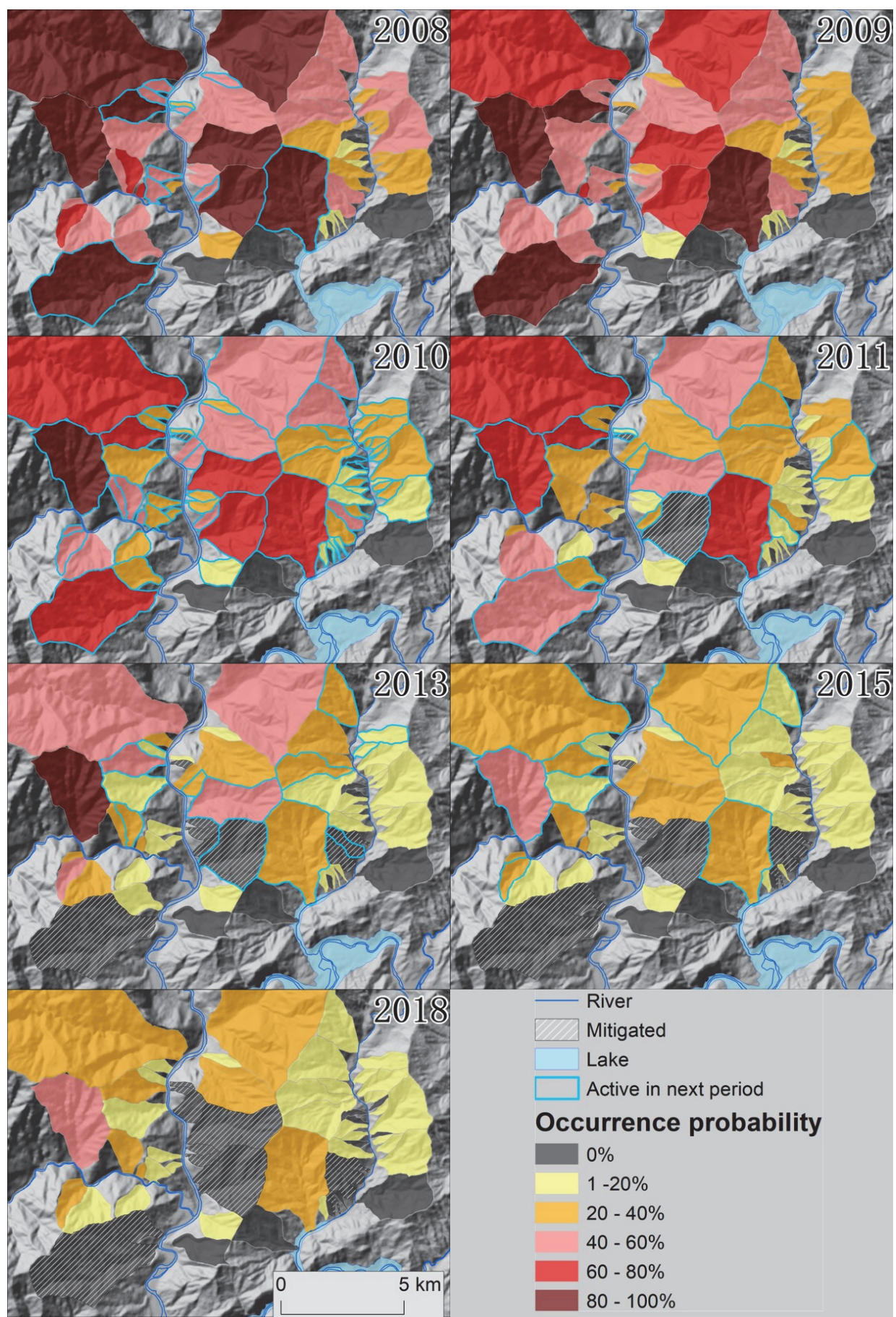

Figure 6.4: Debris flow hazard maps for the seven investigated time periods. 


\subsection{Estimating exposed economic value}

Exposed elements-at-Risk were mapped within the 66 watersheds for the 7 time periods. Exposure was analyzed for those elements-at-risk (EaR) within the reach of debris flows in the 66 investigated watersheds. In the Longchi area the exposure maps were already presented in Chapter 5, except for the year 2009. Therefore also an exposure map was made for 2009 based on the two SPOT 5 images and the inventories from Chapter 5. For the area of Yingxiu, the elements-at-risk before the reconstruction (2008 - 2009) were mapped based on an aerial photograph from 2008 and two SPOT images from 2009, and supported by field investigations. An official map containing buildings and roads was available for 2010 , which was overlaid with the debris-flow-affected zones to extract the exposed EaR. The exposure maps of 2011 and 2013 were modified from the exposure map of 2010 based on the interpretation of satellite images and information gathered in the field. The exposure of 2015 and 2018 was mapped using the same approach with the official map of 2014 as the basis.

The replacement costs of built-up features were investigated mostly by interviews with local residences and government office staffs, and later checked with the data of the study of Zhao and Liu (2005) and the losses mentioned in official reports. The price of sand mining equipment was collected from online sources. The prices were converted into US dollar (USD) with a recent 10-years average exchange rate, which is 1 USD $=6.51$ Chinese Yuan. The unit prices are listed in Table 6.5. For buildings, the economic value was estimated by multiplying polygon area, number of floors and unit price. For roads the width was measured in the images and official road maps, and the value was estimated by multiplying length, width, and unit price.

Table 6.5. Unit price of built-up features. The exchange rate was based on the 10 years average of 1 USD $=6.51$ Chinese Yuan.

\begin{tabular}{|c|c|c|}
\hline Type & \multicolumn{2}{|c|}{ Value } \\
\hline Construction type & $\begin{array}{c}\text { Unit price before } 2008 \\
\text { (USD / } \mathrm{m}^{2} \text { ) }\end{array}$ & $\begin{array}{c}\text { Unit price } 2008-2012 \\
\left(\text { USD } / \mathrm{m}^{2} \text { ) }\right.\end{array}$ \\
\hline RC frame structure & 217 & 415 \\
\hline Reinforced masonry & 144 & 200 \\
\hline Wood \& brick & 54 & 77 \\
\hline Wooden & 27 & 46 \\
\hline Pre-fabricated metal houses & - & 154 \\
\hline Tents \& shacks & - & 6 \\
\hline \multicolumn{3}{|c|}{ Road USD / $\mathrm{m}^{2}$ (2017) } \\
\hline Major road & \multicolumn{2}{|c|}{34.5} \\
\hline Secondary road & \multicolumn{2}{|c|}{7.7} \\
\hline Bridge & \multicolumn{2}{|c|}{184.3} \\
\hline Highway & \multicolumn{2}{|c|}{307.2} \\
\hline Highway bridge & \multicolumn{2}{|c|}{1228.9} \\
\hline \multicolumn{3}{|c|}{ Others } \\
\hline Sand mining equipment & \multicolumn{2}{|c|}{46082.9 / set } \\
\hline
\end{tabular}


For sand mining equipment, the value was estimated per set. Mitigation structures were not included in the economic value estimation, because it was not possible to obtain data for these.

\subsubsection{Quantifying value of exposure}

The total economic value of the EaR in the areas that can be affected by debris flows in the watersheds is shown in Figure 6.5. In June 2008 most of the preearthquake structures were destroyed. The exposed EaR were mainly temporary shelters and their total exposed economic value was only 3.0 million USD (Figure 6.7). By May 2009 the economic value of the exposed EaR increased to 8.3 million USD as more shelters were set up, roads were repaired, and reconstruction started. The economic value of the exposed EaR in the premonsoon period of 2010 was estimated based on the building maps from NASG, the image of 2011 and field investigations. The total value of the exposed EaR drastically increased to 26.2 million USD due to the nearly finished reconstruction of the settlements. The August 2010 debris flows caused huge losses of 21 million USD, which resulted in a large decrease in the exposure value in April 2011 despite of repaired road and replaced buildings. In April 2013 the reconstruction of the settlements and the highway were completed, raising the total value of the exposed EaR to 33.2 million USD. In the same time many mitigation structures were installed, protecting 12.5 million worth of properties. After that more mitigations were installed in 2015 and 2018, lowering the unprotected exposure to 18 and 17 million USD respectively, with a similar total EaR (33.4 and 33.9 million) value as 2013.

\subsubsection{Debris flow potential loss estimation}

Indicative debris flow losses were estimated by multiplying the hazard probability and the value of the exposed EaR. Due to data limitations, the indirect losses, which are caused by disruption of transportation lines and by river damming, could not be analyzed. The estimation was in the form of possible direct losses $(L)$, as we could not determine the vulnerability of the EaR nor the intensity of the debris flows, or their magnitude/frequency relation using the current dataset. The loss maps for the different years are shown in Figure 6.6 and the related statistics are shown in Figure 6.7. 


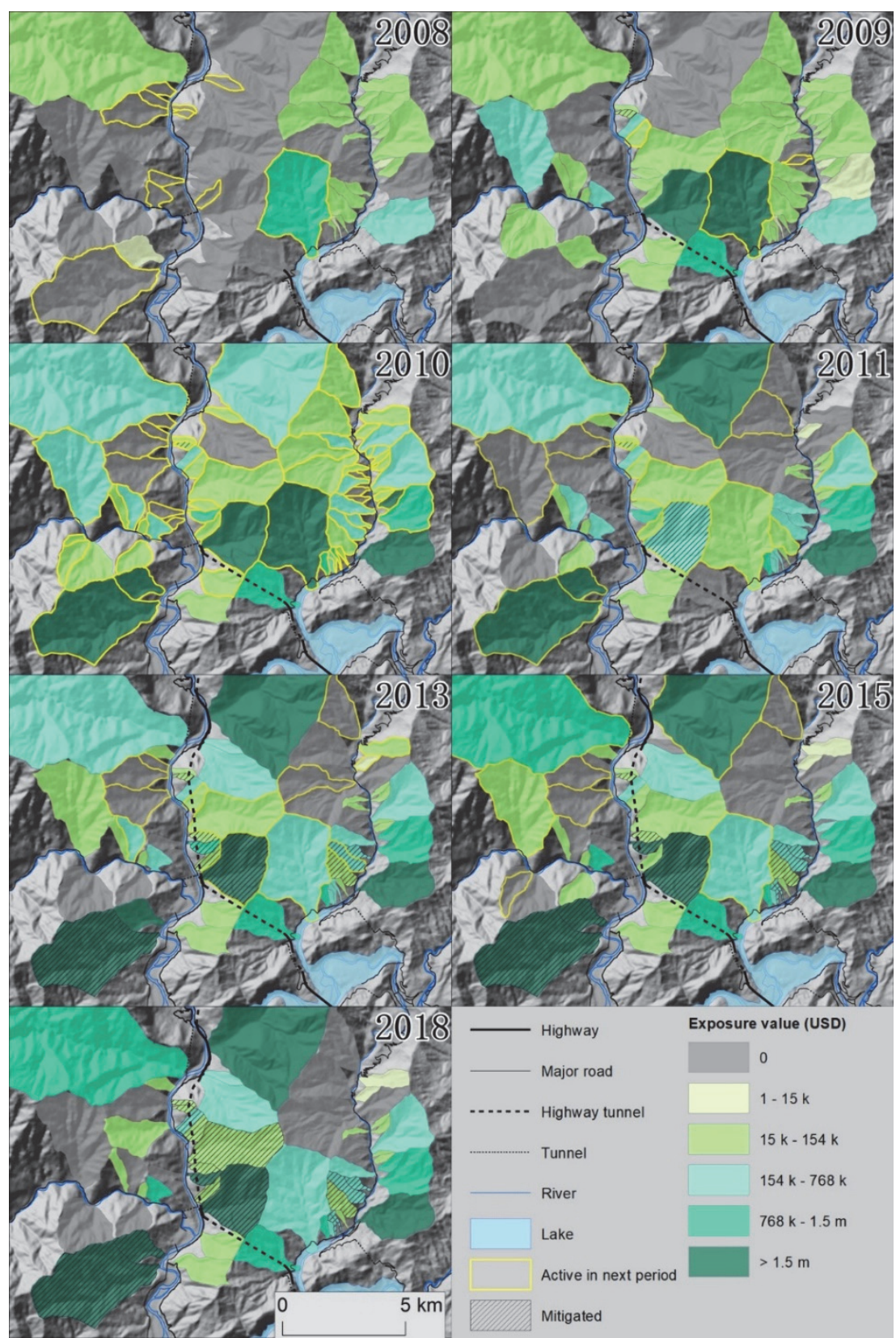

Figure 6.5: Economic value of the exposed elements-at-risk per catchment over the 10year period since the Wenchuan earthquake. $k=1000, m=1$ million USD. The classification is based on the official hazard damage classification standard (Chengdu Municipal People's Government, 2014) 
Although the probability of debris flow occurrence was at its maximum in 2008, the overall $L$ was low (1.6 million USD) as most of the EaR had been destroyed by the earthquake, and the existing exposures were limited to temporary shelters. Many watersheds did not show any significant expected losses as most pre-earthquake structures were destroyed. One temporary settlement was located at the outlet of a catchment, resulting that its $L$ reached 1.4 million, which accounted for most the expected losses of that year. The total $L$ raised to 4.5 million USD in May 2009. With roads repaired, in many of the catchments the $L$ started to increase. A new highway connecting the town of Yingxiu with Dujianyan and Wenchuan, which included several tunnels and bridges, raising the $L$ of one of the catchments (ID 30, see Table 6.4.) it crossed by 1.9 million USD. In 2010 many new buildings were constructed, and sand digging sites for co-seismic landslide materials were set up in several watersheds. The $L$ was more than twice as high as in 2009, reaching 10 million USD. This was the highest $L$ value in the entire series. The most catastrophic debris flow event occurred in August 2010, leading to about 21 million USD losses as 59 catchments produced debris flows. Six months later in April 2011, roads were repaired, and many structures at catchment outlets were abandoned or relocated. Mitigation works that were installed in one more catchment, lowered the $L$ by 0.4 million. The debris flow losses caused a 4.5 million decrease of $L$. In April 2013 the $L$ increased to 12 million USD because of the completed reconstruction and the highway completion. As varies mitigation works were installed in 2011 and 2012, the $L$ was lowered to 6.2 million. From 2013 to 2018, the exposure value kept decreasing and $L$ gradually decreased to 4.1 million, primarily due to the decreasing hazard brought by vegetation regrowth. Mitigation works were made in four more watersheds to protect roads.

The overall trend of $L$ in the early post-seismic stage (2008 - 2010) was dominated by reconstruction activities. After being hit by a series of catastrophic debris flows in 2010, mitigation works were the major reason of risk reduction in the period between 2011 and 2013. $L$ decreased gradually in the late post-seismic stage due to vegetation growth and the decrease in debris flow activities, which were signs of recovery of the environment (Figure 6.7). In 2018 the potential debris flow loss was 4.1 million USD. This value will continue to decrease as the environment recovers. 


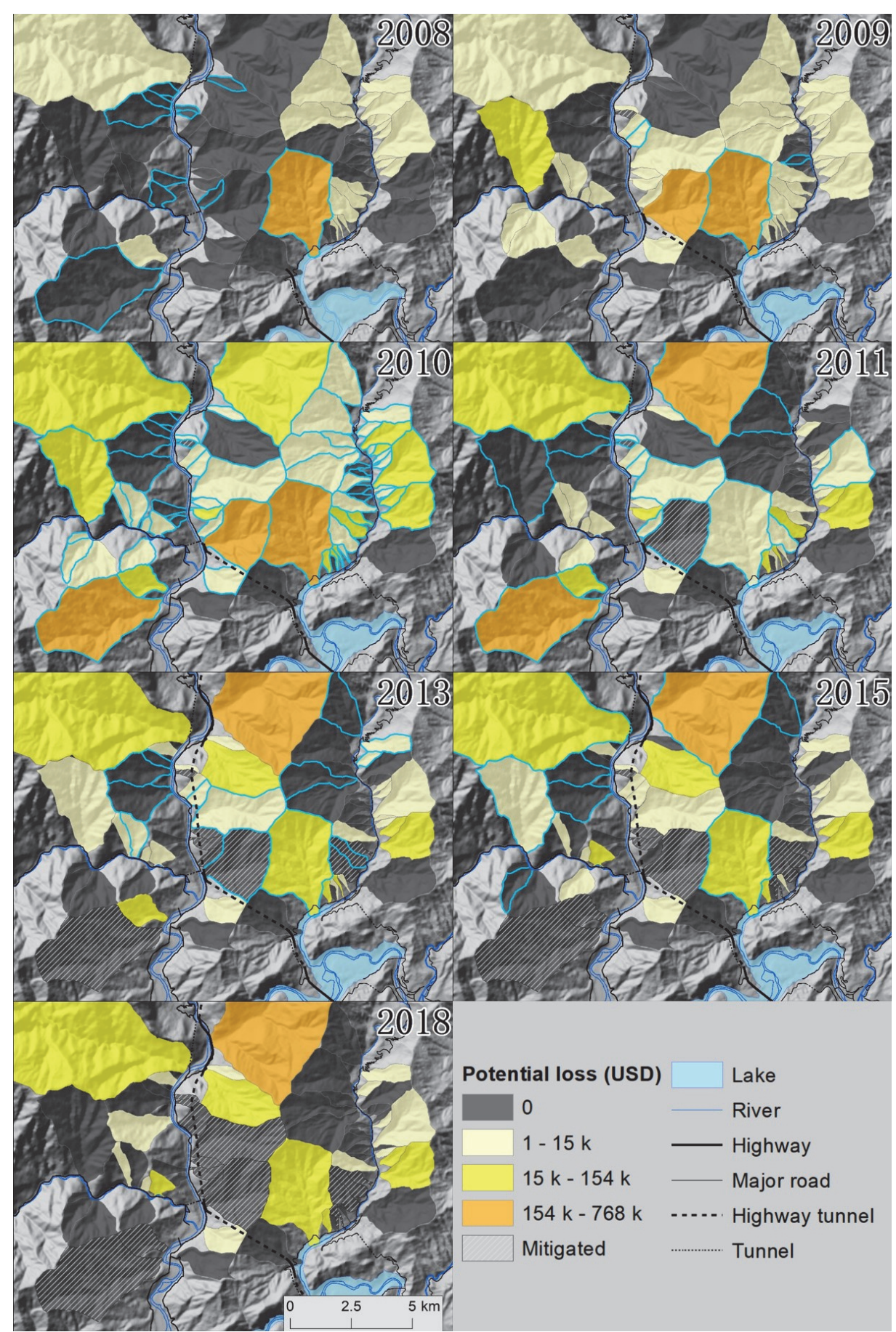

Figure 6.6: Potential debris flow loss per catchment for different time periods. 


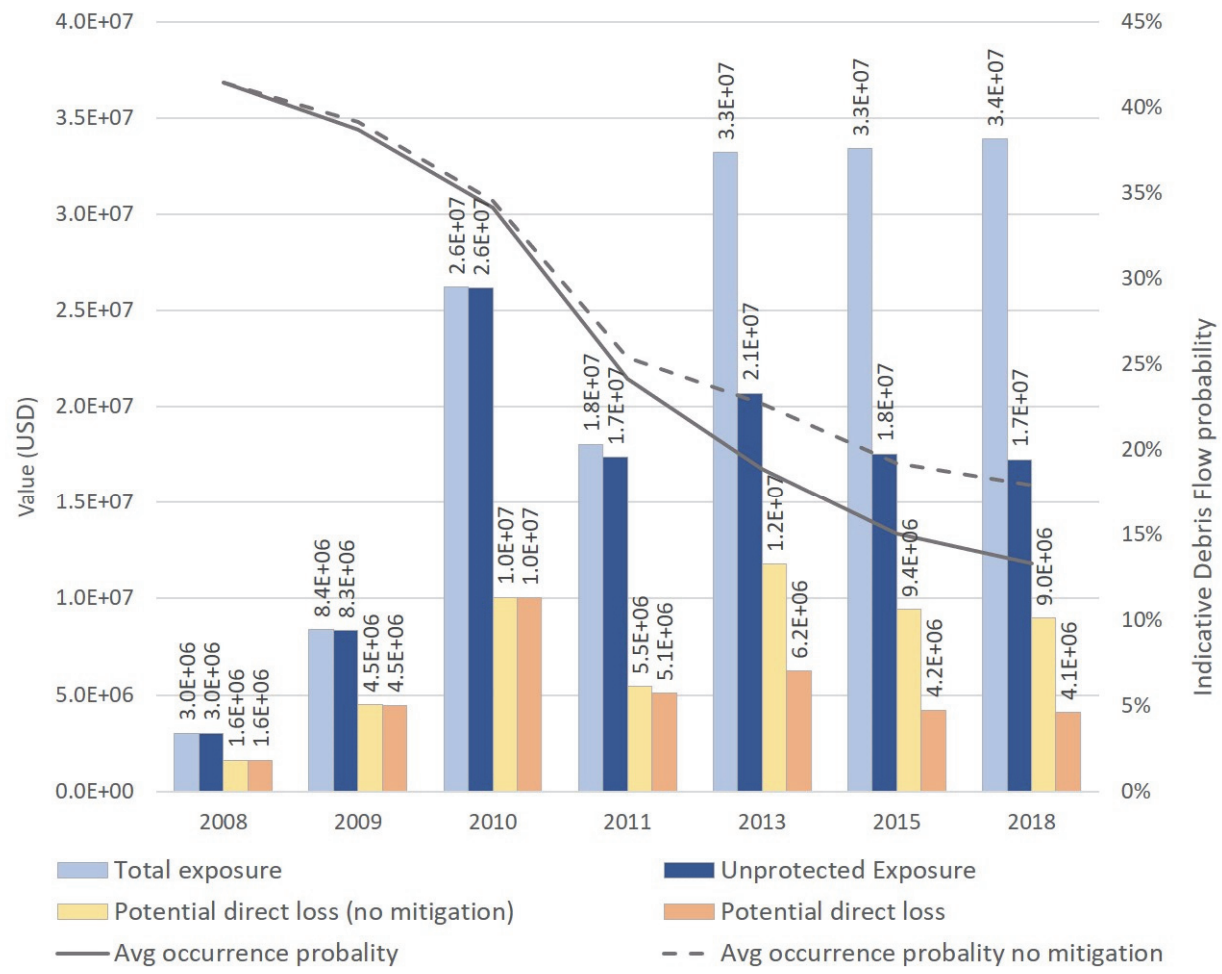

Figure 6.7: Overview of overall changes in exposed economic values, potential direct losses with and without mitigation, and average debris flow probability over the 66 investigated watersheds for a 10 years period following the 2008 earthquake.

\subsection{Discussion and conclusions}

A catchment-based multi-temporal (semi)quantitative debris flow risk analysis was carried out. The results show that the risk increased rapidly in the first three years after the 2008 earthquake due to the ongoing reconstruction, then decreased suddenly due to the impact of the 2010 debris flows that affected 59 of the 66 investigated watersheds (Table 6.3). After that the society adapted by relocating buildings and installing mitigation works. In the later years the risk decreased gradually due to the recovery of the environment, and further protection works. The region showed a low disaster awareness before the catastrophic debris flows of 2010, then quickly learned and adapted. As the previous chapter showed, the value of element-at-risk was raised several times more than in the pre-earthquake stage. Clearly a successful risk management after a large earthquake must involve careful construction planning. Choosing safe places to build to lower the exposure is theoretically one of the most effective ways to control risk. However, in mountainous regions such places are limited, posing great challenges to recovery planning. 
Estimating risk in a changing environment poses many challenges. The major limitations of this study were related to the unknown hazard factor, in terms of intensity/frequency changes for debris flows per watershed and per year. The approach followed, using hazard scores is a simplification, and is not suitable for catchments that have unique situations. For example, small catchments with almost no co-seismic landslides produced debris flows from rainfall triggered slope failures. Another exemption was that debris flows did not reach the outlet of very large catchments, or that landslide dams were too strong to be breached. Since these situations are difficult to describe by only remote sensing analysis, our method will have a large uncertainty when applied to individual watersheds. Another limitation in the risk calculation was the assumption that the installed mitigation works would reduce the debris flow hazard completely, which was not always the case, as in some watersheds the mitigation works were under designed and subsequently destroyed by debris flows (See Figure $5.10 \mathrm{C}$ ). The damage of the mitigation works themselves was not considered as well, as this would require much more data to analyze, which was not realistic for this study.

In conclusion, the study showed how risk components can vary over time in a dynamic environment, and the importance to update hazard and risk maps frequently under such circumstances. It is necessary to use up-to-date data and hazard and risk assessments in urban and rural planning, before carrying out reconstruction work after large earthquakes. 


\section{Synthesis}

\subsection{Summary and discussion}

Large earthquakes damage societies in mountainous regions by intensive ground shaking and triggering co-seismic landslides, resulting in loss of vegetation, weakened hillslopes, and large volumes of co-seismic loose debris, raising the susceptibility of rainfall induced landslides drastically for a prolonged period. Huge losses caused by post-seismic landslides were witnessed after the 1999 Chi-chi earthquake ( $M_{w}$ 7.7) and the 2008 Wenchuan earthquake $\left(M_{w}\right.$ 7.9), as the hazard frequency and magnitude were underestimated. Clearly there is a lack of knowledge on post-seismic hazard and risk dynamics to assist reconstruction planning. This thesis provided a contribution to a better understanding of the topic and its findings are summarized and discussed in this section.

\subsubsection{Post-seismic landslide hazard}

We analyzed changes in landslide activity in a period of seven years after the 2008 Wenchuan earthquake, with five multi-temporal landslide inventories, which we interpreted stereoscopically from high resolution images, followed by field investigation. The results show that most of the post-seismic landslide activities were concentrated within the first three years following the earthquake. The landslide activity decreased considerably from May 2008 until April 2015, from 6727 coseismic landslides to 66 active landslides in 2015. After the 2010 monsoon season, the activity of the post-earthquake landslides dropped considerably and most of the active landslides became dormant. Of the total of 6727 co-seismic landslides, 2221 had one or more phases of reactivation. Apart from the reactivation of co-seismic landslides also 660 new landslides occurred after 2008. This indicates that the landslide activity in the post-earthquake period was not restricted to the co-seismic landslide area only. This is important to consider when making post-earthquake reconstruction planning in other mountainous environments. The pattern of active landslides changes constantly over time. It is not possible to predict after the earthquake which landslides will remain active over the next decade, as this pattern changes constantly, most probably related to the specific variation of rainfall intensity during rainstorms in the postearthquake period.

We collected nine DEMs with different resolutions and from different sources, which were generated in different years, and covered different parts of the study area, in order to analyze the dynamics in landslide material volume. We were only able to estimate the gain from the co-seismic landslides, which was 
an underestimation of the actual landslide volume due to the hidden failure surfaces. However this gain value is still very useful to predict the magnitude of the following debris flows as most of the erosion would take place in channels, where the landslide depth is measured correctly by DEM comparison. In the Wenchuan area the volumetric analysis was not carried out immediately after the earthquake, and this could be the reason that the government underestimated the threat before the debris flow disasters in 2010. The data security policy might be one of the reasons as the LiDAR data was collected by the government but not accessible to the specialists at that time.

Many studies agree that landslide and debris flow activity is high in the first few post-earthquake years and then decays rapidly (Fan et al., 2018a; Hovius et al., 2011; Nakamura et al., 1999; Shieh et al., 2009b; Shou et al., 2011a; Tang et al., 2016). Landslide activity often increases and reaches a peak several years after the earthquake before it starts to decline. This can be observed from several earthquakes. After the 1923 Kanto earthquake ( $\left.M_{w} 7.9\right)$, the peak was reached in 1929. However, this was due to a combined effect of the following Sagami earthquake ( $M_{\mathrm{w}}$ 7.3) and several typhoons (Figure 1.2). For the Chi-chi earthquake the peak was triggered by Typhoon Toraji two years after the earthquake, which created more landslides than the earthquake (Figure 1.3). The peak of post-earthquake landslide activity for the 2008 Wenchuan earthquake was reached in 2010 in the majority of the catchments and in 2013 for the northern Wenchuan county. The occurrence of these peaks was largely depending on the variation in precipitation and the source materials for post-seismic landslides and debris flows. For the Kanto earthquake and the Chi-chi earthquake, the source materials consisted mostly of the soil mantle hanging on the slopes, which was loosened by the ground shaking, and the post-seismic landslides were much more than the earthquake induced landslides. For the Wenchuan earthquake it was the massive amount of coseismic debris deposited in streams, which resulted in catastrophic debris flows.

Figure 7.1 (A) was made to show the changes in active landslides and vegetation. In comparison with the conceptual figure (Figure 1.1), the trend of active landslides matches well, as the number of landslides triggered by the Wenchuan earthquake was much more than in the pre-earthquake situation. The active landslides decreased to 967 (Table 2.6) due to a low precipitation (Table 6.2) of the monsoons of 2008 and 2009. The peak of post-seismic landslide activities occurred in the monsoon of 2010 with 2617 active landslides, then decreased at a fast rate, ranging from 66 to 173 landslides for the monsoons of 2011 to 2017 . The earthquake caused $36 \%$ reduction in vegetation cover in this region. A fast regrowth was observed from 2008 to 2013 , raising vegetation cover rate to $84 \%$ and the growth rate slowed down from 2013 to 2018 , with only $5 \%$ increase. The vegetation reduction due to 
landslides cannot be observed in the figure because of the coarse temporal resolution.
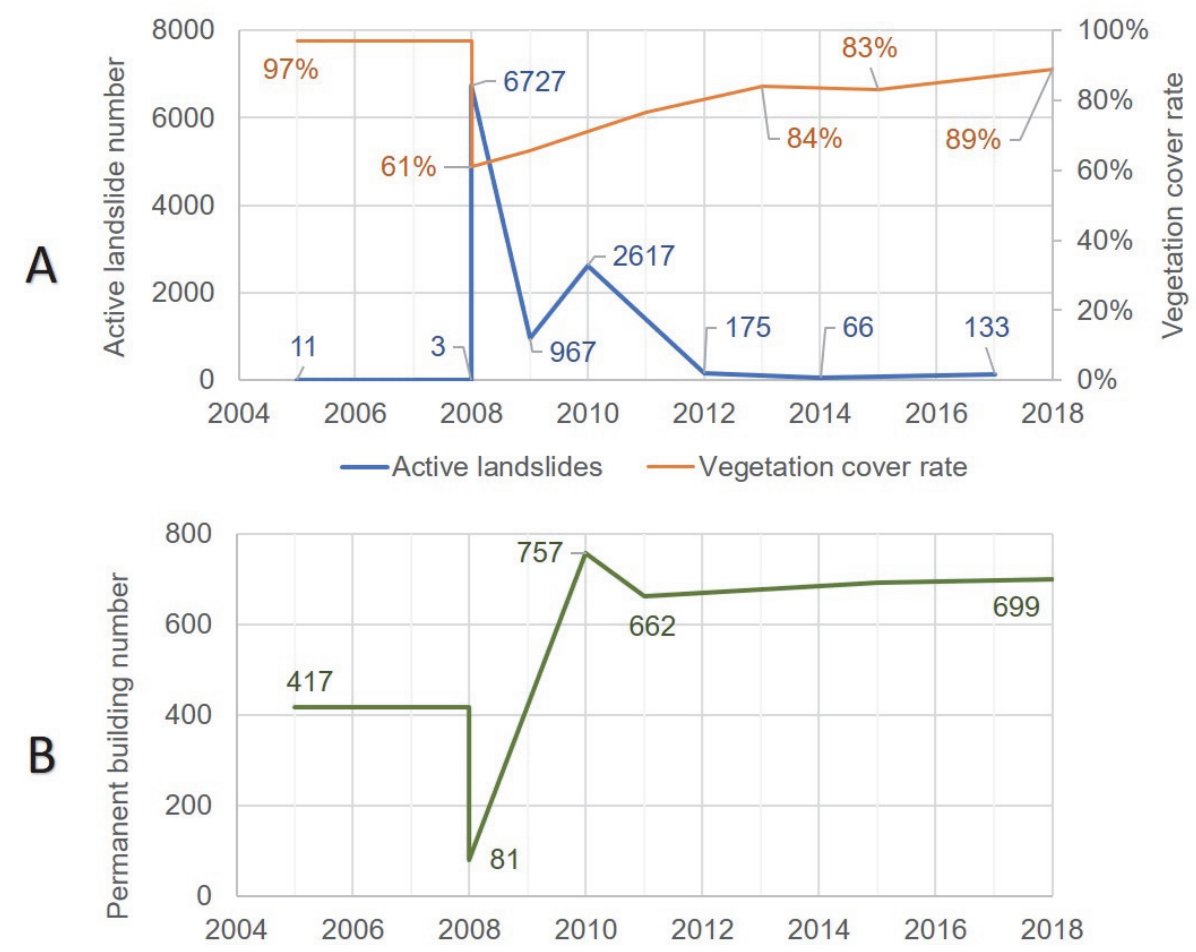

Figure 7.1: A: Graph showing the change in risk components in the 10 years following the Wenchuan earthquake in the case study area, located in the epicentral area of the Wenchuan earthquake. A: Number of active landslides and vegetation cover rate. The landslide numbers are derived from the multi-temporal inventories presented in Chapter 2 and 5, and were plotted with the years of the corresponding monsoon. Vegetation cover was estimated based on Yang et al. (2018) for 2005 - 2015, and a Pleiades multispectral image taken in APR 2018. Water bodies and built-up areas are excluded. $B$ : number of permanent buildings in the Longchi watershed reflecting the impact of disasters and reconstruction.

The time period when landslide activity has returned to the pre-earthquake rate is currently under debate. There are studies claiming a short period of less than 10 years (Fan et al., 2018a; Hovius et al., 2011; Marc et al., 2015), some argue for a medium period of 20 years (Huang and Fan, 2013b; Yang et al., 2018), and others for a long period of more than 40 years (Koi et al., 2008; Nakamura et al., 1999). To estimate the time for environmental recovery, it is important to know what the background rate was before the earthquake. For example, the data presented by Liu et al. (2013) show that over 2000 active landslides already existed before the Chi-chi earthquake, and Nakamura et al. (1999) report that the pre-Kanto-earthquake value was about 200 landslides. As shown in Figure 7.1 (A), both of the active landslide number and vegetation 
cover have not returned to the background rate in 2018. A relatively slow decay in active landslides and a relatively slow vegetation regrowth were observed from 2013 to 2018 indicating that the environmental recovery is not a linear process, and the time before landslide activities restore to the background rate has still not been reached. In the Wenchuan county only 15 landslide events that caused damage were recorded from 1961 to 2005 (Yang et al., 2005) and the largest disaster was a debris flow in 2004 which killed 11 persons. Although only events were reported that caused damages, the hazard frequency and magnitude are significantly higher in recent years. For example, the 2017 Xinmo landslide caused 83 deaths, which was more than one-third of the landslide casualties from 1961 to 2005 combined (214). Till 2018, the government was still building new mitigation works along the roads, or repairing damaged works, which indicates that the landslide activity remains at a relatively high level, and the landslide threat is recognized by the authorities.

The influence of earthquakes on landslide occurrence could last very long. Koi et al. (2008) found that co-seismic debris was involved in mass movement after 80 years. Tang et al. (2011b) investigated a catastrophic debris flow which occurred in 2010, finding seven historical landslide dams, which were triggered by an earthquake ( $\left.M_{w} 8.0\right)$ that occurred in 1879 , amplifying the disaster. Currently most studies are focusing on the landslide evolution within two decades. The very-long-term effect is poorly investigated, and needs further attention.

\subsubsection{Post-seismic landslide risk}

On the aspect of landslide risk dynamics, several studies have recognized the changes brought by urban development and climate change (Abella and Van Westen, 2007; Akgun et al., 2012; Deppisch and Dittmer, 2015; Guzzetti et al., 2005; Rautela and Lakhera, 2000). Studies of Kenneth et al. (1998), Lee and Chi (2011) and Remondo et al. (2005) tried to address the changes of future in the form of hypothesized scenarios. The indirect loss of the Wenchuan earthquake over time was modeled by Wu et al. (2012) using aggregate valueadded data (for example: compensation of employees, net amount of productive tax, depreciation of fixed assets and gross operating surplus), showing a nearly $15 \%$ reduction caused by the Wenchuan earthquake as compared to the pre-earthquake situation, and recovered after November 2011. Their result estimated that the indirect loss was $40 \%$ of the direct loss. However, they did not consider losses caused by post-seismic hazardous events. As far as we know, there is no study that comprehensively investigated the changing risk after major earthquakes.

In chapter 5 and 6 , the dynamics of exposure and potential loss were analyzed. The potential loss in the study area drastically increased after the earthquake 
because of the reconstruction efforts, in an environment with very active landslides (Figure $7.1 \mathrm{~B}$ ). Most of the planned reconstruction was completed before the landslide activity peaked in the monsoon of 2010, resulting in huge losses due to the underestimation of the hazard situation. After the disaster and before the landslide activity reduced to a lower level, many mitigation works were installed in order to control the risk at an acceptable level. Most of the mitigation works were constructed in locations where previous landslide or debris flows caused major damage. Many of the mitigation works have also been damaged or even destroyed in later years. Unfortunately it was not possible to quantify the total investment in mitigation measures in the study area over the 10 year period, due to lack of data. Overall the change in number of elements-at-risk (Figure 7.1 B) is similar to a combination of scenario S1 and S2 in Figure 1.1 B, with S2 (no awareness) in the early-post-seismic phase and S1 (With awareness) in the late-post-seismic phase.

Vegetation regrowth and loose material depletion lower the hazard gradually in the long term, however the recovery speed was not fast enough to lower the risk of landslides and debris flows for rebuilding in the first few years.

Chapter 5 presented a monitoring study of one catchment, showing how the elements-at-risk changed over the 10 years after the Wenchuan earthquake. Chapter 6 aimed to show the changes in debris flow activity, value of exposed elements-at-risk and expected losses for 66 watersheds in the epicentral area of the Wenchuan earthquake. The post-seismic risk could still not be properly quantified, due to lack of information on expected frequencies and hazard intensities.

Evaluation of the changes in risk for different future scenarios, and various alternatives of risk reduction could be analyzed if the hazard could be modelled using physically-based multi-hazard models. For instance Bout et al. (2018) present a model (OpenLISEM) which allows to analyze the hydrometeorological hazards such as landslides, debris flows and flashfloods and their interaction. It also allows to incorporate the changes in the landscape (e.g. vegetation changes and its effect on hydrology and geotechnical properties if this is known) and the effect of mitigation measures on the change of hazard intensities. Future work on post-disaster risk assessment should be based on the application of such multi-hazard modelling approaches, which would allow to generate hazard intensity maps for different return periods, which could then be combined with exposure and physical vulnerability in order to quantify the risk (van Westen and Greiving, 2017). 


\subsubsection{Resilience}

Resilience is defined as a combination of a society's capacity to bounce back after a disaster, its level of preparedness to confront or deal with a disaster and its ability to recover quickly and successfully (Alexander, 2013; Platt et al., 2016). A resilience graph was made using GDP and population of the Wenchuan county, and number of buildings in Longchi (Figure 7.2).

The GDP reached a level much higher than the pre-earthquake value after two years and then rapidly grew to almost twice by 2017 , despite the two major debris flow disasters in 2010 and 2013, which caused 138 million USD of direct loss. This is because of the enormous financial support provided by the national government. In 2018 the GDP stopped growing because the $2017 \mathrm{Ms}_{\mathrm{s}} 7.0$ Jiuzhaigou earthquake which occurred in Sichuan province and killed 25 persons resulted in the closure of one of the most famous touristic attractions in the province, which is located north of the Wenchuan county. This influenced the tourism as the major access road to the attraction passes across the Wenchuan county.

We were only able to collect population data from 2007 to 2016 . The population dropped by 23,603 due to the Wenchuan earthquake and grew back to a number $(111,788)$ that was slightly more than the original number in 2007 $(106,119)$ after two years as well because the government opened job positions as tourist guides and government officials in the county. As the plan to recover the economy through tourism partially failed, a population decrease was observed from 2013 to 2016, probably reflecting a decrease in tourismrelated job positions and businesses.

If measured by recovery time the resilience of the Wenchuan county is very high, as within 2 years the same pre-earthquake level was reached. However, in reality post-seismic landslides and debris flows severely damaged reconstructed buildings, blocked roads, and forced tourist sites to be closed. The negative impact of landslides can only be reflected on the number of buildings in Figure 7.2, as discussed in Chapter 5. The growth rate in such a mountainous region with limited space for construction and widespread landslide threat was much faster than the average rate of the country, indicating it is driven by the large budget invested by the Chinese government. It can be concluded that a strong economy is the key to a rapid reconstruction and gives a large fault tolerance rate in initial planning. 


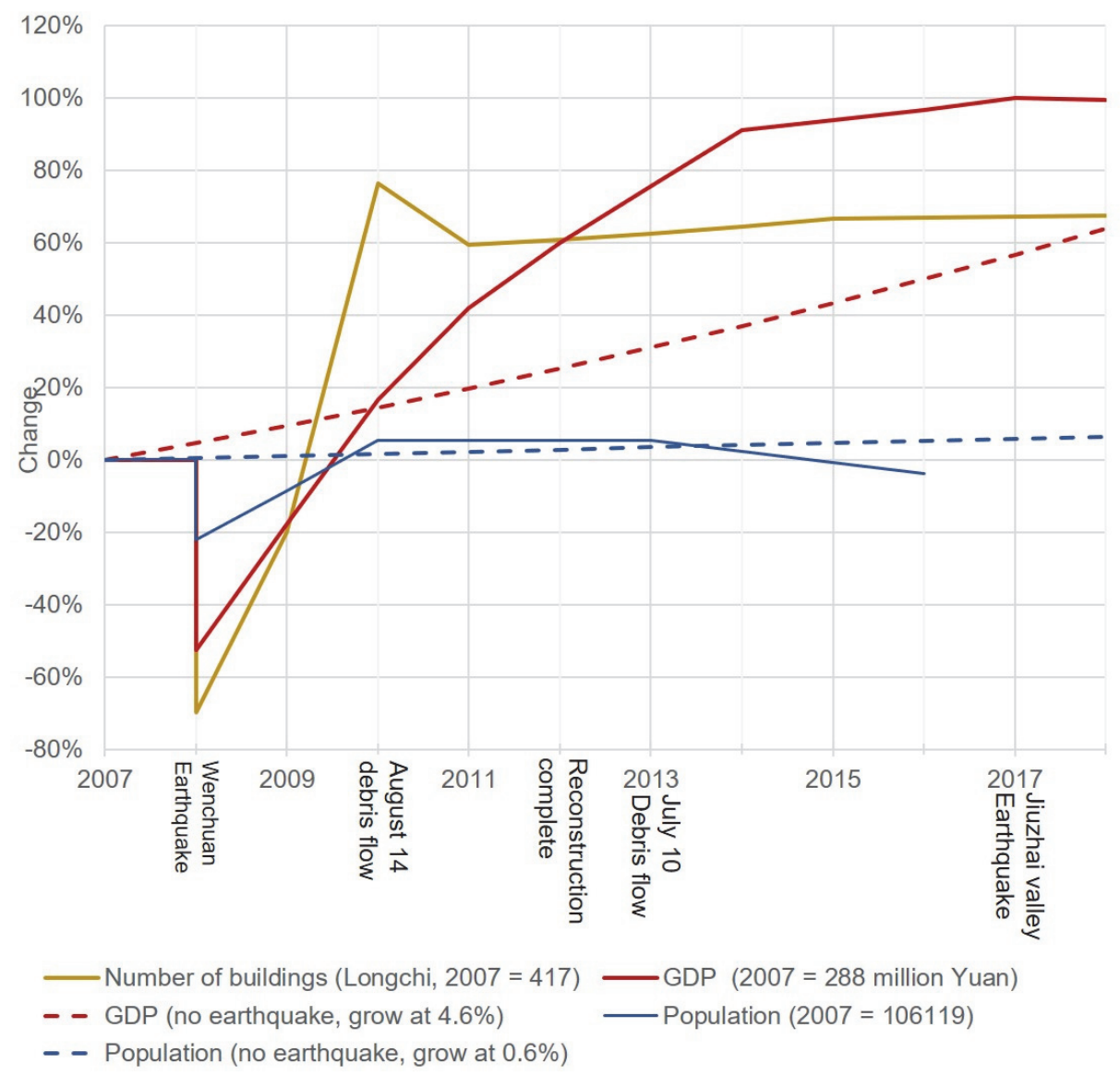

Figure 7.2: Resilience of the Wenchuan county in population and GDP. The "no earthquake" scenario of GDP is assumed to be the average growth rate after the reconstruction completion and population growth is based on the official census data in 2016.

\subsection{Research highlights}

This research studied the dynamics of landslide hazard and risk after the Wenchuan earthquake as a contribution to fill the knowledge gap and to assist future post-seismic reconstruction planning. The major highlights are:

- The research generated detailed multi-temporal post-seismic landslide inventories, where previous studies were using supervised/unsupervised image classification to obtain landslide numbers and area, and did not contain information on material and mass movement types. Landslide activity was assessed by analyzing the freshness of mass movement traces on images, and not by simply assessing bare surfaces. The data is open for downloading on Research Gate website: 
https://www.researchgate.net/publication/326446854_multi_temporal_I andslide inventories after Wenchuan earthquake.

- The research analyzed the changes in co-seismic loose material volumes due to mass movements based on the analysis of multi-temporal and multi-source DEMs. The registration and use of multi-sourced elevation data for volume change estimation was demonstrated. The result shows that the depletion of co-seismic materials was mainly in streams and human activity (sand mining) caused more volume change than mass movements in the later years.

- A script was created to model slope failure volume based on reconstructing the failure surface geometry. The script is able to estimate landslide depth for multiple landslides over an area. It allows a geometry-based volume modeling for single landslides with only elevation models, which can be improved when combined with bore holes, geophysical or geomorphological data.

- The reconstruction after the Wenchuan earthquake was monitored through GIS-based mapping. The reconstructed buildings were much stronger and more expensive than the pre-earthquake buildings. The property losses caused by post-seismic landslides was more than the damage caused by the earthquake, in terms of economic value. The study demonstrates the necessity of carefully choosing locations for reconstruction.

- An analysis was made on the dynamic of post-seismic debris flow risk over a period of 10 years. This was controlled by disaster impact, reconstruction speed, rebuilding locations and exposure, and vegetation recovery. The study contributed to fill the knowledge gap of post-seismic risk dynamics and provided information for reconstruction planning in mountainous regions.

\subsection{Recommendations}

The government planned to finish all the reconstruction activities within 3 years. The rebuilding actually finished in 4 years because of the 2010 debris flow disasters. Although the reconstruction was overall successful, the large losses caused by post-seismic landslides could be avoided by a more proper planning involving hazard management specialists. The buildings should not only be built-back-better, but also be located in better places avoiding postseismic hazards.

A possible time table for recovery actions is presented in Table 7.1. Four postseismic phases are identified based on landslide activity. Period I (very high) means the period when the majority of co-seismic material in streams is not depleted and loosened slope materials have not failed. Period II (High and fast decay) means the time after the first major mass movement event, after which landslides occur frequently but with a lower magnitude. Period III (Low and 
slow decay) is when vegetation has mostly recovered and landslide activity is no longer frequently observed. Landslide activity is much lower compared with the previous two phases, and slowly decays towards the pre-earthquake level. Period IV (Fully recovered) is when landslide activity is at the same level as the pre-earthquake rate.

Table 7.1: Suitability of actions after earthquakes. $0=$ not suitable, $1=$ somewhat suitable, 2 = suitable

\begin{tabular}{|c|c|c|c|c|}
\hline $\begin{array}{c}\text { Post-seismic } \\
\text { landslide threat }\end{array}$ & Very high & $\begin{array}{c}\text { High and fast } \\
\text { decay }\end{array}$ & $\begin{array}{c}\text { Low and slow } \\
\text { decay }\end{array}$ & $\begin{array}{c}\text { Fully } \\
\text { recovered }\end{array}$ \\
\hline Phase number & I & II & III & IV \\
\hline This research & $2008-2010$ & $2010-2015$ & $2015-?$ & Unknown \\
\hline $\begin{array}{c}\text { Rebuilding in risky } \\
\text { zones with } \\
\text { mitigation }\end{array}$ & 0 & 0 & 1 & 2 \\
\hline $\begin{array}{c}\text { Rebuilding in safe } \\
\text { zones }\end{array}$ & 1 & 2 & 2 & 2 \\
\hline $\begin{array}{c}\text { Installing of } \\
\text { mitigation works }\end{array}$ & 0 & 0 & 1 & 2 \\
\hline $\begin{array}{c}\text { Reopen tourism } \\
\text { Hazard surveys } \\
\text { (frequency) }\end{array}$ & High & High & Moderate & $\begin{array}{c}\text { Same as } \\
\text { pre- } \\
\text { earthquake }\end{array}$ \\
\hline
\end{tabular}

In phase I rebuilding should be strictly limited to areas with low disaster threat. Even then risk still exists since rivers could be dammed by mass movement and cause flooding in areas outside of landslide-prone zone (Figure 7.3 A). It is not appropriate to install mitigation works unless it is absolutely necessary because of the highly unstable geo-environment. Landslides should be closely monitored to prevent the forming of barrier lakes. In phase II extreme disasters are less likely to occur but building in landslide-prone area is still too risky. Mitigation works could be installed in key locations to keep critical infrastructure functioning. In non-critical locations it is not beneficial to install mitigation works yet due to large amount of co-seismic debris that could still be activated by rainfall. It is still necessary to monitor landslides closely to assess the threat. Phase III is the best time to install mitigation measures since the landslide threat would be relatively low, therefore easier to be controlled. Buildings are allowed to be constructed in risky areas under the protection of mitigations in order to utilize the limited space in a mountainous area. 
Reopening tourism is possible during dry seasons but should be limited during wet season, which could be periods of monsoon, tropical cyclone and ice melting.

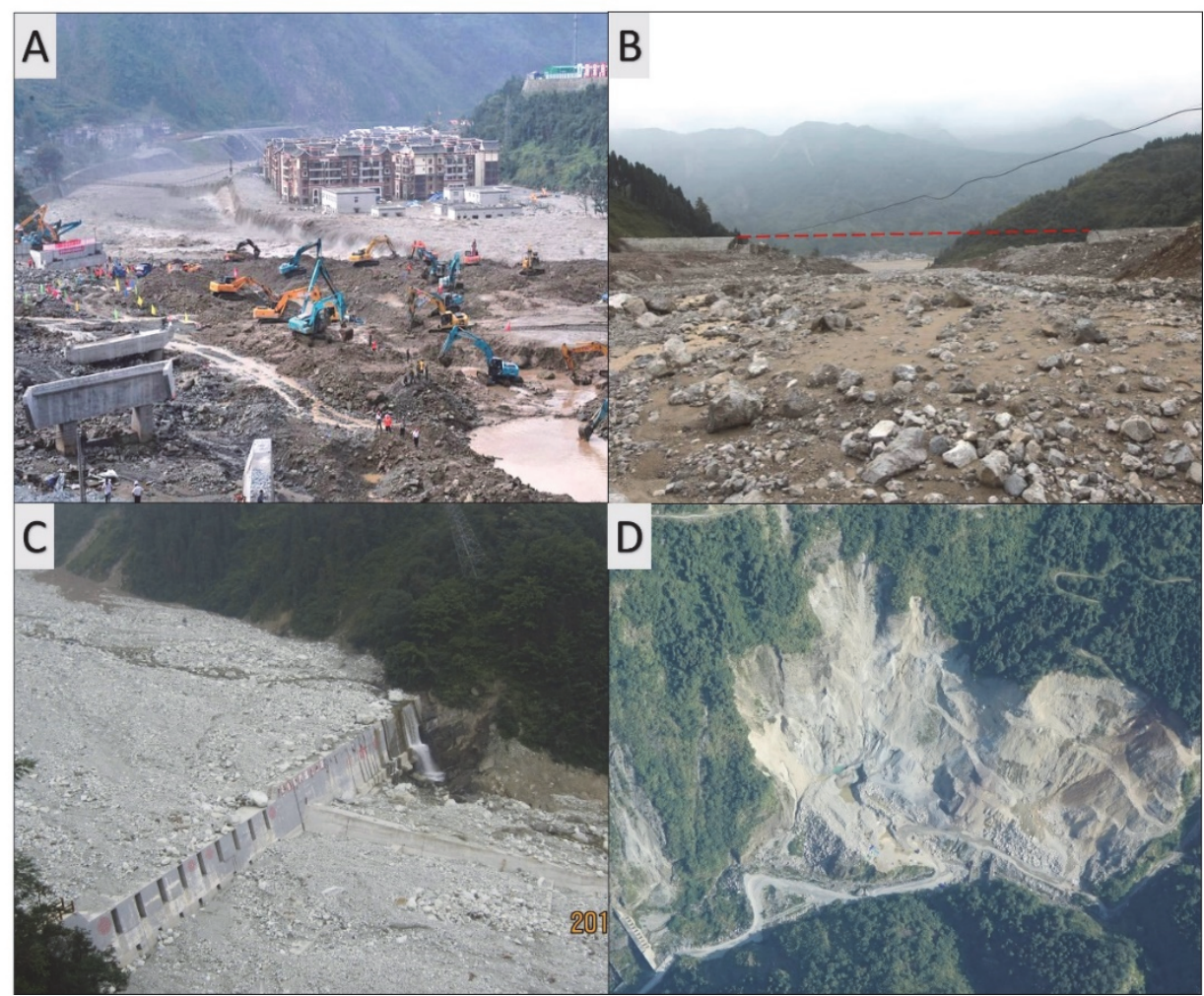

Figure 7.3: A: Debris flow blocked the Minjiang River in 2010, causing flooding to the newly reconstructed Yingxiu town (Produced by catchment 30 in Figure 6.1). B: The August 2010 debris flow destroyed 19 check dams a single catchment (Location in northern Wenchuan county). The red dotted line indicates the destroyed part of a dam. C: Check dams built in 2012 were filled up in 2013 (Catchment 18 in Figure 6.1). D: Careless sand mining destabilized slopes further (Catchment 30 in Figure 6.1).

Hazard surveys frequency should still be higher than per-earthquake situation. In phase IV building and tourism can be operated as pre-earthquake routine. Installing mitigation works is not recommended in Phase I as landslide magnitude could be too large to contain. As a result, check dams could amplify landslide runout with dam-breach effect (Figure 7.3 B). In phase II mitigation is only recommended in key locations, because mass movement are likely to be still highly active, which could easily fill up check dams (Figure 7.2 C). In such situation maintenance could be very costly. A combination of mitigating and sand mining was proven to be a successful in the Wenchuan earthquake area. Sand mines excavate debris flow deposits behand check dams and grind them into fine sands, providing materials for reconstruction and generating 
economy profits. It is advised to apply the combination in Phase II and III with a careful management to avoid disasters. Sand mining should be carefully supervised as several instances were observed that created a new landslide threat in the study area (Figure 7.2 D).

\subsection{Limitations and future research}

The main limitation of this research was the lack of data, either because they are not available or because they could not be used, due to unwillingness to share, data security issues, or inability to access. Lack of data was a main issue, especially related to detailed Digital Elevation Models, dates of occurrence of landslides and debris flows, population data, socio-economic data, and data regarding the types and costs for mitigation works. The lack of high-quality DEMs for the pre-earthquake situation for most of the area was a major problem for the quantification of co-seismic and post-seismic landslide volumes. Also other data were missing especially for the period between 2008 and 2010. This was the period when landslides were most active and the majority of the new buildings were built. We could only use high resolution images captured from Google Earth, and combined them with $2.5 \mathrm{~m}$ SPOT panchromatic images to map the features. The detailed elevation models have very limited spatial and temporal coverage, which limited the study of Chapter 3 to a very small area where detailed DEMs were available from different periods. Rainfall measurements before 2010 were almost absent within the area, making it difficult to do frequency analysis.

When the work on multi-temporal image interpretation reported in Chapter 2 was underway in 2015, a proper quantification of vegetation regrowth could not be carried out due to lack of data. A catchment-based version was carried out in chapter 6 , which was proven to be quite useful. It is important to update the multi-temporal landslide inventory presented in Chapter 2 with vegetation recovery rates for each landslide, and continue to monitor landslide activity in the study area.

The script for landslide volume estimation, presented in Chapter 4, still has limitations when applying it on landslides with long runout or those located in complex terrain. The ultimate goal of the script was to obtain spatial information of landslide depth based on failure surfaces semi-automatically for many landslides over a large area. The script still needs further improvement until it could estimate depth of most of the given landslides regardless of the terrain complexity and runout distance.

One of the main limitations of this research was that it was not possible to quantify the changes in risk, due to the difficulty in expressing magnitude/frequency relations in a changing environment, and the lack of 
intensity maps of debris flows, which also did not allow to use physical vulnerability curves. The method for assessing hazard scores per catchment and its relation with indicative debris flows probabilities presented in chapter 6 are very rudimentary approaches that give an indication how exposure changed in the 10 years after the earthquake. However, to calculate real probability values, and model debris flow intensities for different scenarios, requires the use of physically-based multi-hazard modelling tools, such as OpenLISEM (Bout et al., 2018). But the application of such tools is strongly hampered by the lack of reliable data on soil characteristics over time and space (depth, geotechnical and hydrological properties).

The post-seismic exposure and risk in an area affected by the Wenchuan earthquake were analyzed in Chapter 5 and 6 . The Wenchuan earthquake was, although a huge tragedy from a human point of view, a major challenge and opportunity from a scientific point of view. It generated a huge amount of research and over 6300 papers were published on this event (Fan et al., 2018 b). Relatively few of them deal with analyzing how risk changed during the recovery period, and how risk information could have been used to improve risk management and reconstruction planning in this extremely complex environment.

The circumstances related to post-earthquake landslide problems, data availability, resources for recovery and risk governance could be very different in other mountainous regions that are impacted by large earthquakes. It is necessary to investigate more in the risk dynamics in other locations as well. The 2015 Nepal earthquake was a good study subject as a slow recovery was witnessed which is opposite of the Sichuan province, while co-seismic landslide density was also much lower (Gnyawali and Adhikari, 2017). Similar studies could be expanded to other historical events in order to obtain more information on post-seismic risk dynamics.

In future research post-seismic landslides could be monitored with a more automatic and quantitative manner by machine learning approaches, in order to avoid bias caused by manual digitization. The object-oriented-imageanalysis (OBIA) technique could applied to extract landslides and areas with reactivation more objectively, although visual image interpretation by experts remains essential. LiDAR based DEMs could be collected for areas with frequent tectonic activities, for the preparation of pre-earthquake DEMs to support future disaster response planning and research. In case of low budget, such data could be collected for the inhabited areas only that are expected to have high landslide activities and high exposure. The model presented in Chapter 4 needs further improvement, but would eventually allow to quickly estimate coseismic landslide volumes based on the prepared pre-earthquake LiDAR derived DTM and a post-earthquake high-resolution DEM that could be derived 
from varies sources. The evaluation and prediction of multi-temporal risk dynamics after a major earthquake are still a major challenge, but could be achieved by combining physical based modelling with multi-temporal exposure mapping. 


\section{Bibliography}

Abella, E. A. C., and Van Westen, C. J., 2007, Generation of a landslide risk index map for Cuba using spatial multi-criteria evaluation: Landslides, v. 4 , no. 4 , p. 311-325.

Adhikari, N., 2017, Nepal's earthquake disaster: Two years and $\$ 4.1 \mathrm{bn}$ later, Al Jazeera Media Network.

AIRBUS, 2017, Elevation1 DSM Technical information, http://www.intelligence-airbusds.com/en/4367-elevation1.

Akgiray, V., Barbarosoglu, G., and Erdik, M., 2004, The 1999 Marmara earthquakes in Turkey, Large-scale Disasters, Organisation for Economic Co-operation and Development, p. 77 - 92.

Akgun, A., Kincal, C., and Pradhan, B., 2012, Application of remote sensing data and GIS for landslide risk assessment as an environmental threat to Izmir city (west Turkey): Environ Monit Assess, v. 184, no. 9, p. 5453-5470.

Alexander, D. E., 2013, Resilience and disaster risk reduction: an etymological journey: Nat. Hazards Earth Syst. Sci., v. 13, no. 11, p. 2707-2716.

Anhorn, J., and Khazai, B., 2014, Open space suitability analysis for emergency shelter after an earthquake, 4263-4297 p.:

Asgary, A., Badri, A., Rafieian, M., and Hajinejad, A., Lost and used postdisaster development opportunities in Bam earthquake and the role of stakeholders, in Proceedings Proceedings of the International Conference and Student Competition on post-disaster reconstruction: Meeting stakeholder interests2006, p. 17-19.

Baidu Encyclopedia, 2016, Longchi Town (Dujiangyan city, Sichuan province), Baidu Encyclopedia.

Baills, A., Vandromme, R., Desramaut, N., Sedan-Miegemolle, O., and Grandjean, G., 2013, Changing Patterns in Climate-Driven Landslide Hazard: An Alpine Test Site, in Margottini, C., Canuti, P., and Sassa, K., eds., Landslide Science and Practice: Volume 4: Global Environmental Change: Berlin, Heidelberg, Springer Berlin Heidelberg, p. 93-98.

Barbarella, M., Fiani, M., and Lugli, A., 2015, Landslide monitoring using multitemporal terrestrial laser scanning for ground displacement analysis: Geomatics, Natural Hazards and Risk, v. 6, no. 5-7, p. 398418.

Baron, H. M., 2011, Coastal hazards and community exposure in a changing climate : the development of probabilistic coastal change hazard zones [Master of Science: Oregon State University.

Bjarnadottir, S., Li, Y., and Stewart, M. G., 2011, Social vulnerability index for coastal communities at risk to hurricane hazard and a changing climate: Natural Hazards, v. 59, no. 2, p. 1055-1075. 
Bolin, R., and Stanford, L., 1998, The Northridge Earthquake: Communitybased Approaches to Unmet Recovery Needs: Disasters, v. 22, no. 1, p. 21-38.

Bostenaru Dan, M., Armas, I., and Goretti, A., 2014, Earthquake Hazard Impact and Urban Planning-An Introduction, p. 1-12.

Bout, B., Lombardo, L., van Westen, C. J., and Jetten, V. G., 2018, Integration of two-phase solid fluid equations in a catchment model for flashfloods, debris flows and shallow slope failures: Environmental Modelling \& Software, v. 105, p. 1-16.

Burton, C. G., 2015, A Validation of Metrics for Community Resilience to Natural Hazards and Disasters Using the Recovery from Hurricane Katrina as a Case Study: Annals of the Association of American Geographers, v. 105, no. 1, p. 67-86.

C. Topping, K., C. Eadie, C., E. Deyle, R., and A. Smith, R., 1998, Planning for Post-Disaster Recovery and Reconstruction.

Chai, H., Liu, H., and Zhang, Z., 1995, Event inventory of landslide dams in China (in Chinese): Geol Hazards Environ Protect, v. 6, no. 4, p. 1- 9.

Chang, K.-J., Taboada, A., Chan, Y.-C., and Dominguez, S., 2006, Post-seismic surface processes in the Jiufengershan landslide area, 1999 Chi-Chi earthquake epicentral zone, Taiwan: Engineering Geology, v. 86, no. 2-3, p. 102-117.

Chen, C.-Y., Chen, T.-C., Yu, F.-C., and Hung, F.-Y., 2004, A landslide dam breach induced debris flow - a case study on downstream hazard areas delineation: Environmental Geology, v. 47, no. 1, p. 91-101.

Chen, J.-C., 2011, Variability of impact of earthquake on debris-flow triggering conditions: case study of Chen-Yu-Lan watershed, Taiwan: Environmental Earth Sciences, v. 64, no. 7, p. 1787-1794.

Chen, Q., Cheng, H., Yang, Y., Liu, G., and Liu, L., 2014a, Quantification of mass wasting volume associated with the giant landslide Daguangbao induced by the 2008 Wenchuan earthquake from persistent scatterer InSAR: Remote Sensing of Environment, v. 152, p. 125-135.

Chen, R.-F., Chang, K.-J., Angelier, J., Chan, Y.-C., Deffontaines, B., Lee, C.T., and Lin, M.-L., 2006, Topographical changes revealed by highresolution airborne LiDAR data: The 1999 Tsaoling landslide induced by the Chi-Chi earthquake: Engineering Geology, v. 88, no. 3-4, p. 160-172.

Chen, Z., Chen, X., Li, Q., and Chen, J., 2013a, The temporal hierarchy of shelters: A hierarchical location model for earthquake-shelter planning, 1612-1630 p.:

Chen, Z., Lei, T., Yan, Q., Hu, H., Xiong, M., and Li, Z., 2013b, Measuring and calculation methods for landslide volume with 3-D laser scanner in Wenchuan earthquake area: Transactions of the Chinese Society of Agricultural Engineering, v. 29, no. 8, p. 135-144. 
Chen, Z., Zhang, B., Han, Y., Zuo, Z., and Zhang, X., 2014b, Modeling Accumulated Volume of Landslides Using Remote Sensing and DTM Data: Remote Sensing, v. 6, no. 2, p. 1514-1537.

Cheng, J. D., Huang, Y. C., Wu, H. L., Yeh, J. L., and Chang, C. H., 2005, Hydrometeorological and landuse attributes of debris flows and debris floods during typhoon Toraji, July 29-30, 2001 in central Taiwan: Journal of Hydrology, v. 306, no. 1, p. 161-173.

Chengdu Bureau of Land and Resources, 2018, List of mitigations in Longchi.

Chengdu Municipal People's Government, 2014, Hazard emergency response plan of Chengdu.

Ciborowski, A., 1982, Physical development planning and urban design in earthquake-prone areas: Engineering Structures, v. 4, no. 3, p. 153160.

Clauset, A., Shalizi, C. R., and Newman, M. E. J., 2009, Power-Law Distributions in Empirical Data, Society for Industrial and Applied Mathematics, 661-703 p.:

Contreras Mojica, D., Blaschke, T., Tiede, D., and Jilge, M., 2015, Monitoring recovery after earthquakes through the integration of remote sensing, GIS, and ground observations: the case of L'Aquila (Italy).

Cruden, D., and Varnes, D., 1996a, Landslide types and processes.

Cruden, D. M., and Varnes, D. J., 1996b, Chapter 3-Landslide types and processes, Landslides: investigation and mitigation, Transportation Research Board

National Academy of Sciences, p. '56 - 77.

Cui, P., Xiang, L.-Z., and Zou, Q., 2013, Risk assessment of highways affected by debris flows in Wenchuan earthquake area: Journal of Mountain Science, v. 10, no. 2, p. 173-189.

Dade, W. B., and Huppert, H. E., 1998, Long-runout rockfalls: Geology, v. 26, no. 9, p. 803-806.

Dai, F. C., Xu, C., Yao, X., Xu, L., Tu, X. B., and Gong, Q. M., 2011, Spatial distribution of landslides triggered by the 2008 Ms 8.0 Wenchuan earthquake, China: Journal of Asian Earth Sciences, v. 40, no. 4, p. 883-895.

Dalen, K., Flatø, H., Liu, J., and Zhang, H., 2012, Recovering from the Wenchuan earthquake: Living Conditions and Development in Disaster Areas 2008-2011. : Fafo.

Deppisch, S., and Dittmer, D., 2015, Urban Planning Dealing with Change and Infrastructure.

Dewitte, O., Jasselette, J.-C., Cornet, Y., Van Den Eeckhaut, M., Collignon, A., Poesen, J., and Demoulin, A., 2008, Tracking landslide displacements by multi-temporal DTMs: A combined aerial stereophotogrammetric and LIDAR approach in western Belgium: Engineering Geology, v. 99, no. 1, p. 11-22. 
Dong, J.-J., Li, Y.-S., Kuo, C.-Y., Sung, R.-T., Li, M.-H., Lee, C.-T., Chen, C.C., and Lee, W.-R., 2011, The formation and breach of a short-lived landslide dam at Hsiaolin village, Taiwan - part I: Post-event reconstruction of dam geometry: Engineering Geology, v. 123, no. 1, p. 40-59.

Dunford, M., and Li, L., 2011, Earthquake reconstruction in Wenchuan: Assessing the state overall plan and addressing the 'forgotten phase', 998-1009 p.:

Fan, J., Li, X., Guo, F., and Guo, X., 2011, Empirical-statistical models based on remote sensing for estimating the volume of landslides induced by the Wenchuan earthquake: Journal of Mountain Science, v. 8, no. 5, p. 711-717.

Fan, J. C., Liu, C. H., Wu, M. F., and Yu, S. K., 2003, Determination of critical rainfall thresholds for debris-flow occurrence in central Taiwan and their revision after the 1999 Chi-Chi great earthquake, Rotterdam, Millpress Science Publishers, Debris-Flow Hazards Mitigation: Mechanics, Prediction, and Assessment, Vols 1 and 2, 103-114 p.:

Fan, X., Domènech, G., Scaringi, G., Huang, R., Xu, Q., Hales, T. C., Dai, L., Yang, Q., and Francis, O., 2018a, Spatio-temporal evolution of mass wasting after the $2008 \mathrm{Mw} 7.9$ Wenchuan earthquake revealed by a detailed multi-temporal inventory: Landslides, v. 15, no. 12, p. 23252341.

Fan, X., Juang, C. H., Wasowski, J., Huang, R., Xu, Q., Scaringi, G., van Westen, C. J., and Havenith, H.-B., 2018b, What we have learned from the 2008 Wenchuan Earthquake and its aftermath: A decade of research and challenges: Engineering Geology, v. 241, p. 25-32.

Fan, X., Scaringi, G., Domènech, G., Yang, F., Guo, X., Dai, L., He, C., Xu, Q., and Huang, R., 2019a, Two multi-temporal datasets that track the enhanced landsliding after the 2008 Wenchuan earthquake: Earth Syst. Sci. Data, v. 11, no. 1, p. 35-55.

Fan, X., Scaringi, G., Korup, O., West, A. J., Westen, C. J. v., Tanyas, H., Hovius, N., Hales, T. C., Jibson, R. W., Allstadt, K. E., Zhang, L., Evans, S. G., Xu, C., Li, G., Pei, X., Xu, Q., and Huang, R., 2019b, Earthquakeinduced chains of geologic hazards: patterns, mechanisms, and impacts (under Review): Reviews of Geophysics.

Fan, X., van Westen, C. J., Korup, O., Gorum, T., Xu, Q., Dai, F., Huang, R., and Wang, G., 2012, Transient water and sediment storage of the decaying landslide dams induced by the 2008 Wenchuan earthquake, China: Geomorphology, v. 171-172, p. 58-68.

Fan, X., Xu, Q., Scaringi, G., Dai, L., Li, W., Dong, X., Zhu, X., Pei, X., Dai, K., and Havenith, H.-B., 2017, Failure mechanism and kinematics of the deadly June 24th 2017 Xinmo landslide, Maoxian, Sichuan, China: Landslides, v. 14, no. 6, p. 2129-2146. 
Feima Robotics, F1000, https://www.feimarobotics.com/officialwebsite/html/product-details-f1000.html.

Fell, R., 1994, Landslide risk assessment and acceptable risk: Canadian Geotechnical Journal, v. 31, no. 2, p. 261-272.

Finlay, P. J., Mostyn, G. R., and Fell, R., 1999, Landslide risk assessment: Prediction of travel distance: Revue Canadienne De Géotechnique, $v$. 36, no. 3, p. 556-562.

Forzieri, G., Feyen, L., Russo, S., Vousdoukas, M., Alfieri, L., Outten, S., Migliavacca, M., Bianchi, A., Rojas, R., and Cid, A., 2016, Multi-hazard assessment in Europe under climate change: Climatic Change, v. 137, no. $1-2$, p. 105-119.

Gentile, F., Bisantino, T., and Trisorio Liuzzi, G., 2008, Debris-flow risk analysis in south Gargano watersheds (Southern-Italy): Natural Hazards, v. 44, no. 1 , p. 1-17.

German Aerospace Center, 2014, TanDEM-X - the Earth in three dimensions, http://www.dlr.de/dlr/en/desktopdefault.aspx/tabid$10378 / 566$ read-426/\#/gallery/345.

Ghafory-Ashtiany, M., and Hosseini, M., 2008, Post-Bam earthquake: Recovery and reconstruction, 229-241 p.:

Gnyawali, K. R., and Adhikari, B. R., Spatial Relations of Earthquake Induced Landslides Triggered by 2015 Gorkha Earthquake $\mathrm{Mw}=7.8$, in Proceedings Advancing Culture of Living with Landslides, Cham, 2017// 2017, Springer International Publishing, p. 85-93.

Gonzalez, C., Bräutigam, B., Martone, M., and Rizzoli, P., Relative height error estimation method for TanDEM-X DEM products, in Proceedings EUSAR 2014; 10th European Conference on Synthetic Aperture Radar; Proceedings of 2014, VDE, p. 1-4.

Gorum, T., Fan, X., van Westen, C. J., Huang, R. Q., Xu, Q., Tang, C., and Wang, G., 2011, Distribution pattern of earthquake-induced landslides triggered by the 12 May 2008 Wenchuan earthquake: Geomorphology, v. 133 , no. 3-4, p. 152-167.

Greiving, S., Fleischhauer, M., and Wanczura, S., 2007, Management of natural hazards in Europe: The role of spatial planning in selected EU member states: Journal of Environmental Planning and Management, v. 49, no. 5, p. 739-757.

Guo, X., Cui, P., Li, Y., Ma, L., Ge, Y., and Mahoney, W. B., 2016, Intensityduration threshold of rainfall-triggered debris flows in the Wenchuan Earthquake affected area, China: Geomorphology, v. 253, p. 208-216.

Guzzetti, F., Ardizzone, F., Cardinali, M., Rossi, M., and Valigi, D., 2009, Landslide volumes and landslide mobilization rates in Umbria, central Italy: Earth and Planetary Science Letters, v. 279, no. 3-4, p. 222-229.

Guzzetti, F., Malamud, B. D., Turcotte, D. L., and Reichenbach, P., 2002, Power-law correlations of landslide areas in central Italy: Earth and Planetary Science Letters, v. 195, no. 3, p. 169-183. 
Guzzetti, F., Stark, C. P., and Salvati, P., 2005, Evaluation of flood and landslide risk to the population of Italy: Environ Manage, v. 36, no. 1, p. 15-36.

Hao, H., Yang, X., Huang, Y., Liu, K., and Zeng, Z., 2011, Emergency investigation report of Niujuan catchment debris flows (unpublished report, in Chinese), Sichuan Huadi Construction Engineering Co., Ltd.

Harp, E. L., and Jibson, R. W., 1996, Inventory of Landslides Triggered by the 1994 Northridge, California Earthquake, S319-S332 p.:

Hovius, N., Meunier, P., Lin, C.-W., Chen, H., Chen, Y.-G., Dadson, S., Horng, M.-J., and Lines, M., 2011, Prolonged seismically induced erosion and the mass balance of a large earthquake: Earth and Planetary Science Letters, v. 304, no. 3-4, p. 347-355.

Hovius, N., Stark, C. P., and Allen, P. A., 1997, Sediment flux from a mountain belt derived by landslide mapping: Geology, v. 25, no. 3, p. 231-234.

Hovius, N., Stark, C. P., Hao-Tsu, C., and Jiun-Chuan, L., 2000, Supply and removal of sediment in a landslide-dominated mountain belt: Central Range, Taiwan: The Journal of Geology, v. 108, no. 1, p. 73-89.

$\mathrm{Hu}, \mathrm{T}$. , and Huang, R.-q., 2017, A catastrophic debris flow in the Wenchuan Earthquake area, July 2013: characteristics, formation, and risk reduction: Journal of Mountain Science, v. 14, no. 1, p. 15-30.

Hu, X., Salazar, M., Zhang, Q., Lu, Q., and Zhang, X., 2010, Social Protection during Disasters: Evidence from the Wenchuan Earthquake, 107-115 p.:

Huang, R., and Fan, X., 2013a, The landslide story: Nature Geosci, v. 6, no. 5, p. 325-326.

-, 2013b, The landslide story: Nature Geoscience, v. 6, no. 5, p. 325-326.

Huang, Y., Zhou, L., and Wei, K., 2011, 5.12 Wenchuan earthquake recovery government policies and non-governmental organizations' participation: Asia Pacific Journal of Social Work and Development, v. 21, no. 2, p. 77-91.

Hufschmidt, G., and Crozier, M. J., 2007, Evolution of natural risk: analysing changing landslide hazard in Wellington, Aotearoa/New Zealand: Natural Hazards, v. 45, no. 2, p. 255-276.

Ioane, D., Diaconescu, M., Chitea, F., and Garbacea, G., 2014, Active Fault Systems and Their Significance for Urban Planning in Bucharest, Romania, in Bostenaru Dan, M., Armas, I., and Goretti, A., eds., Earthquake Hazard Impact and Urban Planning: Dordrecht, Springer Netherlands, p. 15-43.

Jayaratne, R., Field Survey of Coastal Dyke Failure due to 2011 Great Eastern Japan Earthquake Tsunami2013.

Jesselyn, C., 2017, 7 Years After Haiti's Earthquake, Millions Still Need Aid, HuffPost. 
Jongmans, D., and Garambois, S., 2007, Geophysical investigation of landslides : a review: Bulletin De La Société Géologique De France, v. 178, no. 2, p. 101-112.

Kargel, J. S., Leonard, G. J., Shugar, D. H., Haritashya, U. K., Bevington, A., Fielding, E. J., Fujita, K., Geertsema, M., Miles, E. S., Steiner, J., Anderson, E., Bajracharya, S., Bawden, G. W., Breashears, D. F., Byers, A., Collins, B., Dhital, M. R., Donnellan, A., Evans, T. L., Geai, M. L., Glasscoe, M. T., Green, D., Gurung, D. R., Heijenk, R., Hilborn, A., Hudnut, K., Huyck, C., Immerzeel, W. W., Liming, J., Jibson, R., Kääb, A., Khanal, N. R., Kirschbaum, D., Kraaijenbrink, P. D. A., Lamsal, D., Shiyin, L., Mingyang, L., McKinney, D., Nahirnick, N. K., Zhuotong, N., Ojha, S., Olsenholler, J., Painter, T. H., Pleasants, M., Pratima, K. C., Yuan, Q. I., Raup, B. H., Regmi, D., Rounce, D. R., Sakai, A., Donghui, S., Shea, J. M., Shrestha, A. B., Shukla, A., Stumm, D., van der Kooij, M., Voss, K., Xin, W., Weihs, B., Wolfe, D., Lizong, W., Xiaojun, Y., Yoder, M. R., and Young, N., 2016, Geomorphic and geologic controls of geohazards induced by Nepal's 2015 Gorkha earthquake, v. 351 , no. 6269 , p. aac8353.

Kenneth, C. T., Charles, C. E., Robert, E. D., and Richard, A. S., 1998, Planning for Post-Disaster Recovery and Reconstruction.

Kerle, N., 2002, Volume estimation of the 1998 flank collapse at Casita volcano, Nicaragua: a comparison of photogrammetric and conventional techniques: Earth Surface Processes and Landforms, v. 27, no. 7, p. 759-772.

Khan, S. F., Kamp, U., and Owen, L. A., 2013, Documenting five years of landsliding after the 2005 Kashmir earthquake, using repeat photography: Geomorphology, v. 197, p. 45-55.

Khattak, G. A., Owen, L. A., Kamp, U., and Harp, E. L., 2010, Evolution of earthquake-triggered landslides in the Kashmir Himalaya, northern Pakistan: Geomorphology, v. 115, no. 1, p. 102-108.

Kılcı, F., Kara, B. Y., and Bozkaya, B., 2015, Locating temporary shelter areas after an earthquake: A case for Turkey: European Journal of Operational Research, v. 243, no. 1, p. 323-332.

Koi, T., Hotta, N., Ishigaki, I., Matuzaki, N., Uchiyama, Y., and Suzuki, M., 2008, Prolonged impact of earthquake-induced landslides on sediment yield in a mountain watershed: The Tanzawa region, Japan: Geomorphology, v. 101, no. 4, p. 692-702.

Kun, P., Han, S., Chen, X., and Yao, L., 2009, Prevalence of post-traumatic stress disorder in Sichuan province China after the 2008 Wenchuan earthquake, 1134-1140 p.:

Larsen, I. J., Montgomery, D. R., and Korup, O., 2010, Landslide erosion controlled by hillslope material: Nature Geoscience, v. 3, no. 4, p. 247251. 
Le Roux, O., Jongmans, D., Kasperski, J., Schwartz, S., Potherat, P., Lebrouc, V., Lagabrielle, R., and Meric, O., 2011, Deep geophysical investigation of the large Séchilienne landslide (Western Alps, France) and calibration with geological data: Engineering Geology, v. 120, no. 1-4, p. 18-31.

Lee, Y.-F., and Chi, Y.-Y., 2011, Rainfall-induced landslide risk at Lushan, Taiwan: Engineering Geology, v. 123, no. 1-2, p. 113-121.

Li, D., Hao, H., Ma, j., Wu, X., Yan, Z., Li, G., Wang, H., Gao, J., Liu, H., Huang, Y., Yang, X., Zeng, Z., Liu, J., Gao, L., Shen, T., Cao, N., Zhang, Y., Li, Z., Liu, K., Li, D., and Xian, Z., 2011, Emergency mitigation engineering design on the catastrohic Hongchun catchment debris flow, Yingxiu, Wenchuan county (unpublished report, in Chinese), Guanghan Institute of Geological Engineering Investigation

Li, G., West, A. J., Densmore, A. L., Jin, Z., Parker, R. N., and Hilton, R. G., 2014, Seismic mountain building: Landslides associated with the 2008 Wenchuan earthquake in the context of a generalized model for earthquake volume balance: Geochemistry, Geophysics, Geosystems, v. 15 , no. 4 , p. $833-844$.

Li, H., Zhao, L., Huang, R., and Hu, Q., 2017, Hierarchical earthquake shelter planning in urban areas: A case for Shanghai in China: International Journal of Disaster Risk Reduction, v. 22, p. 431-446.

Li, L., Yao, X., Zhang, Y., Iqbal, J., Chen, J., and Zhou, N., 2016, Surface recovery of landslides triggered by 2008 Ms8.0 Wenchuan earthquake (China): a case study in a typical mountainous watershed: Landslides, v. 13 , no. 4 , p. 787-794.

Li, Y., Huang, R., Yan, L., L. Densmore, A., and Zhou, R., 2010, Surface Rupture and Hazard of Wenchuan Ms 8.0 Earthquake, Sichuan, China, 21-31 p.:

Lin, C.-W., Liu, S.-H., Lee, S.-Y., and Liu, C.-C., 2006a, Impacts of the Chi-Chi earthquake on subsequent rainfall-induced landslides in central Taiwan: Engineering Geology, v. 86, no. 2, p. 87-101.

Lin, C. W., Shieh, C. L., Yuan, B. D., Shieh, Y. C., Liu, S. H., and Lee, S. Y., 2004, Impact of Chi-Chi earthquake on the occurrence of landslides and debris flows: example from the Chenyulan River watershed, Nantou, Taiwan: Engineering Geology, v. 71, no. 1-2, p. 49-61.

Lin, G.-W., Chen, H., Hovius, N., Horng, M.-J., Dadson, S., Meunier, P., and Lines, M., 2008, Effects of earthquake and cyclone sequencing on landsliding and fluvial sediment transfer in a mountain catchment: Earth Surface Processes and Landforms, v. 33, no. 9, p. 1354-1373.

Lin, W.-T., Lin, C.-Y., and Chou, W.-C., 2006b, Assessment of vegetation recovery and soil erosion at landslides caused by a catastrophic earthquake: A case study in Central Taiwan: Ecological Engineering, v. 28 , no. 1 , p. $79-89$ 
Liu, S.-H., Lin, C.-W., and Tseng, C.-M., 2013, A statistical model for the impact of the 1999 Chi-Chi earthquake on the subsequent rainfallinduced landslides: Engineering Geology, v. 156, p. 11-19.

Liu, X., 2010, The Bayi gully debris flow, State Key Laboratory of Geo-hazard Prevention and Geo-environment Protection (SKLGP), Chengdu University of Technology.

Liu, Y., Liu, R., and Ge, Q., 2010, Evaluating the vegetation destruction and recovery of Wenchuan earthquake using MODIS data: Natural Hazards, v. 54, no. 3, p. 851-862.

Liu, Z., Yuan, B., Mao, Y., Fang, G., Yu, J., Chen, j., and Xie, J., 2007, Geohazard survey and zonation of Dujiangyan city, Sichuan province, Sichuan Geological Survey institute,

Dujiangyan Municipal Bureau of Planning and Natural Resources.

Lo, A. Y., and Cheung, L. T. O., 2015, Seismic risk perception in the aftermath of Wenchuan earthquakes in southwestern China: Natural Hazards, v. 78, no. 3, p. 1979-1996.

Lu, T., Zeng, H., Luo, Y., Wang, Q., Shi, F., Sun, G., Wu, Y., and Wu, N., 2012, Monitoring vegetation recovery after China's May 2008 Wenchuan earthquake using Landsat TM time-series data: a case study in Mao County: Ecological Research, v. 27, no. 5, p. 955-966.

Lugaizi, I., 2008, Landslide volume monitoring using geophysics and multi temporal digital elevation models : a case study of Trieves area, France [Master of Science: University of Twente.

Luo, M., Wei, C., Mo, J., Liao, W., Liang, J., Long, B., Wang, M., Li, H., Zhang, Y., Zhong, J., Wu, F., and Zhang, G., 2010, A detailed hazard survey of Dujiangyan city after the Wenchuan earthquake, Sichuan Geological Survey Institute.

Ma, y., Yu, B., Wu, Y., Zhang, J., and Qi, X., 2011, Research on the Disaster of Debris Flow of Bayi Gully,Longchi,Dujiangyan,Sichuan on August 13,2010: Journal of Sichuan Universitity, v. 43.

Malamud, B. D., Turcotte, D. L., Guzzetti, F., and Reichenbach, P., 2004, Landslide inventories and their statistical properties: Earth Surface Processes and Landforms, v. 29, no. 6, p. 687-711.

Marc, O., Hovius, N., Meunier, P., Uchida, T., and Hayashi, S.-I., 2015, Transient changes of landslide rates after earthquakes.

Marchesini, I., Cencetti, C., and Rosa, P. D., 2009, A preliminary method for the evaluation of the landslides volume at a regional scale: Geoinformatica, v. 13, no. 3, p. 277-289.

Martha, T. R., Kerle, N., Jetten, V., van Westen, C. J., and Vinod Kumar, K., 2010, Landslide Volumetric Analysis Using Cartosat-1-Derived DEMs: IEEE Geoscience and Remote Sensing Letters, v. 7, no. 3, p. 582-586.

Martin, E., Giraud, G., Lejeune, Y., and Boudart, G., 2001, Impact of climate change on avalanche hazard, 163-167 p.: 
Mergili, M., Marchesini, I., Rossi, M., Guzzetti, F., and Fellin, W., 2014, Spatially distributed three-dimensional slope stability modelling in a raster GIS: Geomorphology, v. 206, p. 178-195.

Mikami, T., Shibayama, T., Esteban, M., and Matsumaru, R., 2012, Field survey of the 2011 Tohoku Earthquake and Tsunami in Miyagi and Fukushima prefectures.

Mondini, A. C., Guzzetti, F., Reichenbach, P., Rossi, M., Cardinali, M., and Ardizzone, F., 2011, Semi-automatic recognition and mapping of rainfall induced shallow landslides using optical satellite images: Remote Sensing of Environment, v. 115, no. 7, p. 1743-1757.

Nadim, F., Moghtaderi-Zadeh, M., Lindholm, C., Andresen, A., Remseth, S., Bolourchi, M. J., Mokhtari, M., and Tvedt, E., 2004, The Bam Earthquake of 26 December 2003: Bulletin of Earthquake Engineering, v. 2 , no. 2 , p. 119-153.

Nakamura, H., Tsuchiya, S., and Inoue, K., 1999, Sabo against Earthquakes (in Japanese), Tokyo, Japan, Kokon Shoin.

Nam, W.-H., Hayes, M. J., Svoboda, M. D., Tadesse, T., and Wilhite, D. A., 2015, Drought hazard assessment in the context of climate change for South Korea: Agricultural Water Management, v. 160, p. 106-117.

Naviwala, N., 2017, Kashmir earthquake: What happened to 12 years and $\$ 6$ billion?, IRIN.

Nelson, F. E., Anisimov, O. A., and Shiklomanov, N. I., 2002, Climate Change and Hazard Zonation in the Circum-Arctic Permafrost Regions: Natural Hazards, v. 26, no. 3, p. 203-225.

Ni, H. Y., Zheng, W. M., Tie, Y. B., Su, P. C., Tang, Y. Q., Xu, R. G., Wang, D. W., and Chen, X. Y., 2011, Formation and characteristics of postearthquake debris flow: a case study from Wenjia gully in Mianzhu, Sichuan, SW China: Natural Hazards, v. 61, no. 2, p. 317-335.

Ohnishi, T., 2011, The Disaster at Japan's Fukushima-Daiichi Nuclear Power Plant after the March 11, 2011 Earthquake and Tsunami, and the Resulting Spread of Radioisotope Contamination, 1-14 p.:

Owen, L. A., Kamp, U., Khattak, G. A., Harp, E. L., Keefer, D. K., and Bauer, M. A., 2008, Landslides triggered by the 8 October 2005 Kashmir earthquake: Geomorphology, v. 94, no. 1, p. 1-9.

Papa, N., Medina, V., Ciervo, F., and Bateman, A., 2012, Estimation of debris flow critical rainfall thresholds by a physically-based model, 1279712824 p.:

Parker, R. N., Densmore, A. L., Rosser, N. J., de Michele, M., Li, Y., Huang, R., Whadcoat, S., and Petley, D. N., 2011, Mass wasting triggered by the 2008 Wenchuan earthquake is greater than orogenic growth: Nature Geosci, v. 4, no. 7, p. 449-452.

Pesci, A., Baldi, P., Bedin, A., Casula, G., Cenni, N., Fabris, M., Loddo, F., Mora, P., and Bacchetti, M., 2004, Digital elevation models for landslide 
evolution monitoring: application on two areas located in the Reno River Valley (Italy): Annals of geophysics, v. 47, no. 4.

Platt, S., Brown, D., and Hughes, M., 2016, Measuring resilience and recovery: International Journal of Disaster Risk Reduction, v. 19, p. 447-460.

Poli, D., Remondino, F., Angiuli, E., and Agugiaro, G., 2013, Evaluation of Pleiades-1a triplet on Trento testfield: International archives of the photogrammetry. Remote Sens Spat Inf Sci, v. 11, p. 287-292.

Prokop, A., and Panholzer, H., 2009, Assessing the capability of terrestrial laser scanning for monitoring slow moving landslides: Natural Hazards and Earth System Sciences, v. 9, no. 6, p. 1921-1928.

Rautela, P., and Lakhera, R. C., 2000, Landslide risk analysis between Giri and Tons Rivers in Himachal Himalaya (India): International Journal of Applied Earth Observation and Geoinformation, v. 2, no. 3, p. 153-160.

Reid, M., Christian, S., Brien, D., and Henderson, S., 2015, Scoops3d-Software to Analyze Three-dimensional Slope Stability throughout a Digital Landscape: U.s.geological Survey.

Remondo, J., Bonachea, J., and Cendrero, A., 2005, A statistical approach to landslide risk modelling at basin scale: from landslide susceptibility to quantitative risk assessment: Landslides, v. 2, no. 4, p. 321-328.

Rexer, M., and Hirt, C., 2014, Comparison of free high resolution digital elevation data sets (ASTER GDEM2, SRTM v2. 1/v4. 1) and validation against accurate heights from the Australian National Gravity Database: Australian Journal of Earth Sciences, v. 61, no. 2, p. 213226.

Rice, R. M., Crobett, E. S., and Bailey, R. G., 1969, Soil Slips Related to Vegetation, Topography, and Soil in Southern California: Water Resources Research, v. 5, no. 3, p. 647-659.

Saba, S. B., van der Meijde, M., and van der Werff, H., 2010, Spatiotemporal landslide detection for the 2005 Kashmir earthquake region: Geomorphology, v. 124, no. 1, p. 17-25.

Sakamoto, M., and Yamori, K., 2009, A Study of Life Recovery and Social Capital regarding Disaster Victims \&minus;A Case Study of Indian Ocean Tsunami and Central Java Earthquake Recovery\&minus: Journal of Natural Disaster Science, v. 31, no. 2, p. 49-56.

Samyn, K., Travelletti, J., Bitri, A., Grandjean, G., and Malet, J. P., 2012, Characterization of a landslide geometry using 3D seismic refraction traveltime tomography: The La Valette landslide case history: Journal of Applied Geophysics, v. 86, p. 120-132.

San-Nami, T., Ishikawa, T., Uda, T., Harumi, T., and Akita, K., 2011, Beach erosion as long-term topographic respons to avalanche and landslide associated with the 1923 Kanto Earthquake, p. 250-257.

Santillan, J. R., Makinano-Santillan, M., and Makinano, R. M., Vertical accuracy assessment of ALOS World 3D - 30M Digital Elevation Model over northeastern Mindanao, Philippines, in Proceedings 2016 IEEE 
International Geoscience and Remote Sensing Symposium (IGARSS)10-15 July 2016 2016, p. 5374-5377.

Scaringi, G., Fan, X., Xu, Q., Liu, C., Ouyang, C., Domènech, G., Yang, F., and Dai, L., 2018, Some considerations on the use of numerical methods to simulate past landslides and possible new failures: the case of the recent Xinmo landslide (Sichuan, China): Landslides, no. 1, p. 1-17.

Shieh, Chjeng-Lun, Chen, Y. S., Tsai, Y. J., and Wu, J. H., 2009a, Variability in rainfall threshold for debris flow after the Chi-Chi earthquake in central Taiwan, China: International Journal of Sediment Research, v. 24, no. 2, p. 177-188.

Shieh, C. L., Chen, Y. S., Tsai, Y. J., and Wu, J. H., 2009b, Variability in rainfall threshold for debris flow after the Chi-Chi earthquake in central Taiwan, China: International Journal of Sediment Research, v. 24, no. 2, p. 177-188.

Shou, K. J., Hong, C. Y., Wu, C. C., Hsu, H. Y., Fei, L. Y., Lee, J. F., and Wei, C. Y., 2011a, Spatial and temporal analysis of landslides in Central Taiwan after 1999 Chi-Chi earthquake: Engineering Geology, v. 123, no. 1 , p. $122-128$.

Shou, K. J., Wu, C. C., Fei, L. Y., Lee, J. F., and Wei, C. Y., 2011b, Dynamic environment in the Ta-Chia River watershed after the 1999 Taiwan ChiChi earthquake: Geomorphology, v. 133, no. 3, p. 190-198.

Sichuan Geological Survey institute, 2010, Investigation report on the debris flow threat in Huangyang gully in Wenchuan earthquake hit area (Unpublished work, in Chinese).

Sichuan Geology Engineering Reconnaissance Institute, 2010, Investigation report on the 13 Aug debris flow of Shuida catchment (Unpublished work, in Chinese).

-, 2011, Investigation report on debris flows threat in Maliu gully after the Aug 132010 disaster in Longchi town (Unpublished work, in Chinese).

Soeters, R., and van Westen, C. J., 1996, Slope instability recognition, analysis and zonation: Landslides, investigation and mitigation. Transportation Research Board, National Research Council, Special Report, v. 247, p. 129-177.

Stark, C., and Guzzetti, F., 2009, Landslide rupture and the probability distribution of mobilized debris volumes: Journal of Geophysical Research: Earth Surface, v. 114, no. F2.

Stark, C. P., and Hovius, N., 2001, The characterization of landslide size distributions: Geophysical Research Letters, v. 28, no. 6, p. 10911094.

Stumpf, A., and Kerle, N., 2011, Object-oriented mapping of landslides using Random Forests: Remote Sensing of Environment, v. 115, no. 10, p. 2564-2577.

Stumpf, A., Malet, J. P., Allemand, P., and Ulrich, P., 2014, Surface reconstruction and landslide displacement measurements with Pléiades 
satellite images: Isprs Journal of Photogrammetry \& Remote Sensing, v. 95, p. 1-12.

Sun, M., Chen, B., Ren, J., and Chang, T., 2010a, Natural Disaster's Impact Evaluation of Rural Households' Vulnerability: The case of Wenchuan earthquake: Agriculture and Agricultural Science Procedia, v. 1, p. 5261.

Sun, M., Chen, B., and Shi, G., 2010b, Comparative analysis of influence factors for household income before and after the natural disaster: a study of Wenchuan: Technology Economics, v. 2010, no. 5.

Tai, C.-A., Lee, Y.-L., Lin, C.-Y., and Ishii, H., 2010, Earthquake evacuation shelter feasibility analysis applying with GIS model builder.

Tang, C., and Liang, J., 2008, Case study on the 9.24 storm-triggered debrisflow in Beichuan: Journal of Engineering Geology.

Tang, C., Rengers, N., van Asch, T. W., Yang, Y., and Wang, G., 2011a, Triggering conditions and depositional characteristics of a disastrous debris flow event in Zhouqu city, Gansu Province, northwestern China: Natural Hazards and Earth System Science, v. 11, no. 11, p. 29032912.

Tang, C., Rengers, N., van Asch, T. W. J., Yang, Y. H., and Wang, G. F., 2011b, Triggering conditions and depositional characteristics of a disastrous debris flow event in Zhouqu city, Gansu Province, northwestern China: Nat. Hazards Earth Syst. Sci., v. 11, no. 11, p. 2903-2912.

Tang, C., Tanyas, H., van Westen, C. J., Tang, C., Fan, X., and Jetten, V. G., 2019, Analysing post-earthquake mass movement volume dynamics with multi-source DEMs: Engineering Geology, v. 248, p. 89-101.

Tang, C., van Asch, T. W. J., Chang, M., Chen, G. Q., Zhao, X. H., and Huang, X. C., 2012a, Catastrophic debris flows on 13 August 2010 in the Qingping area, southwestern China: The combined effects of a strong earthquake and subsequent rainstorms: Geomorphology, v. 139-140, p. 559-576.

Tang, C., Van Westen, C. J., Tanyas, H., and Jetten, V. G., 2016, Analysing post-earthquake landslide activity using multi-temporal landslide inventories near the epicentral area of the 2008 Wenchuan earthquake: Nat. Hazards Earth Syst. Sci., v. 16, no. 12, p. $2641-$ 2655.

Tang, C., and Westen, C. J., 2018, Atlas of Wenchuan-Earthquake Geohazards: Analysis of co-seismic and post-seismic Geohazards in the area affected by the 2008 Wenchuan Earthquake, Beijing, Science Press.

Tang, C., Zhu, J., Chang, M., Ding, J., and Qi, X., 2012b, An empiricalstatistical model for predicting debris-flow runout zones in the Wenchuan earthquake area: Quaternary International, v. 250, p. 6373.

Tang, C., Zhu, J., Ding, J., Cui, X. F., Chen, L., and Zhang, J. S., 2011c, Catastrophic debris flows triggered by a 14 August 2010 rainfall at the 
epicenter of the Wenchuan earthquake: Landslides, v. 8, no. 4, p. 485497.

Tang, C., Zhu, J., Li, W. L., and Liang, J. T., 2009, Rainfall-triggered debris flows following the Wenchuan earthquake: Bulletin of Engineering Geology and the Environment, v. 68, no. 2, p. 187-194.

Tanyas, H., Allstadt, K. E., and Westen, C. J. V., 2018, An updated method for estimating landslide-event magnitude: Earth Surface Processes \& Landforms.

Tanyas, H., Westen, C. J., Persello, C., and Alvioli, M., 2019, Rapid prediction of the magnitude scale of landslide events triggered by an earthquake.

Tarhan, C., and Deniz, D., 2013, Sustainable urban planning and risk assessment of earthquake hazards in turkey, 113-117 p.:

Tridon, D. B., Bachmann, M., Schulze, D., Ortega-Míguez, C., Polimeni, M. D., Martone, M., Böer, J., and Zink, M., 2013, TanDEM-X: DEM acquisition in the third year era: International Journal of Space Science and Engineering 5, v. 1, no. 4, p. 367-381.

Tseng, C. M., Lin, C. W., Stark, C. P., Liu, J. K., Fei, L. Y., and Hsieh, Y. C., 2013, Application of a multi-temporal, LiDAR-derived, digital terrain model in a landslide-volume estimation: Earth Surface Processes and Landforms, v. 38, no. 13, p. 1587-1601.

United Nations Office for Disaster Risk Reduction (UNISDR), 2010, Wenchuan earthquake 2008: recovery and reconstruction in Sichuan province.

-, 2015, Sendai Framework for Disaster Risk Reduction 2015-2030: Sendai.

van Asch, T. W. J., Tang, C., Alkema, D., Zhu, J., and Zhou, W., 2013, An integrated model to assess critical rainfall thresholds for run-out distances of debris flows: Natural Hazards, v. 70, no. 1, p. 299-311.

Van Den Eeckhaut, M., Poesen, J., Govers, G., Verstraeten, G., and Demoulin, A., 2007, Characteristics of the size distribution of recent and historical landslides in a populated hilly region: Earth and Planetary Science Letters, v. 256, no. 3, p. 588-603.

van Westen, C. J., and Greiving, S., 2017, Multi-hazard risk assessment and decision making

Environmental Hazards Methodologies for Risk Assessment and Management, in Dalezios, N. R., ed., IWA Publishing, p. 0.

van Westen, C. J., and Lulie Getahun, F., 2003, Analyzing the evolution of the Tessina landslide using aerial photographs and digital elevation models: Geomorphology, v. 54, no. 1-2, p. 77-89.

van Westen, C. J., van Asch, T. W. J., and Soeters, R., 2006, Landslide hazard and risk zonation-why is it still so difficult?: Bulletin of Engineering Geology and the Environment, v. 65, no. 2, p. 167-184.

Varnes, D., 1978, Slope movement types and processes.

Varnes, D. J., 1984, Landslide hazard zonation: a review of principles and practice: UNESCO. 
von Meding, J., Darshan Shrestha, H., Kabir, H., and Ahmed, I., 2017, Nepal earthquake reconstruction won't succeed until the vulnerability of survivors is addressed, The Conversation.

Wang, F., Cheng, Q., Highland, L., Miyajima, M., Wang, H., and Yan, C., 2009a, Preliminary investigation of some large landslides triggered by the 2008 Wenchuan earthquake, Sichuan Province, China: Landslides, v. 6, no. 1, p. 47-54.

Wang, M., Yang, W., Shi, P., Xu, C., and Liu, L., 2014, Diagnosis of Vegetation Recovery in Mountainous Regions After the Wenchuan Earthquake: IEEE Journal of Selected Topics in Applied Earth Observations and Remote Sensing, v. 7, no. 7, p. 3029-3037.

Wang, X., Ding, X., Wang, L., and Wang, Y., 2009b, Fast assessment of earthquake loss and its application to the 2008 MS8.0 Wenchuan earthquake: Earthquake Science, v. 22, no. 2, p. 129-133.

Wang, Y., Chen, H., and Li, J., 2012, Factors affecting earthquake recovery: the Yao'an earthquake of China: Natural Hazards, v. 64 , no. 1, p. 3753.

Wang, Y., Zou, Z., and Li, J., 2015, Influencing factors of households disadvantaged in post-earthquake life recovery: a case study of the Wenchuan earthquake in China: Natural Hazards, v. 75 , no. 2, p. 18531869.

Wen, B., Wang, S., Wang, E., and Zhang, J., 2004, Characteristics of rapid giant landslides in China: Landslides, v. 1, no. 4, p. 247-261.

Wu, J., Li, N., Hallegatte, S., Shi, P., Hu, A., and Liu, X., 2012, Regional indirect economic impact evaluation of the 2008 Wenchuan Earthquake: Environmental Earth Sciences, v. 65, no. 1, p. 161-172.

Wu, J. Y., and Lindell, M. K., 2004, Housing Reconstruction After Two Major Earthquakes: The 1994 Northridge Earthquake in the United States and the 1999 Chi-Chi Earthquake in Taiwan: Disasters, v. 28, no. 1, p. 63-81.

Xu, C., Xu, X., Yao, X., and Dai, F., 2013, Three (nearly) complete inventories of landslides triggered by the May 12, 2008 Wenchuan Mw 7.9 earthquake of China and their spatial distribution statistical analysis: Landslides, v. 11 , no. 3, p. 441-461.

-, 2014, Three (nearly) complete inventories of landslides triggered by the May 12, 2008 Wenchuan Mw 7.9 earthquake of China and their spatial distribution statistical analysis: Landslides, v. 11, no. 3, p. 441-461.

Xu, Q., Zhang, S., Li, W. L., and van Asch, T. W. J., 2012, The 13 August 2010 catastrophic debris flows after the 2008 Wenchuan earthquake, China: Natural Hazards and Earth System Science, v. 12, no. 1, p. 201-216.

Xu, W., Zhao, X., Ma, Y., Li, Y., Qin, L., Wang, Y., and Du, J., 2018, A multiobjective optimization based method for evaluating earthquake shelter location-allocation, 662-677 p.: 
Yamagishi, H., and Iwahashi, J., 2007, Comparison between the two triggered landslides in Mid-Niigata, Japan by July 13 heavy rainfall and October 23 intensive earthquakes in 2004: Landslides, v. 4, no. 4, p. 389-397.

Yang, F., Yuan, Q., Du, S., and Liang, L., 2016, Reserving relief supplies for earthquake: a multi-attribute decision making of China Red Cross: Annals of Operations Research, v. 247, no. 2, p. 759-785.

Yang, J., 2010, Emergency investigation report of Shaofang catchment debris flows (unpublished report, in Chinese), Sichuan Institute of Geological Engineering Investigation.

Yang, S., Du, J., He, S., Shi, M., and Sun, X., 2015a, The emerging vulnerable population of the urbanisation resulting from post-disaster recovery of the Wenchuan earthquake: Natural Hazards, v. 75 , no. 3, p. 21032118.

Yang, W., Qi, W., Wang, M., Zhang, J., and Zhang, Y., 2017, Spatial and temporal analyses of post-seismic landslide changes near the epicentre of the Wenchuan earthquake: Geomorphology, v. 276, p. 8-15.

Yang, W., Qi, W., and Zhou, J., 2018, Decreased post-seismic landslides linked to vegetation recovery after the 2008 Wenchuan earthquake: Ecological Indicators, v. 89, p. 438-444.

Yang, W. T., Wang, M., Kerle, N., Van Westen, C. J., Liu, L. Y., and Shi, P. J., 2015b, Analysis of changes in post-seismic landslide distribution and its effect on building reconstruction: Natural Hazards and Earth System Sciences, v. 15, no. 4, p. 817-825.

Yang, X., Zhang, Y., Hu, C., Hao, H., Huang, Y., Zhou, L., Li, G., Kong, Y., Zhen, Q., Zhang, Y., Shang, X., Jia, L., and Wang, Y., 2005, Geohazard zonation report of Wenchuan county, Aba, Sichuan (Unpublished, in Chinese), Sichuan Guanghan Geology Engineering Reconnaissance Institute.

Ying Wu, J., and Lindell, M., 2004, Housing Reconstruction After Two Major Earthquakes: The 1994 Northridge Earthquake in the United States and the $1999 \mathrm{Chi}-\mathrm{Chi}$ Earthquake in Taiwan, 63-81 p.:

You, Y., Liu, J., Chen, X., and Pan, H., 2011, Debris flow formation conditions and optimal characteristics of drainage canal following Wenchuan earthquake: Environmental Earth Sciences, v. 65, no. 4, p. 1005-1012.

Yu, B., Ma, Y., Zhang, J., Wu, Y., Zhang, H., Li, L., and Chu, S., 2011, Debris flow hazard in Longchi after the Wenchuan earthquake (in Chinese): Journal of Mountain Science, v. 6, p. 738 - 746.

Yu, X., 2010, Mitigation and investigation design on the catastrophic Wenjia catchment debris flow, Qingping, Sichuan province (unpublished report, in Chinese), Sichuan Geological Engineering Corporation.

Zêzere, J. L., Garcia, R. A. C., Oliveira, S. C., and Reis, E., 2008, Probabilistic landslide risk analysis considering direct costs in the area north of Lisbon (Portugal): Geomorphology, v. 94, no. 3-4, p. 467-495. 
Zhang, H., 2016, Household vulnerability and economic status during disaster recovery and its determinants: a case study after the Wenchuan earthquake: Natural Hazards, v. 83, no. 3, p. 1505-1526.

Zhang, H., Fan, J., and Liu, Q., 2013a, Predicting Volume and Runout of Single Gully Debris-Flow Using Hypsometric Integral Value in the Wenchuan Earthquake Area, p. 301-311.

Zhang, S., Zhang, L., Lacasse, S., and Nadim, F., 2016, Evolution of Mass Movements near Epicentre of Wenchuan Earthquake, the First Eight Years: Sci Rep, v. 6, p. 36154.

Zhang, S., Zhang, L. M., Peng, M., Zhang, L. L., Zhao, H. F., and Chen, H. X., 2012, Assessment of risks of loose landslide deposits formed by the 2008 Wenchuan earthquake: Nat. Hazards Earth Syst. Sci., v. 12, no. 5, p. 1381-1392.

Zhang, W., Jiang, L., Li, X., and Yang, T., 2013b, Exploration of mortality and economy vulnerability of wenchuan earthquake, 197-204 p.:

Zhao, Y., and Liu, X., 2005, Risk assessment for debris flow hazard (in Chinese): The Chinese Journal of Geological Hazard and Control, v. 3, p. $42-47$.

Zhong, L., and Ge, Z., 1993, Event inventory of geological disasters (in Chinese), in Ma, Z., and Gao, Q., eds., Natural disasters and countermeasures in China: Beijing, Science Press.

Zhou, W., and Tang, C., 2013, Rainfall thresholds for debris flow initiation in the Wenchuan earthquake-stricken area, southwestern China: Landslides, v. 11 , no. 5, p. 877-887.

Zhou, W., Tang, C., and Zhou, C.-h., 2013, Rainfall Patterns of Post-seismic Debris Flows in the Wenchuan Earthquake Area, p. 895-900.

Zhou, Y., Parsons, B., Elliott, J. R., Barisin, I., and Walker, R. T., 2015, Assessing the ability of Pleiades stereo imagery to determine height changes in earthquakes: A case study for the El Mayor-Cucapah epicentral area: Journal of Geophysical Research: Solid Earth, v. 120, no. 12, p. $8793-8808$.

Zhuang, J.-q., Cui, P., Peng, J.-b., Hu, K.-h., and Iqbal, J., 2012, Initiation process of debris flows on different slopes due to surface flow and trigger-specific strategies for mitigating post-earthquake in old Beichuan County, China: Environmental Earth Sciences, v. 68, no. 5, p. 1391-1403.

Zou, J., and Shao, S., 1996, Landslides induced by Haiyuan earthquake and their distribution (in Chinese): Cont Earthquake, v. 10, p. 1-5.

Zuo, K., Ping, X., Huan, Z., and Lu, X., 2013, Post-Wenchuan Earthquake Reconstruction and Development in China. 


\section{Summary}

Major disasters, such as earthquakes, have a large impact on society, causing massive direct and indirect losses. Large earthquakes may also seriously affect the natural environment, in the form of secondary hazards. In mountainous regions one of the most severe secondary effects is the triggering of co-seismic landslides. These may result in the loss of vegetation and the production of large volumes of landslide deposits, which drastically change the susceptibility to rainfall-induced landslides and flooding after the earthquake. In such circumstances human settlements are not only threatened by co-seismic hazards such ground shaking or landslides, but also face a continuous threat of landslides, debris flows and flash floods during and after reconstruction phase. A monitoring of changes in post-seismic hazards, exposure and vulnerability is important for addressing changing risk as a basis for recovery planning.

We analysed changes in landslide activity in a period of seven years after the 2008 Wenchuan earthquake, with five multi-temporal landslide inventories, which we interpreted stereoscopically from high resolution images, followed by field investigation. The results show that most of the post-seismic landslide activities were concentrated within the first three years following the earthquake. The landslide activity decreased considerably from May 2008 until April 2015, from 6727 co-seismic landslides to 66 active landslides in 2015. After the 2010 monsoon season, the activity of the post-earthquake landslides dropped considerably and most of the active landslides became dormant. Of the total of 6727 co-seismic landslides, 2221 had one or more phases of reactivation. Apart from the reactivation of co-seismic landslides also 660 new landslides occurred after 2008. In April 2015, the number of active landslides had gone down to 66 , less than $1 \%$ of the co-seismic landslides, still much higher than the pre-earthquake situation. We expect that the landslide activity will continue to decay, but may be halted if extreme rainfall events occur.

Due to the lack of adequate pre- and post-Wenchuan-earthquake Digital Elevation Models, the landslide volume estimation was done either using empirical area-volume relationships over large areas or by field surveys in a few catchments with debris flow threats. The trend of the change of volume of loose materials in the earthquake affected area over the decade since the earthquake remains largely unknown. In this study we were able to address this issue using nine DEMs taken at different years and from different sensors to study the change in loose material volume caused by co-seismic and postseismic landslides over a period of 9 years. The area around the towns of Yingxiu and Longchi, for which also multi-temporal landslide inventories were available, was selected for this study. Methods to register the DEMs and minimize their vertically bias were applied. The quality of the DEMs was 
assessed through GCPs and terrain representation. As could be expected, high resolution DEMs showed more realistic volume estimates than the lowresolution ones. The analysis showed that the frequency and magnitude of the landslide volume dynamics decreases significantly after the early post-seismic period ( $<6$ years), and in the last years $(2014$ - 2017) human activities became a more dominate factor than mass movements. The post-seismic material loss from 2008 to 2014 was close to the gained volume of the coseismic landslides, and the depletion of the materials was mostly at the toes of the co-seismic landslides. The analysis was done based on gain and loss calculated from the DEMs, and actual volumes could not be calculated due to unknown failure surface depths of the landslides.

In order to address the issue caused by unknown failure surface depth in landslide volume estimation, we developed a model that integrates MATLAB and ARCMAP functions to simulate the geometry of failure surfaces with exposed scarps. To test our model, a series of analogue experiments were designed to acquire data for model testing in a controlled environment, before applying the model to real landslide cases. The results from the analogue experiments showed that it is essential to use some additional elevation points other that scarps, that could be obtained by overlaying the pre-and postearthquake DEMs and trace the outcropping failure surface along the bottom of the slope. The model was then applied on real landslides. The total landslide volume obtained using the model showed a poor agreement with the results using empirical equations, and for both individual landslides and total volume there were significant differences. Due to lack of measurement from borehole or geophysical investigation it is not possible to know the which method is more accurate.

We monitored the changes in the Longxi valley during ten years related to the impact of the Wenchuan earthquake and the subsequent recovery process, with seven inventories from different years containing buildings, roads, land use and mitigation measures. It was found that the loss caused by post-seismic debris flows was slightly more than the loss caused by the Wenchuan earthquake, due to fast reconstruction of buildings that were more in numbers and value than pre-earthquake situation. Most of the stronger building construction types were only implemented after the areas was impacted by the earthquake, and mitigation structures were only installed after being impacted by debris flows and floods. A greater awareness to avoid living in hazard prone areas was observed after the 2010 debris flows. Despite the extensive and repeated damage, the earthquake, and subsequent landslides, debris flows and floods gave Longchi town a chance to increase its resistance to these hazards in future, and to improve economically. 
Finally, a catchment-based multi-temporal (semi)quantitative debris flow risk analysis was carried out. The results show that the risk increased rapidly in the first three years after the 2008 earthquake due to the ongoing reconstruction, then decreased suddenly due to the impact of the 2010 debris flows that affected 59 of the 66 investigated watersheds. After that the society adapted by relocating buildings and installing mitigation works. In the later years the risk decreased gradually due to the recovery of the environment, and further protection works. The region showed a low disaster awareness before the catastrophic debris flows of 2010, then quickly learned and adapted. the study showed how risk components can vary over time in a dynamic environment, and the importance to update hazard and risk maps frequently under such circumstances. It is necessary to use up-to-date data and hazard and risk assessments in urban planning, before carrying out reconstruction work after large earthquakes. 


\section{Samenvatting}

Grote rampen, zoals aardbevingen, hebben een grote impact op de samenleving en veroorzaken enorme directe en indirecte schade. Grote aardbevingen kunnen ook ernstige gevolgen hebben voor de natuurlijke omgeving, in de vorm van secundaire natuurgevaren. In bergachtige gebieden is één van de meest ernstige secundaire effecten het ontstaan van coseismische aardverschuivingen. Deze kunnen resulteren in het verlies van vegetatie en de productie van grote hoeveelheden los materiaal, die de gevoeligheid voor door neerslag veroorzaakte aardverschuivingen en overstromingen na de aardbeving drastisch vergroten. In dergelijke omstandigheden worden menselijke nederzettingen niet alleen bedreigd door co-seismische gevaren zoals aardschokken of aardverschuivingen, maar worden ze ook geconfronteerd met een voortdurende dreiging van aardverschuivingen, modderstromen en overstromingen tijdens en na de wederopbouwfase. Het monitoren van veranderingen in deze post-seismische gevaren, alsmede in exposure en kwetsbaarheid is belangrijk voor het managen van veranderende risico's als basis voor herstelplanning.

We analyseerden de veranderingen in aardverschuivingsactiviteit in een periode van zeven jaar na de Wenchuan aardbeving in 2008, met vijf multitemporele aardverschuivingsinventarisaties, die we stereoscopisch interpreteerden vanuit afbeeldingen met een hoge resolutie, gevolgd door veldonderzoek. De resultaten laten zien dat de meeste post-seismische aardverschuivingsactiviteiten geconcentreerd waren in de eerste drie jaar na de aardbeving. De aardverschuivingsactiviteit nam aanzienlijk af van mei 2008 tot april 2015, van 6727 co-seismische aardverschuivingen tot 66 actieve aardverschuivingen in 2015. Na het regenseizoen van 2010 daalde de activiteit van de aardverschuivingen aanzienlijk en de meeste van de actieve aardverschuivingen werden inactief. Van de in totaal 6727 co-seismische aardverschuivingen had 2221 een of meer fasen van reactivering. Afgezien van de reactivering van co-seismische aardverschuivingen kwamen ook na 2008 660 nieuwe aardverschuivingen bij. In april 2015 was het aantal actieve aardverschuivingen gedaald tot 66 , minder dan $1 \%$ van de co-seismische aardverschuivingen, nog steeds veel hoger dan de situatie voor de aardbeving. We verwachten dat de aardverschuivingsactiviteit zal blijven verminderen, hoewel deze neerwaartse trend kan worden onderbroken als extreme regenval optreedt.

Als gevolg van het ontbreken van adequate digitale hoogtemodellen (DEM) vóór en na de Wenchuan-aardbeving, werd de schatting van het aardverschuivingsvolume gedaan met behulp van empirische oppervlaktevolumeverhoudingen of door veldonderzoeken in enkele stroomgebieden met modderstroomgevaar. De trend van de volumeverandering van losse 
materialen in het door de aardbeving getroffen gebied was aanvankelijk nog grotendeels onbekend. In deze studie konden we dit probleem aanpakken met behulp van negen DEM's die in verschillende jaren zijn verzameld met verschillende sensoren om de verandering in het volume van losse materialen te bestuderen gedurende een periode van 9 jaar. Het gebied rond de nederzettingen van Yingxiu en Longchi, waarvoor ook multi-temporele aardverschuivingsinventarisaties beschikbaar waren, werd geselecteerd voor deze studie. Specifieke methodes werden toegepast om de DEM's te registreren en hun verticale bias te minimaliseren. De kwaliteit van de DEM's werd beoordeeld aan de hand van GCP's en de weergave van het terrein. Zoals te verwachten was, resulteerde de analyse van DEM's met een hoge resolutie in meer realistische volumeschattingen dan die met een lagere resolutie. De analyse toonde aan dat de frequentie en omvang van de veranderingen van aardverschuivingsvolume aanzienlijk afnam na de vroege post-seismische periode (<6 jaar), en in de laatste jaren (2014 - 2017) werden menselijke activiteiten een meer dominante factor dan massabewegingen. Het postseismische materiaalverlies van 2008 tot 2014 kwam dicht in de buurt van het volumevermeerdering in de co-seismische aardverschuivingen, en de verliezen waren met name in de lager delen van de aardverschuivingen door riviererosie. Een analyse werd uitgevoerd van aanwas en verlies berekend op basis van de DEM's, want werkelijke volumes konden niet worden berekend als gevolg van onbekende glijvlakdieptes van de aardverschuivingen.

Om het probleem te verhelpen dat is veroorzaakt door de onbekende glijvlakdiepte van aardverschuivingen, hebben we een model ontwikkeld dat MATLAB- en ARCMAP-functies integreert om de geometrie van deze oppervlakken te simuleren met behulp van de oriëntatie van ontsluitingen van delen van deze glijvlakken (scarps). Om ons model te testen, werden een reeks analoge experimenten ontworpen om gegevens te verzamelen voor het testen van modellen in een gecontroleerde omgeving, voordat het model werd toegepast op echte aardverschuivingen. De resultaten van de analoge experimenten toonden aan dat het essentieel is om een aantal extra meetpunten te gebruiken, anders dan glijvlakontsluitingen. Dit kunnen bijvoorbeeld boringen of geofysische metingen zijn, of geomorfologische kenmerken die zouden kunnen worden verkregen door de DEM's van voor en na de aardbeving over de onderste delen van het terrein te projecteren, en de glijvlaklocatie op de terreinhelling te traceren. Het model werd vervolgens toegepast op echte aardverschuivingen. Het totale aardverschuivingsvolume verkregen met behulp van het model vertoonde een slechte overeenstemming met de resultaten van empirische vergelijkingen, en er waren significante verschillen voor zowel individuele aardverschuivingen als het totale volume. Door een gebrek aan dieptemetingen van het afglijdingsvlak uit boorgaten of geofysisch onderzoek was het niet mogelijk om te bepalen welke methode nauwkeuriger is. 
We hebben de veranderingen door de impact van de aardbeving in Wenchuan en het daaropvolgende herstelproces in de Longchi-vallei gevolgd over een periode van 10 jaar na de aardbeving. We maakten daarvoor zeven inventarisaties van gebouwen, wegen, landgebruik en mitigatiemaatregelen, voor verschillende jaren. De schade veroorzaakt door modderstromen na de aardbeving bleek meer te zijn dan het verlies veroorzaakt door de aardbeving zelf, vanwege de snelle herbouw van gebouwen die meer in aantal en waarde waren dan de situatie vóór de aardbeving. De meeste van de sterkere bouwconstructies werden pas geïmplementeerd na de aardbeving en de meeste beschermingsmaatregelen werden pas geïnstalleerd na het voorkomen van modderstromen en overstromingen. Een groter risicobewustzijn werd waargenomen na de grote modderstromen die het gebied in 2010 teisterden. Ondanks de grote impact, gaf de aardbeving en de daaropvolgende natuurrampen de gemeente Longchi een kans om zijn weerstand tegen deze gevaren in de toekomst te vergroten en zichzelf economisch te verbeteren.

Ten slotte werd een multi-temporele en semi-kwantitatieve risicoanalyse voor modderstromen ontwikkeld op het niveau van afzonderlijke stroomgebieden. De resultaten tonen aan dat het risico in de eerste drie jaar na de aardbeving van 2008 snel toenam als gevolg van de snelle herbouw en vervolgens plotseling daalde als gevolg van de impact van de modderstromen van 2010 die 59 van de 66 onderzochte stroomgebieden troffen. Daarna paste de maatschappij zich aan door gebouwen te verplaatsen en beschermingsmaatregelen te installeren. In de latere jaren nam het risico geleidelijk af door het herstel van de natuurlijke omgeving en verdere beschermingsmaatregelen. De regio vertoonde een laag risicobewustzijn vóór de catastrofale puinstromen van 2010, maar dit veranderde daarna snel. De studie toonde aan hoe risicocomponenten in de loop van de tijd kunnen variëren in een dynamische omgeving en hoe belangrijk het is om gevaren- en risicokaarten regelmatig bij te werken onder dergelijke omstandigheden. Het is noodzakelijk om actuele gegevens en gevaren- en risicobeoordelingen in de ruimtelijke planning te gebruiken, voordat de wederopbouw na grote aardbevingen wordt uitgevoerd. 


\section{Biography}

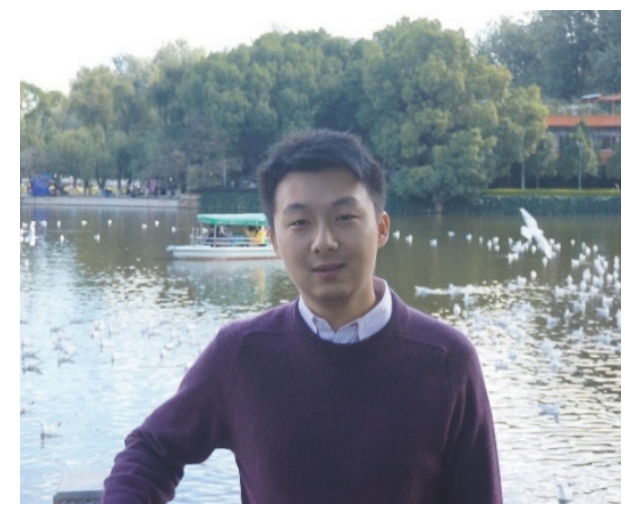

Chenxiao Tang was born on the 30th of March 1988 in Chengdu, Sichuan province of China. He studied in the Chengdu University of Technology, China and received a BSc on Geology in 2010. He started a MSc of Disaster Management in the field of Applied Earth Science in 2010 and received a MSc degree in 2012, at Faculty of Geo-Information Science and Earth Observation (ITC), University of Twente, Netherlands. In 2013 he began the PhD program and closely collaborated with State Key Laboratory of Geo-hazard Prevention and Geo-environment Protection (SKLGP), Chengdu University of Technology, China.

\section{Published papers, books and reports}

1 Tang, C., Van Westen, C.J., Tanyas, H., and Jetten, V.G., 2016. Analysing post-earthquake landslide activity using multi-temporal landslide inventories near the epicentral area of the 2008 Wenchuan earthquake, Nat. Hazards Earth Syst. Sci., 16, 2641-2655. DOI: https://doi.org/10.5194/nhess-16-2641-2016

2 Tang, C., Tanyas, H., van Westen, C. J., Tang, C., Fan, X., and Jetten, V. G., 2019, Analysing post-earthquake mass movement volume dynamics with multi-source DEMs: Engineering Geology, v. 248, p. 89-101. DOI: https://doi.org/10.1016/j.enggeo.2018.11.010

3 Fan, X., Tang, C. X., van Westen, C. J., and Alkema, D., 2012, Simulating dam-breach flood scenarios of the Tangjiashan landslide dam induced by the Wenchuan Earthquake: Natural Hazards and Earth System Science, v. 12, no. 10 , p. 3031-3044. DOI: https://doi.org/10.5194/nhess-12-3031$\underline{2012}$

4 Fan, X., van Westen, C. J., Tang, C., Xu, Q., Huang, R., and Wang, G., The Classification of Damming Landslides and Landslide Dams Induced by the Wenchuan Earthquake, in Proceedings Engineering Geology for Society and Territory - Volume 2, Cham, 2015// 2015, Springer International Publishing, p. 1143-1147. DOI: https://doi.org/10.1007/978-3-31909057-3_201

5 Tang, C., van Westen, C.J., Gorum, T., Li W., Fan, X., Zhu J., Chang, M., Zhou W., Tang C., Bu, X., Huang, J., Huang, X., van Asch, Th.W.J., Gu, F., and Chen, M., 2018, Atlas of Wenchuan-Earthquake Geohazards: Analysis of co-seismic and post-seismic Geohazards in the area affected by the 2008 Wenchuan Earthquake, Beijing, Science Press. 